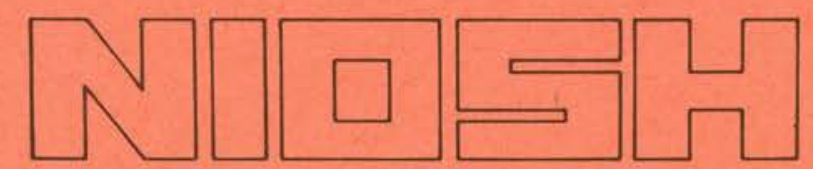

TECHNICAL REPORT

\title{
Petroleum Refinery Workers \\ Exposure to PAHs at Fluid \\ Catalytic Cracker, Coker, and Asphalt Processing Units
}

U.S. DEPARTMENT OF HEALTH AND HUMAN SERVICES

Public Health Service

Centers for Disease Control

National Institute for Occupational Safety and Health 


\title{
PETROLEUM REFINERY WORKERS EXPOSURE TO PAHS AT FLUID CATALYTIC CRACKER, COKER, AND ASPHALT PROCESSING UNITS
}

\author{
Stan K. Futagaki \\ Enviro Control, Inc. \\ Rockville, Maryland 20852
}

NIOSH Contract No. 210-78-0082

U. S. DEPARTMENT OF HEALTH AND HUMAN SERVICES

Public Health Service Centers for Disease Control

National Institute for Occupational Safety and Health Division of Surveillance, Hazard Evaluations and Field Studies Cincinnati, Ohio 45226

May 1983 


\section{DISCLAIMER}

Mention of company names or products does not constitute endorsement by the National Institute for Occupational Safety and Health.

NIOSH Project Officer: Clinton Cox

Enviro Control, Inc., Project Manager:

Donald W. Rumsey

DHHS (NIOSH) Publication No. 83-111 


\section{ABSTRACT}

Worker inhalation exposures to polyaromatic hydrocarbons (PAHs) in three different types of process units were monitored at nine petroleum refineries. Personal and area samples were collected at the fluid catalytic cracking units (FCCUs) and delayed coker units, while area samples were primarily collected at the asphalt processing units. A silver-membrane filter followed by Chromosorb-102 was used for sampling; analysis for 23 individual or groups of PAHs was performed by gas chromatography/mass spectrometry.

The results of more than 250 personal, area, and refinery upwind boundary samples clearly showed that workers at the FCCUs and delayed coker units were exposed to numerous PAHs, usually at low microgram per cubic meter concentrations. The geometric mean of the cumulative PAH concentration exposures (personal samples) was $11.4 \mu \mathrm{g} / \mathrm{m}^{3}$ for the FCCUs and $11.1 \mu \mathrm{g} / \mathrm{m}^{3}$ for the delayed coker units, with an average number of PAHs per sample of 10 and 11 , respectively, for the two types of process units. Although mainly area samples were collected in the asphalt processing units, the results also indicated that detectable quantities of several PAHs were also present in these refinery areas. The light molecular weight, 2- and 3-ring PAHs were found in the highest concentrations ( 83.5 to $100 \%$ range) with generally very small or no quantities of the 4-through 7-ring compounds. This is important since the lighter molecular weight PAHs are not considered as carcinogenic as the heavier PAHs.

Other findings of this study showed that the production of needle coke is associated with higher PAH exposures than the production of the more common sponge coke. Also, the PAHs collected at the FCCUs and the asphalt processing units were associated with the respirable-fraction particulate (and possibly PAH vapor); while at the delayed coker unit, up to $50 \%$ of the PAHs collected downwind of the coke-cutting operation were associated with particulates greater than $10 \mu \mathrm{m}$. The findings also indicated that tobacco smoke probably did not influence the results of this study based on a comparison of data between the smokers and nonsmokers sampled.

This study was performed in fulfillment of Contract No. 210-78-0082 by Enviro Control, Inc., under the sponsorship of the National Institute for Occupational. Safety and Health (NIOSH). 



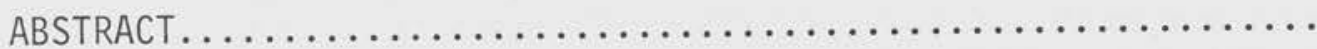

INTRODUCTION.

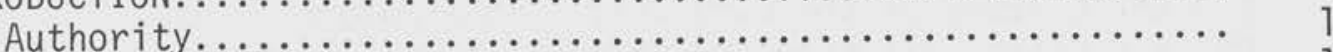

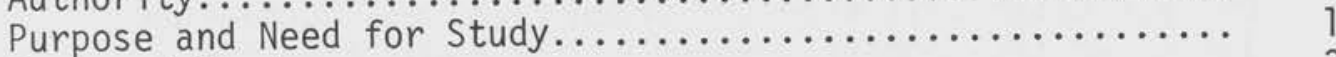

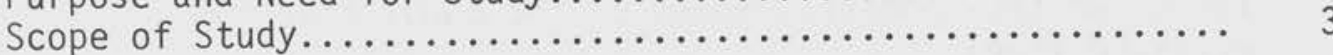

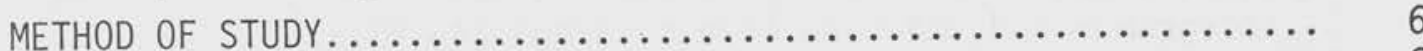

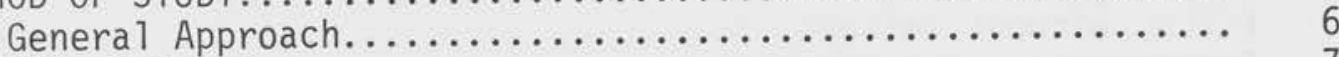

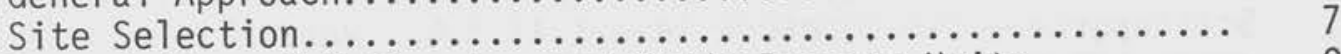

Description of Refineries and Study Process Units......... 9

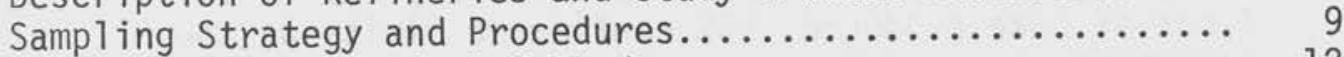

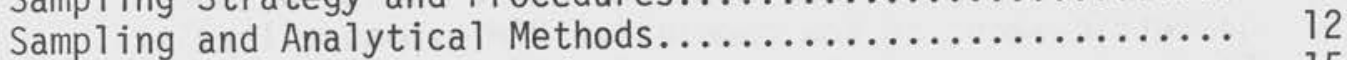

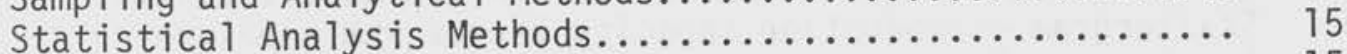

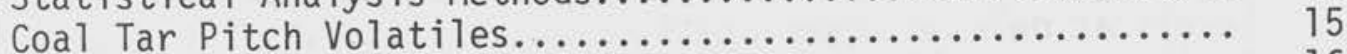

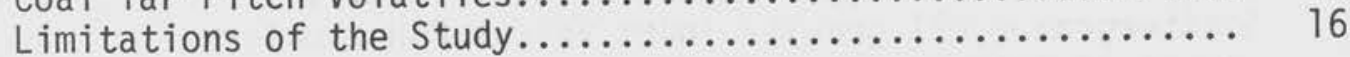

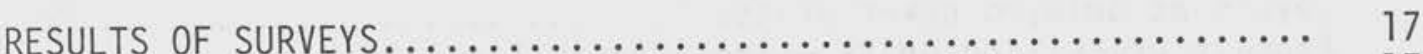

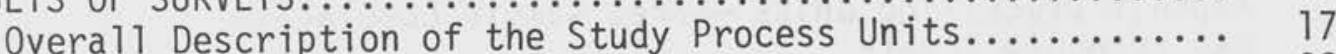

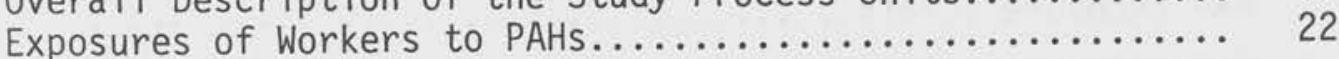

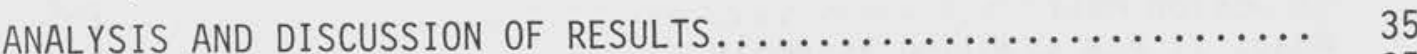

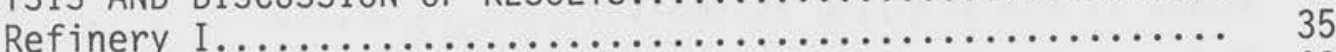

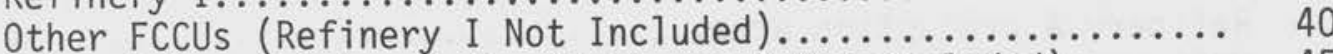

Other Delayed Coker Units (Refinery I Not Included)....... 45

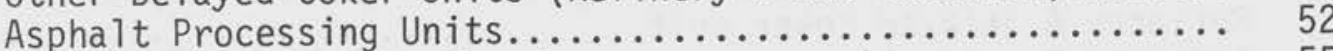

Distribution of PAHs Found......................... 55

Total Particulate Versus Respirable-Fraction

Area Samples and Particle-Size Distribution............ 58

Possible Influence of Tobacco Smoke on PAH Results........ 59

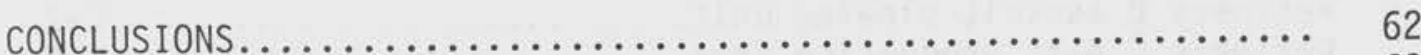

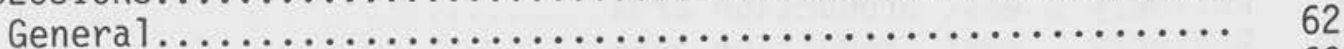

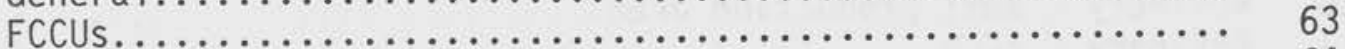

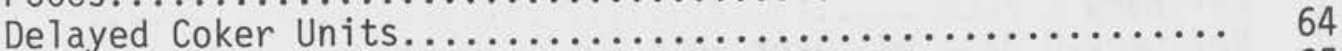

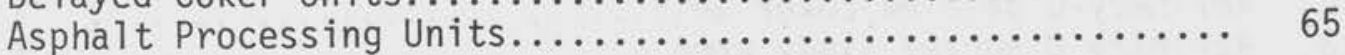

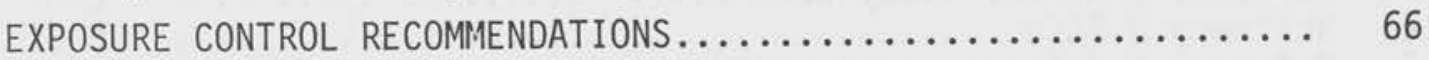

RESEARCH RECOMMENDATIONS......................... 68

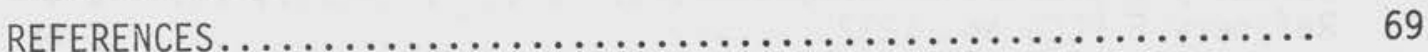
APPENDICES

A. Other Relevant Studies........................ A-1

B. Development of Scope of Study and Phase II Results..... B-1

C. Descriptions of Refineries and Study Process Units..... C-1

D. PAH Extraction and Analytical Procedures

(for Area Cassettes Only)..................... D-1

E. Survey Data......................... 


\section{FIGURES}

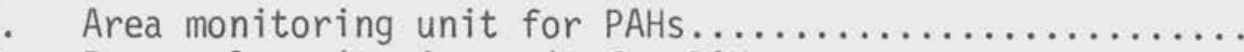

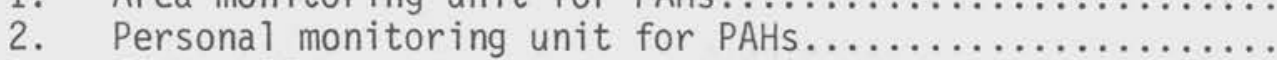

3. FCCUs: $95 \%$ confidence limits on the geometric means

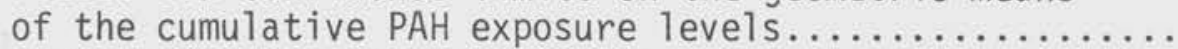

4. FCCU exposure categories: $95 \%$ confidence 1 imits on the geometric means of the cumulative PAH exposure levels...

5. Delayed coker units: $95 \%$ confidence 1 imits on the geometric means of the cumulative PAH exposure levels...

6. Delayed coker unit exposure categories: $95 \%$ confidence limits on the geometric means of the cumulative PAH

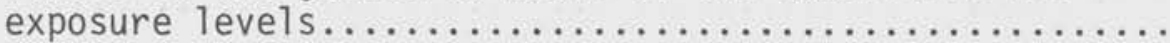

7. Scattergram - PAH exposure levels versus age of

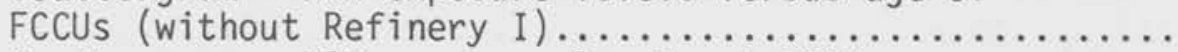

8. Scattergram - PAH exposure levels at FCCUs versus crude API gravity index (without Refinery I) ...........

9. Types of coke produced: $95 \%$ confidence limits on the geometric means of the cumulative PAH exposure levels...

10. Scattergram - Production capacity versus PAH exposure

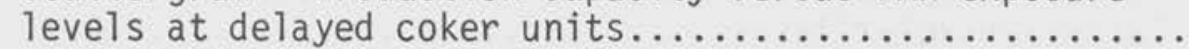

11. Scattergram - API gravity index versus PAH exposure

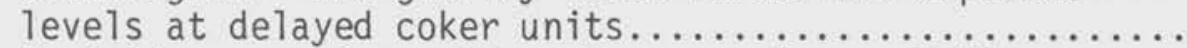

12. Asphalt processing units - Area sample cumulative

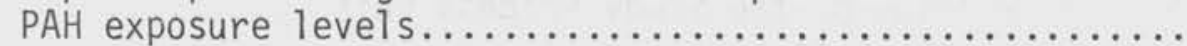

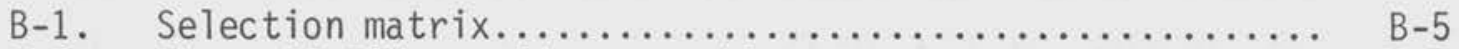

B-2. Phase II PAH sampling assembly............... B-7

C-1. Refinery A production area .................... $\mathrm{C}-2$

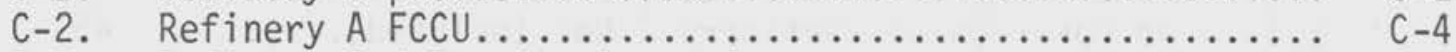

C-3. Refinery $A$ delayed coker unit.................. $C-7$

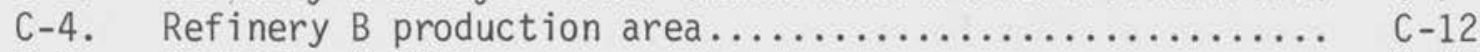

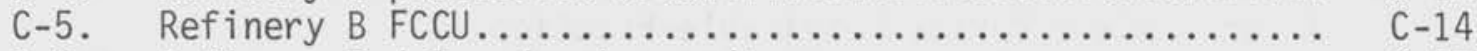

C-6. Refinery B delayed coker unit..........................

C-7. Refinery B deasphalting unit.....................

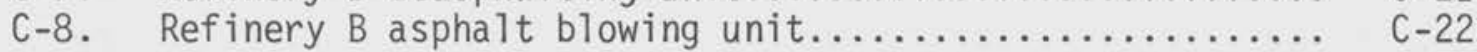

C-9. Refinery $C$ east production area.........................

$\mathrm{C}-10$. Refinery $\mathrm{C}$ west production area..................... $\mathrm{C}-24$

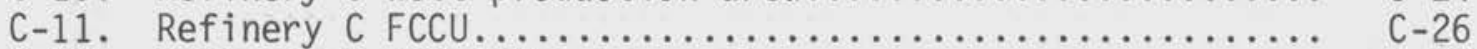

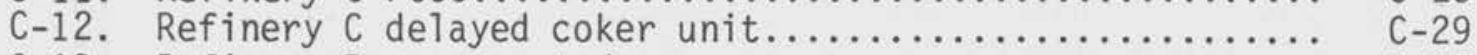

C-13. Refinery $D$ survey study area......................

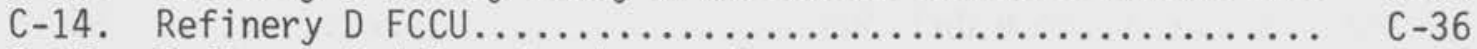

$C-15$. Refinery $D$ delayed coker unit...................

C-16. Refinery E production area....................

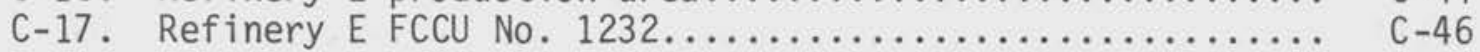

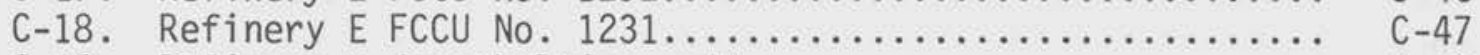

$\mathrm{C}-19$. Refinery $\mathrm{E}$ deasphalting unit............... $\mathrm{C}-51$

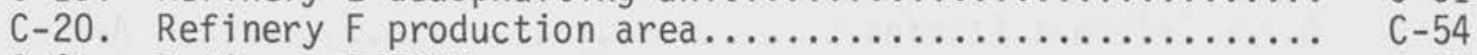

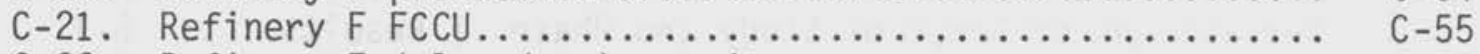

$\mathrm{C}-22$. Refinery $\mathrm{F}$ delayed coker unit................... $\mathrm{C}-59$

$\mathrm{C}$-23. Refinery $\mathrm{G}$ main production area................. $\mathrm{C}-64$

C-24. Refinery G FCCU.................... C-66 


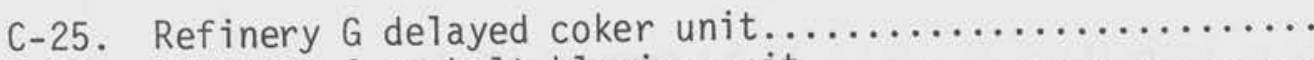

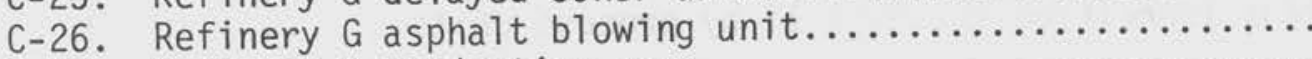

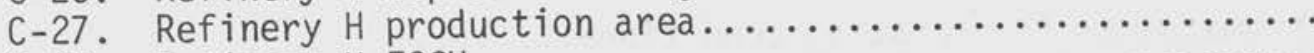

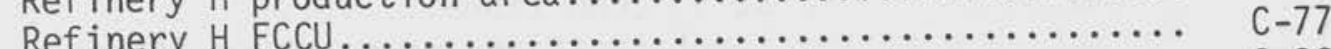

$\mathrm{C}$-29. Refinery $\mathrm{H}$ asphait processing (vacuum) unit........... $\mathrm{C}-80$

C-30. Refinery I main production area ........................

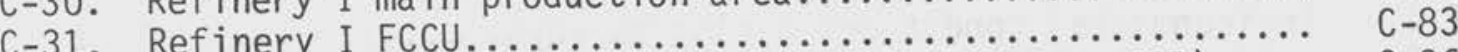

C-32. Refinery I delayed coker unit (pressure coke sti11).... C-86

\section{TABLES}

1. Summary of refineries and process units surveyed....... 10

2. Units and workers in nine refineries studied in

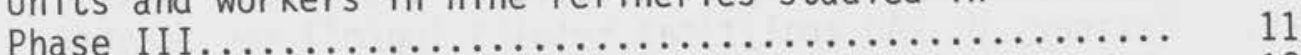

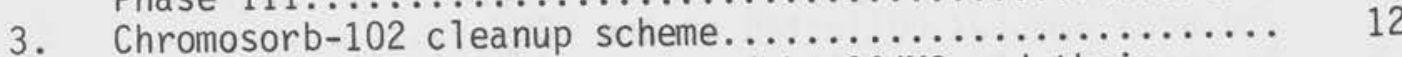

4. PAHs or groups of PAHs analyzed by GC/MS and their

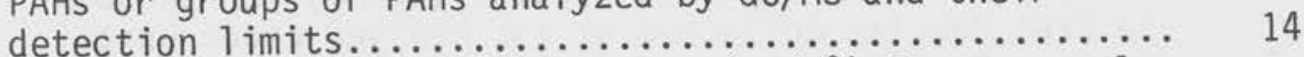

5. Refinery A PAH analytical results $\left(\mu \mathrm{g} / \mathrm{m}^{3}\right)$ for personal and area samples collected at the delayed coker unit....

6. Job titles and exposure categories at FCCU and delayed

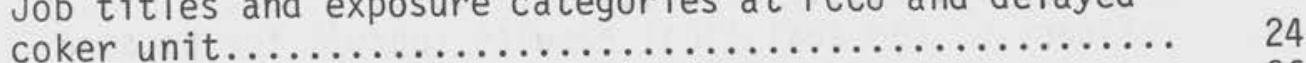

7. FCCUs - Cumulative PAH concentrations................. 26

8. FCCUs - Summary of cumulative PAH concentrations by exposure categories (a11 nine refineries)........... 27

9. FCCUs - Summary of cumulative PAH concentrations by exposure categories (excluding Refinery I) ........... 27

10. Delayed coker units - Cumulative PAH concentrations..... 28

11. Delayed coker units - Summary of cumulative PAH concentrations by exposure categories (a11 seven units). 31

12. Delayed coker units - Summary of cumulative PAH concentrations by exposure categories (excluding

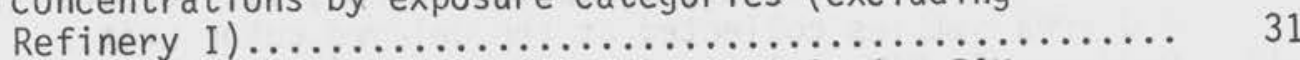

13. Deasphalting unit at Refinery E-Cumulative PAH

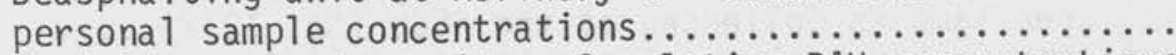

14. Asphalt processing units - Cumulative PAH concentrations

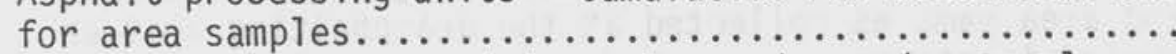

15. Comparison between upwind samples and area/personal

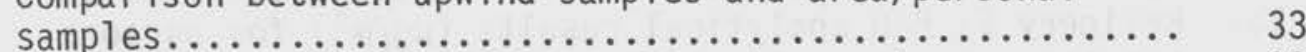

16. Distribution (\%) of PAHs found by ring number......... 33

17. Average distribution (\%) of PAHs at all nine refineries. 34

18. Particle-size distribution (\%) of total particulate

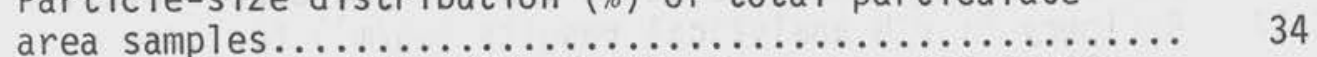

19. Average distribution (\%) of PAHs found by ring number

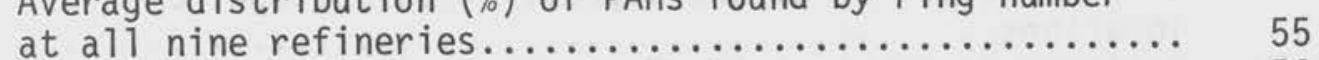

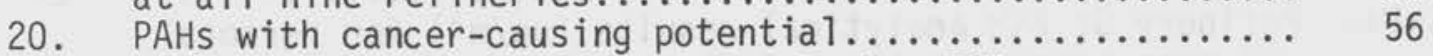

21. Smokers versus nonsmokers - Cumulative PAH exposure

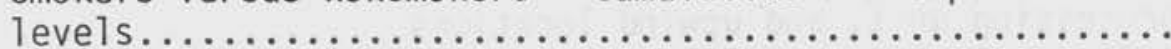


B-1. PAHs identified in Phase II by process units...........

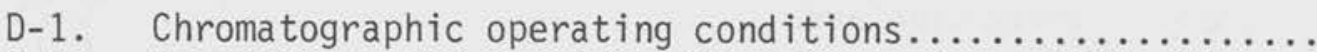

D-2. Parameters used for identification and quantification

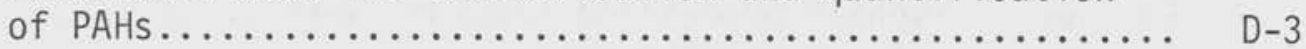

E-1. Environmental conditions during surveys ............ E-1

E-2. Refinery A: PAH analytical results $\left(\mu \mathrm{g} / \mathrm{m}^{3}\right)$ for personal and area samples collected at the FCCU............. E-2

E-3. Refinery A: PAH analytical results $\left(\mu \mathrm{g} / \mathrm{m}^{3}\right)$ for personal and area samples collected at the delayed coker unit.... E-3

E-4. Refinery A: PAH analytical results $\left(\mu \mathrm{g} / \mathrm{m}^{3}\right)$ for area samples collected at the asphalt unit and upwind

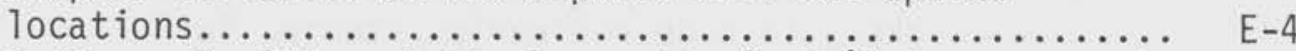

E-5. Refinery B: PAH analytical results $\left(\mu \mathrm{g} / \mathrm{m}^{3}\right)$ for personal and area samples collected at the FCCU............. E-5

E-6. Refinery B: PAH analytical results $\left(\mu \mathrm{g} / \mathrm{m}^{3}\right)$ for personal and area samples collected at the delayed coker unit.... E-6

E-7. Refinery B: PAH analytical results $\left(\mu \mathrm{g} / \mathrm{m}^{3}\right)$ for area samples collected at the asphalt units and upwind

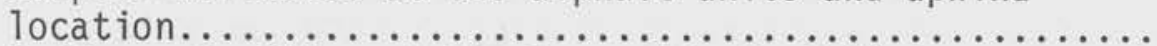

E-8. Refinery C: PAH analytical results $\left(\mu \mathrm{g} / \mathrm{m}^{3}\right)$ for personal and area samples collected at the FCCU............... E-8

E-9. Refinery C: PAH analytical results $\left(\mu \mathrm{g} / \mathrm{m}^{3}\right)$ for personal and area samples collected at the delayed coker unit.... E-9

E-10. Refinery C: PAH analytical results $\left(\mu \mathrm{g} / \mathrm{m}^{3}\right)$ for area samples collected at the asphalt units and upwind

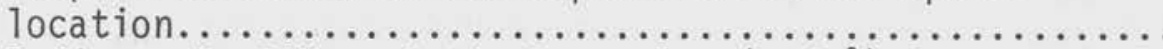

E-11. Refinery D: $P A H$ analytical results $\left(\mu \mathrm{g} / \mathrm{m}^{3}\right)$ for persona and area samples collected at the FCCU and upwind

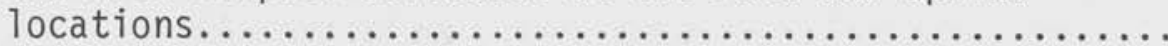

E-12. Refinery D: PAH analytical results $\left(\mu \mathrm{g} / \mathrm{m}^{3}\right)$ for personal and area samples collected at the delayed coker unit.... E-12

E-13. Refinery E: PAH analytical results $\left(\mu \mathrm{g} / \mathrm{m}^{3}\right)$ for personal and area samples collected at the FCCU (No. 1232) ...... E-13

E-14. Refinery E: PAH analytical results $\left(\mu \mathrm{g} / \mathrm{m}^{3}\right)$ for personal and area samples collected at the deasphalting unit and

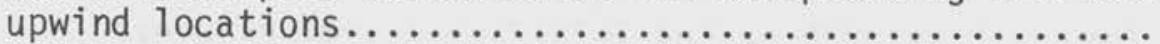

E-15. Refinery F: PAH analytical results $\left(\mu \mathrm{g} / \mathrm{m}^{3}\right)$ for personal and area samples collected at the FCCU.............. E-15

E-16. Refinery F: PAH analytical results $\left(\mu \mathrm{g} / \mathrm{m}^{3}\right)$ for personal and area samples collected at the delayed coker unit.... E-16

E-17. Refinery F: PAH analytical results $\left(\mu \mathrm{g} / \mathrm{m}^{3}\right)$ for area samples collected at the asphalt units and upwind

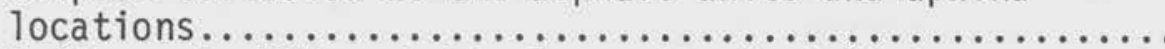

E-18. Refinery G: PAH analytical results $\left(\mu \mathrm{g} / \mathrm{m}^{3}\right)$ for personal and area samples collected at the FCCU, asphalt processing unit, and upwind locations.............. E-18

E-19. Refinery G: $P A H$ analytical results $\left(\mu \mathrm{g} / \mathrm{m}^{3}\right)$ for personal and area samples collected at the delayed coker unit.... 
E-20. Refinery H: PAH analytical results $\left(\mu \mathrm{g} / \mathrm{m}^{3}\right)$ for area, personal, and upwind samples..................... E-20

E-21. Refinery I: PAH analytical results $\left(\mu \mathrm{g} / \mathrm{m}^{3}\right)$ for personal and area samples collected at the FCCU and the asphalt

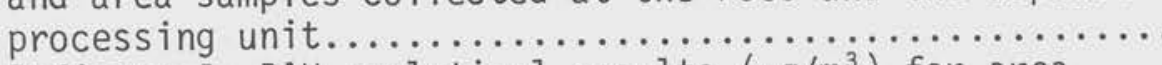

E-22. Refinery I: PAH analytical results $\left(\mu \mathrm{g} / \mathrm{m}^{3}\right)$ for area and personal samples collected at the delayed coker

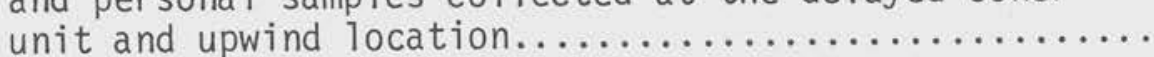





\section{INTRODUCTION}

\section{AUTHORITY}

The Williams-Steiger "Occupational Safety and Health Act of 1970" was passed into law "to assure safe and healthful working conditions for working men and women...." This Act established the National Institute for Occupational Safety and Heaith (NIOSH) in the Department of Health, Education, and Welfare (presently the Department of Health and Human Services) and the Occupational Safety and Health Administration (OSHA) in the Department of Labor. The Act provides for research, informational programs, education, and training in the field of occupational safety and health and authorizes the enforcement of standards.

NIOSH has been given the authority and responsibility under the Act to conduct field research studies in industry, evaluate findings, and report on these findings. Section 20(a)(1) of the Act mandates NIOSH to "conduct (directly or by grants or contracts) research, experiments, and demonstrations relating to occupational safety and health..." Section 20 (c) provides the authority to enter into contracts, agreements, or other arrangements with appropriate public agencies or private organizations for the purpose of conducting studies relating to responsibilities under the Act. For this purpose, NIOSH with the financial support of the Environmental Protection Agency (EPA-IAG-DS-E773) has established a contractual agreement with Enviro Control, Inc. (Enviro) to study worker exposures to potential health hazards in petroleum refineries.

\section{PURPOSE AND NEED FOR STUDY}

The U.S. petroleum refining industry started in 1861 in Pennsylvania, with the first refineries primarily limited to kerosene production. By 1920 , with the increased use of the internal combustion engine, petroleum refining had already become one of the major domestic industries; and by 1946, petroleum replaced coal as the country's number one energy source (API, 1977). Currently there are about 300 operating refineries in 43 states (Cantrel1, 1980) representing a work force of about 100,000. The total U.S. production capacity of 18 million barrels per day is by far the largest of any nation in the world; the U.S.S.R. is second with a capacity of about 11 million barrels per day (Anon., 1980). While there is a significant shift toward the utilization of other energy sources, the demand for petroleum and all of its numerous products will remain strong well into the next century.

The modern refinery is a complex and efficient integration of many separate process units and operations yielding a multitude of end products. Technological advancement has enabled the utilization of almost every fraction of the crude, resulting in very little waste. Major refinery processes include: 
- atmospheric and vacuum distillation

- catalytic cracking

- alkylation

- polymerization
- isomerization

- desulfurization

- catalytic reforming

- solvent extraction

- blending and packaging

Products include:

- gasoline (various grades)

- liquefied petroleum gas (butane, propane)

- fuel oils (\#2, \#6)

- Diesel oil
- kerosene and jet fuel

- lube oils and waxes

- asphalt

- coke

- petrochemicals (benzene, cumene)

In addition, there are numerous chemical additives, intermediates, and byproducts associated with refinery operations. Probably no other major industry incorporates as many different processes and materials; because of this, occupational health is especially important in this industry.

In recent years, there has been growing concern within the petroleum refinery industry. This is demonstrated by the fact that four epidemiology studies involving refinery workers have been published since 1979, whereas only five previous U.S. and Canadian studies have been identified. The overall increased awareness of occupational cancers has been a significant factor influencing the number of recent studies. Unfortunately, instead of answering the question of whether or not refinery workers face increased health risks, these studies viewed as a unit appear to confuse the issue. Six of these studies (API, 1974; Baird, 1967; Baylor and Weaver, 1968; Gafafer and Sitgreaves, 1940; Theriault and Goulet, 1979; Wade, 1963) in general showed favorable results for this industry in terms of worker health compared to the general population; whereas three recent mortality studies (Gottlieb, 1980; Hanis et al., 1979; Thomas et al., 1980) have indicated increased cancer potential for refinery workers. These as well as other relevant health studies are reviewed in detail in Appendix A.

In addition to the questions raised by the confounding findings of these epidemiology studies, a review of the available information reveals that, in general, very few of the numerous potential refinery hazards have been monitored adequately to characterize worker exposure in the industry accurately. This is especially true for many compounds that are known to cause health effects after prolonged exposures at low concentrations (e.g., polyaromatic hydrocarbons (PAHs), aromatic amines, carbon disulfide). Potential hazards that have been monitored extensively in refineries are noise, asbestos, and benzene; this has been largely due in recent years to regulatory and compliance issues.

The purpose of this NIOSH-sponsored industrial hygiene study is to help fill some of these information gaps concerning the petroleum refining industry by (1) identifying and quantitating worker exposure to selected hazardous agents found in the refinery environment, and (2) providing the scientific community with relevant information to assist in the control of these agents. 
It was not the intent of this project to attempt to perform a comprehensive characterization of the entire refinery from start to finish. The number and complexity of processes, as well as the large number of potentially hazardous materials, would have required a level of effort well beyond the resources of this project. Consequently, the project was structured into three main phases, the first two of which were designed to develop the scope of this study. Phase I provided a comprehensive assessment of the entire refinery in terms of the important occupational health concerns and the status of available information. Phase II consisted of three preliminary industrial hygiene surveys which included sampling. Based on the successful completion of these two initial phases, a meaningful yet manageable scope of study was developed for the nine in-depth refinery surveys which comprised Phase III.

\section{SCOPE OF STUDY}

The scope of study for the main phase of this project was the characterization of worker inhalation exposure to PAHs in the fluid catalytic cracking, delayed coking, and asphalt processing units. Since process units are the basic components of every refinery, the task of limiting the scope of study was initiated by limiting the number of process units to be investigated. The unit selection procedure involved a detailed evaluation of the available information on the major process units in terms of the associated hazards, toxicity of these hazards (paying particular attention to suspected carcinogens), and the status of available worker exposure information. The importance of the unit in terms of the total industry was also considered. The three types of process units selected for study ranked highest in the overall evaluation. The detailed evaluation and selection process is described in Appendix B.

The decision to limit the study further to worker exposure to PAHs was made on the basis of the findings of both preliminary phases. Among the numerous potential hazards listed for each of the selected process units in Phase I, there were several chemicals or classes of chemicals associated with some cancer-causing potential. To produce a study protocol that was thorough enough to characterize worker exposure accurately in the nine refineries, it was decided that the characterization should be focused primarily on potential carcinogenic hazards. It was felt that a detailed characterization of worker exposure to this group of toxic materials within these three important refinery processes or types of processes would contribute a great deal to the understanding of whether or not petroleum refinery workers in general are exposed to these occupational health risks. This approach seemed especially relevant in light of the concerns mentioned previously related to occupational cancer risk in the petroleum refining industry.

During the three preliminary sampling surveys performed in Phase II, area air samples were collected in the study process units for the following chemicals or classes of chemicals listed below; each is associated with carcinogenic potential.

- PAHs (including several azoheterocyclic compounds)

- aromatic amines
- trace metals

- nitrosamines

- nickel carbonyl 
Although only a limited number of samples were collected at a small number of process units, the results showed that PAHs (and several azo-heterocyclic compounds) were the only compounds sampled for that were consistently found. For convenience in this report, the term PAH will also include azo-heterocyclic compounds. The literature review revealed that PAHs are being looked at with suspicion, especially since concern over occupational-related cancers has increased (Bjorseth and Dennis, 1980; Blot et al., 1977; Gordon and Bryan, 1973; Maugh, 1977). PAHs are known to be present in numerous process industries including refineries, and occur either as naturally present constituents in the crude oil or through conversion of organic material by hightemperature and high-pressure systems. Monitoring for these compounds has increased recently in various areas, such as coal conversion industries (Tanita et al., 1980), with improved analytical methods (Jackson and Cupps, 1978; Jones et al., 1976; Lamb and Roberts, 1980; Zelenski et al., 1980). In regard to refineries, this is another area where several of the larger oil companies are developing monitoring programs specifically for PAHs, but very little worker exposure information exists.

Two studies by Exxon in this area were found and are summarized in Appendix A. Based on the preliminary sampling results and the general lack of detailed information available in this area, PAHs were selected for in-depth study during the nine refinery surveys. Detailed descriptions of these preliminary surveys and results are presented in Appendix B.

The fact that the PAHs were the only group of compounds sampled for in the preliminary phase that were found consistently should not rule out the presence of the other compounds or classes of compounds. It must be remembered that only a small number of three process units were sampled, and that the number of samples collected was limited. Even though the other potential hazards were not studied any further in this project, the possibility of their presence in petroleum refineries certainly still exists.

It is realized that the significance of the PAH data generated in this study will not be clear-cut and that the data will not immediately provide the answers to questions such as whether PAHs are causing occupational cancers. Even though there are strong suggestions that some PAHs can cause cancer in humans when inhaled, there is no definitive evidence that indicates what concentrations are required, or for how long (National Academy of Sciences, 1972; WHO, 1973). Despite this, the results will provide important information in areas such as:

- The specific PAHs to which refinery workers are exposed, with special attention to those with specific evidence of carcinogenic potential. This will help identify priorities for future toxicity and epidemiology research.

- The background levels of PAHs at refineries (upwind boundary samples) relative to worker exposures.

- The relative exposure levels between study units and job categories. 
- The effect of such variables as refinery size, age and location, size of parent company, crude type, etc.

- The effectiveness of control methods such as specific engineering controls and work practices.

- The relative PAH concentrations in this industry compared to those in other industries. This may be beneficial to new energy technologies (e.g., coal conversion) where PAH emissions are of particular concern. 
METHOD OF STUDY

\section{GENERAL APPROACH}

The study, designed to characterize worker exposure to PAHs, consists of nine industrial hygiene surveys of selected petroleum refineries located throughout the country. The primary emphasis of each survey was to collect personal and area PAH samples at the three types of process units selected for this study. Other sampling included respirable fraction samples for PAHs and total particulate samples for size-distribution determination.

A relatively new sampling and analytical method for PAHs was used, consisting of a two-stage sampling unit (filter and solid sorbent) and analysis by gas chromatography/mass spectroscopy. The major advantage of this method is that a large number of individual PAHs can be quantitatively evaluated at extremely low concentrations $\left(\mu \mathrm{g} / \mathrm{m}^{3}\right)$. The primary disadvantage is the very high cost associated with this method relative to more conventional analytical methods; consequently, the number of samples generated during these nine surveys had to be limited. This was achieved by a carefully planned sampling strategy that included performing personal sampling only at the fluiid catalytic cracking units (FCCUs) and at the delayed coker units; sampling was restricted to area samples at the asphalt processing units. This decision was based on information accumulated during the preliminary phases (discussed later).

Each survey was conducted over 3 days, with sampling performed during the day shifts of the second and third days. During the morning of the first day, an opening meeting was held with the appropriate plant personnel and the NIOSH representatives. The survey team explained the project, the purpose and objective of the surveys, and answered any questions. These meetings were further utilized to coordinate the survey and sampling schedule so that plant operations and personnel would incur minimal interference.

The first day of the survey also enabled the survey team to familiarize themselves with the refinery and specific process units. Discussions were held with the operators and other unit workers to inform them of the sampling activities. The area and upwind sample locations were also selected this first day.

On the second and third days, samples were collected for the entire day shift. One industrial hygienist was in charge of the FCCU and one was in charge of the coker, the two units where most of the sampling activity took place. The survey team gathered information on process specifics, unit design, control technology, and work practices, as well as kept in touch with each worker being sampled to document work activity. 


\section{SITE SELECTION}

The objective in selecting the nine refineries was to provide a group as representative of the entire industry as possible, while allowing for the attainment of the specific project goals. The three refineries visited in the preliminary sampling phase were automatically included in this group of nine, which left six additional refineries to be selected.

At the time of the selection process (January 1979), there were approximately 285 operating domestic refineries (Cantrel1, 1978) representing a wide variety in terms of complexity and processes, size or capacity, number of workers, geographical location, crude type, etc. In order to select the six additional study refineries, a set of criteria consistent with the project objectives was developed; this enabled a systematic approach to make the selections. Obviously, the selection criteria were dependent on the available information. The 1978 Annual Refinery Survey published by the 0 il and Gas Journal (Cantrel1, 1978) was the source for the majority of the refinery data used and included the following:

- refinery company name and location,

- crude capacity,

- charge capacity of process units, and

- production capacity and end products.

Further specific data on all refineries were not readily accessible. Based on the available information, the following four criteria were chosen for the selection process.

Presence of A11 Three Units

According to the 1978 Annual Refinery Survey, 142 (50\%) of the 285 refineries have catalytic crackers, $104(36.5 \%)$ produce asphalt, and $52(18.2 \%)$ produce coke. Out of the 285 domestic refineries, only $13-$ plus one of the refineries visited in the preliminary phase-had all three process units of interest for this study. Therefore, it seemed logical that the presence of al1 three process units be the first criterion employed in selecting refineries for further consideration. Being able to study as many selected process units as possible during the nine plant visits has obvious advantages. This group of 13 refineries could then be further evaluated against the remaining three criteria.

Plant Size

The processing capacity of refineries varies widely, ranging from 200 to 640,000 barrels per day. Twenty-nine refineries had processing capabilities greater than 150,000 barrels per day and produced $47.6 \%$ of the total U.S. capacity. One-third of the refineries had a capacity of less than 12,000 barrels per day, yet these refineries represented only $3.2 \%$ of the total processing capacity. 
An EPA study (Rosenberg et al., 1976) used the following refinery classifications in characterizing domestic refineries:

\begin{tabular}{|c|c|c|}
\hline Sma11: & $\begin{array}{l}\text { less } \operatorname{than} 5,600 \mathrm{~m}^{3} / \text { day } \\
(35,000 \mathrm{bbl} / \text { day })\end{array}$ & $139(56 \%)$ \\
\hline Medium: & $\begin{array}{l}5,600 \text { to } 16,000 \mathrm{~m}^{3} / \text { day } \\
35,000 \text { to } 100,000 \mathrm{bbl} / \text { day })\end{array}$ & $64(26 \%)$ \\
\hline Large: & $\begin{array}{r}\text { more than } 16,000 \mathrm{~m}^{3} / \text { day } \\
(100,000 \mathrm{bbl} / \text { day })\end{array}$ & $44(18 \%)$ \\
\hline
\end{tabular}

Also included is the number of refineries in each class and their percentage distribution.

The size (capacity) of a refinery will correspond to some degree to variations in operations, control methods, number and duties of employees, etc.; therefore, it was felt that refineries of all sizes should be included in the final nine. For the purpose of this study, the recommended distribution was :

$$
\begin{aligned}
& \text { - small - } 2 \\
& \text { - medium }-3 \\
& \text { large }-4
\end{aligned}
$$

This included all three sizes but was weighted more heavily towards the large refineries where there is a likelihood of greater numbers of employees, greater segregation of employees by process units, and increased control technology. The larger refineries would probably provide more data and information during the detailed surveys.

Major and Nonmajor $0 i 1$ Companies

The 15 largest oil refining companies had a total of 96 refineries $(34 \%$ of total number) and a combined crude capacity of $70 \%$ of the total. These are the companies that generally have complex corporate structures, large research and development programs, and occupational safety and health programs that include industrial hygienists. For the purposes of this study, these were referred to as "major" oil companies; the remaining companies were referred to as "nonmajor" companies. It was considered important to include two or three of these "nonmajor" or independent refineries in the study to see if there were any significant variations from the large, "major" companies.

\section{Geographical Location}

Refineries were located in 41 of the 50 states (Cantre11, 1978), with heavy concentrations in Texas (52), California (40), and Louisiana (23). Location and weather can influence the type of crude, process modifications, and control technology. Therefore, the last criterion used in site selection was that the nine locations chosen should represent the general distribution pattern of the refineries. 


\section{Selection Criteria}

There were 13 domestic refineries, in addition to one already included in the study, that met the first criterion of having all three process units. Using the other three criteria, six refineries were selected from the 13 . These six refineries, in addition to the original three, gave the following distribution for this study.

- Size

Sma11: 2

Medium: 3

Large: 4

- Major or Nonmajor

Major: 6

Nonmajor: 3

- Geographic Distribution

$\begin{array}{ll}\text { Oklahoma: } & 2 \\ \text { Texas: } & 1 \\ \text { California: } & 1 \\ \text { Montana: } & 1 \\ \text { Wyoming: } & 1 \\ \text { Minnesota: } & 1 \\ \text { Ohio: } & 1 \\ \text { Pennsylvania: } & 1\end{array}$

DESCRIPTION OF REFINERIES AND STUDY PROCESS UNITS

Table 1 represents a summary of the nine refineries and their study process units surveyed during this project. More detailed descriptions are given in Appendix C.

\section{SAMPLING STRATEGY AND PROCEDURES}

In the FCCUs and delayed cokers, the focus was on personal monitoring, whereas only area samples were taken in the asphalt processing units. Table 2 shows the number of process units and associated workers in the nine refineries that were studied in this phase.

The following sampling strategy was followed as closely as possible.

- Sampling at each refinery was scheduled during the day shifts only, on 2 consecutive days. At several delayed coking units, this had to be slightly modified because of the coke cutting schedule.

- Personal monitoring at each FCCU and coker unit included two 8-hour samples (collected on successive days) for every (or almost every, depending on the refinery) worker assigned to these units. 


\begin{tabular}{|c|c|c|c|c|}
\hline ב্য & 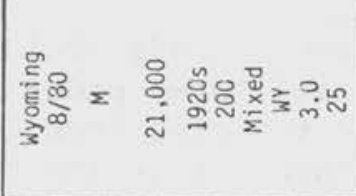 & 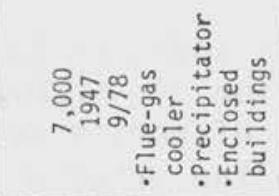 & 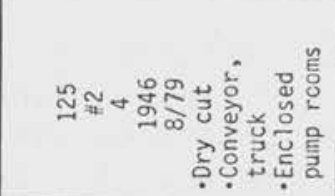 & ร \\
\hline 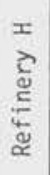 & 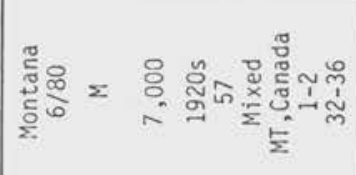 & 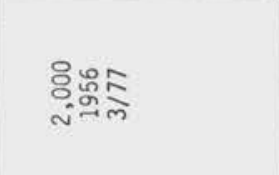 & $\stackrel{0}{a}$ & > 애ㅇㅛㅛ \\
\hline 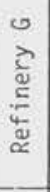 & 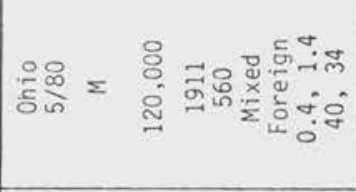 & 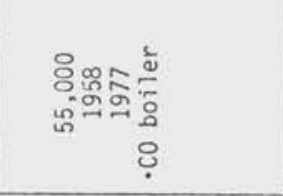 & 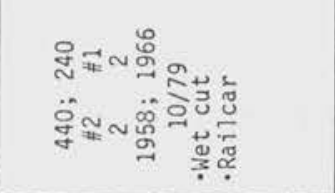 & 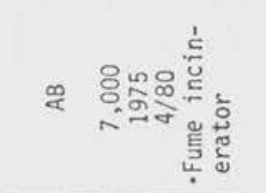 \\
\hline 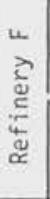 & 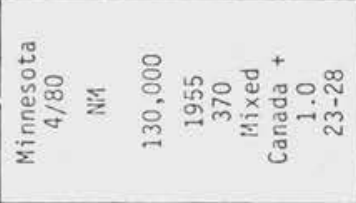 & 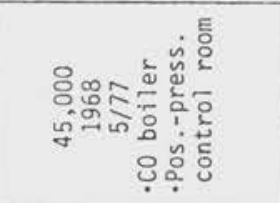 & 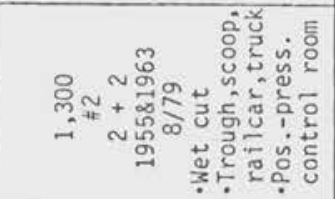 & 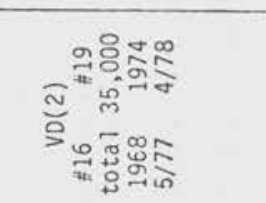 \\
\hline 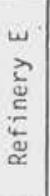 & 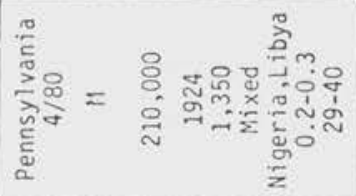 & 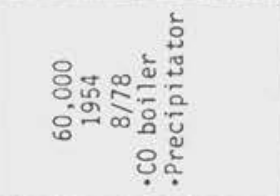 & $\stackrel{20}{a}$ & 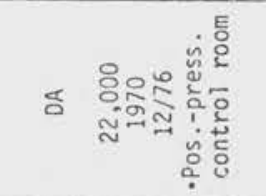 \\
\hline 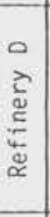 & 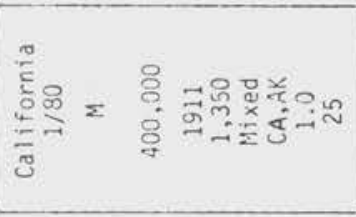 & 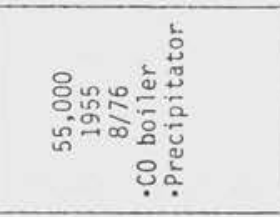 & 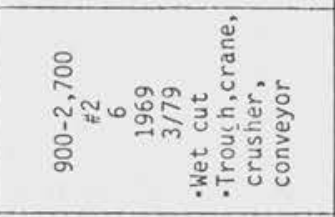 & 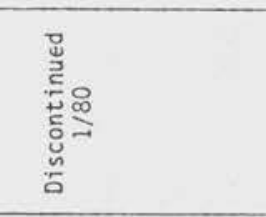 \\
\hline 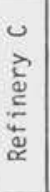 & 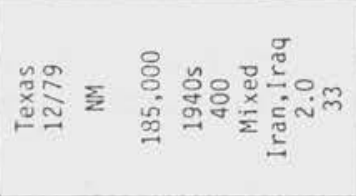 & 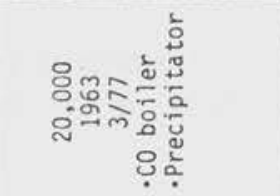 & 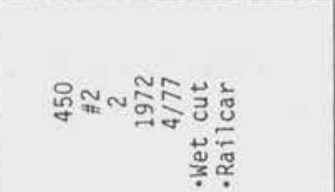 & స. \\
\hline 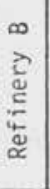 & 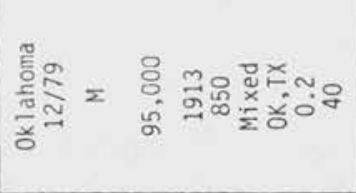 & 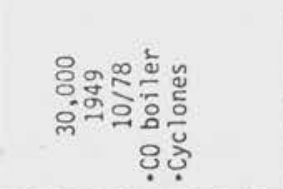 & 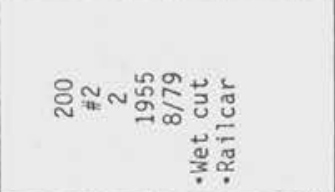 & 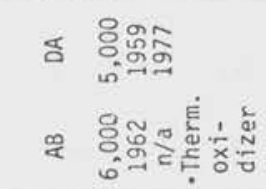 \\
\hline 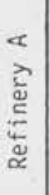 & 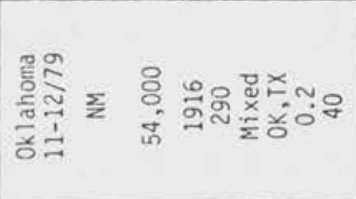 & 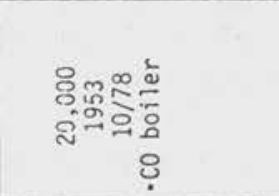 & 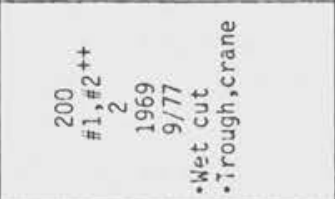 & ஐ \\
\hline 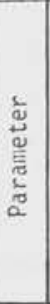 & 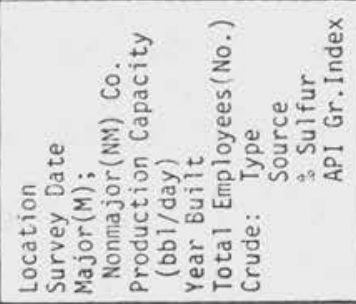 & 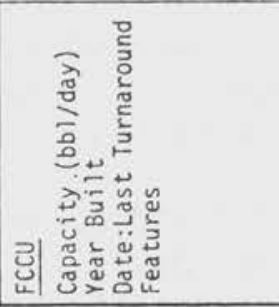 & 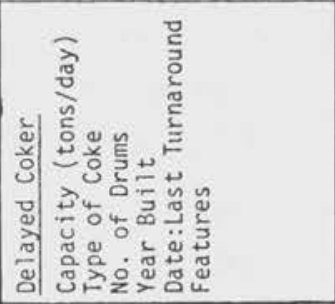 & 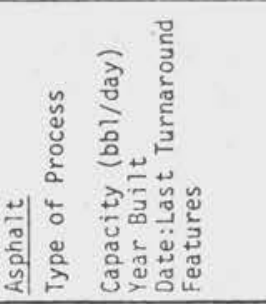 \\
\hline
\end{tabular}


Table 2. Units and workers in nine refineries studied in Phase III.

\begin{tabular}{|c|c|c|c|c|c|}
\hline \multirow{2}{*}{ Refinery } & \multicolumn{2}{|c|}{ FCCU } & \multicolumn{2}{c|}{ Coker } & Asphalt \\
\cline { 2 - 6 } & $\begin{array}{c}\text { No. of } \\
\text { units }\end{array}$ & $\begin{array}{c}\text { No. of } \\
\text { workers }\end{array}$ & $\begin{array}{c}\text { No. of } \\
\text { units }\end{array}$ & $\begin{array}{c}\text { No. of } \\
\text { workers }\end{array}$ & $\begin{array}{c}\text { No. of } \\
\text { units }\end{array}$ \\
\hline A & 1 & 5 & 1 & 7 & 1 \\
B & 1 & 6 & 1 & 6 & 2 \\
C & 1 & 4 & 1 & 5 & 2 \\
D & 1 & 7 & 1 & 8 & 1 \\
E & 1 & 8 & 1 & 9 & 2 \\
F & 1 & 5 & 1 & 7 & 1 \\
G & 1 & 3 & 1 & 4 & 1 \\
H & 1 & 3 & & 46 & 11 \\
I & 1 & 4 & 1 & & \\
\hline Total & 9 & 45 & 7 & 46 & \\
\hline
\end{tabular}

- Two area samples, taken in locations where PAH concentrations were suspected to be relatively high, were included for each FCCU and coker unit.

- Only area samples were collected in the asphalt processing units. Personal monitoring was not conducted here because: (1) Phase II area samples showed PAH concentrations to be much lower than in the other two units (much greater possibility of nondetectable personal monitoring results), and (2) the workers in these units are often assigned to other process units as well. Two area samples per asphalt processing unit were collected.

- In the first four refinery visits, alongside each area sample in the three process units, an identical sampling unit with a cyclone preselector was set up. The purpose of this was to estimate the effect of nonrespirable-size particles on the amounts of PAHs collected. The nonrespirable particulates were removed from the cyclones periodically during the sampling period to minimize any volatilization of PAHs off these particulates and onto the adsorbent collection medium.

- During the last five refinery surveys, alongside each area sample in the three process units, a total particulate area air sample was collected for optical sizing. The particle-size distribution is of interest since airborne PAHs are believed to be primarily in the form of aerosols (National Academy of Sciences, 1972). This can be either as coke or catalyst particulate matter, or as PAH vapors that condense or adsorb on other particles.

- At least one upwind area sample was collected at each refinery's boundary line, and also several blank samples were prepared and analyzed for each visit. 
PAHS

NIOSH Method No. P\&CAM 183 (NIOSH, 1977) for PAHs has the disadvantages of: (1) having a limited detection range for the individual compounds ( 0.2 to $2.7 \mu \mathrm{g} /$ sample), and (2) not providing for the collection of PAH vapor. Because of this, a more suitable method, detailed below, was developed for this project. This method is currently undergoing a series of detailed analytical validation tests.

Sampling for airborne PAHs was performed by drawing air through a two-stage sampling unit consisting of a silver-membrane filter followed by Chromosorb $102(\mathrm{C}-102)$, a porous polymer adsorbent. The commercially-available $\mathrm{C}-102$ used for this study was heavily contaminated with PAHs and consequently required extensive pre-extraction prior to use. The C-102 cleanup scheme is presented in Table 3 . The area and personal sampling units were slightly different, as illustrated by Figures 1 and 2 . The area sampling cassette contained a silver-membrane filter followed by 3 to 4 grams of $\mathrm{C}-102$ sandwiched in the middle section of a three-piece cassette. A cyclone preselector was attached to this cassette for those samples intended to collect respirable-size particulate only. A modified sampling unit was used for personal monitoring. Approximately $150 \mathrm{mg}$ of $\mathrm{C}-102$ was packed in a glass tube following the silver-membrane-containing cassette, rather than in the cassette itself. The larger quantity of solid sorbent in the area cassettes minimized the possibility of sample breakthrough in high-concentration areas. The NIOSH method (P\&CAM 183) recommends the use of a glass-fiber filter in front of the silver-membrane filter to prevent clogging. Since this was not a problem in this study, the glass-fiber filter was not used.

Table 3. Chromosorb-102 cleanup scheme.

\begin{tabular}{|l|c|c|}
\hline \multicolumn{1}{|c|}{ Solvent } & $\begin{array}{c}\text { Number of } \\
\text { solvent changes }\end{array}$ & $\begin{array}{c}\text { Soxhlet extraction } \\
\text { time (hr) }\end{array}$ \\
\hline Methylene chloride & 4 & 48 \\
Methanol & 2 & 24 \\
$\begin{array}{c}\text { Methylene chloride/ } \\
\text { Methanol }(1: 1 ; \mathrm{v} / \mathrm{v})\end{array}$ & 2 & 48 \\
\hline
\end{tabular}

A portable MSA Model $S$ sampling pump, calibrated at about 1.7 liters per minute, was used with the area sampling unit. The personal sampling unit was used with a portable Dupont Model P-4000 pump, calibrated at about 2 liters per minute. These Dupont pumps were especially suited for this purpose since there was a very high pressure difference (about 25 inches of water) across the two-stage personal sampling unit. A bubble meter was used to calibrate the pumps before and after each survey. In the field, a calibrated precision rotameter was used to ensure maintenance of the proper flow rate. 


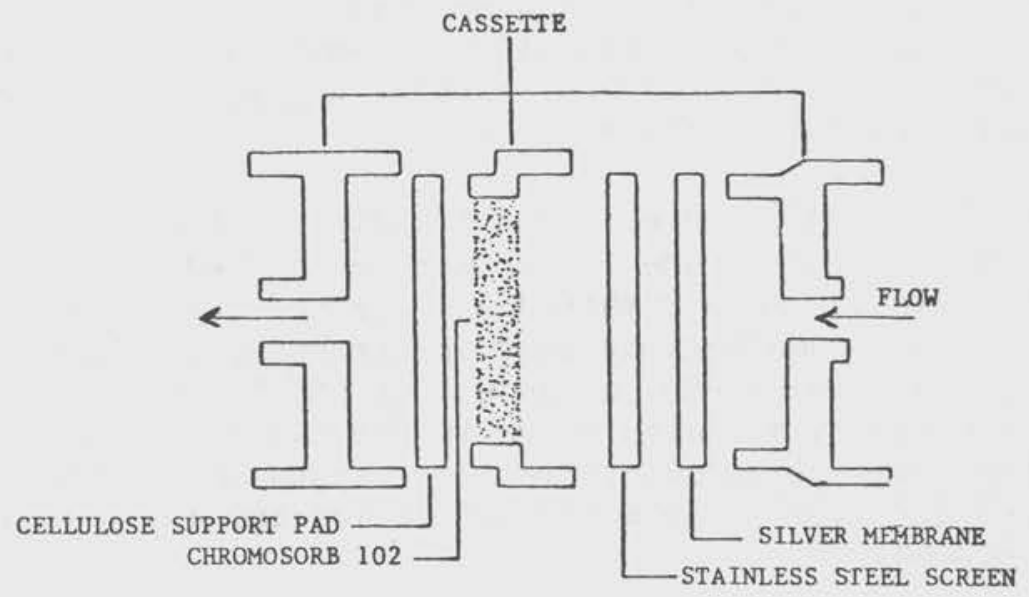

Figure 1. Area monitoring unit for PAHs.

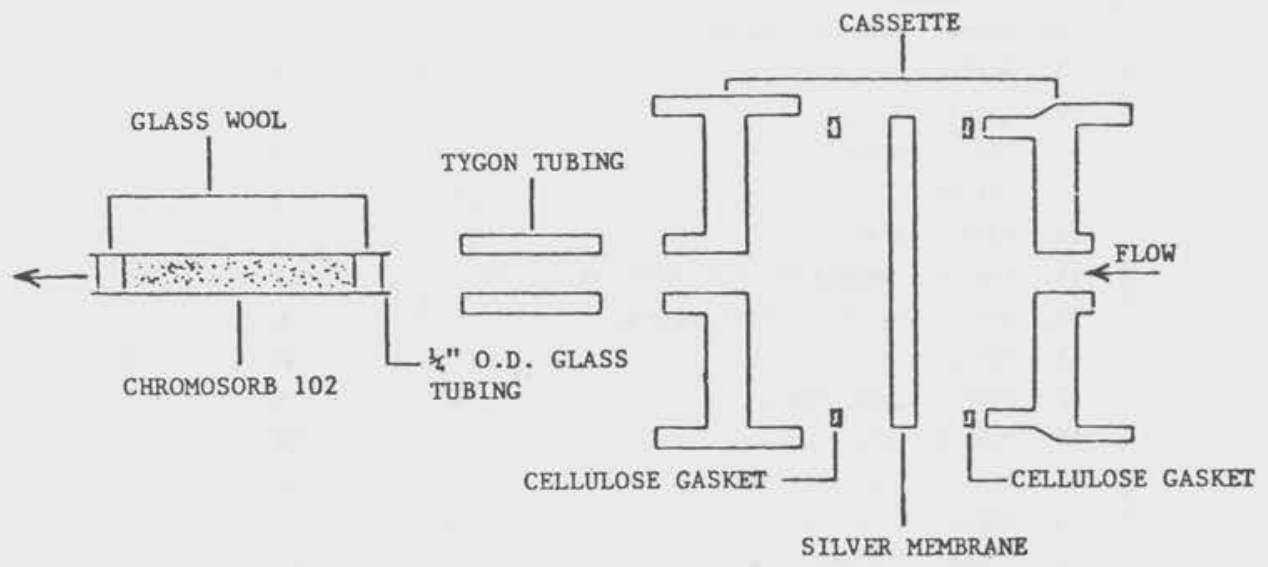

Figure 2. Personal monitoring unit for PAHs. 
Personal sampling units were clipped to the collar of the worker's shirt or jacket, as close as possible to his or her breathing zone without interfering with work or comfort. The faces of the cassettes were directed downward to minimize possible channeling through the C-102 tube. Each sampling unit, personal and area, was wrapped with aluminum foil in the field to prevent photodecomposition. As a further precaution against sample breakdown, the samples were stored in a refrigerator or freezer and packed with dry ice in an insulated shipping container for transport.

At the laboratory, the samples were stored at $-20^{\circ} \mathrm{C}$ in the dark until analysis. The C-102 and silver-membrane filter were extracted separately. After concentration, the extracts were combined and further concentrated to a specified volume. Gas chromatography/mass spectrometry (GC/MS) was used to analyze the samples for the 23 PAHs or groups of PAHs* listed in Table 4 . The individual detection limits are also shown in the table. Assuming a sample volume of $1 \mathrm{~m}^{3}$, these detection quantities correspond to detection concentrations of $0.001-0.017 \mathrm{\mu g} / \mathrm{m}^{3}$. Detailed extraction and analytical procedures are presented in Appendix D.

Table 4. PAHs or groups of PAHs analyzed by GC/MS and their detection limits.

\begin{tabular}{|l|c|c|}
\hline Compound or group of compounds & $\begin{array}{r}\text { Ring } \\
\text { No. }\end{array}$ & $\begin{array}{c}\text { Detection limits } \\
\text { (nanograms) }\end{array}$ \\
\hline 1. Naphthalene & $(2)$ & 1 \\
2. Quinoline & $(2)$ & 1 \\
3. 2-Methylnaphthalene & $(2)$ & 1 \\
4. 1-Methylnaphthalene & $(2)$ & 1 \\
5. Acenaphthalene & $(2)$ & 1 \\
6. Acenaphthene & $(2)$ & 1 \\
7. Fluorene & $(3)$ & 1 \\
8. Phenanthrene/Anthracene & $(3)$ & 1 \\
9. Acridine & $(3)$ & 2 \\
10. Carbazole & $(3)$ & 2 \\
11. Fluoranthene & $(4)$ & 1 \\
12. Pyrene & $(4)$ & 1 \\
13. Benzofluorene & $(4)$ & 4 \\
14. Benz(a)anthracene/Chrysene/Triphenylene (4) & 1 \\
15. Benzo(e)pyrene/Benzo(a)pyrene & $(5)$ & 6 \\
16. Perylene & $(5)$ & 4 \\
17. Dibenz(a,j)acridine & $(5)$ & 14 \\
18. Dibenz(a,i)carbazole & $(5)$ & 14 \\
19. Indeno(l,2,3-cd)pyrene & $(6)$ & 17 \\
20. Dibenzanthracene & $(5)$ & 14 \\
21. Benzo(g,h,i)perylene & $(6)$ & 10 \\
22. Coronene & $(7)$ & 14 \\
23. Dibenzpyrene & $(6)$ & 15 \\
\hline
\end{tabular}

* The term "PAHs" will be used to refer to individual and groups of PAHs. 
Particle-Size Distribution

Total particulate area air samples were collected at each sampling site for optical sizing. These samples were collected using an open-face sampling cassette containing a mixed cellulose ester filter $(0.45-\mu \mathrm{m}$ pore size) and a portable MSA Model G pump, calibrated at approximately 2 liters per minute.

For sizing, the particulate sample is prepared for optical microscopy by rendering the mixed ester filter transparent with a clearing solution. The prepared slide is focused in the field of the optical microscope and particles are sized using a Porton reticle grid which is mounted in the ocular lens, so that the grid is superimposed on the field of the microscope. The reticle is calibrated at the magnification to be used by means of a stage micrometer.

\section{STATISTICAL ANALYSIS METHODS}

The statistical methods used assume that the within-shift and interday РАH exposure concentrations were log-normally and independently distributed. Therefore, descriptive statistics included geometric means and geometric standard deviations. Confidence limits were calculated from the log-transformed data and the student t-test was used to compare geometric means.

In evaluating the variables which may contribute to the PAH exposure concentrations at the FCCUs and the delayed coker units, the data were plotted on a scattergram and Pearson Product-Moment Correlation Coefficients were calculated (Downie and Health, 1959). Values of " $r$ " greater than 0.50 were tested for significance using the student t-test. Inspection of the plots indicated that non-linear regressions might provide a better fit of the data, therefore, regressions of several forms were calculated. It was found the non-linear regressions of the form $y=a e^{b x}$ were more appropriate.

\section{COAL TAR PITCH VOLATILES}

There are no federal standards pertaining to airborne concentrations of individual PAHs for the purpose of minimizing the risk of cancer to workers. There is a standard for naphthalene of $10 \mathrm{ppm}$ or $50 \mathrm{mg} / \mathrm{m}^{3}$, measured as a time-weighted average (TWA) (29 CFR 1910.1000), but the goal of this level was to prevent ocular effects and not cancer. In 1967, the American Conference of Governmental Industrial Hygienists (ACGIH) adopted a threshold limit value (TLV) of $0.2 \mathrm{mg} / \mathrm{m}^{3}$ for coal tar pitch volatiles (CTPV) described as the "benzene-soluble" fraction. The purpose of this TLV was to minimize worker exposure to PAHs which were known to be present in CTPVs; six specific PAHs were listed: anthracene, benzo(a)pyrene, phenanthrene, acridine, chrysene, and pyrene. This TLV was promulgated as a federal standard under OSHA in 1970 (29 CFR 1910.1000). In 1972, the term CTPV was defined under 29 CFR 1910.1002 as "the fused polycyclic hydrocarbons which volatilize from the distillation residues of coal, petroleum, wood, and other organic matter."

The major disadvantage of using the benzene-soluble fraction as an indicator of total PAH exposure is that there is no certainty that there is a correla- 
tion between the two. The analytical method for measuring the benzenesoluble fraction is not limited to PAHs but will include all organic compounds collected on the filter and soluble in benzene. A recent NIOSH study investigating $\mathrm{PAH}$ exposure levels in coal liquefaction processes (Enviro Control, Inc., 1980a,b) has shown that in two industrial hygiene surveys there was no correlation between the benzene-soluble fraction and the total level of up to 29 PAHs analyzed individually by GC/MS and high-pressure liquid chromatography. Because of this, sampling for CTPVS was not performed in this study.

\section{LIMITATIONS OF THE STUDY}

Before discussing the results of this summary report, it is important to keep the basic limitations of this study in perspective. The first is that the sampling and analytical method for PAHs used in this study has not yet been thoroughly validated. As mentioned previously, this method was recently developed to improve several important aspects of the previously recommended NIOSH method. The new method is currently undergoing detailed NIOSH-sponsored validation tests which include collection and desorption efficiencies, effect of environmental conditions, sample stability, etc. Preliminary results indicate that there are no major problems with the overal1 method. In any case, extremely small quantities (nanograms) of numerous PAHs are being analyzed. Problems with individual samples in the field or in the laboratory are distinct possibilities since the method is new and many of the procedures are still in a relatively developmental stage.

The other basic limitation of this study is that the samples were collected over two work shifts during two consecutive days at eâch refinery. The surveys represent an evaluation of conditions present on the days during which the study was conducted at each refinery. In general, however, there were no unusual operational or environmental conditions during the surveys that would cause one to believe that these results are not representative of the process units and refineries. 
RESULTS OF SURVEYS

OVERALL DESCRIPTION OF THE STUDY PROCESS UNITS

Fluid Catalytic Cracking Units (FCCUs)

Although the production capacities of the nine FCCUs studied ranged from as low as 2,000 barrels per day (Refinery $H$ ) to as high as 60,000 barrels per day (Refinery E), all of the units were quite similar in terms of process, equipment, structures, and even work forces.

The fresh feed to the units consisted of atmospheric gas oil from the crude distillation unit and light and heavy gas oils from the vacuum unit. In most cases, this feed was preheated by a gas-fired furnace. The feed plus heavy gas oil and slurry recycle from the unit fractionator were mixed with the hot catalyst at the beginning of the riser leading to the reactor. The catalytic cracking process can take place in the riser and/or the reactor. The type of catalyst used in all of the units was an alumina-type synthetic zeolite. After the cracking process, the product vapors and catalyst were separated, usually by a series of cyclones. The hydrocarbons were transferred from the top of the reactor to the fractionator where the various products were separated. The catalyst was stripped of any remaining oil with steam and delivered to the regenerator where the spent catalyst was reactivated by oxidizing the accumulated carbon at a temperature of about $1,200^{\circ} \mathrm{F}\left(649^{\circ} \mathrm{C}\right)$.

The main products from the fractionator normally included the following:

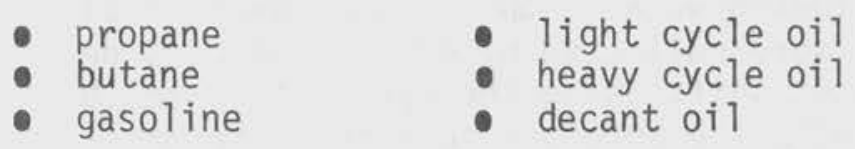

One of the major differences observed between FCCUs was the way in which the regenerator flue gas was treated, if at all, before being released to the atmosphere. Seven of the nine units utilized a CO boiler that burned the gas with an auxiliary fuel before it was released; of these seven, three plus one other used an electrostatic precipitator for the removal of catalyst fines. Only ore unit (Refinery H) did not use either method; nowever, this was also the unit having the smallest production capacity.

Most of the FCCUs had their own individual control room or building located within the unit area. This was not the case at Refineries $G$ and $H$, where several or all of the production units were run out of one centrally licated control room. These control centers were usually small, separate buildings or rooms in larger pump or compressor buildings built of brick or cinder block. While almost all were air-conditioned, only the control center at Refinery $F$ was under positive pressure. Eating, washing, and locker 
rooms were usually adjacent to the control room. Most unit production workers spent a good percentage of their shift inside the control rooms (or adjacent rooms). This portion of the shift ranged from up to 50 to $60 \%$ for the outside operators to essentially 100\% for the inside operators.

The average work force observed for the FCCUs surveyed was five workers (not including trainees) per shift. This generally included a supervisor or lead operator, an inside operator (boardman), and three outside operators. The actual number varied slightly with the size of the particular unit. At Refinery $\mathrm{H}$, the smallest refinery with the smallest FCCU (production capacity), there was a total of only three production workers per shift for all five of the process units. The unit at Refinery $E$ had the largest production capacity and included a work crew of eight per shift. Refinery $G$ had a rather unique system: even though the FCCU there was a large unit $(55,000$ bbl/day), there were only two operators assigned full time to this unit. This refinery utilized a large, central control center for numerous units in the vicinity. Several of these units, including the FCCU, shared a supervisor, inside operator, and outside operator who worked out of this control center.

Besides the control room and associated worker facilities (e.g., locker and wash room), enclosed buildings at the FCCUs were normally limited to housing unit blowers or compressors. The equipment and structures used to handle heavy fractions (more likely to contain PAHs) were in fairly open areas, minimizing potential vapor accumulation. The heavy-fraction pumps (e.g., heavy gas oil, slurry recycle, and decant oil pumps) were generally located close together in a row outside in the open. This was not the case at Refinery I, where several enclosed buildings housed not only the control room and compressors, but also the heavy-fraction pumps and the base sections of the reactor, regenerator, and riser. The likelihood of PAH accumulation in these buildings was clearly shown by the sample results discussed in the next section.

The number of process stream samples collected daily for quality control varied widely among the units. Excluding water samples, the number could be as high as 8 to 10. Most of these were collected by one of the outside operators during the evening or night shift using the open-spigot-and-bottle method with and without sampling loops. Laboratory technicians normally collected the gas stream samples using a sample bomb or pre-evacuated inner tube.

Like most of the other continuous, closed-system process units, the FCCUs were normally smooth-running operations. Apart from the pump areas, most of the units were quite clean and well kept. Equipment breakdown is infrequent, but when it does occur it often involves a pump or compressor. These problems are repaired either by the unit operators or by in-house maintenance crews if more extensive repair is required. 


\section{Delayed Coker Units}

Although there were many similarities in the seven delayed coker units (Refineries $E$ and $H$ did not have this type of unit), there were more basic differences in the processes and equipment than in the FCCUs. The delayed coker unit at Refinery I was referred to as a "pressure coke still" by the refinery. This unit was quite different from the others in the group; the thermal cracking process was essentially the same, however. Therefore, for the purpose of this study, the unit is considered to be a delayed coker unit. There were two types of coke produced at the various units: a No. 1 grade coke referred to as "needle" coke, and the more commonly produced No. 2 grade coke or "sponge" coke. Needle coke is a higher quality coke that is much harder and denser than the sponge type. Needle coke was produced only at Refineries $A$ and $G$; sponge coke was produced at all seven refineries.

The total operations performed at a delayed coking unit can be divided into: (1) coke production, and (2) coke cutting and handling. The coke production process was very similar at Refineries A, B, C, D, F, and G. This was a semi-batch process with each complete batch cycle lasting between 40 and 48 hours. The charge stock was decant oil from the FCCU for needle coke, and primarily residual from the vacuum unit for sponge coke. The process cycle started with the feed, preheated by the convection portion of a gas-fired heater, going to the fractionator where the light ends were flashed off. The bottoms from the fractionator were then normally pumped back to the radiant side of the furnace where the charge for sponge coke was heated to about $900^{\circ} \mathrm{F}\left(482^{\circ} \mathrm{C}\right)$; the charge for needle coke was heated to a slightly higher temperature. The heated charge then was passed to one of the coking drums; the number of drums ranged from two to six at the six units. Each drum had a 40 - to 48-hour cycle with coke formation lasting about half that period ( 20 to 24 hours). The drums at each unit worked in pairs. The lighter vapor fractions of the thermal cracking operation were removed from the top of the drum and sent to the fractionator where the various products were separated and eventually recovered. Products from this type of unit, besides coke, included:

- propane gasoline
- butane
gas oil naphtha

At Refinery I, the production process was somewhat different. The charge was a mixture mainly of vacuum residual from the crude unit with smaller amounts of light cycle gas oil and decant oil from the FCCU and recycled gas oil ("clean oil"). This mixture was pumped to the \#1 tower fractionator that separated the lighter fraction from the heavy "black oil." This black oil was pumped directly to the soaker, while the lighter fraction went on to the \#2 tower fractionator where "clean oil" was separated from the naphtha and fuel gas fraction. The clean oil was pumped to the charge furnace, then to the soaker where it mixed with and heated the black oil. This heated mixture of clean and black oils was then directed to one of the four drums where the thermal cracking process began. Each drum had a 32-hour cycle with coke formation lasting about 16 hours. Because there were four drums, one drum was cut every 8 hours. The lighter vapor fractions of the thermal cracking operation were removed from the top of the drum and recycled back 
to the \#1 tower fractionator. The clean 0il, most of which is not thermally cracked, was included in this recycled portion. Products from this unit, other than sponge coke, included: fuel gas, propane, butane, naphtha, cycle gas oil, and cycle fuel oil.

At all seven delayed coker units, the production process was terminated and coke cutting was started by the switching of the feed to the second drum of the pair. After 6 to 9 hours, during which time both steam and water were used to cool the drum, the top and bottom were opened. At Refineries $A, B, C, D, F$, and $G$, the coke was cut with a high-pressure hydraulic bit. An initial hole was bored through the coke, and then the coke was cut from the bottom up. At Refineries $A, D$, and $F$, the coke fell down a chute into a storage pit. From there, a crane or drag scoop transferred the coke onto a truck. At Refineries B, C, and G, the cut coke fell directly into a railcar positioned beneath the drum. The cutting operation lasted from 2 to 6 hours.

The cutting operation was also different at Refinery I. After the top and bottom of the drum were opened, the coke was cut from the bottom with a steam-driven mechanical dri11. As the coke was cut, it fell onto a moving conveyor belt which loaded a truck. This cutting operation lasted about 2 hours.

The work force at each coking unit was divided into two groups: the operational group and the coke-cutting/handling group. The operational group, in charge of the normal unit operations, generally consisted of two or three individuals. This included an inside operator (boardman) and one or two outside operators. The size of the coke-cutting/handling group was generally from three to five workers. This included a driller, two to four helpers, and at Refineries $A$ and $F$ a crane operator. The work shift of this latter group depended directly on the coke-cutting schedule at each refinery. For those refineries that scheduled coke cutting the same time each day, whether once a shift or once a day, the coke cutters worked the corresponding shift. However, at Refineries $A$ and $C$, the cutting schedule changed every day. At these units, the coke cutters worked independently of any shift and reported about 1 hour before the scheduled cutting, whenever that might be.

Most of the delayed coking units had their own individual control room within the unit; this was the case at Refineries A, D, F, and I. At the other three refineries, the control room was shared to some extent. Most of these control centers also had eating, washing or showering, and locker facility areas nearby. As with the FCCUs, most of these control centers were air-conditioned, but only the one at Refinery $G$ was under positive pressure.

The unit at Refinery I was different from the rest of the units, in that equipment associated with heavy-fraction process streams was in an enclosed building without mechanical ventilation. While there were not as many heavy-fraction pumps as at the FCCU, the accumulation of PAH concentrations was of special concern at this unit. 
Equipment breakdown and minor delays were observed much more at this unit than at the others in the survey. Because of the coke-cutting and mechanical equipment involved here, this was not unexpected. Problems during surveys included a bent drill shaft, a stuck drill, leakage from the drum bottom, excess coke on the tracks preventing the movement of railcars, and breakdown of the coke crusher and conveyor belt. Even though cleanup was a routine operation during and after each coke cutting, because of the nature of the operation many areas of the delayed coking units were black and often appeared much dirtier than the closed-process units such as the FCCUs.

\section{Asphalt Processing Units}

The asphalt processing units studied at the nine refineries included three asphalt blowing $(A B)$ units, two deasphalting (DA) units, and six vacuum distillation (VD) units. It was the original intent of the study plan to include only $A B$ and $D A$ units. However, four of the refineries selected for study produced asphalt by utilizing the bottoms from the vacuum distillation units without any $A B$ or $D A$ unit. Since the product was still considered to be asphalt, this simplified asphalt processing was included for study.

\section{Asphalt Blowing (AB)}

The three $A B$ units studied were at Refineries $A, B$, and $G$. These units were all small and relatively simple in terms of process flow and equipment. The feed, which was normally vacuum bottoms, entered the vertical blowing vessels in the upper half at two or three points. Compressed air was then discharged into the bottom of the vessels oxidizing the heavy residue material. The blown asphalt was then pumped to storage, and the vent gas was normally burned in an incinerator of some type. The unit at Refinery A was not in total operation during the survey. The feed was being pumped through the unit without being blown. This was normal procedure when the finished asphalt product was not currently in demand.

The $A B$ units at Refineries $B$ and $G$ were quite similar. Each unit had two blowing towers side by side, and similar production capacities. Both units also had their own control building, which was not under positive pressure, within the unit. The work forces consisted of an inside board operator and a general outside operator on each shift. The unit at Refinery A had only one blowing tower and a much smaller production capacity. This unit was also operated out of a control room of an adjacent process unit. No workers were assigned full time to this unit; two outside operators from the adjacent unit spent a small percentage of their shift at this unit performing the limited routine operations.

\section{Deasphalting (DA)}

The two DA units at Refineries $B$ and $E$ had many similarities including the process and equipment. Residual from the crude unit was extracted with propane or a mixture of propane and butane to yield gas oil and asphalt. The oil was used as feed for the FCCU and in lube and wax units. The asphalt from the unit at Refinery $B$ went to the delayed coker and asphalt blowing 
units; the asphalt at Refinery $E$ was used for No. 6 fuel oil. The unit at Refinery B actually had two separate, almost identical sets of equipment and structures with the process streams yielding different proportions of oil and asphalt.

There was a separate control room or building within each unit. Both control rooms were air-conditioned with the one at Refinery $E$ also under positive pressure. There were three workers per shift assigned to each unit. This included one inside operator/boardman and two outside operators who performed the routine outside tasks on a continuous, closed-system process unit. One difference observed between units was that there was noticeably less heavy oil and asphalt-like material on the equipment, structures, and foundation at Refinery B than at Refinery E. At Refinery E, this type of material was especially present near the charge and asphalt pumps.

\section{Vacuum Distizzation (VD)}

Of the three methods in this study, this is the most simple type of asphalt processing by far. The bottoms from the vacuum distillation unit are considered to be asphalt and are pumped to storage. Four of the refineries surveyed (Refineries C, F, H, and I) had this type of process; Refinery C actually had three VD units, two of which were operating during the survey; Refinery F also had two operating VD units. None of these six VD units had a separate control room or any workers assigned to them full time. The control rooms and operators from larger adjacent process units were used. All of the asphalt pumps were outside in the open except at Refinery I. As at the FCCU and delayed coker unit of this refinery, this pump was in an enclosed building without mechanical ventilation.

\section{EXPOSURES OF WORKERS TO PAHS}

This section includes numerous tables of data presenting the results of the sampling performed during the nine surveys. More than 250 personal and area samples were analyzed for 23 different PAHs or groups of PAHs. Table 5 illustrates the type of detailed data generated for one study process unit at a single refinery. From this, it is clear that the large quantity of concentration values could very easily become unwieldy for subsequent evaluation unless effective methods for summarizing and presenting the data were developed. The use of the cumulative PAH concentration for each sample was the first decision; this enabled each sample to be associated with one general overall concentration rather than as many as 23 . The obvious disadvantage to this is that information regarding what specific compounds and what type of compounds (e.g., lighter molecular weight) actually found is obscured. This has been partially compensated for by calculating the percent distribution of individual PAHS, by ring number (2-7) and also the average number of PAHs found per sample. The complete data for each survey and a summary of the environmental conditions during the sampling periods are included in Appendix E. 


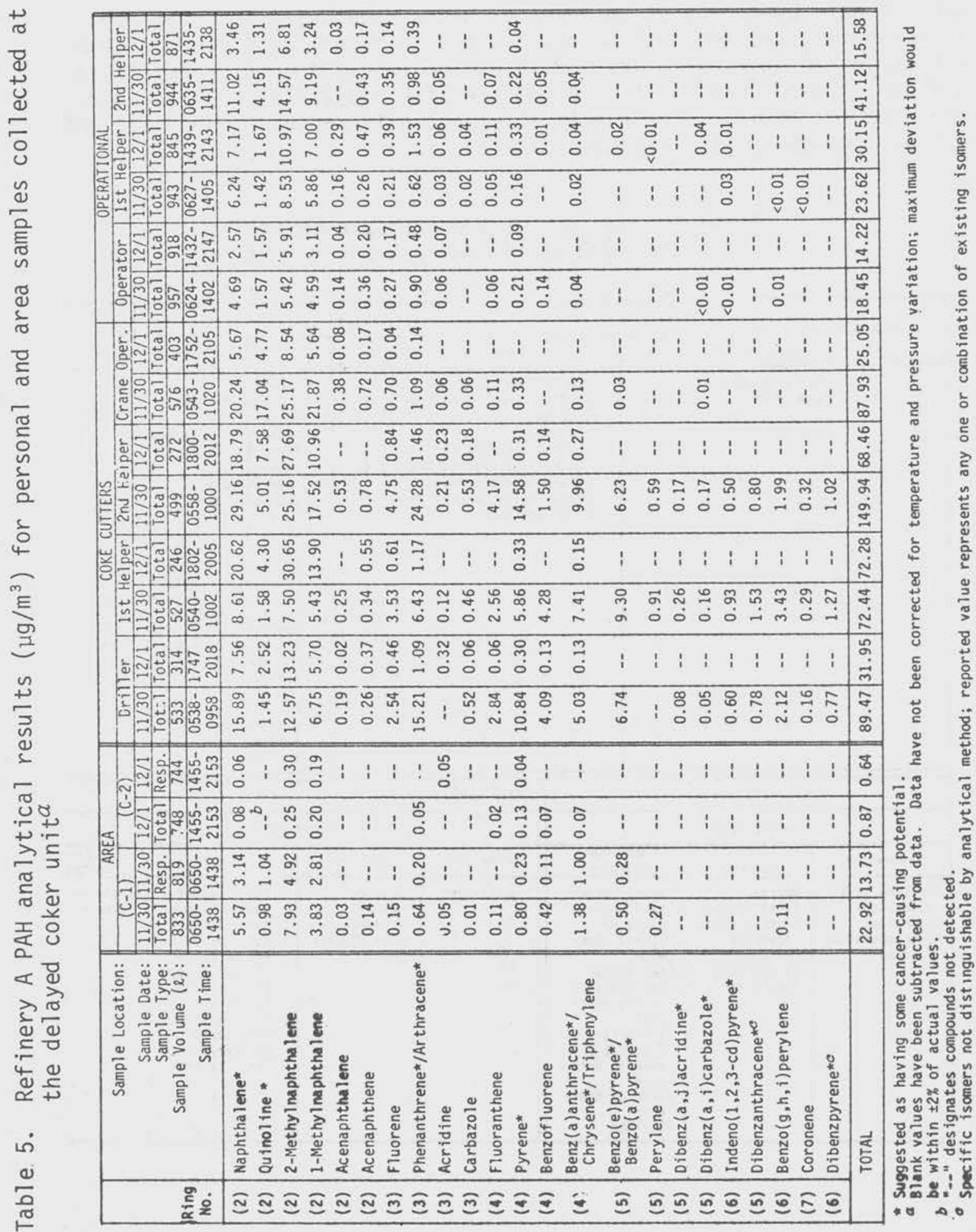


One of the basic objectives of the study was to compare personal sampling results across the refining industry. To enable this, job titles that were basically similar in the type of work associated with them were grouped within common exposure categories. The results of individual personal samples have been grouped by these exposure categories in an attempt to give a meaningful picture of this industry and to identify those major exposure categories of interest. Table 6 shows the exposure categories at the FCCU and the delayed coker unit, and the specific job titles they include, from the nine refineries. The similarities and differences between the refineries and process units were also examined.

Table 6. Job titles and exposure categories at FCCU and delayed coker unit.

\begin{tabular}{|c|c|c|c|c|c|c|}
\hline \multicolumn{7}{|c|}{ FCCU } \\
\hline \multicolumn{3}{|c|}{ Supervisor } & \multicolumn{2}{|c|}{ Inside operator } & \multicolumn{2}{|c|}{ Outside operator } \\
\hline \multicolumn{2}{|c|}{$\begin{array}{l}\text { Shift foreman } \\
\text { Supervisor }\end{array}$} & & \multicolumn{2}{|c|}{$\begin{array}{l}\text { Control room operator } \\
\text { Control room process operator } \\
\text { Boardman } \\
\text { Houseman } \\
\text { Control operator-cat side } \\
\text { Control operator-recovery side } \\
\$ 2 \text { operator/boardman } \\
\text { North inside general operator } \\
\text { Chief operator }\end{array}$} & \multicolumn{2}{|c|}{$\begin{array}{l}\text { Operator } \\
\text { CO boiler operator } \\
\text { Helper } \\
\text { Chief process operator } \\
\text { Process operator } \\
\text { Lead operator } \\
\text { Head operator } \\
\text { Unit operator } \\
\text { Operator I } \\
\text { Operator II } \\
\text { Operator IV } \\
\text { Operator-cat side } \\
\text { Operator-recovery side } \\
\text { Assistant operator-cat side } \\
\text { Assistant operator-recovery side } \\
\text { Outside control operator } \\
\text { Assistant operator-engineer } \\
\text { \#1 operator } \\
\text { \#2 operator } \\
\text { FCC \#1 } \\
\text { FCC \#2 } \\
\text { A operator } \\
\text { B operator } \\
\text { Stilliman }\end{array}$} \\
\hline \multicolumn{7}{|c|}{ DELAYED COKER UNIT } \\
\hline \multicolumn{3}{|c|}{ Operational } & \multicolumn{4}{|c|}{ Coke Handlers } \\
\hline Supervisor & $\begin{array}{l}\text { Inside } \\
\text { operator }\end{array}$ & $\begin{array}{l}\text { Outside } \\
\text { operator }\end{array}$ & Supervisor & Oriller & Helper & $\begin{array}{c}\text { Crane } \\
\text { operator }\end{array}$ \\
\hline $\begin{array}{l}\text { Division shift } \\
\text { supervisor } \\
\text { Supervisor } \\
\text { North operating } \\
\text { foreman }\end{array}$ & $\begin{array}{l}\text { Operator } \\
\text { First helper } \\
\text { Chief process } \\
\text { operator } \\
\text { Boardman } \\
\text { \#2 operator } \\
\text { Controlman }\end{array}$ & $\begin{array}{l}\text { Second helper } \\
\text { Chief process } \\
\text { operator } \\
\text { Process oper- } \\
\text { ator } \\
\text { Coke helper } \\
\text { Lead operator } \\
\text { Outside oper- } \\
\text { a tor } \\
\# 1 \text { operator } \\
\$ 2 \text { operator } \\
\text { Coker \#1 oper- } \\
\text { ator } \\
\text { Coker } \# 2 \text { oper- } \\
\text { ator } \\
\text { Stillman }\end{array}$ & Supervisor & $\begin{array}{l}\text { Oriller } \\
\text { Helper } \\
\# 1 \text { decoker } \\
\text { Head cleaner }\end{array}$ & $\begin{array}{l}\text { First helper } \\
\text { Second helper } \\
\text { Head cutter } \\
\text { Helper } \\
\text { Bottom cutter } \\
\text { Driller helper } \\
\text { Deck operator } \\
\# 2 \text { decoker } \\
\# 2 \text { cleaner } \\
\# 3 \text { cleaner } \\
\$ 4 \text { cleaner } \\
\text { Still cleaner }\end{array}$ & $\begin{array}{l}\text { Crane operator } \\
\text { Beltman }\end{array}$ \\
\hline
\end{tabular}


In several of the tables, it was assumed for the personal samples that each exposure category/refinery cell was an intact sample, and that the exposure categories within each refinery were internally consistent and mutually distinct. Under this assumption, the results have been presented by calculating the sample geometric means, geometric standard deviations, and $95 \%$ confidence limits on the means, calculated from the individual sample results. The results of the area samples were not treated in this manner. The number of area samples collected at each unit was very small, and the sampling locations were not always consistent between units. Area samples were collected in locations suspected of having relatively high $\mathrm{PAH}$ concentrations; the results were intended to supplement the personal data during the evaluation within individual refineries.

Table 7 shows the cumulative PAH concentrations for the personal and area samples collected at the nine FCCUs. Tables 8 and 9 summarize the data from Table 7 by exposure categories. As noted previously, the process units at Refinery I were quite different from those at the other refineries in several ways. The PAH results for this refinery are also noticeably different (higher) relative to the other refineries. Because of this, in addition to total values for all of the refineries, the values in several of the tables have also been calculated excluding Refinery I. Tables 10, 11, and 12 are the equivalent tables for the delayed coker units. Tables 13 and 14 show the results for the asphalt processing units where mainly area samples were collected; personal samples were collected at only one deasphalting unit (Table 13).

The refinery upwind samples are compared with the totals of the area and personal samples for each refinery in Table 15 . Table 16 breaks down the percent distribution of PAHs found by ring number for each refinery process unit. This is not meant to be an approximation of the actual distribution of PAHs in the sampling locations, but only of those 23 PAHs or groups of PAHs (total of 28) for which the samples were analyzed. An equal number of PAHs were not analyzed in each ring-number category, and also there is no indication that these 28 PAHs are representative of a 11 the PAHs actually present in the particular sampling environment. Table 17 shows average distribution (\%) of individual PAHs for all surveys. The last table (Table 18) shows the particle-size distribution of the total particulate samples collected during the last five surveys. 
Table 7. FCCUs - Cumulative PAH concentrations.

\begin{tabular}{|c|c|c|c|c|c|c|c|c|c|c|c|c|}
\hline \multirow[b]{2}{*}{ Refinery } & \multicolumn{7}{|c|}{ Personal } & \multicolumn{5}{|c|}{ Area } \\
\hline & Exposure category & $\begin{array}{c}N^{a} \\
(K)\end{array}$ & $\begin{array}{c}G M^{b} \\
\left(\mu \mathrm{g} / \mathrm{m}^{3}\right)\end{array}$ & $\mathrm{GSO}^{\circ}$ & $\underset{\left(\mu \mathrm{g} / \mathrm{m}^{3}\right)}{\mathrm{LCL}^{d}}$ & $\begin{array}{c}\mathrm{UCL}^{d} \\
\left(\mu \mathrm{g} / \mathrm{m}^{3}\right)\end{array}$ & $\begin{array}{l}\text { Average } \\
\text { PAHs/ } \\
\text { sample }\end{array}$ & Location & Type & $N^{2}$ & $\begin{array}{l}\text { Concen- } \\
\text { tration } \\
\left(\mu \mathrm{g} / \mathrm{m}^{3}\right)\end{array}$ & $\begin{array}{l}\text { PAHs/ } \\
\text { Sar.ple }\end{array}$ \\
\hline \multirow[t]{4}{*}{ A } & Supervisor & 2 & 16.7 & 1.2 & 3.2 & 85.9 & 14 & \multirow{4}{*}{$\begin{array}{l}\text { 1. Slurry recycle pump } \\
\text { 2. Decant oil pump }\end{array}$} & \multirow{4}{*}{$\begin{array}{l}\text { Total } \\
\text { Resp. } \\
\text { Tota } 1 \\
\text { Resp. }\end{array}$} & \multirow{4}{*}{$\begin{array}{l}1 \\
1 \\
1 \\
1\end{array}$} & \multirow{4}{*}{$\begin{array}{l}36.8 \\
18.4 \\
19.0 \\
27.4\end{array}$} & \multirow{4}{*}{$\begin{array}{l}16 \\
13 \\
14 \\
14\end{array}$} \\
\hline & Inside operator & 2 & 11.9 & 2.0 & $<0.1$ & $6 \times 10^{3}$ & 12 & & & & & \\
\hline & Outside operator & 5 & 27.2 & 1.3 & 19.6 & 37.8 & 15 & & & & & \\
\hline & $\begin{array}{l}\text { Means and totals } \\
\text { (Refinery A) }\end{array}$ & 9 & 20.3 & 1.6 & 14.2 & 29.1 & 14 & & & & & \\
\hline \multirow[t]{3}{*}{ B } & Inside operator & 4 & 10.3 & 1.3 & 6.8 & 15.7 & 16 & \multirow{3}{*}{$\begin{array}{l}\text { 1. Heavy-fraction pumps } \\
\text { 2. Heavy-fraction pumps }\end{array}$} & \multirow{3}{*}{$\begin{array}{l}\text { Total } \\
\text { Resp. } \\
\text { Total } \\
\text { Resp. } \\
\end{array}$} & \multirow{3}{*}{$\begin{array}{l}1 \\
1 \\
1 \\
1\end{array}$} & \multirow{3}{*}{$\begin{array}{l}50.6 \\
47.8 \\
50.7 \\
54.6\end{array}$} & \multirow{3}{*}{$\begin{array}{l}14 \\
22 \\
14 \\
21\end{array}$} \\
\hline & Outside operator & 8 & 32.5 & 1.6 & 21.8 & 48.4 & 14 & & & & & \\
\hline & $\begin{array}{l}\text { Means and totals } \\
\text { (Refiliery B) }\end{array}$ & 12 & 22.2 & 2.0 & 14.3 & 34.5 & 15 & & & & & \\
\hline \multirow[t]{3}{*}{ c } & Inside operator & 2 & 1.9 & 1.2 & 0.4 & 9.8 & 9 & \multirow{3}{*}{$\begin{array}{l}\text { 1. Slurry eflux pump } \\
\text { 2. Slurry reflux pump }\end{array}$} & \multirow{3}{*}{$\begin{array}{l}\text { Total } \\
\text { Resp. } \\
\text { Total } \\
\text { Resp. }\end{array}$} & \multirow{3}{*}{$\begin{array}{l}1 \\
1 \\
1 \\
1 \\
\end{array}$} & \multirow{3}{*}{$\begin{array}{l}123.5 \\
136.8 \\
132.3 \\
166.7\end{array}$} & \multirow{3}{*}{$\begin{array}{l}14 \\
15 \\
13 \\
14\end{array}$} \\
\hline & Outside operator & 6 & 2.5 & 3.3 & 3.4 & 43.3 & 11 & & & & & \\
\hline & $\begin{array}{l}\text { Mears and totals } \\
\text { (Refinery C) }\end{array}$ & 8 & 2.4 & 2.7 & 1.0 & 5.6 & 11 & & & & & \\
\hline \multirow[t]{3}{*}{ D } & Inside operator & 2 & 13.4 & 1.3 & 1.3 & 14.1 & 8 & \multirow{3}{*}{$\begin{array}{l}\text { 1. Slurry pump } \\
\text { 2. Slurry pump }\end{array}$} & \multirow{3}{*}{$\begin{array}{l}\text { Total } \\
\text { Resp. } \\
\text { Total } \\
\text { Resp. } \\
\end{array}$} & \multirow{3}{*}{$\begin{array}{l}1 \\
1 \\
1 \\
1\end{array}$} & \multirow{3}{*}{$\begin{array}{r}27.5 \\
57.8 \\
145.7 \\
82.5 \\
\end{array}$} & \multirow{3}{*}{$\begin{array}{l}14 \\
16 \\
12 \\
11\end{array}$} \\
\hline & Outside operator & 10 & 12.7 & 1.4 & 9.9 & 16.2 & 10 & & & & & \\
\hline & $\begin{array}{l}\text { Means and totals } \\
\text { (Refinery D) }\end{array}$ & 12 & 12.8 & 1.4 & 10.3 & 15.8 & 10 & & & & & \\
\hline E & Inside operator & 4 & 8.9 & 2.0 & 2.9 & 27.0 & 9 & 1. Charge pump & Total & 1 & 12.2 & 12 \\
\hline & Outside operator & 12 & 9.4 & 3.0 & 4.7 & 18.9 & 9 & 2. Slurry recycle pump & Total & 1 & 202.2 & 15 \\
\hline & $\begin{array}{l}\text { Meane and totals } \\
\text { (Refinery E) }\end{array}$ & 16 & 9.2 & 2.7 & 5.5 & 15.5 & 9 & & & & & \\
\hline $\mathrm{F}$ & Supervisor & 2 & 4.6 & 2.8 & $<0.1$ & $>10^{4}$ & 7 & 1. Slurry pump & Total & 1 & 32.6 & 10 \\
\hline & Outside operator & 8 & 2.7 & 1.9 & 1.6 & 4.7 & 8 & & & & & \\
\hline & $\begin{array}{l}\text { Means and totals } \\
\text { (Refinery F) }\end{array}$ & 10 & 3.0 & 2.0 & 1.8 & 5.0 & 8 & & & & & \\
\hline G & Inside operator & 2 & 2.9 & 1.1 & 1.2 & 6.8 & 9 & 1. Slurry recjele pump & Total & 1 & 57.4 & 11 \\
\hline & Outside operator & 4 & 5.1 & 1.5 & 2.7 & 9.8 & 9 & 2. Decant oil pumip & Total & 1 & 3.6 & 11 \\
\hline & $\begin{array}{l}\text { Means and totals } \\
\text { (Ref inery G) }\end{array}$ & 6 & 4.2 & 1.5 & 2.7 & 6.5 & 9 & & & & & \\
\hline H & Inside operator & 2 & 12.6 & 1.2 & 2.5 & 64.8 & 6 & 1. Fractionator tower & Total & 1 & 7.9 & 7 \\
\hline & Outside operator & 4 & 15.8 & 1.3 & 10.4 & 24.0 & 7 & 2. Reactor/riser & Total & 1 & 2.2 & 4 \\
\hline & $\begin{array}{l}\text { Means and totals } \\
\text { (Refinery H) }\end{array}$ & 6 & 14.6 & 1.3 & 11.1 & 19.3 & 6 & & & & & \\
\hline 1 & Inside operator & 4 & 84.5 & 1.6 & 39.8 & 179.2 & 6 & $\begin{array}{l}\text { 1. Slurry recycle pump } \\
\text { in building }\end{array}$ & Total & 1 & 1,347 & 8 \\
\hline & Outside operator & 4 & 172.5 & 2.2 & 48.9 & 609.1 & 8 & & & & & \\
\hline & $\begin{array}{l}\text { Means and totals } \\
\text { (Refinery I) }\end{array}$ & 8 & 120.7 & 2.0 & 67.0 & 217.3 & 7 & $\begin{array}{l}2 \text { Reactor/regenerator } \\
\text { building }\end{array}$ & Total & 1 & 101.5 & 6 \\
\hline$A-1$ & $\begin{array}{l}\text { Sumary of } \\
\text { refinery totals }\end{array}$ & (9) & 11.2 & 3.3 & 4.5 & 28.0 & 10 & & & & & \\
\hline$A-H$ & & (8) & 8.3 & 2.4 & 3.9 & 17.4 & 10 & & & & & \\
\hline
\end{tabular}

$a_{N}=$ Number of individual air samples, $(x)=$ number of refineries.

$b_{\text {Gi }}=$ Geometric mean concentration for tne $N$ samples or $K$ refineries.

${ }_{G}$ GSO $=$ Geometric standard deviation of the $N$ samples or $K$ refineries.

Lower (LCL) and upper (UCL) $95 \%$ confidence limits on geometric mean for the $N$ samples or $K$ refineries. 
Table 8. FCCUs - Summary of cumulative PAH concentrations by exposure categories (all nine refineries).

\begin{tabular}{|l|c|c|c|c|c|c|c|}
\hline $\begin{array}{c}\text { Exposure } \\
\text { Category }\end{array}$ & $\mathrm{N}^{a}$ & $\mathrm{~K}^{b}$ & $\begin{array}{c}\mathrm{GM}^{c} \\
\left(\mu \mathrm{g} / \mathrm{m}^{3}\right)\end{array}$ & $\mathrm{GSO}^{d}$ & $\begin{array}{c}\mathrm{LCL}^{e} \\
\left(\mu \mathrm{g} / \mathrm{m}^{3}\right)\end{array}$ & $\begin{array}{c}\mathrm{UCL} \\
\left(\mu \mathrm{g} / \mathrm{m}^{3}\right)\end{array}$ & $\begin{array}{c}\text { Average } \\
\mathrm{PAHs} / \\
\text { sample }\end{array}$ \\
\hline Supervisor & 4 & 2 & 8.8 & 2.6 & 2.3 & 33.5 & 11 \\
Inside operator & 22 & 8 & 11.9 & 3.3 & 3.3 & 20.3 & 10 \\
Outside operator & 61 & 9 & 11.4 & 3.7 & 3.7 & 15.9 & 10 \\
\hline Total & 87 & 9 & 11.4 & 3.5 & 3.5 & 14.9 & 10 \\
\hline
\end{tabular}

$a_{\text {iN }}=$ Number of individual air samples.

$b_{K}=$ Number of refineries.

$c_{G M}=$ Geometric mean concentration for the $\mathrm{N}$ samples.

$d_{G S D}=$ Geometric standard deviation of the $N$ samples.

e Lower (LCL) and upper (UCL) $95 \%$ confidence 1 imits on geometric mean for the $N$ samples.

Table 9. FCCUs - Summary of cumulative PAH concentrations by exposure categories (excluding Refinery I).

\begin{tabular}{|l|c|c|c|c|c|c|c|}
\hline $\begin{array}{c}\text { Exposure } \\
\text { Category }\end{array}$ & $\mathrm{N}^{a}$ & $\mathrm{~K}^{b}$ & $\begin{array}{c}\mathrm{GM}^{c} \\
\left(\mu \mathrm{g} / \mathrm{m}^{3}\right)\end{array}$ & $\mathrm{GSO}^{d}$ & $\begin{array}{c}\mathrm{LCL} \\
\left(\mu \mathrm{g} / \mathrm{m}^{3}\right)\end{array}$ & $\begin{array}{c}\text { UCL } \\
\left(\mu \mathrm{g} / \mathrm{m}^{3}\right)\end{array}$ & $\begin{array}{c}\text { Average } \\
\mathrm{PAHs} / \\
\text { sample }\end{array}$ \\
\hline Supervisor & 4 & 2 & 8.8 & 2.6 & 2.3 & 33.5 & 11 \\
Inside operator & 18 & 7 & 7.7 & 2.1 & 5.3 & 11.1 & 10 \\
Outside operator & 57 & 8 & 9.4 & 3.1 & 7.0 & 12.7 & 10 \\
\hline \multicolumn{1}{|c|}{ Total } & 79 & 8 & 8.9 & 2.8 & 7.1 & 11.2 & 10 \\
\hline
\end{tabular}

${ }^{a} \mathrm{~N}=$ Number of individua' air samples.

$b_{K}=$ Number of refineries.

$c_{G M}=$ Geometric mean concentration for the $\mathrm{N}$ samples.

$d_{\text {GSD }}=$ Geometric standard deviation of the $\mathrm{N}$ samples.

$e_{\text {Lower }}(\mathrm{LCL})$ and upper (UCL) $95 \%$ confidence 1 imits on geometric mean for the $\mathrm{N}$ samples. 


\begin{tabular}{|c|c|c|c|c|c|c|c|c|c|c|c|c|c|c|c|c|}
\hline \multirow{5}{*}{ 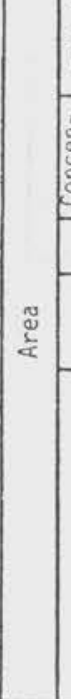 } & 爱产 & \multicolumn{5}{|l|}{$=a n$} & \multicolumn{5}{|c|}{$\cong \pm \cong}$. & \multicolumn{5}{|l|}{$\pm \infty \stackrel{m}{=}$} \\
\hline & 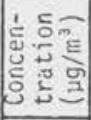 & \multicolumn{5}{|l|}{ 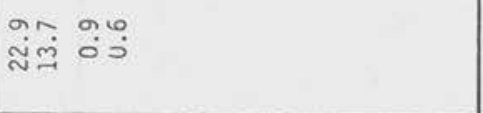 } & \multicolumn{5}{|c|}{ 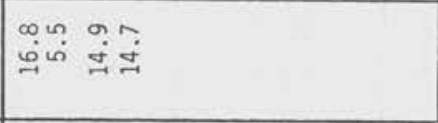 } & \multicolumn{5}{|l|}{ 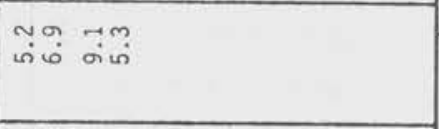 } \\
\hline & $\geq$ & \multicolumn{5}{|l|}{ ナルナー } & \multicolumn{5}{|c|}{ 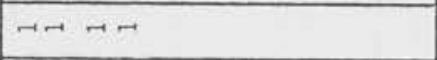 } & \multicolumn{5}{|l|}{ 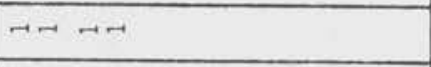 } \\
\hline & $\stackrel{2}{2}$ & \multicolumn{5}{|l|}{ 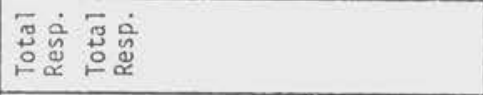 } & \multicolumn{5}{|c|}{ 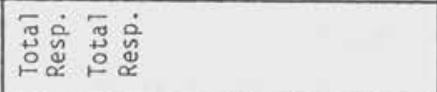 } & \multicolumn{5}{|l|}{ 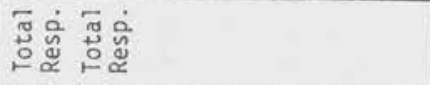 } \\
\hline & : & \multicolumn{5}{|l|}{ 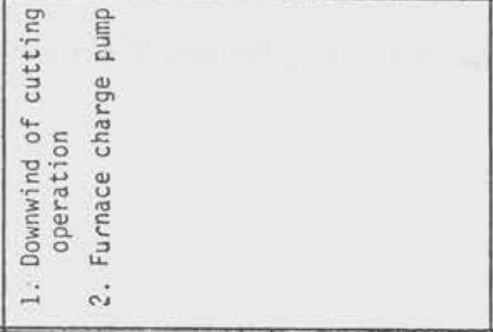 } & \multicolumn{5}{|l|}{ 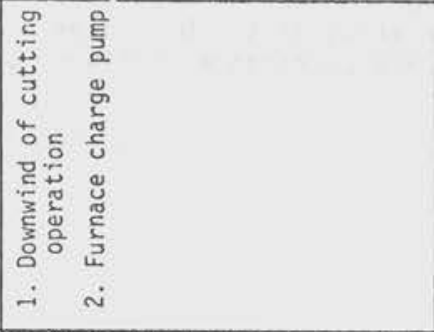 } & \multicolumn{5}{|l|}{ 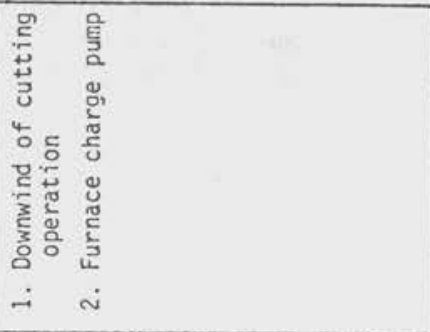 } \\
\hline \multirow{7}{*}{ 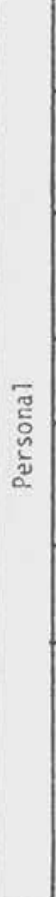 } & & $\stackrel{\sim}{=}$ & \pm & $\stackrel{\infty}{=} \approx$ & 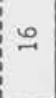 & \pm & $\simeq 9$ & $m$ & $2 \approx$ & 요 & $\cong$ & $\simeq \approx$ & $\simeq$ & $\Rightarrow=$ & 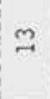 & $\simeq$ \\
\hline & 금 & $\stackrel{0}{\dot{m}}:$ & $\overrightarrow{\text { ले }}$ & 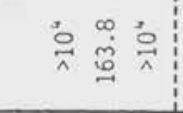 & $\begin{array}{l}9 \\
\vdots \\
\vdots \\
\vdots\end{array}$ & $\mid$ & & 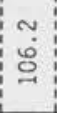 & \begin{tabular}{ll:}
0 & + \\
\hdashline & 0
\end{tabular} & : & 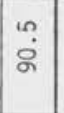 & $\stackrel{\sim}{\wedge} \approx$ & : & $\stackrel{\circ}{\circ} \stackrel{9}{x}$ & $\stackrel{\sim}{\ddot{m}}$ & $\stackrel{m}{\sim}$ \\
\hline & 굴 & $\vec{\simeq} \overrightarrow{\dot{q}}$ & 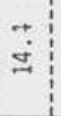 & $\overrightarrow{\dot{v}} \mathfrak{\dot { q }} \overrightarrow{0}$ & $\begin{array}{l}0 \\
\dot{y}\end{array}$ & $\vec{\sim}$ & ปั & $\frac{a}{\sigma}$ & \begin{tabular}{ll|l}
$m$ & $\infty$ \\
0 & 0 & 0
\end{tabular} & $\infty$ & $\stackrel{n}{m}$ & $\vec{i} \stackrel{0}{\sim}$ & $\cong$ & $\vec{i} \stackrel{0}{0}$ & $\stackrel{?}{-}$ & in \\
\hline & : & $\stackrel{\circ}{i}$ & $\stackrel{n}{-1}$ & $\vec{i} \stackrel{\sim}{i} \stackrel{0}{i}$ & $\hat{-}$ & $\vec{i}$ & $\cong$ & $\vec{\sim}$ & $\stackrel{0}{\circ} \stackrel{0}{-}$ & $\hat{i}$ & $\vec{i}$ & $\hat{i} \stackrel{m}{-i}$ & $\stackrel{\infty}{-}$ & $\tilde{m} \tilde{j}$ & 암 & $\stackrel{n}{n}$ \\
\hline & 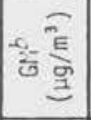 & 文 $\stackrel{m}{\stackrel{n}{\sim}}$ & $\tilde{\tilde{N}}$ & 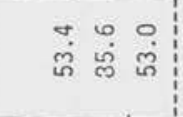 & $\stackrel{0}{6}$ & के & $\vec{g}:$ & $\stackrel{\sim}{\stackrel{m}{m}}$ & $\stackrel{a}{2} \stackrel{\sim}{=}$ & $\vec{m}$ & 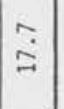 & 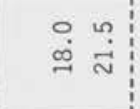 & 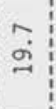 & 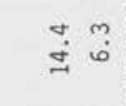 & $\stackrel{m}{\infty}$ & $\grave{\Xi}$ \\
\hline & $z=\bar{z}$ & $\sigma \sim$ & $\circ$ & $\sim \sigma \omega$ & $\infty$ & \pm & tm & + & $\sim 0$ & $\infty$ & $\approx$ & $\sim \sim$ & + & $\sim \sigma$ & 0 & 우 \\
\hline & 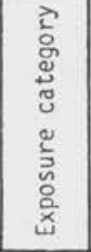 & 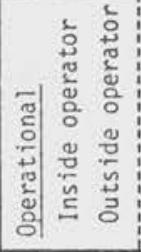 & 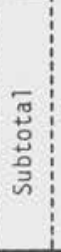 & 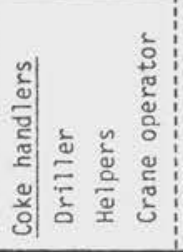 & 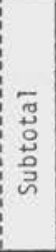 & 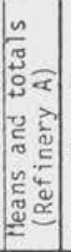 & 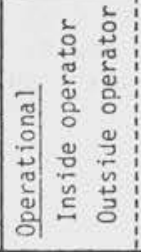 & 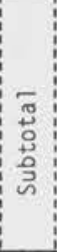 & 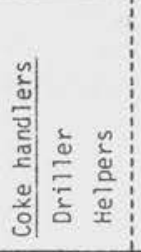 & \begin{tabular}{lll}
0 \\
\hdashline \\
3 \\
0
\end{tabular} & 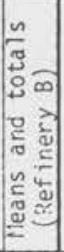 & 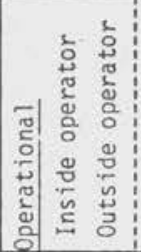 & $\begin{array}{l}-\pi \\
0 \\
0 \\
0 \\
\overrightarrow{0}\end{array}$ & 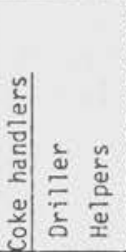 & 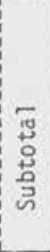 & 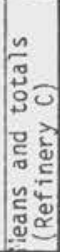 \\
\hline & $\underset{c}{\Phi}$ & $\ll$ & & & & & $\infty$ & & & & & 0 & & & & \\
\hline
\end{tabular}




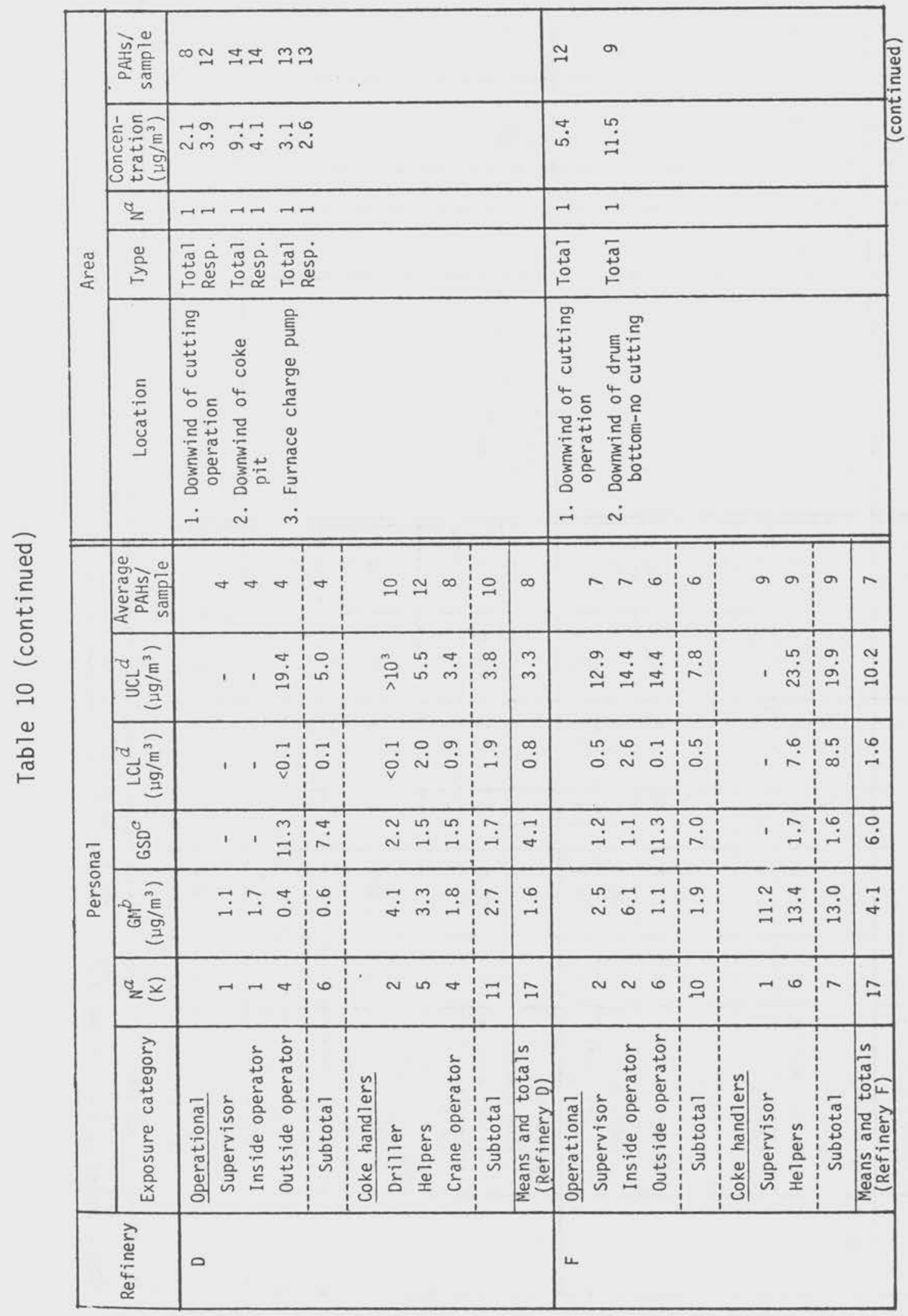




\begin{tabular}{|c|c|c|c|c|c|c|c|c|c|c|c|c|c|}
\hline \multirow{5}{*}{ 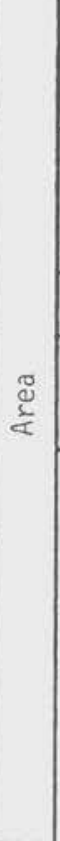 } & 产竞高 & \multicolumn{5}{|l|}{$\simeq \quad=$} & \multicolumn{5}{|l|}{$a \simeq$} & & \\
\hline & 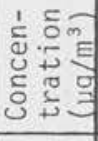 & 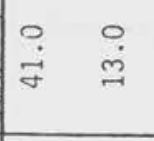 & & & & & \multicolumn{5}{|l|}{ ڤ్ } & & \\
\hline & $z$ & $\rightarrow \quad \rightarrow$ & & & & & \multicolumn{5}{|l|}{$\rightarrow-1$} & & \\
\hline & 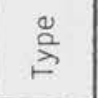 & $\begin{array}{ll}\bar{\pi} & \overline{3} \\
\stackrel{3}{0} & \stackrel{0}{0}\end{array}$ & & & & & \multicolumn{5}{|l|}{$\begin{array}{ll}\bar{J} & \overline{3} \\
\stackrel{5}{0} & \stackrel{5}{\circ}\end{array}$} & & \\
\hline & 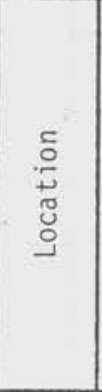 & \multicolumn{5}{|c|}{ 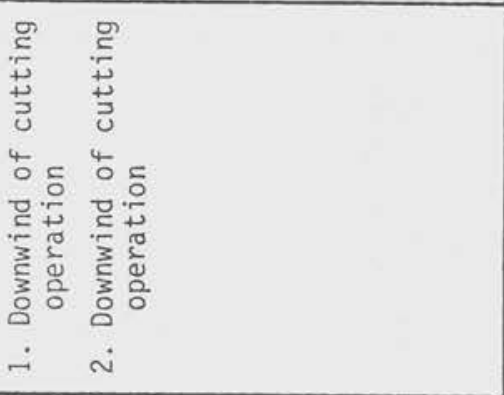 } & \multicolumn{5}{|l|}{ 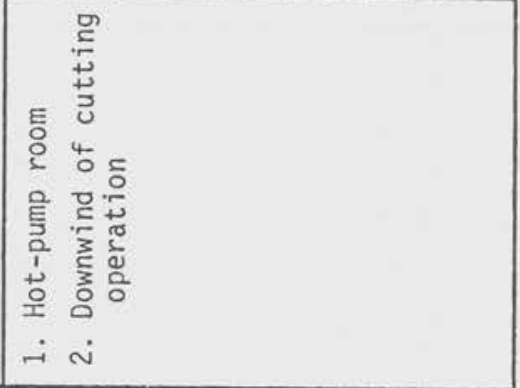 } & & $\stackrel{\dot{\tilde{u}}}{ \pm}$ \\
\hline \multirow{7}{*}{ 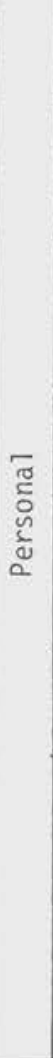 } & 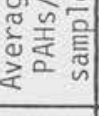 & 응으 & 응 & $\Rightarrow \Rightarrow$ & $\Rightarrow$ & $\Rightarrow$ & $-\infty$ & - & $\infty$ a & $\begin{array}{l}\infty \\
\infty\end{array}$ & $\infty$ & $\simeq \approx$ & $\stackrel{\Perp}{5}$ \\
\hline & 勇急 & $\stackrel{\infty}{\circ} \stackrel{\infty}{-}$ & $\stackrel{\sim}{\sim}$ & 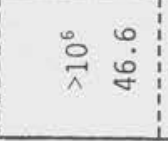 & $\stackrel{m}{-\dot{\sigma}}$ & $\stackrel{\check{m}}{\sim}$ & స̊ & $\begin{array}{ll}n \\
\text { in } \\
\text { in } \\
m\end{array}$ & $\stackrel{m}{\circ} \stackrel{m}{\circ}$ & $\begin{array}{l}0 \\
\text { ஸे } \\
\text { ஸ }\end{array}$ & 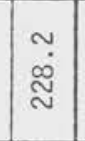 & $\ddot{m} \dot{m}$ & 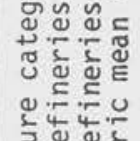 \\
\hline & 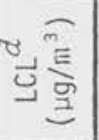 & $\begin{array}{ll}\longrightarrow & \infty \\
\dot{p} & \text { in }\end{array}$ & in & $\begin{array}{ll:}\because & 0 \\
0 & 0\end{array}$ & $\begin{array}{l}\infty \\
\infty\end{array}$ & m. & $\begin{array}{l}\simeq \\
\approx \\
\approx\end{array}$ & $\begin{array}{ll}-7 \\
5 \\
5\end{array}$ & $\begin{array}{ll}0 & \sim \\
\sigma & \stackrel{\sim}{\sim}\end{array}$ & $\begin{array}{l}\sim \\
\tilde{m} \\
=\end{array}$ & $\hat{\dot{\Xi}}$ & $\stackrel{\infty}{\sim} \hat{m}$ & $\begin{array}{l}0 \\
0 \\
0 \\
0\end{array}$ \\
\hline & ¿ & $\hat{m} \mathfrak{i}$ & $\vec{a}$ & $\begin{array}{ll:}m & 9 \\
m & -\end{array}$ & $\vec{\sim}$ & $\vec{i}$ & $\stackrel{-}{-} \rightarrow$ & $=$ & ¿ & $\stackrel{m}{-}$ & $\stackrel{-1}{-}$ & $\tilde{m} \stackrel{0}{\sim}$ & 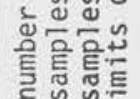 \\
\hline & 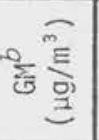 & $\begin{array}{ll}\infty & 0 \\
\infty & \ddot{m}\end{array}$ & 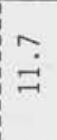 & $\begin{array}{l}0 \\
\dot{\sim}\end{array}$ & $\begin{array}{l}\infty \\
\infty \\
-\infty\end{array}$ & $\dot{\square}$ & స̃ & 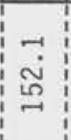 & $\begin{array}{l}0 \\
\dot{0} \\
\stackrel{्}{0}\end{array}$ & $\begin{array}{l}\sim \\
\approx \\
\approx\end{array}$ & $\begin{array}{l}\infty \\
\dot{0} \\
-\end{array}$ & $\hat{\sigma} \stackrel{\mathscr{\sigma}}{\square}$ & 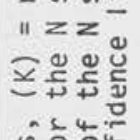 \\
\hline & 品 & $\sim \sigma$ & 0 & $\sim \sigma$ & 0 & $\simeq$ & $\sim \sim$ & + & $\sim \sim$ & + & $\infty$ & $6 \equiv$ & \\
\hline & 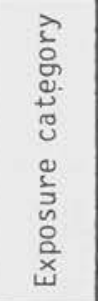 & 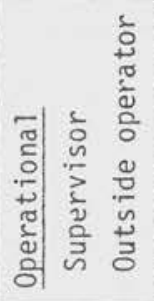 & \begin{tabular}{l}
$\pi$ \\
\multirow{3}{0}{} \\
0 \\
0 \\
0 \\
$\omega$
\end{tabular} & 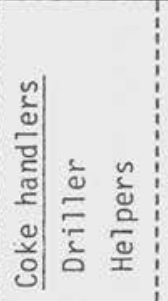 & $\begin{array}{l} \\
\pi \\
\pi \\
0 \\
0 \\
0 \\
0 \\
n\end{array}$ & 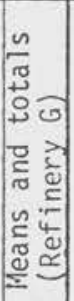 & 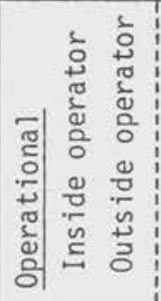 & 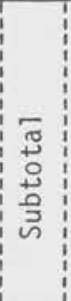 & 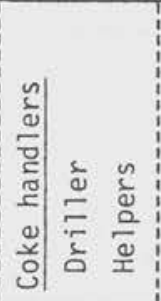 & 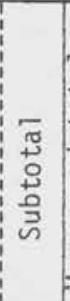 & 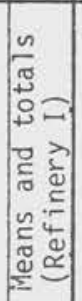 & \multirow{2}{*}{\multicolumn{2}{|c|}{ 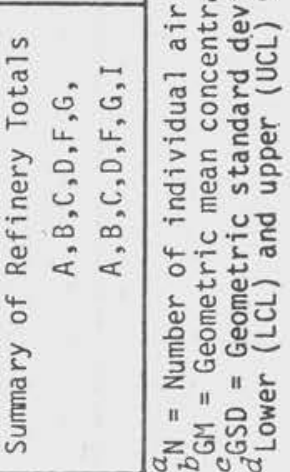 }} \\
\hline & 离 & \multicolumn{5}{|l|}{$\sigma$} & \multicolumn{5}{|l|}{ 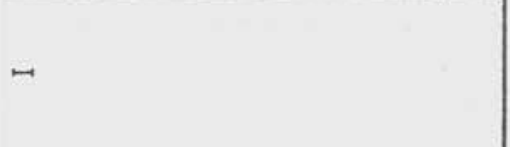 } & & \\
\hline
\end{tabular}


Table 11. Delayed coker units - Summary of cumulative PAH concentrations by exposure categories (a11 seven units).

\begin{tabular}{|c|c|c|c|c|c|c|c|}
\hline $\begin{array}{l}\text { Exposure } \\
\text { category }\end{array}$ & $N^{a}$ & $k^{b}$ & $\begin{array}{c}G M^{C} \\
\left(\mu g / m^{3}\right)\end{array}$ & GSD $^{d}$ & $\begin{array}{c}\mathrm{LCL}^{e} \\
\left(\mu \mathrm{g} / \mathrm{m}^{3}\right)\end{array}$ & $\begin{array}{c}U C L^{e} \\
\left(\mu \mathrm{g} / \mathrm{m}^{3}\right)\end{array}$ & $\begin{array}{c}\text { Average } \\
\text { PAHs/ } \\
\text { sample }\end{array}$ \\
\hline Operationa! & & & & & & & \\
\hline Supervisor & 5 & 3 & 3.5 & 3.1 & 0.9 & 14.4 & 8 \\
\hline Inside operator & 12 & 7 & 16.5 & 3.2 & 7.9 & 34.5 & 10 \\
\hline Outside operator & 23 & 7. & 6.3 & 13.0 & 2.0 & 19.5 & 8 \\
\hline Subtotal & 40 & 7 & 7.8 & 8.4 & 4.0 & 15.3 & 9 \\
\hline Coke Handlers & & & & & & & \\
\hline Supervisor & 1 & 1 & 11.2 & - & - & - & 9 \\
\hline Driller & 12 & 6 & 25.8 & 3.9 & 2.4 & 61.2 & 14 \\
\hline Helper & 31 & $?$ & 14.3 & 3.7 & 8.9 & 22.9 & 13 \\
\hline Crane operator & 6 & 2 & 5.5 & 6.1 & 0.8 & 37.5 & 9 \\
\hline Subtotal & 50 & 7 & 14.6 & 4.1 & 9.8 & 21.8 & 14 \\
\hline Total & 90 & 7 & 11.1 & 5.9 & 7.6 & 16.1 & 11 \\
\hline
\end{tabular}

${ }_{b} \mathrm{~N}=$ Number of individual air samples.

$b_{K}=$ Number of refineries.

c GM = Geometric mean concentration for the $\mathrm{N}$ samples.

GSD $=$ Geometric standard deviation of the $N$ samples.

$e$ Lower (LCL) and upper (UCL) $95 \%$ confidence limits on geometric mean for the

$\mathrm{N}$ samples.

Table 12. Delayed coker units - Summary of cumulative PAH concentrations by exposure categories (excluding Refinery I).

\begin{tabular}{|c|c|c|c|c|c|c|c|}
\hline $\begin{array}{l}\text { Exposure } \\
\text { category }\end{array}$ & $\mathrm{N}^{a}$ & $k^{b}$ & $\begin{array}{c}G M^{C} \\
\left(\mu g / m^{3}\right)\end{array}$ & $\mathrm{GSD}^{d}$ & $\begin{array}{c}\mathrm{LCL}^{e} \\
\left(\mu \mathrm{g} / \mathrm{m}^{3}\right)\end{array}$ & $\begin{array}{c}\mathrm{UCL}^{e} \\
\left(\mu \mathrm{g} / \mathrm{m}^{3}\right)\end{array}$ & $\begin{array}{c}\text { Average } \\
\text { PAHs / } \\
\text { sample }\end{array}$ \\
\hline \multicolumn{8}{|l|}{ Operational } \\
\hline Supervisor & 5 & 3 & 3.5 & 3.1 & 0.9 & 14.4 & 8 \\
\hline Inside operator & 10 & 6 & 11.6 & 2.5 & 6.0 & 22.6 & 11 \\
\hline Outside operator & 21 & 6 & 4.5 & 11.2 & 1.5 & 13.6 & 8 \\
\hline Subtotal & 36 & 6 & 5.6 & 7.2 & 2.9 & 13.9 & 9 \\
\hline \multicolumn{8}{|l|}{ Coke Handlers } \\
\hline Supervisor & 1 & 1 & 11.2 & - & - & - & 9 \\
\hline Driller & 10 & 5 & 17.4 & 3.0 & 7.8 & 38.7 & 15 \\
\hline Helper & 29 & 6 & 12.1 & 3.2 & 7.9 & 18.6 & 13 \\
\hline Crane operator & 6 & 2 & 5.5 & 6.1 & 0.8 & 37.5 & 9 \\
\hline Subtotal & 46 & 6 & 11.8 & 3.5 & 8.2 & 17.1 & 13 \\
\hline Total & 82 & 6 & 8.5 & 5.2 & 5.9 & 12.2 & 11 \\
\hline
\end{tabular}

$a_{N}=$ Number of individual air samples.

$b_{K}=$ Number of refineries.

$C_{G M}=$ Geometric mean concentration for the $N$ samples.

$d_{G S D}=$ Geometric standard deviation of the N samples.

$e_{\text {Lower }}(\mathrm{LCL}$ ) and upper (UCL) $95 \%$ confidence 1 imits on geometric mean for the $N$ samples. 
Table 13. Deasphalting unit at Refinery E - Cumulative PAH personal sample concentrations.

\begin{tabular}{|l|c|c|c|c|c|c|}
\hline $\begin{array}{c}\text { Exposure } \\
\text { Category }\end{array}$ & $\mathrm{N}^{a}$ & $\begin{array}{c}\mathrm{GM}^{b} \\
\left(\mu \mathrm{g} / \mathrm{m}^{3}\right)\end{array}$ & $\mathrm{GSD}^{c}$ & $\begin{array}{c}\mathrm{LCL}^{d} \\
\left(\mu \mathrm{g} / \mathrm{m}^{3}\right)\end{array}$ & $\begin{array}{c}\mathrm{UCL} \mathrm{C}^{\mathrm{d}} \\
\left(\mu \mathrm{g} / \mathrm{m}^{3}\right)\end{array}$ & $\begin{array}{c}\text { Average } \\
\mathrm{PAHs} / \\
\text { sample }\end{array}$ \\
\hline $\begin{array}{l}\text { Inside operator } \\
\text { Outside operator }\end{array}$ & 2 & 8.4 & 3.6 & 0.1 & 10 & 5 \\
\hline Total & 5 & 13.8 & 4.7 & 0.3 & 643.3 & 6 \\
\hline
\end{tabular}

${ }_{\mathrm{N}} \mathrm{N}=$ Number of individual air samples.

${ }_{G M}=$ Geometric mean concentration for the $N$ samples.

GSD $=$ Geometric standard deviation of the $N$ samples.

$d_{\text {Lower }}(\mathrm{LCL}$ ) and upper (UCL) $95 \%$ confidence limits on geometric mean for the $\mathrm{N}$ samples.

Table 14. Asphalt processing units - Cumulative PAH concentrations for area samples.

\begin{tabular}{|c|c|c|c|c|c|c|}
\hline Type of process & Refinery & Location & $\begin{array}{l}\text { Sample } \\
\text { type }\end{array}$ & $\mathrm{N}^{b}$ & $G M^{C}$ & $\begin{array}{l}\text { Average } \\
\text { PAHs/ } \\
\text { sample }\end{array}$ \\
\hline \multirow[t]{5}{*}{ Asphalt blowing } & \multirow[t]{2}{*}{ A } & & $\begin{array}{l}\text { Total } \\
\text { Resp. }\end{array}$ & $\begin{array}{l}1 \\
1\end{array}$ & $\begin{array}{l}30.6 \\
12.2\end{array}$ & $\begin{array}{l}12 \\
11\end{array}$ \\
\hline & & 2. Downwind (DW) of blowing tower & $\begin{array}{l}\text { Total } \\
\text { Resp. }\end{array}$ & $\begin{array}{l}1 \\
1\end{array}$ & $\begin{array}{l}3.3 \\
2.9\end{array}$ & $\begin{array}{l}5 \\
5\end{array}$ \\
\hline & \multirow[t]{2}{*}{ B } & 1. DW of blowing tower & $\begin{array}{l}\text { Total } \\
\text { Resp. }\end{array}$ & $\begin{array}{l}1 \\
1\end{array}$ & $\begin{array}{l}2.9 \\
3.5\end{array}$ & $\begin{array}{l}14 \\
13\end{array}$ \\
\hline & & 2. DW of thermal oxidizer & $\begin{array}{l}\text { Total } \\
\text { Resp. }\end{array}$ & $\begin{array}{l}1 \\
1\end{array}$ & $\begin{array}{l}1.6 \\
5.3\end{array}$ & $\begin{array}{l}10 \\
12\end{array}$ \\
\hline & G & 1. Asphalt product pump & Total & 1 & 2.1 & 8 \\
\hline \multirow[t]{3}{*}{ Deasphalting } & \multirow[t]{2}{*}{ B } & $\begin{array}{l}\text { 1. Between deasphalting tower and } \\
\text { asphalt stripper }\end{array}$ & & 1 & 1.4 & 12 \\
\hline & & $\begin{array}{l}\text { 2. Asphalt flash tower/stripper } \\
\text { and asphait pump }\end{array}$ & Total & 1 & 12.0 & 7 \\
\hline & E & $\begin{array}{l}\text { 1. Charge pump } \\
\text { 2. Asphait product pump }\end{array}$ & $\begin{array}{l}\text { Total } \\
\text { Total }\end{array}$ & $\begin{array}{l}1 \\
1\end{array}$ & $\begin{array}{l}41.2 \\
28.9\end{array}$ & $\begin{array}{r}7 \\
12\end{array}$ \\
\hline \multirow[t]{6}{*}{$\begin{array}{l}\text { Vacuum } \\
\text { distillation }\end{array}$} & \multirow[t]{2}{*}{$(2$ units) } & 1. Asphalt pump ( $\# 1$ unit) & $\begin{array}{l}\text { Total } \\
\text { Resp. }\end{array}$ & $\begin{array}{l}2 \\
1\end{array}$ & $\begin{array}{r}8.7 \\
14.1\end{array}$ & $\begin{array}{l}15 \\
13\end{array}$ \\
\hline & & 1. Asphalt pump ( $\# 4$ unit) & $\begin{array}{l}\text { Total } \\
\text { Resp. }\end{array}$ & $\begin{array}{l}2 \\
1\end{array}$ & $\begin{array}{l}7.8 \\
8.1 \\
\end{array}$ & $\begin{array}{l}14 \\
15\end{array}$ \\
\hline & \multirow{2}{*}{$\stackrel{F}{\text { (2 units) }}$} & 1. Asphalt pump ( $\# 16$ unit) & Total & 1 & 17.3 & 7 \\
\hline & & 1. Asphalt pump (\#19 unit) & Total & 2 & 4.9 & 9 \\
\hline & H & $\begin{array}{l}\text { 1. Asphalt pump } \\
\text { 2. Asphalt pump near stream } \\
\text { sampling site }\end{array}$ & $\begin{array}{l}\text { Total } \\
\text { Total }\end{array}$ & $\begin{array}{l}1 \\
1\end{array}$ & $\begin{array}{l}2.8 \\
2.9\end{array}$ & $\begin{array}{l}6 \\
8\end{array}$ \\
\hline & 1 & 1. Asphalt pump room & Total & 2 & 18.0 & 6 \\
\hline
\end{tabular}

$a_{\text {Total }}$ = samples include total particulates, Resp. = samples include respirable-size particulate only.

$b_{\mathrm{N}}=$ Number of individual air samples.

${ }_{G M}=$ Geometric mean concentration for the $N$ samples. 
Table 15. Comparison between upwind samples and area/personal samples.

\begin{tabular}{|c|c|c|c|c|c|c|}
\hline \multirow{2}{*}{ Refinery } & \multicolumn{3}{|c|}{ Upwind samples } & \multicolumn{3}{c|}{ Area and personal samples } \\
\cline { 2 - 7 } & $\mathrm{N}^{\alpha}$ & $\begin{array}{c}\mathrm{GM}^{b} \\
\left(\mu \mathrm{g} / \mathrm{m}^{3}\right)\end{array}$ & $\begin{array}{c}\text { Average } \\
\text { PAHs/sample }\end{array}$ & $\mathrm{N}^{\alpha}$ & $\begin{array}{c}\mathrm{GM}^{b} \\
\left(\mu \mathrm{g} / \mathrm{m}^{3}\right)\end{array}$ & $\begin{array}{c}\text { Average } \\
\text { PAHs/sample }\end{array}$ \\
\hline A & 2 & 0.6 & 7 & 35 & 20.4 & 13 \\
B & 1 & 1.1 & 13 & 38 & 15.7 & 16 \\
C & 1 & $<0.1$ & 2 & 32 & 9.5 & 13 \\
D & 2 & 2.6 & 6 & 39 & 5.1 & 10 \\
E & 2 & $<0.1$ & 2 & 25 & 12.2 & 9 \\
F & 2 & $<0.1$ & 2 & 33 & 4.1 & 8 \\
G & 2 & 0.2 & 2 & 23 & 10.2 & 10 \\
H & 2 & 1.3 & 5 & 10 & 8.2 & 6 \\
I & 1 & 0 & 0 & 22 & 136.8 & 8 \\
\hline Total & 15 & 0.9 & 4 & 257 & 11.9 & 11 \\
\hline
\end{tabular}

${ }_{\mathrm{a}}^{a}=$ Number of individual samples.

$b_{G M}=$ Geometric mean concentration for $\mathrm{N}$ samples .

Table 16. Distribution (\%) of PAHs found by ring number.

\begin{tabular}{|c|c|c|c|c|c|c|c|c|c|c|}
\hline \multirow{2}{*}{$\begin{array}{l}\text { Ring } \\
\text { No. }\end{array}$} & \multicolumn{4}{|c|}{ Refinery $A$} & \multicolumn{5}{|c|}{ Refinery $B$} & \\
\hline & FCCU & OCU & $A B$ & UW & FCCU & DCU & AG & $O A$ & Uh & \\
\hline $\begin{array}{l}2 \\
3 \\
4 \\
5 \\
6 \\
7\end{array}$ & $\begin{array}{r}83.2 \\
5.1 \\
7.5 \\
0.2 \\
<0.1 \\
0\end{array}$ & $\begin{array}{r}74.5 \\
9.5 \\
10.4 \\
3.9 \\
1.6 \\
0.1\end{array}$ & $\begin{array}{c}75.1 \\
24.5 \\
0.4 \\
0 \\
0 \\
0\end{array}$ & $\begin{array}{l}89.5 \\
5.6 \\
4.8 \\
0 \\
0 \\
0\end{array}$ & $\begin{array}{r}87.0 \\
9.5 \\
3.2 \\
0.2 \\
0.1 \\
0\end{array}$ & $\begin{array}{r}90.8 \\
4.5 \\
1.8 \\
1.9 \\
0.9 \\
0.1\end{array}$ & $\begin{array}{l}92.8 \\
5.4 \\
0.9 \\
0.9 \\
0 \\
0\end{array}$ & $\begin{array}{l}95.0 \\
5.0 \\
0 \\
0 \\
0 \\
0\end{array}$ & $\begin{array}{l}86.0 \\
10.3 \\
3.7 \\
0 \\
0 \\
0\end{array}$ & \\
\hline \multirow{2}{*}{$\begin{array}{l}\text { Ring } \\
\text { No. }\end{array}$} & \multicolumn{4}{|c|}{ Refinery $C$} & \multicolumn{3}{|c|}{ Refinery $D$} & \multicolumn{3}{|c|}{ Refinery E } \\
\hline & FCCU & OCU & vo & UW & FCCU & $\mathrm{OCU}$ & UN & FCCU & DA & Uw \\
\hline $\begin{array}{l}2 \\
3 \\
4 \\
5 \\
6 \\
7\end{array}$ & $\begin{array}{c}73.4 \\
19.5 \\
7.1 \\
0 \\
0 \\
0\end{array}$ & $\begin{array}{l}94.1 \\
4.6 \\
0.8 \\
0.5 \\
0 \\
0\end{array}$ & $\begin{array}{c}72.5 \\
19.8 \\
6.1 \\
1.6 \\
0 \\
0\end{array}$ & $\begin{array}{l}85.7 \\
14.3 \\
0 \\
0 \\
0 \\
0\end{array}$ & $\begin{array}{c}83.7 \\
14.6 \\
1.7 \\
0 \\
0 \\
0\end{array}$ & $\begin{array}{l}90.2 \\
6.9 \\
2.6 \\
0.3 \\
0 \\
0\end{array}$ & $\begin{array}{r}100 \\
0 \\
0 \\
0 \\
0 \\
0\end{array}$ & $\begin{array}{l}92.0 \\
7.2 \\
0.8 \\
0 \\
0 \\
0\end{array}$ & $\begin{array}{l}98.9 \\
1.0 \\
0.1 \\
0 \\
0 \\
0\end{array}$ & $\begin{array}{r}100 \\
0 \\
0 \\
0 \\
0 \\
0\end{array}$ \\
\hline \multirow{2}{*}{$\begin{array}{l}\text { aing } \\
\text { Mo. }\end{array}$} & \multicolumn{4}{|c|}{ Refinery $F$} & \multicolumn{5}{|c|}{ Refinery $G$} & \\
\hline & FCCU & OCU & vo & $U H$ & FCCU & $\mathrm{OCU}$ & $\begin{array}{l}\text { North-side } \\
\text { operators }\end{array}$ & $A B$ & Uw & \\
\hline $\begin{array}{l}2 \\
3 \\
4 \\
5 \\
6 \\
7 \\
\end{array}$ & $\begin{array}{c}78.4 \\
17.4 \\
4.2 \\
0 \\
0 \\
0 \\
\end{array}$ & $\begin{array}{l}91.7 \\
7.1 \\
1.2 \\
0 \\
0 \\
0\end{array}$ & $\begin{array}{c}86.9 \\
12.7 \\
0.4 \\
0 \\
0 \\
0\end{array}$ & $\begin{array}{r}100 \\
0 \\
0 \\
0 \\
0 \\
0\end{array}$ & $\begin{array}{l}9 c .2 \\
8.8 \\
1.0 \\
0 \\
0 \\
0\end{array}$ & $\begin{array}{c}57.2 \\
26.3 \\
15.6 \\
1.0 \\
0 \\
0\end{array}$ & $\begin{array}{l}92.6 \\
7.1 \\
0.3 \\
0 \\
0 \\
0\end{array}$ & $\begin{array}{c}88.3 \\
11.7 \\
0 \\
0 \\
0 \\
0 \\
\end{array}$ & $\begin{array}{c}95.7 \\
4.3 \\
0 \\
0 \\
0 \\
0\end{array}$ & \\
\hline \multirow{2}{*}{$\begin{array}{l}\text { Ring } \\
\text { No. }\end{array}$} & \multicolumn{4}{|c|}{ Refinery $\mathrm{H}$} & \multicolumn{4}{|c|}{ Ref inery $\mathrm{I}$} & & \\
\hline & Personal & FCCU & $\frac{\text { rea }}{1}$ vo & UW & FCCU & OCU & vo & UN & & \\
\hline $\begin{array}{l}2 \\
3 \\
4 \\
5 \\
5 \\
7\end{array}$ & $\begin{array}{l}92.3 \\
7.5 \\
0.2 \\
0 \\
0 \\
0\end{array}$ & $\begin{array}{c}57.0 \\
42.2 \\
0.8 \\
0 \\
0 \\
0\end{array}$ & $\begin{array}{c}83.3 \\
14.0 \\
2.7 \\
0 \\
0 \\
0\end{array}$ & $\begin{array}{l}91.2 \\
8.8 \\
0 \\
0 \\
0 \\
0\end{array}$ & $\begin{array}{c}98.6 \\
1.3 \\
0.1 \\
0 \\
0 \\
0\end{array}$ & $\begin{array}{l}96.2 \\
3.6 \\
0.2 \\
0 \\
0 \\
0\end{array}$ & $\begin{array}{l}98.2 \\
1.7 \\
0.1 \\
0 \\
0 \\
0\end{array}$ & $\begin{array}{l}0 \\
0 \\
0 \\
0 \\
0 \\
0\end{array}$ & & \\
\hline
\end{tabular}


Table 17. Average distribution (\%) of PAHs at all nine refineries.

\begin{tabular}{|c|c|c|c|c|c|}
\hline Ring No. & Compound & FCCU & Coker & Asphalting & Upwind \\
\hline 2 & Naphthalene* & 25.9 & 27.1 & 31.8 & 51.0 \\
\hline 2 & Quinoline* & 1.1 & 3.3 & 1.4 & 2.6 \\
\hline 2 & 2-Methylnaphthalene & 38.6 & 35.4 & 33.2 & 19.1 \\
\hline 2 & 1-Hethyl naphtha lene & 20.1 & 18.2 & 20.0 & 19.8 \\
\hline 2 & Acenaphthalene & 0.4 & 1.1 & 0.1 & 0 \\
\hline 2 & Acenaphthene & 2.6 & 1.6 & 2.3 & 0.9 \\
\hline 3 & Fluorene & 2.5 & 1.9 & 5.0 & 0.8 \\
\hline 3 & Phenanthrene ${ }^{\star} /$ Anthracene ${ }^{\star}$ & 7.3 & 6.3 & 4.6 & 4.4 \\
\hline 3 & Acridine & 0.2 & 0.2 & 0.3 & 0.1 \\
\hline 3 & Carbazole & 0.1 & 0.1 & 0.4 & 0.1 \\
\hline 4 & Fluoranthene & 0.2 & 0.5 & 0.3 & 0.2 \\
\hline 4 & Pyrene* & 0.6 & 1.6 & 0.4 & 0.5 \\
\hline 4 & Benzof luorene & $<0.1$ & 0.3 & 0 & 0 \\
\hline 4 & $\begin{array}{l}\text { Benz (a)anthracene }{ }^{\star} / \\
\text { Chrysene*/Triphenylene }\end{array}$ & 0.2 & 1.0 & $<0.1$ & 0.5 \\
\hline 5 & $\begin{array}{l}\text { Benzo(e)pyrene* } \\
\text { Benzo(a)pyrene* }\end{array}$ & $<0.1$ & 0.7 & 0 & 0 \\
\hline 5 & Perylene & 0 & 0.1 & 0 & 0 \\
\hline 5 & Dibenz $(a, j)$ acridine* & 0 & $<0.1$ & 0 & 0 \\
\hline 5 & Dihenz $(a, i)$ carbazole ${ }^{\star}$ & $<0.1$ & 0.1 & 0 & 0 \\
\hline 6 & Indeno $(1,2,3-c d)$ pyrene* & 0 & 0.1 & 0 & 0 \\
\hline 5 & Dibenzanthracene* & 0 & 0.1 & 0 & 0 \\
\hline 6 & Benzo $(g, h, i)$ perylene & 0 & 0.2 & 0 & 0 \\
\hline 7 & Coronene & 0 & $<0.1$ & 0 & 0 \\
\hline 6 & Dibenzpyrene* & $<0.1$ & 0.1 & 0 & 0 \\
\hline
\end{tabular}

* Suggested as having some cancer-causing potential.

Table 18. Particle-size distribution (\%) of total particulate area samples.*

\begin{tabular}{|c|r|r|r|r|r|r|r|r|r|r|r|r|r|r|}
\hline $\begin{array}{c}\text { Particle size } \\
(\mu \mathrm{m})\end{array}$ & \multicolumn{1}{|c|}{ Refinery E } & \multicolumn{4}{|c|}{ Refinery $F$} & \multicolumn{3}{|c|}{ Refinery G } & \multicolumn{2}{|c|}{ Refinery H } & \multicolumn{3}{|c|}{ Refinery I } \\
\cline { 2 - 13 } & FCCU & \multicolumn{1}{|c|}{ DA } & FCCU & DCU & \multicolumn{1}{|c|}{ VD } & UW & FC SU & DCU & AB & FCCU & VD & FCCU & DCU & VD \\
\hline $0.4-0.7$ & 68.2 & 69.0 & 43.5 & 38.8 & 38.1 & 32.9 & 44.9 & 33.2 & 55.0 & 51.5 & 53.1 & 4.6 & 2.1 & 3.3 \\
$0.7-1.0$ & 21.1 & 17.6 & 29.1 & 17.5 & 24.1 & 20.7 & 29.0 & 31.1 & 32.4 & 26.1 & 26.0 & 6.3 & 3.6 & 4.4 \\
$1.0-1.5$ & 6.8 & 11.8 & 14.4 & 21.9 & 17.4 & 23.4 & 12.8 & 20.9 & 6.1 & 9.2 & 15.2 & 7.5 & 4.5 & 9.3 \\
$1.5-2.1$ & 2.9 & 1.5 & 4.1 & 8.0 & 6.2 & 8.9 & 4.8 & 4.2 & 3.7 & 4.4 & 4.2 & 9.5 & 8.0 & 12.7 \\
$2.1-2.9$ & 0.7 & 0 & 3.4 & 7.1 & 5.9 & 7.2 & 3.7 & 3.5 & 1.9 & 0.6 & 1.4 & 20.2 & 13.4 & 19.8 \\
$2.9-4.2$ & 0.1 & 0 & 2.7 & 4.0 & 3.8 & 2.6 & 1.3 & 2.4 & 0.5 & 0.2 & 0.1 & 15.9 & 16.5 & 24.3 \\
$4.2-5.9$ & 0.2 & 0 & 1.0 & 1.5 & 2.5 & 2.6 & 2.1 & 2.7 & 0.2 & 0 & 0 & 14.4 & 26.2 & 8.7 \\
$5.9-8.3$ & 0 & 0 & 1.0 & 1.2 & 1.3 & 1.0 & 1.1 & 1.4 & 0.2 & 0 & 0 & 13.4 & 19.3 & 8.6 \\
$8.3-11.8$ & 0 & 0 & 0.7 & 0 & 0.7 & 1.0 & 0.3 & 1.6 & 0 & 0 & 0 & 8.2 & 8.4 & 3.9 \\
\hline
\end{tabular}

*Average percentages of samples collected at each unit. 


\section{ANALYSIS AND DISCUSSION OF RESULTS}

The data on the cumulative PAH exposure levels are represented pictorially in Figures 3 to 6 . Figures 3 and 5 show the confidence limits on the geometric means of the personal samples collected at each FCCU and delayed coker unit; Figures 4 and 6 compare the results by exposure categories. Also included in these figures is the average number of PAHs per sample. Semi-log scales have been used to facilitate data presentation. Because most of the samples collected during the nine refinery surveys were at the FCCU and the delayed coker unit, this section will focus primarily on these process units and to a lesser extent on the various types of asphalt processing.

\section{REFINERY I}

Figures 3 and 5 clearly show that the PAH exposure levels at Refinery I were by far the highest of any recorded for the nine FCCUs (student t-test, $p<0.0005$ ) and the seven delayed coker units $(p<0.005)$ surveyed. For the FCCUs, the geometric mean exposure at Refinery I was more than five times the second highest value; and for the delayed coker units, the value for Refinery I was almost four times the second highest. The results for the area samples collected at Refinery I's vacuum distillation unit were also the highest of the six units (at four refineries) that had this type of asphalt processing, although not by such a large margin (see Table 14). Because the results from the FCCU and delayed coker unit at Refinery I were so much higher than the others, much of the analysis in this chapter will separate out Refinery I to allow a more accurate comparison and evaluation of the results.

It should be noted briefly that, while the cumulative PAH concentrations at Refinery I were the highest, the average number of PAHs per sample was the second lowest. Furthermore, the PAHs found at Refinery I were almost entirely the two-ring compounds, and the particle-size distribution (see Table 18) is different than the other refineries. This will be discussed further in a later section.

The most obvious difference of Refinery I from the other eight surveyed was that all three study process units at this refinery used enclosed buildings to house the heavy-fraction pumps and other equipment associated with process streams likely to contain PAHs. The major disadvantage of buildings of this type without mechanical ventilation is that the potential for the accumulation of airborne contaminants (in this case, PAHs) from spil1s and fugitive emissions is greatly elevated. This point was clearly illustrated at Refinery I by the results of the area samples collected inside the heavyfraction pump rooms at the FCCU $\left(1,347 \mu \mathrm{g} / \mathrm{m}^{3}\right)$ and delayed coker unit $(399.7$ $\left.\mu \mathrm{g} / \mathrm{m}^{3}\right)$. These results were by far the highest of the samples collected at each unit. 


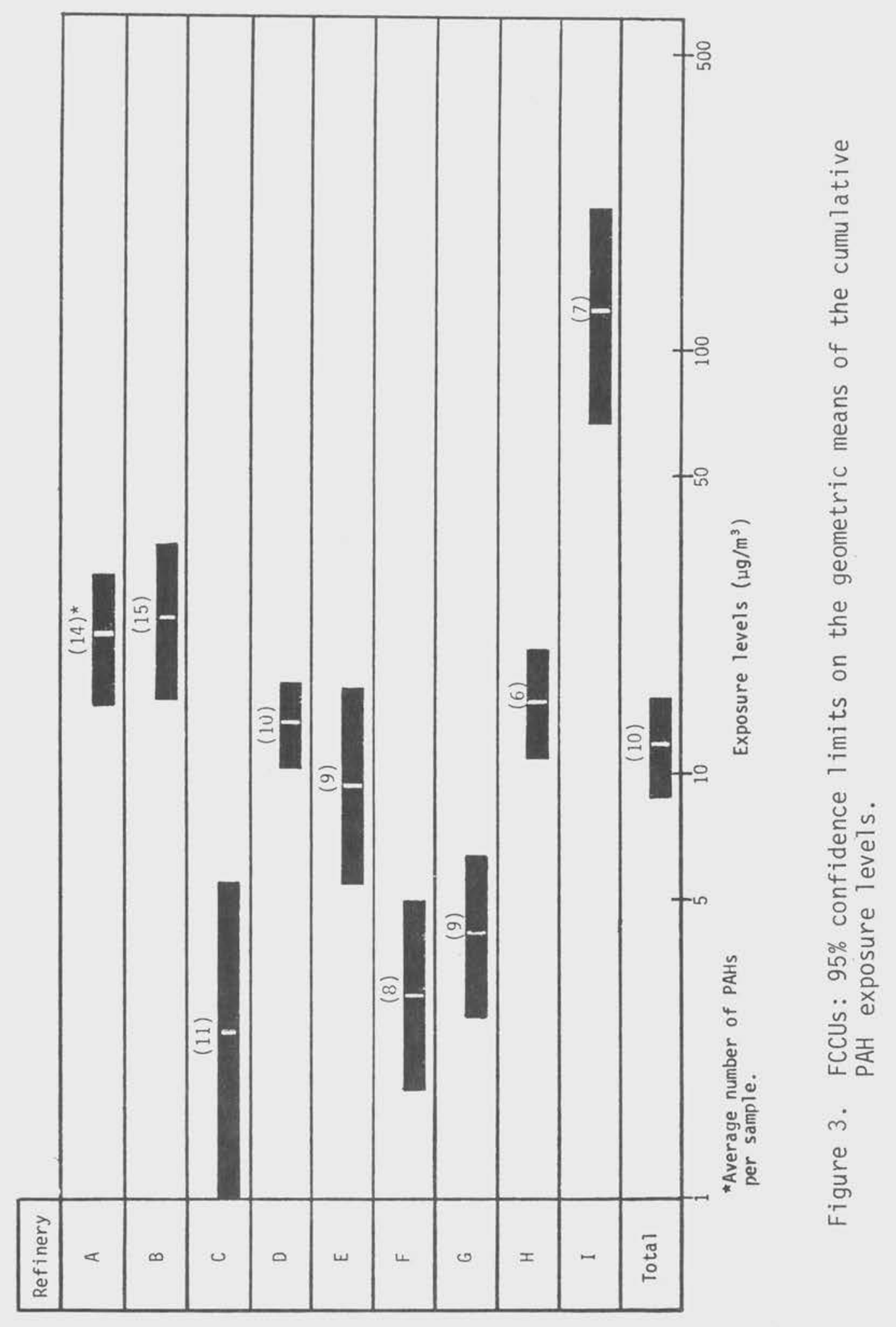




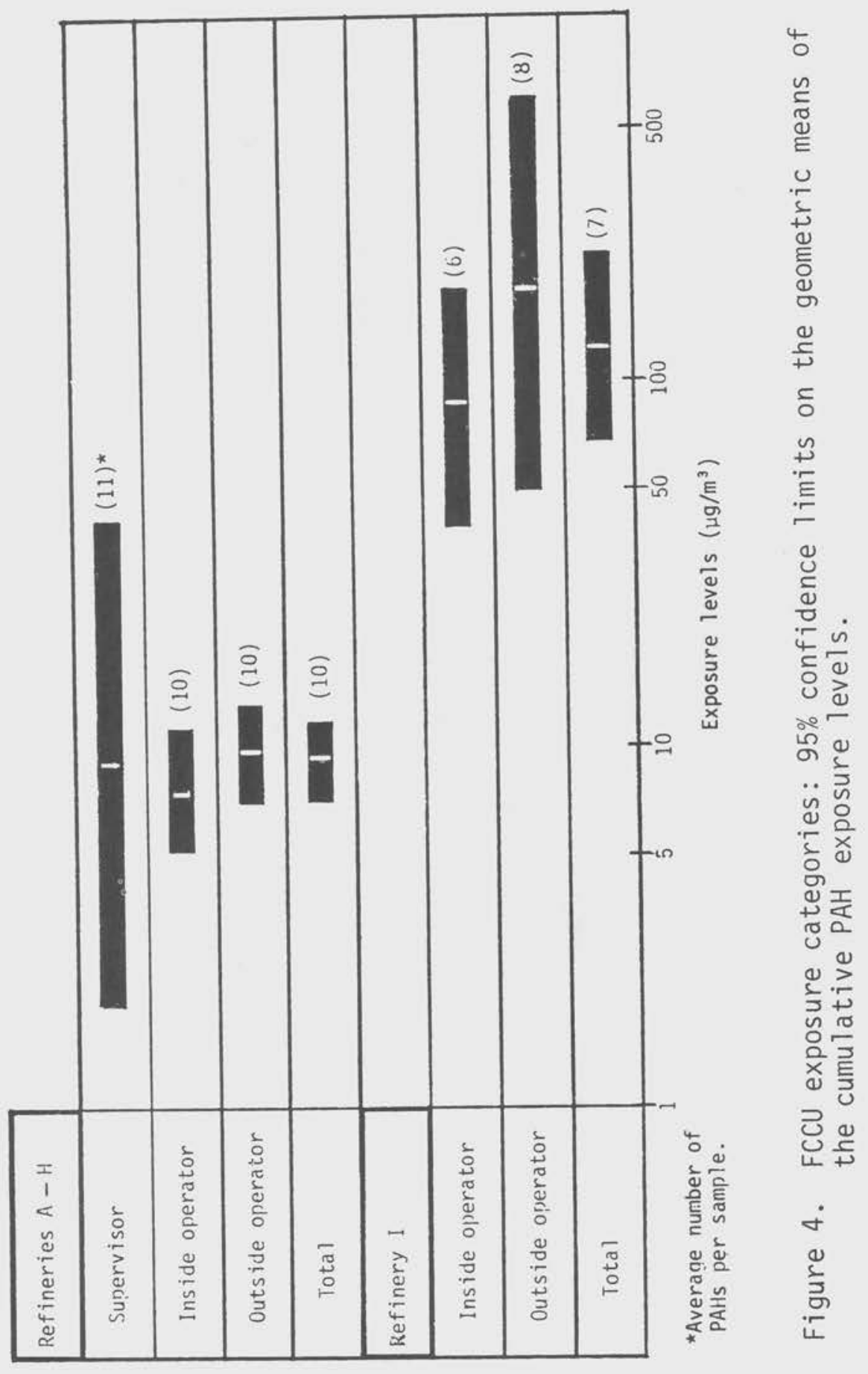




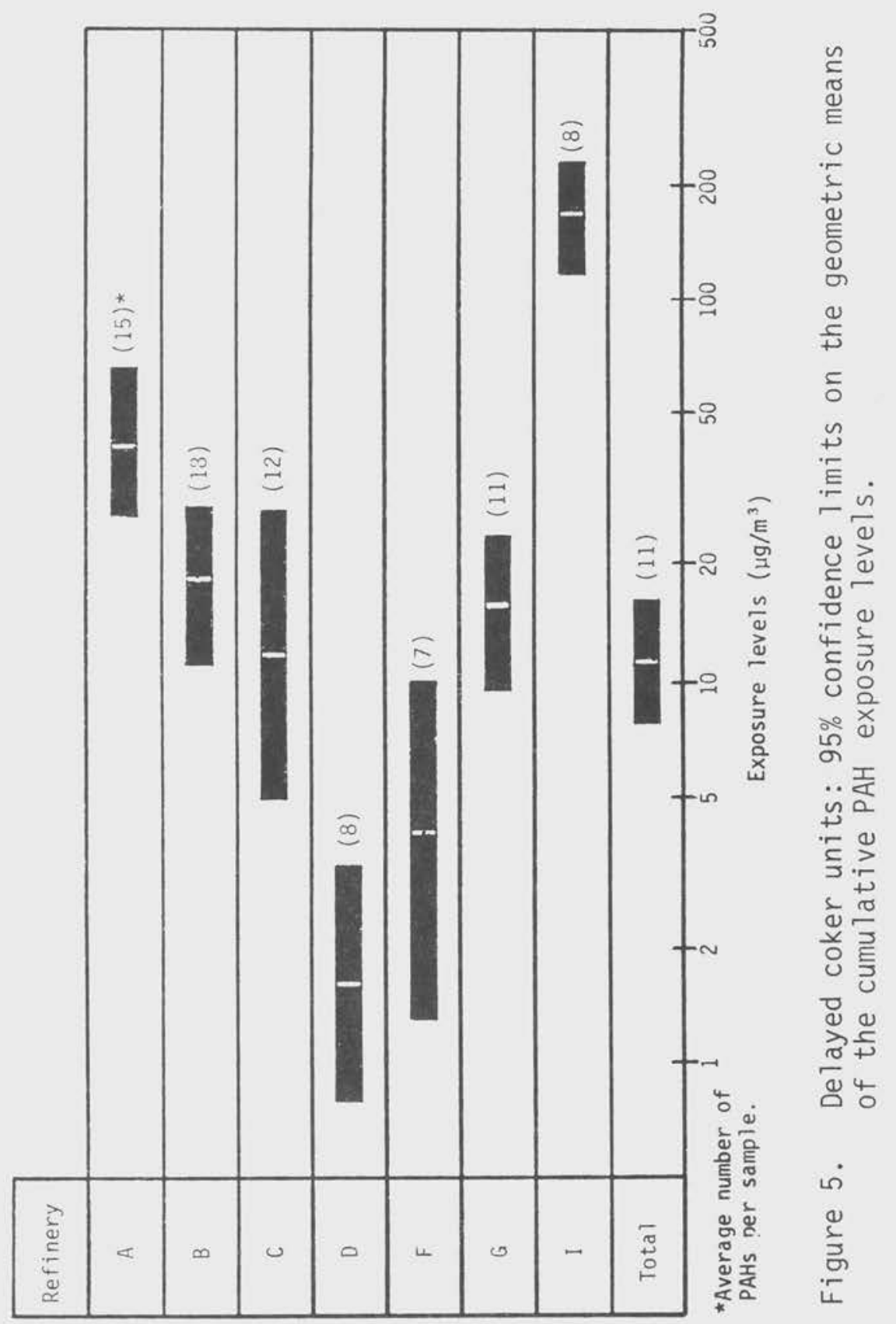




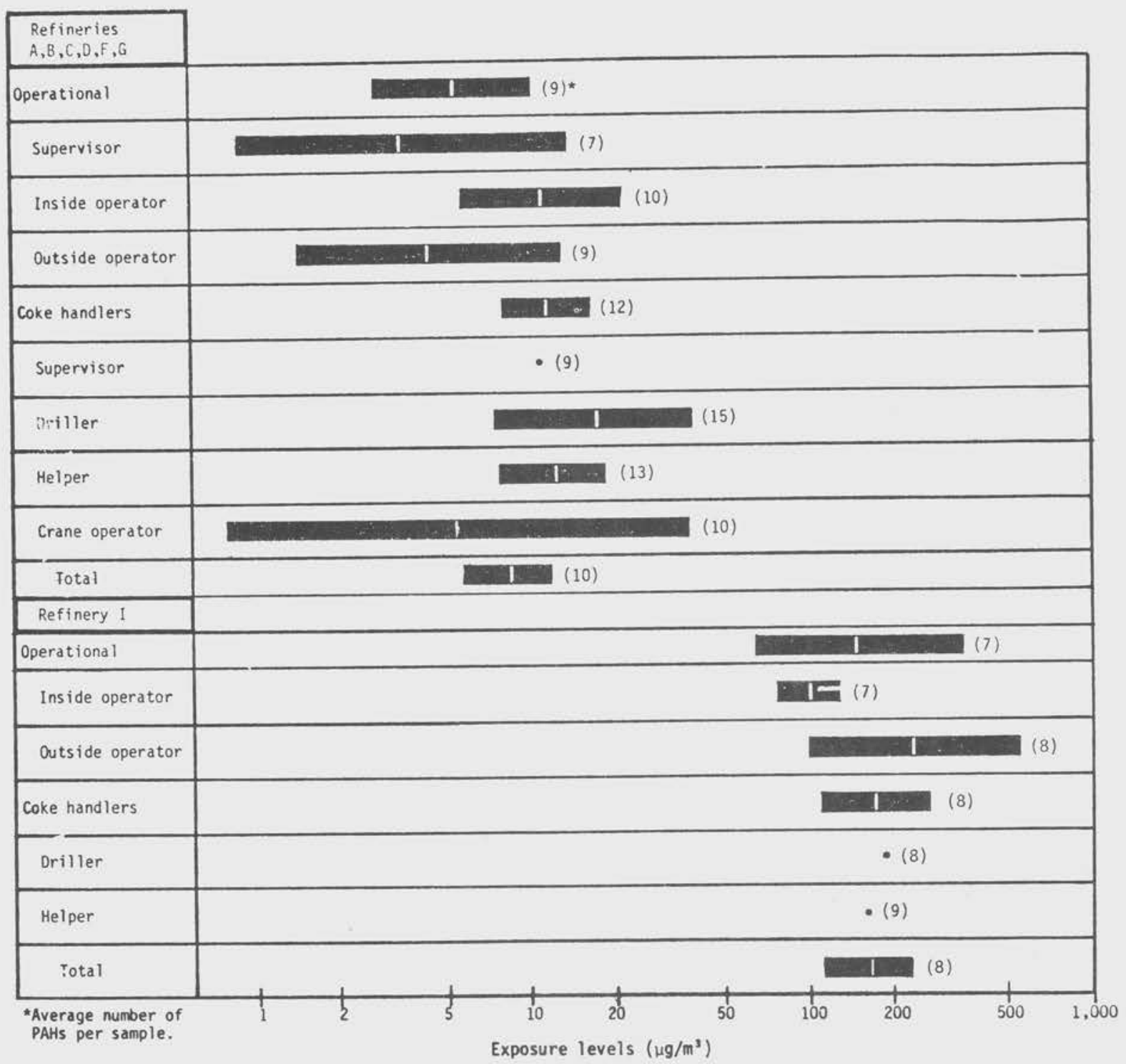

Figure 6. Delayed coker unit exposure categories: 95\% confidence 1 imits on the geometric means of the cumulative PAH exposure levels. 
The delayed coker unit at Refinery I had several basic process differences from the other coker units surveyed; however, the major difference was that the coke-cutting operation was performed using a mechanical drill while the other six units used hydraulic cutting. The mechanical drilling was not a totally dry process since water was used to cool the drum prior to cutting; however, hydraulic cutting uses much larger quantities of water during the actual cutting operation which tends to suppress dispersion of any fine particulates.

A careful examination of the complete data set (Appendix E) indicates that the enclosed buildings and mechanical drilling alone cannot account for the wide variation between Refinery I and the rest of the refineries. The elevated levels at Refinery I were consistent among all of the operators sampled, including the inside operators who do not normally go into the enclosed pump rooms or in the vicinity of the coke-cutting operation. At the delayed coker unit, the control room and the hot-pump room were both in the same building quite close to each other; cross-contamination was a possibility here. Despite this, it appears that the unusually high concentrations of PAHs at these two units were not restricted to the enclosed buildings containing heavy-fraction process streams or to the vicinity of the cutting operation, but occurred throughout many areas of both units.

If this was the case, other factors or combination of factors were also important in influencing the levels found at this refinery. The weather was quite warm during the survey; Appendix E shows that the temperature range during the survey of Refinery I was one of the three highest $\left(15-27^{\circ} \mathrm{C}\right)$, and that the wind velocity was quite low (0-10 $\mathrm{mph})$. The relative humidity during this survey appears to have been about average $(35-75 \%)$. Table 1 indicates that the three study process units at Refinery I were the oldest of each type surveyed, although all three had major turnarounds within 24 months prior to the survey. Refinery I was processing a Wyoming crude that had the highest sulfur content $(3.0 \%)$ and one of the lowest API Gravity Indexes (25) of those crudes included in the nine surveys. About two-thirds of the time, Refinery I processes a lighter, lower sulfur-containing crude. The FCCU at Refinery I was one of only two that did not use a CO boiler to burn the regenerator flue gas (which may contain PAHs) before release to the atmosphere. The possible importance of these and other factors to influence the PAH levels found at units is discussed further in the next section.

\section{OTHER FCCUS (REFINERY I NOT INCLUDED)}

The mean (geometric) cumulative PAH exposure levels for the eight other FCCUs ranged from 2.4 to $22.2 \mu \mathrm{g} / \mathrm{m}^{3}$, and the average number of PAHs per sample ranged from 6 to 15. All eight of these FCCUs were quite similar in terms of general process, equipment, structures, job descriptions of the work force, housekeeping and maintenance of the unit, etc. Unlike Refinery I, they exhibited no obvious differences that might explain the 10 -fold range of mean exposure levels. Consideration was given to more subtle factors that might influence the airborne levels of PAHs. Figure 3 shows that the results for Refineries $A$ and $B$ were very similar in both exposure levels and number of PAHs per sample. Appendix E further shows that the actual distribution of PAHs found was quite similar. The 
information from Table 1 shows that these two refineries and FCCUs were very similar in terms of geographical location, capacity of units, age of units, dates of last turnaround, features (e.g., CO boiler), and source and type of crude. To determine if there was a general relationship between any of these types of variables and the geometric means of the cumulative PAH concentrations, a limited statistical analys is was performed.

First, a qualitative assessment was performed on the variables listed below; these were selected on the basis of available information and their potential for influencing the levels of airborne PAHs at the units:

- age of unit

- production capacity of unit

- duration since last major turnaround

- environmental conditions during sampling

- crude type (sulfur content and API Gravity Index)

- major or nonmajor oil company

If even a slight trend was indicated, the data were plotted on a scattergram and the Pearson product-moment correlation coefficient was calculated (Downie and Health, 1959). Values of " $r$ " greater than 0.50 were tested for significance using the Student's t-test.

Qualitative assessment of the data showed that only two of the above six variables appeared to correlate with the exposure data; these were age of unit and crude type (API Gravity Index). Figures 7 and 8 display the scattergrams for these two relationships. The calculated " $r$ " values for age of unit and API Gravity Index were 0.83 and 0.51 , respectively. The " $r$ " value for age of unit passed the test for correlation $(p<0.01)$ at the $95 \%$ confidence level while the API Gravity Index $(p>0.1)$ did not.

Figure 4 shows the results of the personal samples collected at the FCCUs, grouped by exposure categories; the data for Refinery I have been separated. In both sets of data (Refineries A-H and Refinery I), the geometric mean for the outside operators was higher than for the inside operators; from the individual refinery data (Table 7 ), the results were higher for the outside operators at seven of the eight units where both exposure categories were sampled. The differences between the two categories, however, were not significant at the $95 \%$ confidence level $(p>0.3)$. The average number of PAHs per sample was the same for these two exposure categories at Refineries $\mathrm{A}-\mathrm{H}$, and S1jightly lower for the outside operators at Refinery I.

Considering the job descriptions of the workers who made up these two exposure categories, it was surprising that the results for the inside operators were as similar as they were to those for the outside operators. All of the inside operators spent the great majority of their shift inside the control room monitoring and logging in the various meters and charts on the control panel. The inside operator at Refinery $H$ was the only one who had any routine outside duties. This particular operator toured the production area during the first hour of the shift. It was very unlikely that these inside 


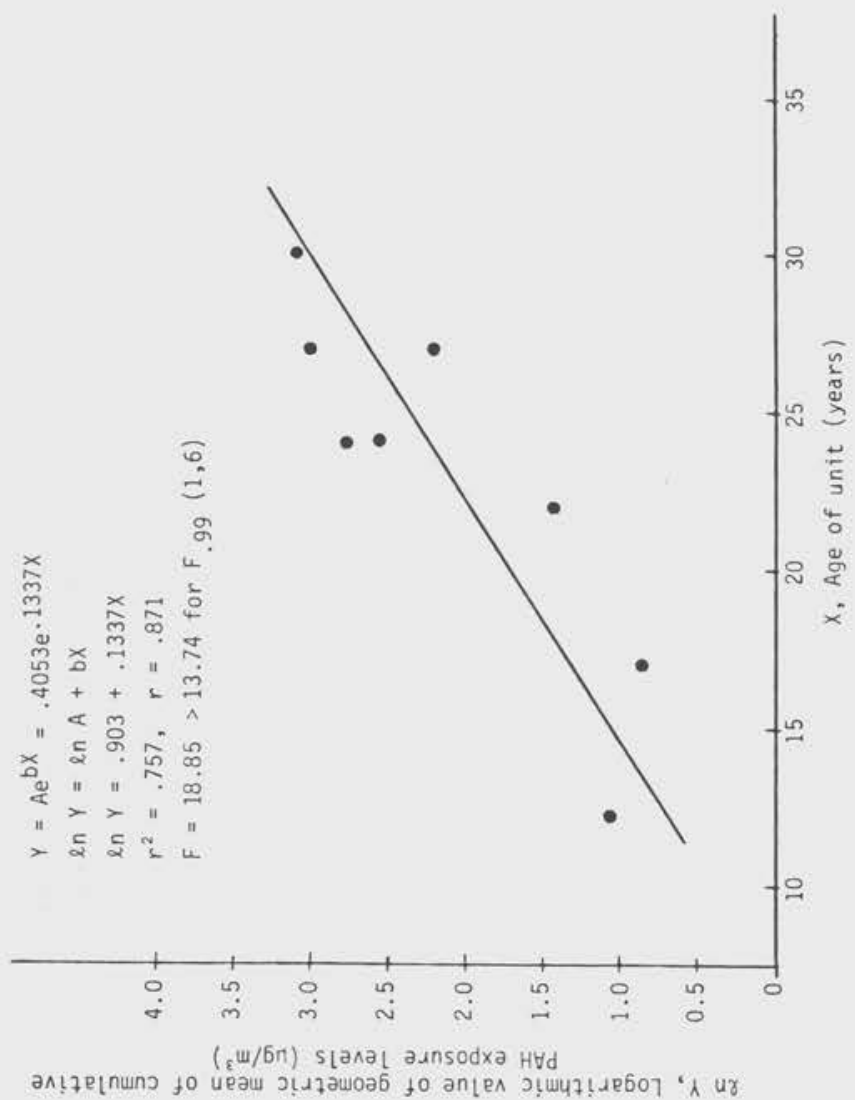

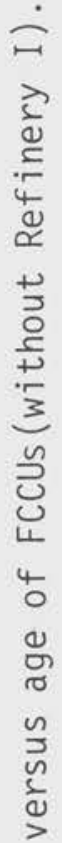

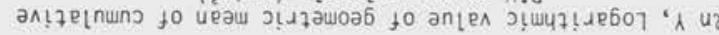
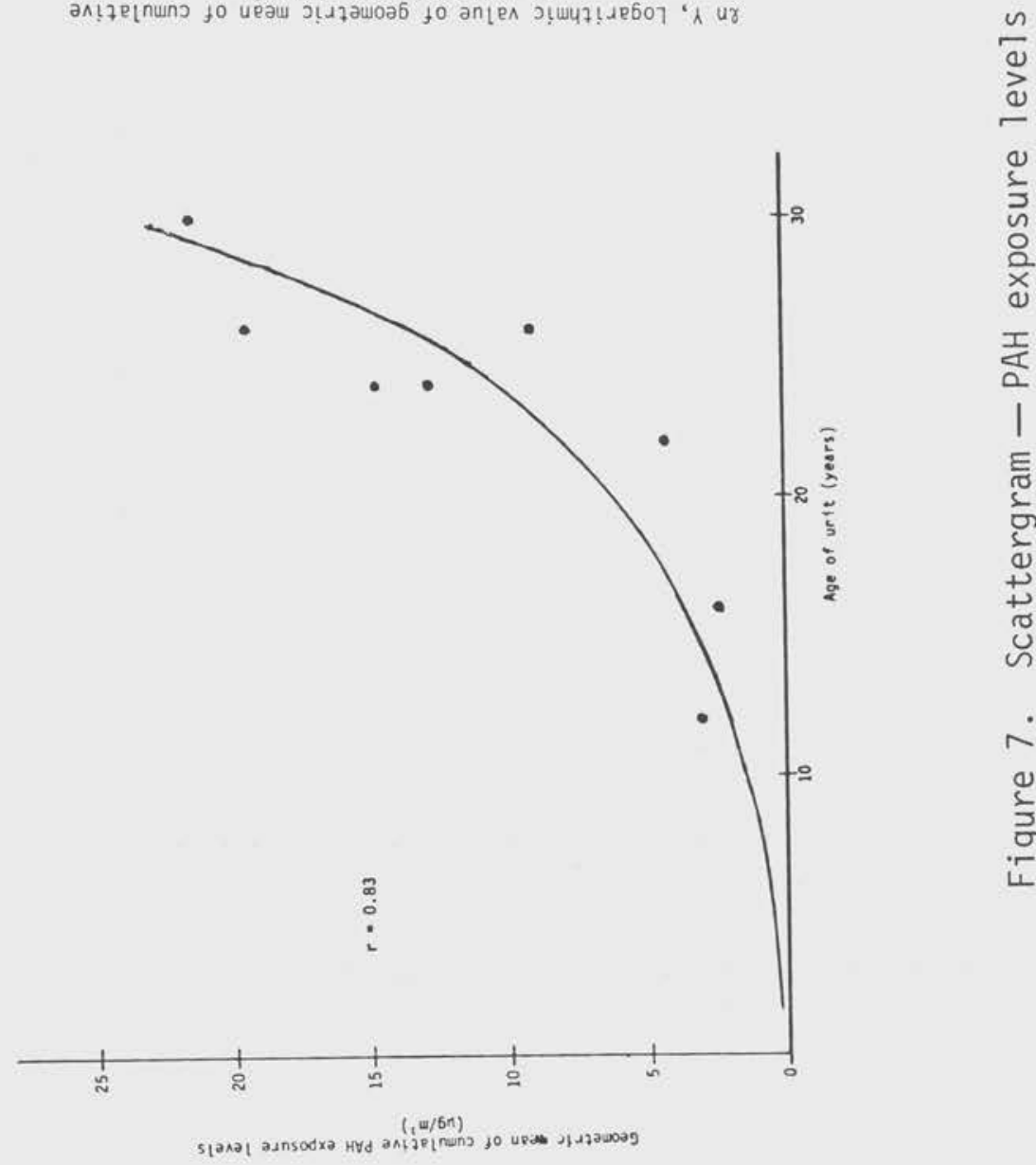

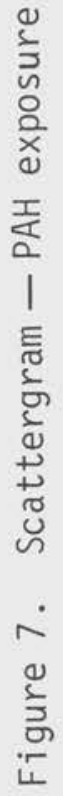




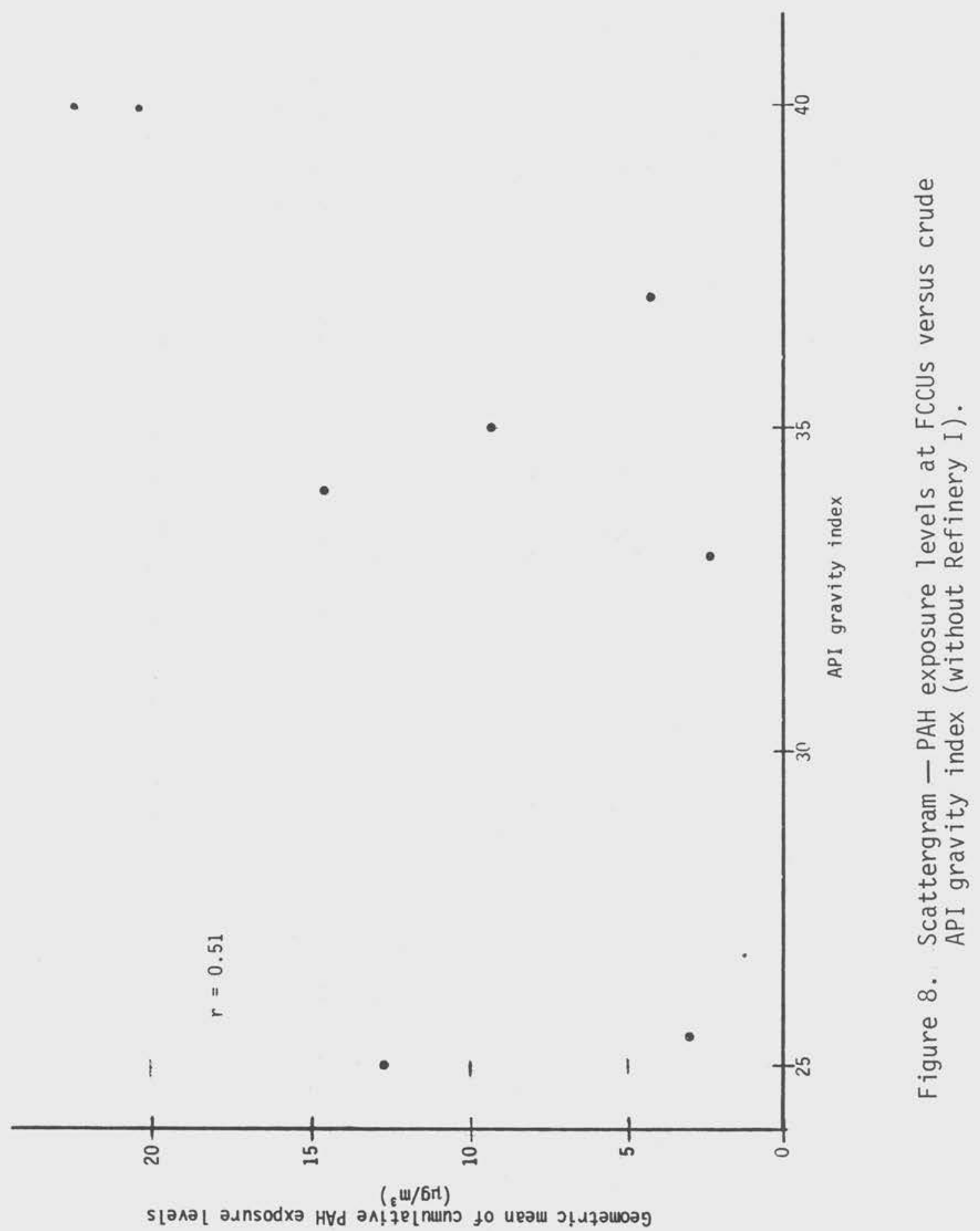


operators came into direct contact with any PAH-containing material. On the other hand, the outside operator category included the lead operators and helpers who performed all of the routine outside duties. This included the direct handling of equipment or material (e.g., sample collection, minor maintenance and repair of pumps) associated with PAHs.

During the surveys, it was observed that the FCCU control rooms were by no means isolated from the production areas. There was usually a considerable amount of traffic through the control rooms by the outside operators. In addition, the control rooms were generally in the midst of the units and occasionally directly downwind of equipment or structures containing the heavy-fraction process streams. While most of the control rooms were airconditioned, only one was under positive pressure.

Many of the FCCUs had supervisors or foremen who spent a good percentage of their shift outside directing others, but who did not directly handle any equipment. These individuals often had responsibility for at least one other unit. A very small number of samples were collected for this exposure category at two units. Figure 4 reflects this with the large confidence limits. From the limited data available, the only statement that can be made about this exposure category is that the results were generally consistent with the overall results of the individual unit.

At the lärger FCCUs, there were operators assigned specifically to the "cat" side of the unit, which included the reactor, regenerator, and heavy-fraction pumps, and to the recovery side (lighter fraction process streams). While the results from two of these units (Refineries $E$ and F) indicated that the operators assigned to the cat side were exposed to higher PAH concentrations, the results from several other units (Refineries B, D, and G) did not. Because of this initial evaluation and the limited number of samples involved, it was decided not to further divide the exposure categories for evaluation.

A review of the complete personal sampling data set in Appendix $E$ shows that there was a general consistency between the duplicate samples collected on successive days. During the nine surveys, 42 pairs of duplicate samples were collected at the FCCUs and, of these, 27 , or $64 \%$, showed 1 ess than $40 \%$ variation between the two samples. Excluding the results from Refinery $E$, this percentage increases to $76.5 \%$. The inconsistency at this one unit could not be explained by information accumulated during the survey. The overall consistency reflects the fact that the FCCU is an example of a normally smooth-running, continuous-operation process unit.

The intention of the limited amount of area sampling conducted at the FCCUs was to supplement the personal sampling data by determining the quantities and distributions of PAHs at locations suspected of having relatively high concentrations. Sampling locations were chosen near the heavy-fraction pumps at each of the units; at Refineries $H$ and I, one sample was also collected near the reactor/regenerator structure. It was not possible to sample at comparable locations at each unit; convenience of hanging the pump often dictated the exact sampling location. Because of this, comparison of 
area sampling results between refineries should be 1 imited. The results did consistently show that the slurry recycle pump areas were 2 to 20 times higher (cumulative PAH concentrations) than the results for outside operators at each unit. Exceptions were noted, especially at Refinery $H$ where the samples were collected farther away from the pumps. The area results also showed that the distribution of PAHs was quite consistent with the personal samples. While the slurry pump areas were quite definitely associated with elevated $\mathrm{PAH}$ concentrations, the results of the small number of samples collected near the decant oil pumps, charge pumps, and reactor/regenerator areas were not nearly as high.

\section{OTHER DELAYED COKER UNITS (REFINERY I NOT INCLUDED)}

The mean (geometric) cumulative PAH exposure levels for the six delayed coker units, excluding the one at Refinery I, ranged from 1.6 to $41.9 \mu \mathrm{g} / \mathrm{m}^{3}$, and the average number of PAHs per sample ranged from 7 to 18 . Many aspects of these six units were quite similar, such as the process, equipment, cutting method, and work force. However, there were two basic differences that stand out when comparing these units and the results from the surveys. The first has to do with the type of coke produced. The units at Refineries $A$ and $G$ produced both needle (\#1 type) and sponge (\#2 type) coke while the rest of the units produced only sponge coke. The second basic difference was the method of handling the coke after it was cut. Three refineries used a railcar positioned directly beneath the drum; the other three refineries directed the falling coke into a large containment pit, from which it was transferred to trucks by crane or other equipment. The possible impact of these and other unit characteristics on the levels of PAHs found during the surveys is discussed in this section.

During the surveys at Refineries $A$ and $G$, needle coke was cut during the first sampling shift and sponge coke was being cut during the second. Figure 9 shows a comparison of the personal sampling results between the two sampling shifts at each refinery and both refineries combined. Only paired samples collected during both cutting shifts were included. It is quite clear that the cumulative PAH concentration exposures were higher during the cutting of needle coke. At Refinery $A$, there was also a substantially larger number of PAHs per sample collected during this period. The differences between the combined means of the cumulative exposures were statistically significant at the $95 \%$ confidence level (student t-test, $p<0.01$ ). When comparing the data, it is important to realize the limitations involved when sampling only one cutting operation for each type of coke at only two refineries. Despite this, the results from the two delayed coker units that produced both types of coke indicate that the cutting of needle coke is associated with higher cumulative PAH exposure levels and possibly with exposure to a larger number of different PAH compounds.

Both advantages and disadvantages were observed for the method of cutting the coke directly into railcars. This method eliminates the necessity of a crane or any other type of coke-moving equipment such as front-end loaders and trucks. However, this method does require that at least one of the coke 


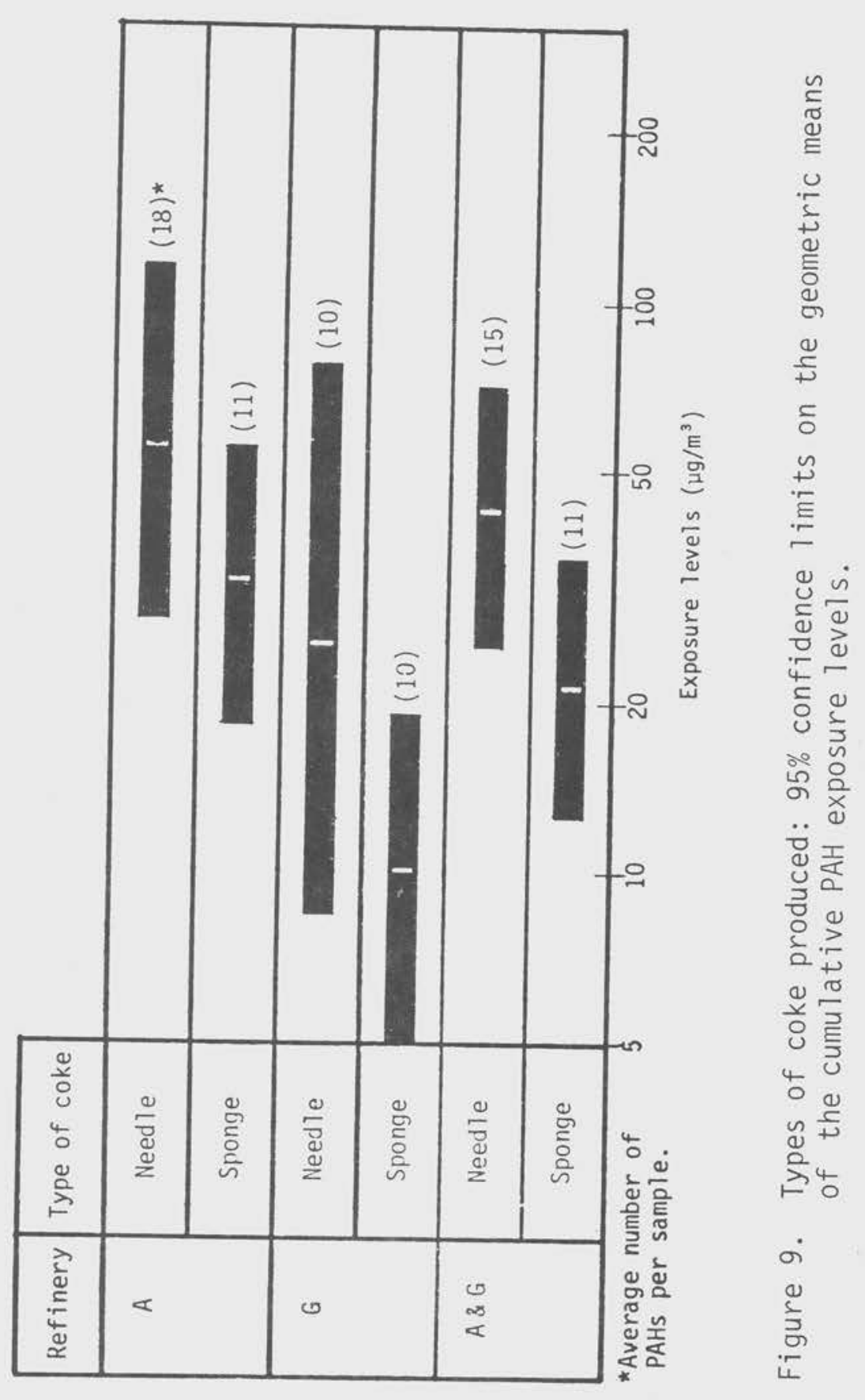


handlers be stationed at the drum bottom area to ensure proper railcar loading. This worker is in very close proximity to the falling coke, splashing water, and water mist. The coke at this point has been cooled, and hydrocarbon vapor is not likely. Dermal exposure to coke particulates is more probable. A comparison of the data (Table 7) from Refineries B, C, and $G$, that used railcars, and from Refineries $A, D$, and $F$, that used a containment pit, does not clearly show a difference between methods. Figure 5 shows that of the six delayed coker units surveyed, the three using railcars ranked second, third, and fourth with an average of 14 PAHs per sample; the other three units ranked first, fifth, and sixth with an average of 10 PAHs per sample. Based on the data from these six surveys, a meaningful statement as to whether one method of handling the cut coke is associated with higher levels of airborne PAHs cannot be made.

The six variables selected in the previous section as being potential factors influencing the PAH results at the FCCUs were also felt to be relevant for the delayed coker units. The presence of a relationship between any one of these variables and the results from the delayed coker units was tested for in the same manner as before. These variables were:

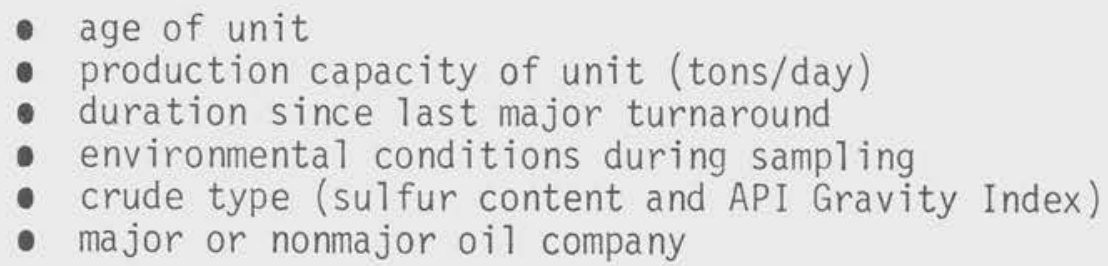

A qualitative evaluation of the data showed that only two of the above variables appeared to correlate with the exposure data from the six units: the production capacity of the unit, and the API Gravity Index. Figures 10 and 11 display the scattergrams for these two relationships. The calculated " $r$ " values for production capacity and for the API Gravity Index were -0.76 $(p<0.05)$ and $0.80(p<0.02)$, respectively. While both passed the test for correlation at the $95 \%$ confidence level, neither passed at the $99 \% 1$ evel. The negative " $r$ " value for production capacity indicates that at least at these six delayed coker units, as the production capacity increased, the cumulative PAH concentrations decreased. The positive " $r$ " value for the API Gravity Index indicates that the exposure levels are inversely proportional to the density of the crude levels. This relationship with the crude density was similar to that found in the previous section for the results of the FCCUs.

Figure 6 shows the results of the personal samples collected at the delayed coker units by exposure categories; the data for Refinery I have again been separated. The work force at this type of unit is divided into two general categories, the operational workers and coke handlers. The operational group is similar to the normal work force at the FCCU or any other continuoustype refinery process unit. This operational group is further divided into the inside and outside operators and the supervisor. The second major exposure category at the delayed coker unit is the coke handlers group which is divided into the supervisor, driller, helper, and crane operator categories. 


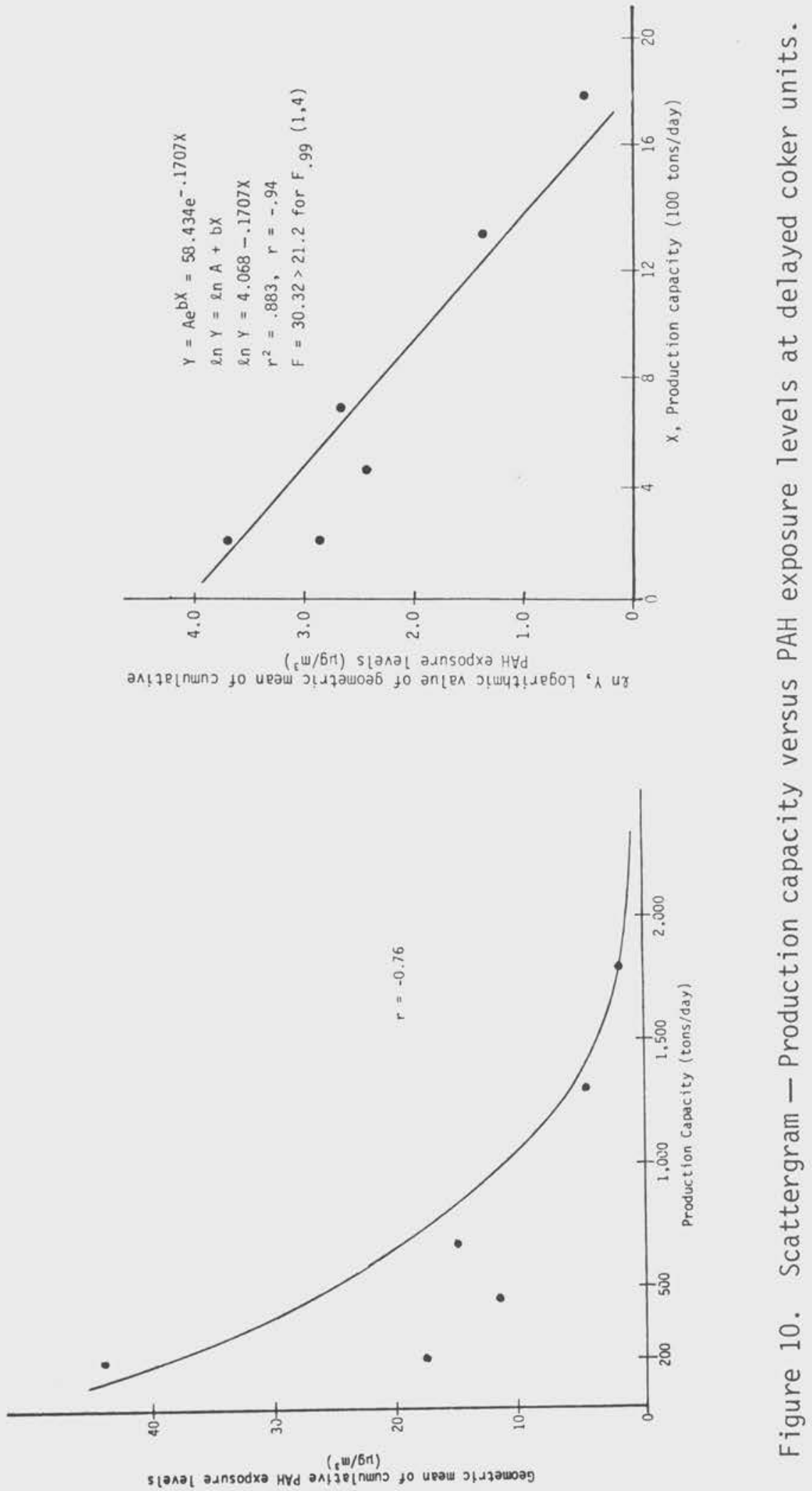



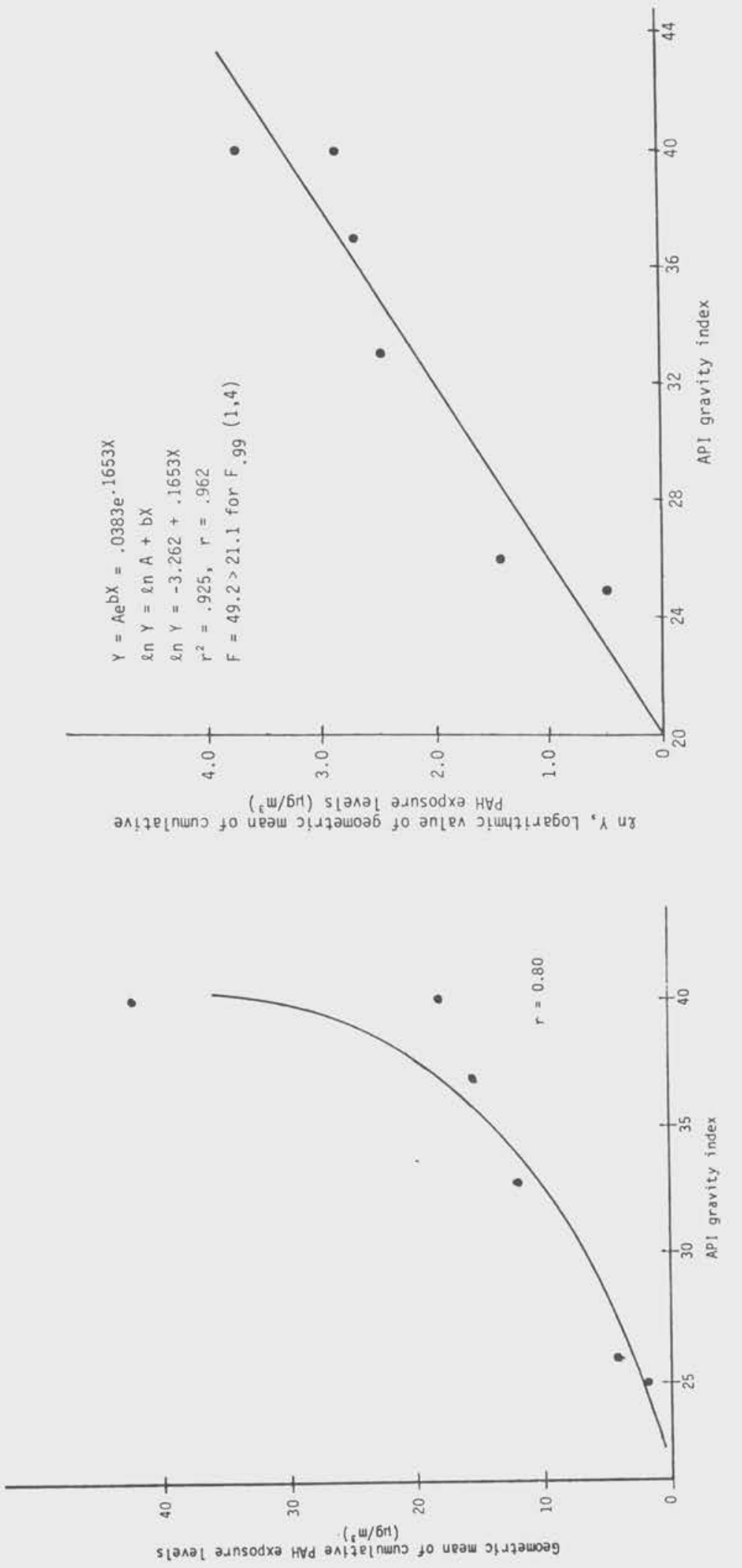
Both sets of data (Refineries A, B, C, D, F, and G together and Refinery I alone) show that the geometric mean for the coke handlers was higher than the operational group (Figure 6 ), although not statistically significant. Both sets of data also show that the average number of PAHs per sample was higher for the coke handlers. The results for the individual units (Table 10) show that the coke handlers were exposed to a higher concentration of PAHs at five of the seven units surveyed. Figure 6 shows that, within the operational group, the inside operators had a higher mean cumulative PAH concentration than the outside operators (Refineries A, B, C, D, F, and G); this was not the case at Refinery I. The supervisor group had the lowest mean value of the operational exposure categories. However, a total of only five samples were collected for this category at three units; this is reflected in the large confidence limits (Figure 6 ). Both sets of data again show that within the coke handlers group the driller exposure category had the highest mean value. The helpers group had the next highest mean value. The small number of samples (six) collected for the crane operator category is reflected by the large confidence limits (Figure 6). Only one sample was collected for the coke handler supervisor category.

The results showing that the coke handlers were exposed to high PAH concentrations and to a large number of PAHs is not surprising when considering their normal duties. The coke-cutting and handling operation is one of the few in a refinery that is not a closed system. Because of this, it is more difficult to minimize worker exposure during this operation. During every cutting cycle at a typical delayed coker unit, the top and bottom of the drum must be opened manual1y, the coke must be cut by the driller, the helpers must clean and lubricate the fittings and direct the loading of the railcars; at other units, the crane operator must move the coke out of the containment area. The driller was normally positioned at the top of the coke tower in a station called the "penthouse." The penthouse was normally an enclosed room with several windows and other openings that provided natural ventilation. A large number of job titles (Table 6) and descriptions made up the helpers exposure category. The duties of helpers varied, depending on the cutting method used, but they all spent some of their shift on or near the coker tower. Because of this, it was decided that the beltman at Refinery D should not be considered a helper and was placed into the crane operator category. This particular coke handler worked away from the coke tower and near the containment pit, crusher, conveyor, and storage areas.

At all of the units in this study where personal sampling was conducted, the results have consistently shown the PAH concentrations and variety of PAHs to be greater than expected for the inside operators. This was based on their job descriptions. However, at the delayed coker units, the geometric mean and the average number of PAHs per sample for these inside operators at Refineries $A, B, C, D, F$, and $G$ were actually higher than those for the outside operators. The inside operators spent the great majority of their shift $(85-100 \%)$ inside the control room; the outside operators spent from 40 to $90 \%$ of their shift outside in the production area. As at the FCCUs, the control rooms for most of the delayed coker units were in the midst of the unit close to equipment and structures, and it was not unusual during the surveys for the control rooms to be downwind of the coke-cutting operation. It was also 
noticed that foot traffic through the control room by the outside operators and, to a lesser degree, by the coke handlers, was common.

The complete personal sampling data set (Appendix E) reveals that there was less consistency between the duplicate or paired samples collected on successive days at the delayed coker units than at the FCCUs discussed in the previous section. During the surveys of all seven delayed coker units, a total of 40 pairs of samples were taken; of these, 20 or $50 \%$ showed less than $40 \%$ variation. Of these 40 pairs of samples, 17 were collected on operational workers and 23 on coke handlers. There was much more consistency among the operational group paired samples $(65 \%)$ than among the coke handler group paired samples $(39 \%)$. This was consistent with the observations that the duties performed by the drillers, helpers, and crane operators were much more likely to vary from one shift to another. The duration of the cutting operation often varied at the same unit because of the type of coke being cut, amount of coke in the drum, and performance of the equipment. As seen at the FCCU, the duties and schedules of the operational group were much more stable from day to day. This is illustrated by the fact that the percentages of paired samples collected for these two groups of workers (operational and FCCU operators) having less than $40 \%$ variation were almost identical $(64 \%$ and $65 \%)$.

At each delayed coker unit surveyed, at least one area sample was collected downwind (5-20 yards) from the bottom of the drum during the cutting operation. The results of these area samples were generally consistent with the personal sampling results of the individual unit's coke-handling group (Table 10) for both cumulative PAH concentrations and average number of PAHs per sample. This finding was not surprising since many of the coke handlers spent almost all of their outside time on or near the coke tower near the cutting operation. At Refinery $G$, where both types of coke were produced, an area sample was collected downwind during both cutting operations. The PAH concentration results for the first sampling shift when needle coke was cut were more than three times higher than the results for the second sampling shift when sponge coke was cut. The number of PAHs was also slightly higher when the needle coke was cut. This supports the comparison made earlier between the types of coke and the personal samples.

At five of the delayed coker units (Refineries A, B, C, D, and I) a sample was collected near the charge pump to the unit or the charge pump from the fractionator to the furnace. Both types of pumps contained heavy-fraction process streams. The results for these area samples were also quite similar to the personal sampling results for the coke handler groups of the separate units (Table 10). Exceptions to this were found at Refinery $A$ where the charge pump sample results were very low, and at Refinery I where the results were high. The high value at Refinery I can be explained, as discussed earlier, by the fact that the pump was in an enclosed room.

The results from all nine surveys which included nine FCCUs and seven delayed cokers show that the overall results for these two types of units were very similar. The geometric mean of the cumulative PAH exposure levels (personal samples) was $11.4 \mu \mathrm{g} / \mathrm{m}^{3}$ for the FCCUs and $11.1 \mu \mathrm{g} / \mathrm{m}^{3}$ for the delayed coker units. The average number of PAHs per sample was 10 for the FCCUs and 11 for the delayed coker units. 
The original study plan did not include any personal sampling at the three types of asphalt processing units; however, because one of the two FCCUs scheduled for detailed sampling at Refinery $E$ was down for maintenance, personal sampling was conducted at the refinery's deasphalting unit. At the rest of the asphalt processing units, sampling was usually limited to two area samples in locations near the heavy-fraction pumps. The duplicate samples collected with a cyclone preselector during the first four surveys will be discussed in a later section. The objective of this very limited sampling program at the various asphalt processing units was to allow a qualitative comparison between these units and the FCCUs and delayed coker units that were sampled in more detail.

Figure 12 is a plot diagram of the cumulative PAH concentrations of each area sample collected at the asphalt processing units; the average number of PAHs per sample by process is also indicated. As mentioned previously, it is not appropriate to compare the processes or refineries statistically using the area sampling data. The sampling sites were selected subjectively; selection was often influenced by the convenience of placing the sampling units. As a result, the sites were not always consistent or comparable among units.

\section{Asphalt Blowing ( $A B)$}

The five area samples collected at the three $A B$ units (Refineries $A$, B, and $G$ ) ranged from 1.6 to $30.6 \mu \mathrm{g} / \mathrm{m}^{3}$ cumulative $P A H$ concentration, and the average number of PAHs per sample ranged from 5 to 14 . Four of the five samples were similar in cumulative concentration, ranging from 1.6 to $3.3 \mu \mathrm{g} / \mathrm{m}^{3}$ (Table 14 ). The highest sample by far $\left(30.6 \mu \mathrm{g} / \mathrm{m}^{3}\right)$ was collected at Refinery A near the vacuum bottoms pump ( $A B$ charge pump), which was not actually within the $A B$ unit. Excluding this sample, the cumulative $P A H$ results for the $A B$ units were lower than the comparable results for the deasphalting and vacuum distillation processes. This might be explained by the observation that the $A B$ units were simple units with a small amount of structures and equipment. Because of this, the units were very open, thus minimizing the potential for the accumulation of airborne contaminants such as PAHs.

Relative to the area samples collected at the FCCUs and the delayed coker units at these three refineries, the results for the $A B$ units were much lower with a smaller number of PAHs identified. Even though the cumulative concentration was much lower at the $A B$ unit of Refinery $B$, the number and distribution of PAHS was consistent with the other two study units.

\section{Deasphalting (DA)}

The personal and area sampling results for the DA unit at Refinery E were much higher (cumulative PAH concentrations and average number of PAHs per sample) than expected based on the results of the Phase II area sampling (Appendix B). In fact, the mean (geometric) cumulative PAH concentration for the personal samples collected at this DA unit was over $24 \%$ higher than the comparable results for the FCCU surveyed at this refinery. However, the number of workers was small at the DA unit, and unfortunately one of the 


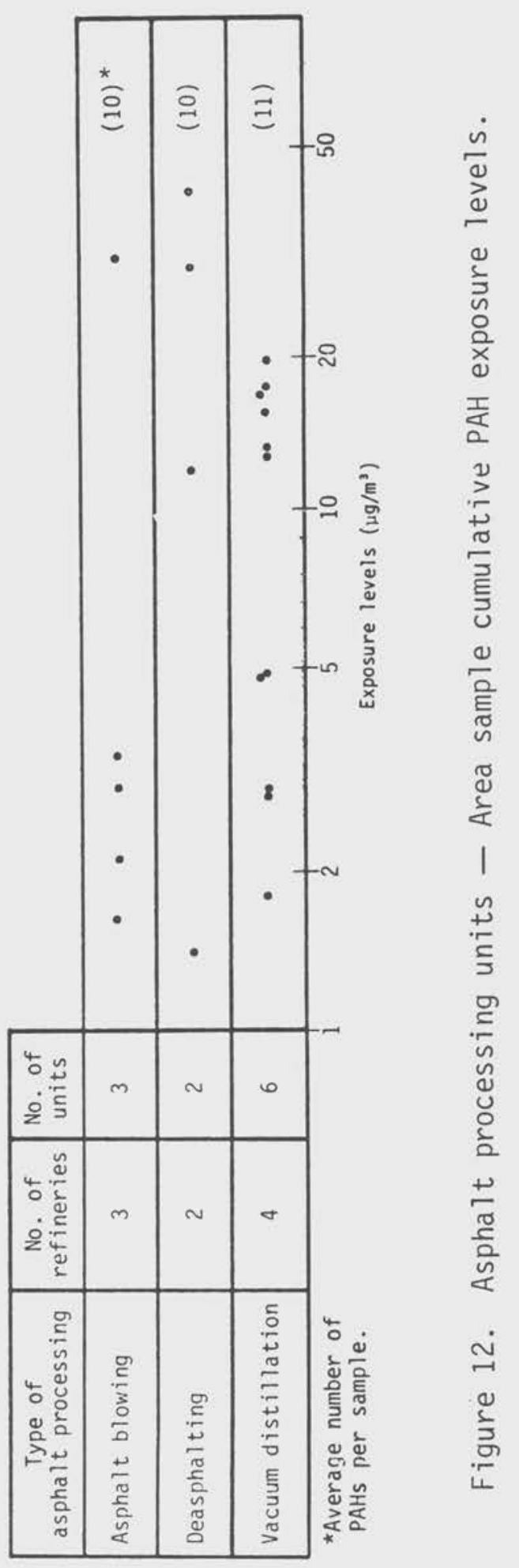


samples was lost to analysis, reducing the total number of personal samples to five. The samples varied greatly between workers and days (Appendix E). Both outside operators performed similar duties, yet one (Assistant Operator 1) was exposed at much higher levels than the other $\left(32.5 \mathrm{vs} .2 .5 \mu \mathrm{g} / \mathrm{m}^{3}\right)$. It should be noted that the outside operator with the high results did work on a gasoline-powered internal combustion engine (not part of the refinery equipment) for several hours on the day yielding the highest PAH results $\left(49.8 \mu \mathrm{g} / \mathrm{m}^{3}\right)$. The geometric mean of the cumulative PAH concentration exposures for the two outside operators was higher than that for the inside operator (Table 13).

The cumulative PAH concentration results for the area samples collected at the other DA unit (Refinery B) were considerably lower (Table 14), although the number of PAHs identified was the same. Refinery $E$ did have a much larger capacity than Refinery B (Table 1) and, as mentioned previously, there was much more heavy $0 i l$ and asphalt-like material on the equipment and structures near the sampling locations at Refinery B. At Refinery B, the results (cumulative PAH concentration and number of PAHs) of the area samples at the DA unit were generally less than the area samples collected at the FCCU and delayed coker unit.

Vacuum Distillation (VD)

The 11 samples collected near the bottoms pump at the six vacuum distillation units (Refineries C, F, H, and I) ranged from 2.8 to $18.0 \mu \mathrm{g} / \mathrm{m}^{3}$ and from 5 to 15 PAHs per sample. At Refineries C and F, the results (cumulative concentration and number of PAHS) of the VD area samples were quite similar to those for their delayed coker units. At Refinery $H$, where there was no delayed coker unit, the results were consistent with the FCCU. The two area samples from the VD unit at Refinery I ranked first and third among the 11 in cumulative PAH concentration. As mentioned before, this can probably be explained by the fact that the bottoms pump was in an enclosed room. The enclosed room also contributed to the consistency of results between the two sampling days at this unit $\left(17.1\right.$ and $\left.19.0 \mu \mathrm{g} / \mathrm{m}^{3}\right)$. It should also be noted that the VD unit at Refinery I was by far the oldest ( 33 years) of the six units (Table 1).

The VD unit at Refinery I did have the lowest number of PAHs per sample (6) while Refinery $C$ had the highest (15). Even though the cumulative concentration results for Refinery I were the highest of the six VD units, the results were much lower than those for the FCCU and delayed coker unit at Refinery I. 


\section{DISTRIBUTION OF PAHS FOUND}

The distribution of PAHs found by compound ring number was consistent in the majority of the samples analyzed from all nine surveys. The 2-ring compounds were found in the highest concentrations and, as the ring numbers increased, the concentrations decreased. Of the 2-ring compounds, naphthalene and its two methyl derivatives normally represented a large percentage of the total PAHs found. The majority of the samples from all three types of study process units contained very little or none of the heavier 5-, 6-, and 7-ring PAHS.

Table 19. (calculated from Table 17) shows the average percent distribution of PAHs by ring number for the three types of process units and the upwind locations at all nine refineries. At all units, at least $84.9 \%$ of the PAHs found were the 2-ring compounds. Although there was overall consistency among the three types of process units, the delayed coker unit did have the highest percentages of the 4-, 5-, and 6-ring compounds. The table shows that the results for the upwind samples were distributed even more heavily toward the lighter molecular weight PAHs.

Table 19. Average distribution (\%) of PAHs found by ring number at all nine refineries.

\begin{tabular}{|c|c|c|c|c|}
\hline Ring No. & FCCU & $\begin{array}{c}\text { Delayed } \\
\text { coker unit }\end{array}$ & $\begin{array}{c}\text { Asphalt } \\
\text { processing }\end{array}$ & Upwind \\
\hline 2 & 86.1 & 84.9 & 87.9 & 93.4 \\
3 & 10.9 & 8.9 & 10.6 & 5.4 \\
4 & 2.9 & 4.7 & 1.2 & 1.2 \\
5 & $<0.1$ & 1.1 & 0.3 & 0 \\
6 & 0 & 0.4 & 0 & 0 \\
7 & 0 & 0 & 0 & 0 \\
\hline
\end{tabular}

It must be remembered that the calculations of percent distribution by ring number have been used in this summary report primarily to facilitate the presentation and evaluation of the complete data included in Appendix $E$. The percentages are not meant to be accurate estimations of the actual PAH distributions in the specific sampling environments. While these 23 individual or groups of PAHs (total of 28 PAHs) for which the samples were analyzed range from 2 to 7 rings, it cannot be certain how representative they are of each sampling location. For example, the fact that only one 7-ring PAH was included in the 1 ist of 28 probably does not reflect the actual refinery situation. Despite this, this approach does allow a comparison of what types of PAHs were found between units and refineries, and hopefully also gives a general indication of the actual PAH distribution. 
The lower molecular weight PAHs generally are not considered as potentially carcinogenic as the higher molecular weight compounds. Therefore, another benefit of calculating the distribution of PAHs by ring number is that it gives a rough indication of the carcinogenic potential of the PAHs found. The information from two references (NIOSH, 1980; WHO, 1973) has been used to show which of these 28 PAHs included in this study are more likely to cause cancer. NIOSH's 1980) Registry of Toxic Effects of Chemical Substances (RTECS) classified 14 of the 28 PAHs as potential carcinogens. These are indicated in Table 20. The limitations of using this file must be noted. There were over 2,000 chemicals on this NIOSH carcinogens file. The presence of a substance on the file meant only that the substance had documented potential of causing cancer. Quantity, route of exposure, species of test animal, etc., were not evaluated for inclusion on this particular file. In 1978, NIOSH changed the printed format of RTECS so that it no longer contained a separate suspected carcinogens subfile. The categorization used in the 1980 RTECS is used here as a convenient indicator of which PAHs are more likely to be carcinogenic. The second reference is an IARC (International Agency for Research on Cancer) monograph (WHO, 1973) which categorized seven of the 28 PAHs as carcinogenic or strongly carcinogenic based on a review of the 1iterature. All seven of these PAHs were 4-, 5-, and 6ring compounds; they are also shown on Table 20. Clearly, both groups of PAHs identified as having the potential for causing cancer were primarily the heavier molecular weight PAHs containing 4, 5, and 6 rings.

Table 20. PAHs with cancer-causing potential.

\begin{tabular}{|c|c|c|c|}
\hline Ring No. & Compound & 1980 RTECS & 1973 IARC \\
\hline 2 & $\begin{array}{l}\text { Naphthalene } \\
\text { Quinoline } \\
\text { 2-Methylnaphthalene } \\
\text { 1-Methylnaphthalene } \\
\text { Acenaphthalene } \\
\text { Acenaphthene }\end{array}$ & $\begin{array}{l}x \\
x\end{array}$ & \\
\hline 3 & $\begin{array}{l}\text { Fluorene } \\
\text { Phenanthrene } \\
\text { Anthracene } \\
\text { Acridine } \\
\text { Carbazole }\end{array}$ & $\begin{array}{l}x \\
x\end{array}$ & \\
\hline 4 & $\begin{array}{l}\text { Fluoranthene } \\
\text { Pyrene } \\
\text { Benzofluorene } \\
\text { Benz(a)anthracene } \\
\text { Chrysene } \\
\text { Triphenylene }\end{array}$ & $\begin{array}{l}x \\
x \\
x\end{array}$ & $\begin{array}{l}x \\
x\end{array}$ \\
\hline 5 & $\begin{array}{l}\text { Benzo(e)pyrene } \\
\text { Benzo(a)pyrene } \\
\text { Perylene } \\
\text { Dibenz }(a, j) \text { acridine } \\
\text { Dibenz }(a, i) \text { carbazole } \\
\text { Dibenzanthracene }\end{array}$ & $\begin{array}{l}x \\
x \\
x \\
x \\
x\end{array}$ & $\begin{array}{l}\text { suspect } \\
x \\
x \\
x\end{array}$ \\
\hline 6 & $\begin{array}{l}\text { Indeno }(1,2,3-c d) \text { pyrene } \\
\text { Benzo }(g, h, i) \text { perylene } \\
\text { Dibenzpyrene }\end{array}$ & $\begin{array}{l}x \\
x\end{array}$ & $\begin{array}{l}x \\
x\end{array}$ \\
\hline 7 & Coronene & & \\
\hline
\end{tabular}


Naphthalene, one of the three 2-ring PAHs that were found in substantial quantities in almost every sample, is one of the 14 PAHs on the RTECS file. The other PAHS on the RTECS list and also consistently found in the refinery samples include phenanthrene and anthracene (analyzed as one group), pyrene, and benz(a)anthracene and chrysene (analyzed as one group also including triphenylene which was not in RTECS). None of the six PAHs on IARC's list were definitely found consistently. However, the group consisting of benz(a)anthracene/chrysene/triphenylene was found in the majority of the samples, and benz(a)anthracene was one of the six compounds listed as carcinogenic by IARC.

Of the seven delayed coker units surveyed, the results from Refineries A, B, and $G$ showed larger percentages of the higher molecular weight PAHs. Several of the samples from Refineries $A$ and $B$, especially for the coke handlers group, had 20-23 PAHs or groups of PAHs present. As mentioned previously, the units at Refineries $A$ and $G$ were the only two that produced both needle and sponge coke. At Refinery A, clearly more higher molecular weight PAHs were present during the cutting of needle coke compared to the cutting of sponge coke. This included concentrations greater than $5 \mu \mathrm{g} / \mathrm{m}^{3}$ of the benz(a)pyrene/benz(e)pyrene and benz(a)anthracene/chrysene/triphenylene groups and concentrations of about $1 \mu \mathrm{g} / \mathrm{m}^{3}$ of dibenzpyrene. At Refinery $\mathrm{G}$, this was not the case, at least not for the personal samples. The distribution of PAHs for the two shifts when needle and sponge coke were cut were quite similar. The area sample collected downwind of the cutting of needle coke accounted for much of the 3- and 4-ring PAHs found at this unit.

At the delayed coker unit at Refinery B, the single area sample collected downwind of the cutting operation accounted for a large percentage of the higher molecular weight PAHs. Air concentrations greater than $0.45 \mu \mathrm{g} / \mathrm{m}^{3}$ were found for all six of the PAHs classified as carcinogenic by IARC. Several of the personal samples for the coke handlers also had detectable quantities of these PAHs; compared to the area sample, however, the concentrations were minimal.

The results for the samples collected at the delayed coker units at Refineries C, D, F, and I were almost entirely the 2- and 3-ring PAHs (at least $97.1 \%$ for each unit). This was especially noticeable at Refinery I, where $99.8 \%$ of the PAHs found were these lighter molecular weight compounds. This was important since the cumulative PAH concentrations discussed previously were by far the highest for this unit and refinery.

Of the nine FCCUs surveyed, the results from Refineries $A, B, C$, and $F$ show relatively large percentages of the heavier molecular weight PAHs, but not to the extent of the delayed coker units. Besides benz(a)anthracene, only very small concentrations of the six PAHs termed carcinogenic by IARC were found in this type of process unit. Again, benz(a)anthracene was analyzed only as a group of three PAHs and as such could not be definitely identified.

Of the three types of asphalt processing units surveyed, only the two vacuum distillation units at Refinery $C$ yielded results containing appreciable quantities of PAHs with greater than 3 rings. Small concentrations of benz(a)anthracene/chrysene/triphenylene, benz(e)pyrene/benz(a)pyrene, dibenz( $a, j)$ - 
acridine, and dibenz $(a, i)$ carbazole were found in the area samples. The only personal samples collected at an asphalt processing unit were collected at Refinery E's deasphalting unit. Almost al1 $(98.9 \%)$ of the PAHs found were the 2-ring compounds.

TOTAL PARTICULATE VERSUS RESPIRABLE-FRACTION AREA SAMPLES AND PARTICLE-SIZE DISTRIBUTION

Airborne PAHS are thought to exist primarily as aerosols, either as relatively pure PAH particulate matter or as PAH vapor that has condensed on other particles in the atmosphere (National Academy of Sciences, 1972). The purpose of collecting duplicate area samples with cyclone preselectors during the first four surveys and total particulate (mass) samples for optical sizing in the last five surveys was to estimate the contribution of the nonrespirable-size particles $(>10 \mu \mathrm{m})$ on the measured PAH concentrations.

At the FCCUs and asphalt processing units, the results of the total mass and respirable-fraction area samples collected side by side did not consistently show larger cumulative PAH concentrations in the total mass samples. Eight locations were sampled in the FCCUs; three yielded higher cumulative PAH concentrations for the total mass samples while five were higher for the respirable-fraction samples. Of the six locations sampled in the various asphalt processing units, only two yielded higher results for the total mass samples. The results also did not reveal a larger number of PAHs in either type of sample. This was not the case in the delayed coker units, where, as expected, the side-by-side area samples showed a consistent pattern of higher cumulative PAH concentrations (average of $50 \%$ ) and a larger number of PAHs per sample (15 versus 13) in the total mass samples. Nine locations were sampled in the delayed coker units, and seven yielded higher results for the total mass samples. These results are not surprising since the delayed coker unit, especially downwind of the coke-cutting operation, is dustier than the other two types of process units.

Table 18 shows the average particle-size distribution of the total particulate samples collected alongside the PAH area samples at Refineries E, F, G, $\mathrm{H}$, and I. The tables shows a consistent particle-size distribution between units at each refinery; at Refineries E, F, G, and H, all or almost all of the particles were $8.3 \mu \mathrm{m}$ or less. The distribution at Refinery I included larger percentages of particles between 2.0 and $11.8 \mu \mathrm{m}$; all particles, however, were still less than $11.8 \mu \mathrm{m}$. While these sized particles cannot be directly correlated with the PAH levels found in the area PAH samples, the particle-size results do clearly show that the airborne particles at the sites of the area PAH samples were generally of respirable size.

The results of the particle-sizing and the total mass versus respirablefraction samples were consistent at the FCCUs and asphalt processing units. If all the PAH-containing particles were of respirable size, there should be no difference between samples collected with or without a cyclone preselector. Despite similar particle-sizing results, the higher levels observed in the total mass samples at the delayed coker units might be attributed to the fact that copious amounts of water were used during the coke-cutting operation. Water aerosol containing PAHs could have accounted for the increased PAHs collected on the samples without cyclones. 


\section{POSSIBLE INFLUENCE OF TOBACCO SMOKE ON PAH RESULTS}

Tobacco smoke is known to contain PAHs such as benzo(a)pyrene, pyrene, and chrysene (National Academy of Sciences, 1972; WHO, 1973). Limited smoking was allowed at all nine refineries included in this study. Since many of the workers sampled during the surveys did smoke, there is a question of what influence tobacco smoke had on the PAH results.

Because of the obvious safety hazard, smoking is restricted to some extent at all refineries. Most of the refineries surveyed allowed smoking only in designated areas away from the immediate process units. This meant that the unit operators normally smoked only during the three or four work breaks taken during the shift. Refineries $D$ and $H$ were the only two that allowed smoking in the control rooms. At Refinery $G$, smoking was very limited since the only designated smoking areas were at the front of the refinery away from the process units.

A relatively simple method was chosen to investigate the possible influence of tobacco smoke on the results of this study. All of the workers sampled at the nine refineries were separated into "smokers" and "nonsmokers" without attempting to quantitate the number of cigarettes smoked (or amount of pipe smoking) during the sampling periods. The mean (geometric) cumulative PAH exposure concentrations and average number of PAHs per sample were calculated and compared between these two groups by process units and by process units combined. This is shown in Table 21. As before, the results for Refinery I have been listed separately. The data, including confidence limits on the mean cumulative PAH concentrations, are represented pictorially in Figure 13. This data analys is reveals that, for both the FCCU and delayed coker unit individually and for all of the personal samples combined, the mean cumulative PAH concentration exposures were actually lower, though not significantly, for the smoker group. There was also virtually no difference between the average number of PAHs per sample between the two groups. A qualitative review of the complete results (Appendix E) comparing the distribution of PAHs found between the two groups did not indicate that the smokers were exposed to a different set or proportion of PAHs.

This comparison of smokers versus nonsmokers was not meant to be a thorough investigation leading to a definite conclusion on the influence of tobacco smoke. The number of cigarettes smoked was not quantitated, workers were not separated into exposure categories, and other possibly influencing factors were not taken into account. Limitations were put on the analysis by the number of samples and the available information. Despite this, the data analysis clearly shows that the results for the smokers were not higher than the results for the nonsmokers. It is probable that if tobacco smoke did have a significant influence on the PAH results collected during this study, a tendency would have been noted in the almost 200 personal samples collected. 
Table 21. Smokers versus nonsmokers - Cumumulative $\mathrm{PAH}$ exposure levels.

\begin{tabular}{|c|c|c|c|c|c|c|c|c|}
\hline Process unit & Refinery & $\begin{array}{l}\text { Smokers (S) } \\
\text { Nonsmokers (NS) }\end{array}$ & $\mathrm{N}^{a}$ & $\begin{array}{c}G M^{b} \\
\left(\mu g / m^{3}\right)\end{array}$ & $G S D^{\circ}$ & $\begin{array}{c}\mathrm{LCL}^{d} \\
\left(\mu \mathrm{g} / \mathrm{m}^{3}\right)\end{array}$ & $\begin{array}{c}U \mathrm{UCL}^{d} \\
\left(\mu \mathrm{g} / \mathrm{m}^{3}\right)\end{array}$ & $\begin{array}{c}\text { Average } \\
\text { PAHs/sample }\end{array}$ \\
\hline \multirow[t]{3}{*}{ FCCU } & $\mathrm{A}-\mathrm{H}$ & $\begin{array}{l}\text { NS } \\
\text { S }\end{array}$ & $\begin{array}{l}54 \\
27\end{array}$ & $\begin{array}{l}9.2 \\
8.2\end{array}$ & $\begin{array}{l}2.8 \\
2.9\end{array}$ & $\begin{array}{l}6.9 \\
5.4\end{array}$ & $\begin{array}{l}12.2 \\
12.5\end{array}$ & $\begin{array}{l}11 \\
10\end{array}$ \\
\hline & I & $\begin{array}{l}\text { NS } \\
\text { S }\end{array}$ & $\begin{array}{l}7 \\
1\end{array}$ & $\begin{array}{r}97.5 \\
537.9\end{array}$ & $\begin{array}{c}1.5 \\
-\end{array}$ & $\begin{array}{c}67.0 \\
-\end{array}$ & 141.9 & $\begin{array}{l}7 \\
8\end{array}$ \\
\hline & $A-I$ & $\begin{array}{r}\text { NS } \\
\text { S }\end{array}$ & $\begin{array}{l}61 \\
28\end{array}$ & $\begin{array}{r}12.1 \\
9.5\end{array}$ & $\begin{array}{l}3.5 \\
3.7\end{array}$ & $\begin{array}{l}8.8 \\
5.7\end{array}$ & $\begin{array}{l}16.7 \\
15.8\end{array}$ & $\begin{array}{l}10 \\
10\end{array}$ \\
\hline \multirow[t]{3}{*}{$\begin{array}{l}\text { Delayed } \\
\text { coker unit }\end{array}$} & $A-H$ & $\begin{array}{r}\text { NS } \\
\text { S }\end{array}$ & $\begin{array}{l}36 \\
42\end{array}$ & $\begin{array}{r}11.1 \\
7.8\end{array}$ & $\begin{array}{l}4.1 \\
4.4\end{array}$ & $\begin{array}{l}6.9 \\
4.9\end{array}$ & $\begin{array}{l}17.9 \\
12.4\end{array}$ & $\begin{array}{l}12 \\
11\end{array}$ \\
\hline & I & $\begin{array}{r}\text { NS } \\
\text { S }\end{array}$ & $\begin{array}{l}3 \\
4\end{array}$ & $\begin{array}{l}194.6 \\
159.1\end{array}$ & $\begin{array}{l}1.4 \\
1.5\end{array}$ & $\begin{array}{l}84.4 \\
83.5\end{array}$ & $\begin{array}{l}448.7 \\
303.1\end{array}$ & $\begin{array}{l}7 \\
8\end{array}$ \\
\hline & $A-I$ & $\begin{array}{l}\text { NS } \\
\text { S }\end{array}$ & $\begin{array}{l}39 \\
46\end{array}$ & $\begin{array}{l}13.9 \\
10.1\end{array}$ & $\begin{array}{l}4.7 \\
5.2\end{array}$ & $\begin{array}{l}8.4 \\
6.2\end{array}$ & $\begin{array}{l}23.1 \\
16.5\end{array}$ & $\begin{array}{l}11 \\
11\end{array}$ \\
\hline $\begin{array}{c}\text { Deasphalting } \\
\text { unit }\end{array}$ & E & $\begin{array}{l}\text { NS } \\
\text { S }\end{array}$ & $\begin{array}{l}1 \\
4\end{array}$ & $\begin{array}{r}2.5 \\
16.5\end{array}$ & 3.1 & 2.7 & $9 \overline{9} .7$ & $\begin{array}{l}5 \\
6\end{array}$ \\
\hline \multirow[t]{3}{*}{ All units } & $A-H$ & $\begin{array}{r}\text { NS } \\
\text { S }\end{array}$ & $\begin{array}{r}90 \\
.73\end{array}$ & $\begin{array}{l}9.7 \\
8.3\end{array}$ & $\begin{array}{l}3.3 \\
3.7\end{array}$ & $\begin{array}{l}7.5 \\
6.1\end{array}$ & $\begin{array}{l}12.5 \\
11.3\end{array}$ & $\begin{array}{l}11 \\
10\end{array}$ \\
\hline & I & $\begin{array}{r}\text { NS } \\
\text { S }\end{array}$ & $\begin{array}{r}10 \\
5\end{array}$ & $\begin{array}{l}120.0 \\
203.0\end{array}$ & $\begin{array}{l}1.6 \\
1.9\end{array}$ & $\begin{array}{l}85.8 \\
91.4\end{array}$ & $\begin{array}{l}167.9 \\
450.9\end{array}$ & $\begin{array}{l}7 \\
8\end{array}$ \\
\hline & $A-1$ & $\begin{array}{r}\text { NS } \\
\text { S }\end{array}$ & $\begin{array}{r}100 \\
78\end{array}$ & $\begin{array}{l}12.5 \\
10.2\end{array}$ & $\begin{array}{l}4.0 \\
4.5\end{array}$ & $\begin{array}{l}9.5 \\
7.3\end{array}$ & $\begin{array}{l}16.5 \\
14.3\end{array}$ & $\begin{array}{l}10 \\
10\end{array}$ \\
\hline
\end{tabular}

$a_{N}=$ Number of individual air samples.

$b_{G M}=$ Geometric mean concentration for the $N$ samples.

${ }^{c}$ GSD $=$ Geometric standard deviation of the $\mathrm{N}$ samples.

${ }^{\text {Lower }}$ (LCL) and upper (UCL) 95\% confidence limits on geometric mean for the $\mathrm{N}$ samples. 


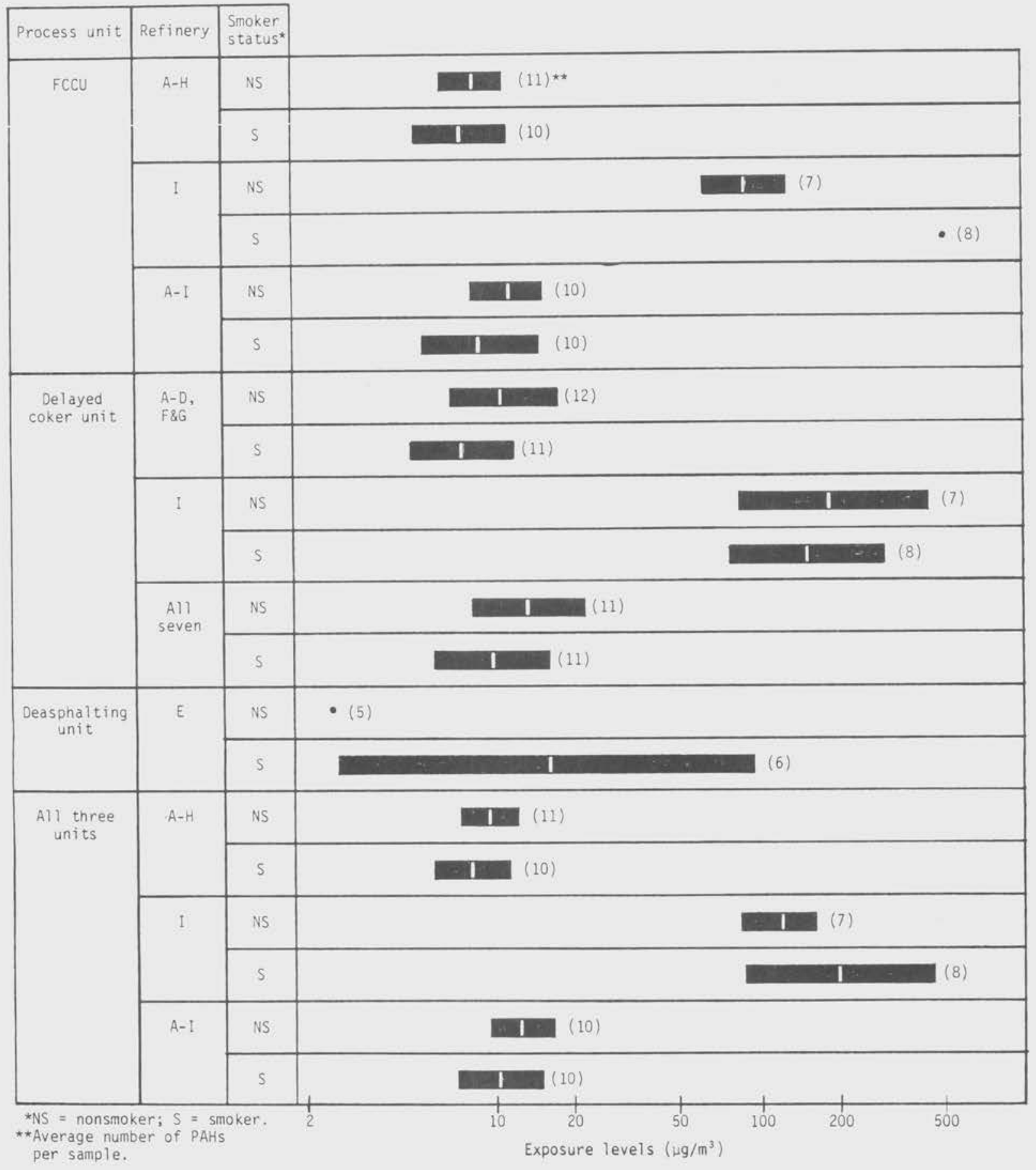

Figure 13. Smokers versus nonsmokers - Confidence limits on the mean cumulative PAH exposure levels. 


\section{CONCLUSIONS}

\section{GENERAL}

The results of the personal, area, and upwind air samples from the nine refinery surveys clearly indicate that workers at the FCCUs and delayed coker units are exposed by inhalation to numerous PAHs, generally at $10 \mathrm{w} \mathrm{mg} / \mathrm{m}^{3}$ concentrations. Although sampling at the asphalt processing units was limited primarily to area sampling, the results indicate that worker exposure to detectable quantities of PAHs possibly also exists in these refinery areas. The results from each refinery were consistent in that the lighter molecular weight, 2- and 3-ring PAHs were found in the highest concentrations, with generally only minimal amounts of the heavier 4-, 5-, 6-, and 7ring compounds. This is important, since it is primarily the heavier molecular weight PAHs that are associated with cancer-causing potential.

One of the nine refineries had extremely high cumulative PAH concentrations for the FCCU and delayed coker unit relative to the other units surveyed. The fact that this refinery used totally enclosed buildings to house pumps and other equipment associated with the heavy-fraction process streams was felt to be one of the primary reasons responsible for this. Other possible factors included the dry, mechanical coke-cutting operation used at the delayed coker unit, and the fact that both the FCCU and delayed coker unit at this refinery were the oldest of each type included in this study.

An unexpected observation was that, overal1, the workers from the FCCUS and delayed coker units were exposed to similar cumulative PAH concentrations and numbers of PAHs. The workers at the delayed coker unit, especially the coke-handler group, were exposed to a slightly higher percentage of the heavier molecular weight compounds.

The airborne PAHs collected at the FCCUs and asphalt processing units were not associated with particulate matter greater than $10 \mu \mathrm{m}$ (nonrespirable). This was based on the results of the side-by-side area samples collected with and without a cyclone preselector (Refineries A, B, C, D), and the particlesizing performed on the total particulate area samples (Refineries $E, F, G, H$, I). At the delayed coker units, the side-by-side area samples showed that an average of $50 \%$ of the total PAHs collected were in the nonrespirable fraction. This finding was inconsistent with the particle-sizing results of the last three delayed coker units surveyed, which showed the great majority of the particles to be less than $10 \mu \mathrm{m}$. Most of these area samples were collected 5 to 20 yards downwind of the bottom of the drum being cut. 
Although tobacco smoke is known to contain PAHs, an analysis of the data indicates that tobacco smoke probably did not influence the results of this study to any appreciable extent, if at all. The data showed that the mean cumulative PAH concentration exposure for the samples collected by workers who smoked was lower, although not significantly, than the value for the samples of workers who did not smoke. The average number of PAHs per sample was the same for both groups, and an analysis of the data by process units did not change the results. In addition, a qualitative review of the PAH distribution for both groups of samples did not show any difference.

FCCUS

Even though FCCUs vary widely in production capacity, most units are quite similar in terms of process, equipment, and work force. As already mentioned, the unit at Refinery I had very high cumulative PAH concentrations relative to the other units, and this may be explained at least in part by the enclosed buildings and old age of the unit. An analys is of the data from the other eight units shows that there is a strong correlation between the age of an FCCU and the cumulative concentrations found: the older the unit, the higher the concentration. The PAH data also showed a weaker correlation with the type of crude being processed in terms of the API Gravity Index: the lighter the crude (higher index number), the higher the cumulative PAH concentrations. There was no correlation between the concentrations and the time since the previous major turnaround.

As expected based on their job descriptions, the outside operators were exposed to a higher mean cumulative PAH concentration than were the inside operators, although not statistically significant. It is surprising that the values for the two exposure categories were as close together as they were, however. Furthermore, the average number of PAHs per sample was the same for both groups. Based on these results, it is apparent that the control rooms of FCCUs are not free of contaminants such as PAHs which are associated with the production areas. The inside operators spend up to $100 \%$ of their shift inside the control room, and the outside operators may spend up to $50-60 \%$ of their shift inside.

The FCCU is an example of a refinery process unit that is normally a smoothrunning, continuous-type operation. Because of this, the duties of the work force are quite routine from day to day. This was illustrated by the consistency in the results of the duplicate or paired samples collected for each of the workers over 2 consecutive days. The results showed less than $40 \%$ difference between $64 \%$ of these duplicate samples collected.

Most FCCUs have a pump area near the main fractionator that contains several pumps associated with heavy-fraction process streams. Only a small number of area samples were taken at each unit; however, they were consistent in showing that this pump area, and more specifically the slurry pump area, is a location where PAH levels are elevated but still low. The very few samples collected near the base of the reactor/regenerator structure, charge pump, and decant oil pump indicated that PAH levels are not normally as high in these areas. 


\section{DELAYED COKER UNITS}

There is a direct relationship between the type of coke being produced and the PAH concentrations present at a delayed coker unit. Sponge (\#2) coke, the more common of the two types, was produced at all seven units while needle (\#1) coke was produced at only two. Needle coke is associated with greater worker exposures to PAHs and may also be associated with a larger number of the heavier molecular weight PAHs. The results from the delayed coker units also show a correlation with the production capacities of the units and with the API Gravity Indexes. As the capacity of the units increased, the PAH levels decreased; and as the API Gravity Index increased, the PAH levels also increased. This relationship with the density of the crude was similar to that observed at the FCCUs.

Because of the nature of the operation, it is difficult to minimize the dissemination of coke particulates and worker exposure during the coke-cutting and handling operation. As already discussed, the delayed coker unit at Refinery I had by far the highest cumulative PAH concentration results. The fact that this unit was the only one of the seven surveyed that used a dry, mechanical cutting method may have been an important influencing factor on the PAH results. The other six units used hydraulic cutting and let the coke fall either directly into railcars or into a large containment trough from which it would later be transferred. There are advantages and disadvantages to both methods in terms of worker exposure to PAHs, and a review of the results reflects this. The results do not show clearly whether either method is associated with higher PAH concentrations than the other.

Of the two major exposure categories at this unit, the coke-handlers groupwhich includes the driller, helpers, crane operator, and occasionally a supervisor-is exposed to higher cumulative PAH concentrations, although not statistically significant, and to a larger number of the heavier molecular weight PAHs. Within this group, the driller, followed by the helpers, had the highest exposures. For the operational group, the relatively high results for the inside operators were again surprising but consistent with the results discussed earlier for the inside operators at the FCCU. However, at the delayed coker unit, the inside operators were exposed to higher cumulative PAH concentrations and number of different PAHs compared to the outside operators. This can be explained by the fact that the control rooms are normally in the midst of the unit near and often downwind of equipment and structures associated with PAHs. Foot traffic through the control rooms can also contribute to the contaminants being brought inside.

Compared to the FCCU, the operations at the delayed coker unit are not nearly as consistent from day to day; breakdowns and delays causing extended cutting operations were not unusual. This fact was reflected in the data for the duplicate samples collected at this unit, especially for the coke handlers, which showed much more variation than at the FCCU. 
The results of the small number of area samples collected at the three types of asphalt processing units were generally lower than the area samples collected at the FCCUs and delayed coker units; however, these results from the asphalt units were higher in total PAH concentration and number of PAHs found than expected based on the preliminary surveys conducted during Phase II. The only personal sampling conducted at an asphalt processing unit (deasphalting unit at Refinery E) showed a mean cumulative PAH concentration exposure higher than the comparable value for the refinery's FCCU. The PAHs identified at this deasphalting unit were almost entirely 2-ring compounds, and the results of the area samples collected here were among the highest of all the asphalt processing area samples. This indicates that the personal sampling results at this one unit are probably not indicative of the situation at the other asphalt units. 


\section{EXPOSURE CONTROL RECOMMENDATIONS}

The following control recommendations are intended to help reduce worker inhalation and dermal exposures to PAHs based on observations made during this study.

- Since the survey results indicate that the control rooms are extremely important when considering worker exposure, control rooms should be as far away as practical from the production area, and as far upwind (prevailing wind direction) as possible from equipment or processes associated with PAH emissions. This includes the heavy-fraction pumps at all units and the coke tower at the delayed coker units. Control rooms under positive pressure with filtered (e.g., charcoal) makeup air will also help to reduce PAH levels.

- Because of the nature of the operation, good housekeeping is especially important at the delayed coker unit control room. The control room and adjoining facilities (eating area, locker and shower facilities) should be cleaned on a daily basis. A shoe-cleaning station at entrances would possibly reduce contamination due to tracking.

- Enclosed buildings should not be used to house heavy-fraction pumps or any other equipment or structures associated with possible PAH emissions. Where these building are used, a suitable mechanical ventilation system should be provided, and the pumps and equipment should be especially well maintained to minimize spills and fugitive emissions. Workers should spend as little time as possible in these buildings.

- Outside areas of the unit where heavy-fraction pumps are located should be kept as open as possible to maximize the effect of natural ventilation. Buildings, towers, piping, and any overhead structures (e.g., fin fans) should be minimized around these pumps to prevent a "tunneling" effect.

- Good housekeeping and routine maintenance should be practiced at all units, particularly in the pump and coke-cutting areas where heavy oils, asphalt-like materials, and coke are likely to accumulate on the foundation, equipment, and structures. Effective sewer and runoff systems should be built into these areas to facilitate housekeeping and the cleanup of spills.

- Operators should be properly trained regarding the possible health hazards of certain operations and the most effective way to perform these operations to minimize exposures. An example of this is the collection of process stream samples. Operators should be instructed to stand upwind of the sampling port and to use the proper clothing 
and/or equipment (e.g., gloves) to prevent dermal contact. Sampling loops should be used on all open-spigot sampling ports. The American Petroleum Institute is currently investigating the proper sampling methods and equipment for refineries. When they are released, these recommendations should be followed.

Another example of the necessity for proper training regards the drilling operation. Twice during the surveys, improper drilling techniques led to extended cutting operations, repairs of the equipment, and increased maintenance and cleanup-ail quite possibly increasing worker exposures to PAHs during this study. At least in one situation, the problem arose while the regular driller was on a break.

- The coke handlers should be provided with adequate locker and shower facilities convenient to the unit. This group of workers should wear separate change of work clothes (e.g., coveralls) and shower at the end of each shift. Good personal hygiene is especially important to the coke handlers because of the probability of dermal exposure to coke.

- During the cutting of coke directly into railcars, at least one helper (coke handler group) is needed near the bottom of the drum in proximity to the falling coke, water, and steam. Precautions should be taken to minimize exposures by using protective clothing such as slicker suits, face shields, rubber boots, etc.; work stations should be as sheltered or as enclosed as possible.

- Because problems related to the coke-cutting/handling operations are not uncommon, the coke handlers should be properly instructed in handling these situations in a manner which minimizes worker exposures. Examples of such problems that were observed included a leaking drum bottom during coke formation and difficulty in removing the drum bottom because of adhesion to the coke.

- The drilling station should be positioned so that the driller is not directly downwind of the drum being cut. If the drilling station is in an enclosed room such as a "penthouse," mechanical ventilation with filtered air would be an advantage over natural ventilation.

- Although the coke-cutting/handling operation is not a closed process, attempts should be made to enclose the process as much as possible. This might include tight enclosures around the drilling shaft in the penthouse and chute extenders at the bottom of the drum.

- Since this study showed that needle coke is associated with higher levels of PAHs, all precautionary measures to minimize worker exposure should especially be followed when needle coke is being produced. 


\section{RESEARCH RECOMMENDATIONS}

- Investigate the relationship between the airborne exposure levels of PAHs at the process units and the corresponding concentrations of PAHs in the coke, the asphalt, the crude oil, and the FCCU process streams.

- Application of control technology research to improve the material handling and the removal of coke.

- Investigate the differences in exposure levels and distributions of individual PAHs between needle and sponge coke.

- Since naphthalene and substituted naphthalenes contributed $80 \%$ of the measured PAHs, control technology research should concentrate on reducing these PAHS.

- Investigate the correlation of individual PAHs with the particle-size distribution.

- Include in future epidemiological studies of oil refinery workers the variables, PAH exposure levels and individual process units; plant records should include employee work histories along with chemical exposure levels and process units at which they worked.

- Toxicological studies of PAHs present in oil refineries should concentrate on naphthalene and the substituted naphthalenes.

- Determine whether all the relevant PAHs and related organic compounds have been identified.

- Investigate the use of identifier compounds as an adequate measure for all PAHs, e.g., naphthalene for 2-ring PAHs, pyrene for higher ring PAHs, possibly using gas liquid chromatography and eliminating the need for mass spectrometry.

- Future studies should evaluate the importance and measurement of dermal exposures to PAHs, particularly at the coker and asphalt units.

- Other oil refinery process areas should be evaluated for worker exposures to PAHs, particularly at the crude unit and asphalt loading docks. 


\section{REFERENCES}

Anon. 1978. What is cost of controlling emissions? 0 il Gas J. 76(41):72.

Anon. 1980. 1980 refining process handbook. Hydrocarbon Process. 59(9): 93-220.

API. 1973. Industrial Hygiene Monitoring Manual for Petroleum Refineries and Selected Petrochemical Operations. American Petroleum Institute, Washington, D.C.

API. 1974. A Mortality Study of Petroleum Refinery Workers. Project OH-1. Medical Research Report \#EA 7402. American Petroleum Institute, Washington, D.C.

API. 1977. Facts About 0i1. American Petroleum Institute, Washington, D.C.

Arthur, J.L. 1977. Special Occupational Hazard Review and Control Recommendations for Nickel Carbonyl. DHEW Publication No. (NIOSH) 77-184. U.S. Department of Health, Education, and Welfare, Public Health Service, Center for Disease Control, National Institute for Occupational Safety and Health, Rockville, Maryland. 34 pp.

Baird, V.C. 1967. Effects of atmospheric contamination on cancer mortality in petroleum refinery employees. J. Occup. Med. 9(8):415-420.

Baylor, C.H., and N.K. Weaver. 1968. A health survey of petroleum asphalt workers. Arch. Environ. Health 17:210-214.

Bjorseth, A., and A.J. Dennis, eds. 1979. Polynuclear Aromatic Hydrocarbons: Chemistry and Biological Effects. Battelle Press, Columbus, Ohio. $1097 \mathrm{pp}$.

Blot, W.J., L.A. Brinton, J.F. Fraumeni, Jr., and B.J. Stone. 1977. Cancer mortality in U.S. counties with petroleum industries. Science 198:51-53.

Bombaugh, K.J., et al. 1976. Sampling and Analytical Strategies for Compounds in Petroleum Refinery Streams, Vols. I \& II. Publication EPA$600 / 2-76 / 012 a$. U.S. Environmental Protection Agency, Research Triangle Park, North Carolina.

Brief, R.S., J.W. Blanchard, R.A. Scala, and J.H. Blacker. 1971. Metal carbonyls in the petroleum industry. Arch. Environ. Health 23:373-383. 
Brief, R.S., F.S. Venable, and R.S. Ajemian. 1965. Nickel carbonyl-Its detection and potential for formation. Am. Ind. Hyg. Assoc. J. 26:72-76.

Burroughs, G.E. 1977. Health Hazard Evaluation Determination Report No. 77-47-427. U.S. Department of Health, Education, and Welfare, Public Health Service, Center for Disease Control, National Institute for Occupational Safety and Health, Cincinnati, Ohio.

Cantre11, A. 1978. Annual refining survey. $0 i 1$ Gas J. 76(12):108-146.

Cantrel1, A. 1980. Annual refining survey. 0il Gas J. 78(12):130-160.

Cavanaugh, G., C.E. Burklin, J.C. Dickerson, H.E. Lebowitz, S.S. Tam, G.R. Smithson, Jr., H. Nack, and J.H. Oxley. 1975. Environmental Protection Technology Series: Potentially Hazardous Emissions from the Extraction and Processing of Coal and 0i1. Publication EPA-650/1-75-038. U.S. Environmental Protection Agency, Office of Research and Development, Washington, D.C. $153 \mathrm{pp}$.

Dickerman, J.C., R.D. Raye, J.D. Colley, and R.H. Parsons. 1977. Industrial Process Profiles for Environmental Use. Chapter 3: Petroleum refining industry. Publication EPA-600/1-77-023c. U.S. Environmental Protection Agency, Office of Research and Development, Washington, D.C. $147 \mathrm{pp}$.

Downie, N.M., and R.W. Health. 1959. Pp. 78-93 and 123-141. In H.H. Remmers, ed. Basic Statistical Methods. Harper \& Row Publishers, New York, New York.

Enviro Control, Inc. 1980a. A Study of Coal Liquefaction Processes: Industrial Hygiene Comprehensive Survey. Final Report, Cresap Test Facility, Cresap, West Virginia. DHEW Publication Contract No. 210-78-0101. U.S. Department of Health, Education, and Welfare, Public Health Service, Center for Disease Control, National Institute for Occupational Safety and Health, Morgantown, West Virginia. 45 pp.

Enviro Control, Inc. 1980b. A Study of Coal Liquefaction Processes: Industrial Hygiene Comprehensive Survey. Final Report, Solvent Refined Coal Pilot Plant, Fort Lewis, Washington. DHEW Publication Contract No. 21078-0101. U.S. Department of Health, Education, and Welfare, Public Health Service, Center for Disease Control, National Institute for Occupational Safety and Health, Morgantown, West Virginia. $66 \mathrm{pp}$.

Gafafer, W.M., and R.S. Sitgreaves. 1940. Disabling morbidity, and mortality from cancer among the male employees of an oil refining company with reference to age, site, and duration, 1933-1938, inclusive. Public Hea1th Rep. 55:1517-1526.

Gordon, R.J., and R.J. Bryan. 1973. Patterns in airborne polynuclear hydrocarbon concentrations at four Los Angeles sites. Environ. Sci. Technol. 7(11):1050-1053. 
Gottlieb, M.S. 1980. Lung cancer and the petroleum industry in Louisiana. J. Occup. Med. $22(6): 384-388$.

Hanis, N.M., K.M. Stavraky, and J.L. Fowler. 1979. Cancer mortality in oil refinery workers. J. Occup. Med. 21(3):167-174.

Hervin, R.L., R. Rivera, and J.P. Flesch. 1973. Health Hazard Evaluation/ Toxicity Determination Report No. 72-91-37. U.S. Department of Health, Education, and Welfare, Public Health Service, Center for Disease Control, National Institute for Occupational Safety and Health, Rockville, Maryland. $19 \mathrm{pp}$.

Jackson, J.O., and J.A. Cupps. 1978. Field evaluation and comparison of sampling matrices for polynuclear aromatic hydrocarbons in occupational atmospheres. Pp. 183-191. In: P.W. Jones and R.I. Freudenthal, eds. Carcinogenesis, Vol. 3: Polynuclear Aromatic Hydrocarbons. Raven Press, New York, New York.

Jones, P.W., A.P. Graffeo, R. Detrick, P.A. Clarke, and R.J. Jakobsen. 1976. Technical Manual for Analysis of Organic Materials in Process Streams. Publication EPA-600/2-76-072. U.S. Environmental Protection Agency, Office of Research and Development, Research Triangle Park, North Carolina. $92 \mathrm{pp}$.

Krul1, I.S., T.Y. Fan, and D.H. Fine. 1978. Problem of artifacts in the analys is of $\mathrm{N}$-nitroso compounds. Anal. Chem. $50(6): 698-701$.

Laub, R.J., and W.L. Roberts. 1979. Use of mixed phases for enhanced gaschromatographic separation of polycyclic aromatic hydrocarbons: Preliminary studies with liquid crystals. Pp. 25-58. In: A. Bjorseth and A.J. Dennis, eds. Polynuclear Aromatic Hydrocarbons: Chemistry and Biological Effects. Battelle Press, Columbus, Ohio.

Lautner, G.M., and F.S. Venable. 1980. A comprehensive study for benzene solubles and PNA's on a large delayed petroleum coking unit. Am. Ind. Hyg. Conf., May 18-May 23, Houston, Texas. (Abstract)

Maugh, T.H. II. 1977. Carcinogens in the workplace: Where to start cleaning up. Science 197:1268-1269.

Menck, H.R., J.T. Casagrande, and B.E. Henderson. 1974. Industrial air pollution: Possible effects on lung cancer. Science 183:210-212.

National Academy of Sciences. 1972. Medical and Biological Effects of Environmental Pollutants Series: Particulate Polycyclic Organic Matter. National Academy of Sciences, Washington, D.C. $361 \mathrm{pp}$.

NIOSH. 1977. Manual of Analytical Methods. Part I: NIOSH Monitoring Methods. Vol. I, 2nd edit. U.S. Department of Health, Education, and Welfare, Public Health Service, Center for Disease Control, National Institute for Occupational Safety and Health, Cincinnati, Ohio. 
NIOSH. 1980. Registry of Toxic Effects of Chemical Substances (RTECS). Vols. I \& II. U.S. Department of Health, Education, and Welfare, Public Health Service, Center for Disease Control, National Institute for Occupational Safety and Health, Cincinnati, Ohio.

Rosenberg, D.G., et al. 1976. Assessment of Hazardous Waste Practices in the Petroleum Refining Industry. Jacobs Engineering Co., Pasadena, California, for U.S. Environmental Protection Agency, Washington, D.C.

SRI International. 1978. Investigations of Industries with Agents Which Are Newly Suspected as Occupational Health Hazards: Task 1-Zeolites Report. U.S. Department of Health, Education, and Welfare, Public Health Service, Center for Disease Control, National Institute for Occupational Safety and Health, Cincinnati, Ohio. 59 pp.

Tanita, R., D. Telesca, J. Walker, and S. Berardinelli. 1980. Organic contaminants in direct coal liquefaction-a preliminary assessment. Am. Ind. Hyg. Assoc. J. 41(11):851-853.

Theriault, G., and L. Goulet. 1979. A mortality study of oil refinery workers. J. Occup. Med. 21(5):367-370.

Thomas, T.L., P. Decoufle, and R. Moure-Eraso. 1980. Mortality among workers employed in petroleum refining and petrochemical plants. $J$. Occup. Med. 22(2):97-103.

Vandervort, R., and J.B. Lucas. 1974. Health Hazard Evaluation/Toxicity Determination Report No. 72-79-109. U.S. Department of Health, Education, and Welfare, Public Health Service, Center for Disease Control, National Institute for Occupational Safety and Health, Rockville, Maryland. 16 pp.

Venable, F.S. 1975. Skin and respiratory exposure to polynuclear aromatics from delayed coking units. Med. Bul1. Exxon Corp. Affil. Co. 1975:120128.

Wade, L. 1963. Observations on skin cancer among refinery workers. Arch. Environ. Health 6:730-735.

WHO. 1973. International Agency for Research on Cancer Monographs on the Evaluation of Carcinogenic Risk of the Chemical to Man: Certain polycyclic aromatic hydrocarbons and heterocyclic compounds. Vol. 3. 271 pp.

Wisseman, C., C. Xintaras, and B. Hollett. 1978. Health Hazard Evaluation Determination Report No. 77-43-500. U.S. Department of Health, Education, and Welfare, Public Health Service, Center for Disease Control, National Institute for Occupational Safety and Health, Cincinnati, Ohio.

Zelenski, S.G., G.T. Hunt, and N. Pangaro. 1979. Comparison of SIM GC/MS and HPLC for the detection of polynuclear aromatic hydrocarbons in fly ash collected from stationary combustion sources. Pp. 589-597. In: A. Bjorseth and A.J. Dennis, eds. Polynuclear Aromatic Hydrocarbons: Chemistry and Biological Effects. Battelle Press, Columbus, Ohio. 
APPENDIX A

OTHER RELEVANT STUDIES

\section{EPIDEMIOLOGY AND HEALTH HAZARD EVALUATIONS}

The literature review on the petroleum refining industry reveals that there have been six epidemiology studies (API, 1974; Baird, 1967; Baylor and Weaver, 1968; Gafafer and Sitgreaves, 1940; Thériault and Goulet, 1979; Wade, 1963) that indicate that refinery workers are not subjected to increased health risks over the general population.

The first study was reported by Gafafer and Sitgreaves in 1940 on cancers among the male employees of an oil refining company between 1933 and 1938 . The employees ranged in age from 15 to 69 and totaled almost 60,000 years of employment during the study period. A total of 70 cases of cancer were reported, which included 46 deaths. The authors noted that this average annual cancer rate of $\overline{0} .7 \overline{8}$ per $\overline{1}, 000$ years of employment was considérabiy lower than the rate of 0.96 per 1,000 years for all U.S. White males of similar age during 1933 to 1937 . The data also indicated that the 46 refinery death cases included a higher percentage of digestive system sites $(69.6 \%)$ than that expected from the U.S. data $(57.8 \%)$, and a lower percentage of genitourinary sites $(8.7 \%)$ compared to that expected $(15.0 \%)$. The report did not include any information on the number of years worked prior to onset of illness, or job descriptions.

In 1963, Wade reported that refinery workers dermally exposed to high-boiling catalytically-cracked oils did not show increased skin cancer rates. Workers from three refineries were categorized into two groups, those having potential exposure to heavy slurry oil and those not exposed. A total of 1,862 matched pairs were selected from these two groups on the basis of: age and company service, race and sex (only white males in the study), complexion, hair color, personal hygiene, family history of cancer, and exposure to other "possible etiologic factors." Due to various factors, 785 of the matched pairs were lost to the study. During the 12-year observation period (1949-1961), 45 "neoplasms" occurred in the control group and 46 in the exposed group. Of these neoplasms, 24 (53.5\%) in the control group and 27 $(58.7 \%)$ in the exposed group were "skin lesions." Wade concluded that skin cancers occurred with about equal frequency and at about the same age among the matched pairs of exposed and nonexposed refinery workers. The author stated that the results could have been due to: (1) the fact that the slurry oil was not carcinogenic to the workers, (2) the effectiveness of the company's prevention program, or (3) the insufficient duration or number of workers involved in the study. 
In 1967, Baird reported the results of a mortality study of 15,437 Humble $0 i 1$ and Refining Company workers, covering a 29-year period (1935-1963). The author compared various cancer mortality rates for the company workers with the expected rates for the general population (adult males). Of the 15,437 workers, 6,239 were refinery workers; the others were in production and marketing. The overall cancer mortality rate (cancer deaths $/ 100,000$ / year) and the relative frequency of cancer deaths (\% of cancer deaths/all deaths) for the refinery workers, as well as for the entire work group, were consistently below the expected national and geographical values. Mortality rates for skin and respiratory cancers were reported for the total work group, and these were also well below the expected values.

An API publication in 1974 presented the findings of a mortality study of 20,163 petroleum workers (representing 137,153 man-years of observation) in 17 refineries. The observation period covered 10 years. The Standardized Mortality Ratio (SMR) for all causes of death was 69.1 (an SMR of 100 is expected in a comparable U.S. male population); and the SMR from cardiovascular/renal diseases, digestive cancer, and ulcers was highest in men with the lowest estimated exposure to atmospheric hydrocarbons. The categorization of workers into three main exposure levels was the only attempt at segregating exposed workers. Mortality from lymphomas was greater than expected but was not statistically significant, and respiratory cancer mortality increased with increased exposure but was still below the expected value.

The results of a mortality study on a Canadian population of oil refinery workers were reported by Theriault and Goulet in 1979. The study included a 11 the men $(1,205)$ who were employed for more than 5 years in an oil refinery in East Montreal from 1928 to 1976. Company work records and death certificates were used to determine job categories and survival status. The expected numbers of deaths were estimated from the age- and cause-specific death rates for the Province of Quebec. The results of information accumulated for 1,015 men (190 lost to follow-up) showed an overall SMR of 78.43 . The SMRs for several specific causes were above 100, but none of these was statistically significant. The SMR for all cancer deaths was 89.29. Theriault and Goulet noted three observations in the evaluation of specific cancer types. (1) Lung cancer was less frequent than expected (3 cases vs. 7.42). (2) There were three brain cancer cases, and these were in the "less than 20 years since start of exposure" group. This corresponded to an SMR of 652.17. No common exposure could be determined for the three employees. (3) The digestive system should be an area for further attention based on the combined findings of an SMR of 117 (not significant) for cancers of this system and of an elevated number of deaths due to diseases of this system. The authors also stated that there was no statistically significant difference in cancer mortality between the three work categories that they used for comparison: operators, office employees, and maintenance workers.

Besides the mortality studies cited above, an occupational health study (Baylor and Weaver, 1968) on asphalt workers was found in the literature. Asphalt, like other heavy residual fractions of petroleum, has been suspected of containing components which could be toxic. In 1968, Baylor and Weaver published the results of a health survey of 462 petroleum asphalt workers and 379 control workers; both groups were taken from 25 different 
petroleum refineries. Each asphalt worker had a minimum of 5 years of experience working with asphalt, and the average experience was 15.1 years. The health survey included a physical examination, which emphasized the skin and lungs, and a detailed work and medical history. The results of the study did not reveal any major differences in the health between the study and control groups. There were some differences in rates of lung and skin diseases, other than cancer, between the two groups. The rates of lung disease (aside from cancer) reported in the medical histories were $8.6 \%$ for the asphalt workers and $4.3 \%$ for the control group. These cases were mainly chronic bronchitis, with some asthma and emphysema. At the time of the survey, the physical examinations revealed that $8.6 \%$ of the asphalt workers and $6.3 \%$ of the controls had some type of lung disease (aside from cancer). other-than-cancer skin disease was reported as being mainly nonsevere dermatitis. The medical histories revealed rates of $10.3 \%$ for the asphalt workers and $17 \%$ for the controls. The results of the physical examinations for skin disease showed similar rates between the asphalt workers and controls, $5.6 \%$ and $5.3 \%$, respectively.

Based on their findings of workers involved with asphalt in the petroleum refining industry, as well as on information received from several other industries involved with asphalt, Baylor and Weaver (1968) concluded that "petroleum asphalt cannot rationally be considered a hazardous substance." When considering the results of this study, one must realize the limitations of this type of health survey. By looking at medical histories and health status of currently employed workers only, the study does not include any employee no longer working because of a work-related $i 11$ ness or retired employees.

In contrast to these previous reports, three very recent mortality studies (Hanis et al., 1979; Gottlieb, 1980; Thomas et al., 1980) have shown increased cancer rates in the refining industry.

In 1979, Hanis et al. reported the results of a cancer mortality study that included a study population of 15,032 male employees of Imperial 0il Limited of Canada. Members of this study group were either active employees or annuitants during al1 or part of the 10-year period from 1964 to 1973 . The study population was categorized in two separate ways: (1) employees exposed, moderately exposed, and not exposed to petroleum and its products; and (2) refinery workers and nonrefinery workers. The authors reported that workers in the exposed category had more than three times the risk of developing esophageal and stomach cancer and about twice the risk of develojing lung cancer compared to the nonexposed workers. The study also reported that, for the exposed group, increased duration of employment increased the risks to these two types of cancers. The results comparing refinery workers to nonrefinery workers, not considering degree of exposure, showed that the former group had twice the risk of cancer of the intestines and other digestive organs; however, no relationship with employment duration was found. The authors indicated that additional information and records on the study groups are needed before definitive statements on the carcinogenic potential of petroleum or its products can be made, and recommended further investigation. 
Gottlieb (1980) reported his findings of an elevated risk of lung cancer mortality for petroleum workers in 19 Louisiana counties. Mining and refining were grouped together in the petroleum industry for the purposes of this study. Death certificates from 1960 to 1975 were screened for cause of death, occupation, age at death, and other statistics. There were 346,041 males in the study area during 1970. A total of 2,803 deaths (cases) due to lung cancer were uncovered during the 16-year period. An equal number of non-cancer deaths were selected as controls and matched as closely as possible to the lung-cancer deaths (cases) by sex, race, year of death, location, and age at death. Each subject's (case and control) industry of employment was classified into 1 of 22 industry categories. Results showed that a total of 200 cases were employed in the petroleum industry ( 125 in mining, 75 in refining); whereas only 170 controls (112 in mining, 58 in refining) were employed in this industry. A modification to the RothmanBoice method for relative risk analysis was used by the author to show that these results were statistically significant. The results also showed that several occupational categories within the petroleum industry were associated with greater risks of lung cancer mortality. These included three maintenance categories-boilermakers, painters, and welders. Gottlieb stated that an excess of cases for boilermakers and painters had been observed across many industries, whereas the excess for welders was unique to the petroleum industry. 0ilfield workers and operators also showed increased risk of lung cancer mortality.

Results recently published by Thomas et al. (1980) showed increased cancer rates among workers employed in petroleum refining and petrochemical plants in Texas. The study group consisted of 3,105 males whose deaths were reported by union (OCAW) locals between 1947 and 1977. Several other industry classifications were represented by these cases; however, petroleum refining and petrochemical plants represented by far the largest number of cases $(2,131)$. The summary of the study results presented here is limited to this primary area of the study. The proportionate mortality ratio (PMR) was used to compare the observed number of deaths by cause to what would have been expected based on the experience of the general population. Analysis of the data showed statistically significant elevated PMRs for cancer among white males, and for arteriosclerotic heart disease for both white and nonwhite males. Site-specific PMRs for white males were significantly elevated for cancers of the digestive and respiratory systems, skin, and brain. The only measure of worker exposure provided by the available information was length of membership in OCAW. Not all of the cancer sites with elevated PMRs showed a positive gradient in relationship to this measure of exposure; however, the results did show that risks of stomach and brain cancers, leukemia, and multiple myeloma increased with longer union membership. Thomas et al. emphasized the limitations of the study's data and methodology, and that the principal use of this type of study is for "hypothesis-generating." However, the authors concluded by suggesting that "workers in this industry are at an increased risk of certain cancers."

Two additional studies reported increased cancer mortality rates in geographical areas where petroleum refineries were present. A survey (Blot et al., 1977) of cancer mortality rates amona males was conducted in 39 U.S. 
counties where the petroleum industry is highly concentrated, and was compared with 117 counties without this type of industry. The survey covered the years 1950 to 1969 , and showed that male residents of these counties had significantly higher mortality rates, for a total of 23 cancer sites, and were highest for cancers of the lung, skin, nasal cavity, and sinuses. Another study (Menck et al., 1974) conducted in Los Angeles County showed higher lung cancer mortality rates in areas that were heavily industrialized (including petroleum refining) and that had higher concentrations of benz(a)pyrene and other polyaromatic hydrocarbons in the soil and air.

Among the few scattered reports of health problems specifically related to refineries are three NIOSH Health Hazard Evaluations. The first report (Hervin et al., 1973) concerned four refinery employees exposed to asbestos while working with pipe insulation. Area sampling of 30 work locations showed levels from 0.1 to 0.9 fiber ( $>5 \mu \mathrm{m}$ in length)/cc; personal monitoring yielded levels from 0.6 to 3.3 fibers/cc. Because exposure was considered intermittent, the TWA was estimated at 0.3 to $0.6 \mathrm{fiber} / \mathrm{cc}$. Symptoms from overexposure to asbestos were not apparent after interviews with the four, and review of their medical records was negative. Two cases of heat exhaustion were reported, due to wearing paper coveralls during these operations.

In the second Health Hazard Evaluation (Vandervort and Lucas, 1974), seven of nine petroleum pitch workers reported recurring skin redness, peeling, and burning (similar to sunburn) during the summer, and six reported eye and throat irritation. The four members of the NIOSH survey team also complained of burning, smarting, and stinging skin after only 1 day of being exposed to the petroleum pitch. The symptoms cleared up in 24 hours. Air monitoring for vapor and particulates showed concentrations of pitch less than $0.2 \mathrm{mg} / \mathrm{m}^{3}$; analysis by thin-layer chromatography and ultraviolet fluoresence spectrophotometry showed the presence of several PAHs, including phenanthrene, a known photosensitizer.

The third Health Hazard Evaluation (Wisseman et al., 1978) reported that there appeared to be a possible excess of peripheral neuropathy among employees in a lube dewaxing unit of a Texas oil refinery. The medical survey included both clinical examination and electrodiagnostic testing, and indicated that the cases as a whole were quite mild with the affected employees showing signs of discomfort rather than functional impairment. This survey did not uncover a specific etiology for these neuropathies. Because methyl ethyl ketone (MEK) and toluene were the only chemicals involved in the processing, they were suspected. Sampling data accumulated previously by both the company and OSHA showed air concentrations of MEK and toluene to be quite low (less than $20 \mathrm{ppm}$ ), except during maintenance operations. The report discussed several limitations in the health study, including the lack of adequate control data. However, because of the possible role of MEK and toluene in causing peripheral neuropathy, it was recommended that worker exposure to these chemicals be minimized as much as possible. 
In 1975, Venable reported some initial findings on skin and respiratory exposure to PAHs from delayed coking units. The study was conducted at Exxon's Baton Rouge refinery, after it was reported that there were tar-like deposits on the delayed coking unit's structure near the cutting rig and the vent system, and also that there were soot-like deposits in the control room. It was determined that the source of the material on the structure was the condensable tars vented directly to the atmosphere from the drums during depressurization. Normally these emissions are passed through a scrubbing system; however, during periodic overloading, this is bypassed. The material in the control room was thought to be brought in through the airconditioning system or by foot traffic. Analysis of the tar-like substance condensed from the coker drum vent identified 21 different PAHs, five of which the author categorized as being possibly carcinogenic. These were dimethyl benz(a)anthracene, dimethyl benzo(k)fluoranthene, dimethyl benzo(j)fluoranthene, dimethyl benzo(a)pyrene, and methyl benzo(a)pyrene. The author mentioned the possibility of the others acting as cocarcinogens or initiators. The only air sample data reported were high-volume filter samples showing benzene-soluble-fraction values well below the $0.2 \mathrm{mg} / \mathrm{m}^{3}$ OSHA standard (29 CFR 1910.1000, Table Z-1).

In this same study (Venable, 1975), bulk samples of wet and dry product coke were analyzed for five PAHs (not specified). By weight, the dry coke contained 9.5-12.6 ppm of these five PAHs combined; the wet coke contained 2.7$4.6 \mathrm{ppm}$ by weight. The author suggested that these levels of PAH content indicated that coke dust itself was not a special hazard.

The apron of a "coke handler" at this same Exxon refinery (Venable, 1975) was analyzed for PAHs to provide information on potential dermal exposure in this process unit. Extraction of the total apron showed 11 different PAHs io be present in quantities ranging from 0.37 to $1.3 \mathrm{mg}$. Pyrene $(1.0 \mathrm{mg})$, methyl benz(a)anthracene $(1.1 \mathrm{mg})$, benz(e)pyrene $(1.1 \mathrm{mg})$, and methyl benzo(e)pyrene $(1.3 \mathrm{mg})$ were the compounds found in greatest amounts.

At the 1980 American Industrial Hygiene Conference, Lautner and Venable presented the results of area, source, and personal samples collected for benzenesoluble fraction (BSF) and 10 specific PNAs (PAHs) at a delayed coker unit. Sampling for PAHs was performed using a glass fiber and silver-membrane filter followed by XAD2 solid sorbent; analysis was performed by highpressure liquid chromatography. More than $90 \%$ of the BSF samples were well within the current federal standard $\left(0.2 \mathrm{mg} / \mathrm{m}^{3}\right)$, and only one personal sample yielded a detectable quantity of a specific PAH. The authors suggested that the existing engineering controls were the primary reasons for these results. 
APPENDIX B

DEVELOPMENT OF SCOPE OF STUDY AND PHASE II RESULTS

\section{SELECTION OF STUDY PROCESS UNITS}

The first step in formulating the scope of study was the development of a system by which petroleum refineries could be categorized and assessed in terms of the criteria established for this industrial hygiene study. This task was complicated by the facts that, between receiving the crude and transferring the end products, there exists a myriad of processes and potential hazards to the workers and that no two refineries are identical. Size, plant age, location, crude type, and end products are just some of the factors that determine the makeup of a particular refinery.

Despite this, every refinery is made up of several main process units, most of which are common to the majority of refineries. Specific process units may vary among the refineries because of size and also because there may be more than one type (e.g., fluid-bed and moving-bed catalytic crackers). However, the potential hazards associated with these different types of units are generally quite similar because of the similarity of the feedstock and end products. The approach taken was to divide a refinery up by major process units and to identify the potential hazards associated with each. Each of the identified hazards was then further categorized in terms of type and severity, and the extent to which the area had already been studied. Completion of this process for the main refinery units enabled a comprehensive and meaningful assessment of what and where potential hazards existed. This in turn enabled a ranking of units in terms of which should be emphasized during this project.

To illustrate the toxic agents associated with the various refinery units, a matrix system was employed, plotting the process units on one axis and the toxic agents on the other. A similar type of matrix was used in an EPA study (Cavanaugh et al., 1975) to predict potentially hazardous fugitive emissions from refinery process streams. For the purposes of this project where worker exposure is being assessed, process units rather than individual streams are more relevant.

The development of the matrix framework was critical to this method, accurately illustrating where potentially hazardous materials would likely be encountered. There are lists of hundreds of potentially hazardous chemicals present in refineries and dozens of smaller process units within or near the major units. Thus, there was a potential for making the matrix extremely detailed and complicated. However, it was also realized that there was 1 imited, but not always consistent, information that could be used to fill in the matrix; there would have to be a certain amount of subjective selection. For this reason, an overly detailed matrix would have been impossible to complete accurately. 
The matrix developed for this study was limited to major classes of potential chemical hazards. Although noise was considered an important physical hazard occurring throughout the refinery, this area has been studied thoroughly and was considered a very low priority for this project. Other potential physical hazards such as heat stress and ultraviolet radiation (welding operations) exist in refineries; however, the hazards of these are limited and were not considered important relative to the large number of potential chemical hazards.

The classes of toxic agents considered were adapted from an EPA study (Cavanaugh et al., 1975) which divided the toxic compounds found in petroleum refineries and coal conversion processes into 25 main groups. The classes that were not identified with any petroleum refining process were el iminated from the matrix.

Asbestos is known to be present in refineries as insulation material. However, since it could not be associated with any particular unit, and because of the extensive work on asbestos (including worker exposure in refineries), it was not considered in this matrix under fine particulates.

The refinery was divided into 10 major process units; the tenth was actually a group of three auxiliary processes. Each unit actually represented a number of integrated smaller units that are normally located together within the refinery. For example, within "crude distillation" there exist the desalter, atmospheric and vacuum distillation units, and gas processors such as the debutanizer and depropanizer. It would have been very difficult to attempt to characterize toxic agents to each one of these smaller units. Physically they are usually located very close to each other, making it almost impossible to define emission sources. Even more important, a worker assigned to a particular unit would be exposed to emissions from the total unit.

The information used to associate a particular class of toxic compounds with a process unit was gathered from many sources. The most important were the studies done by Radian Associates and EPA on fugitive emissions from petroleum refineries (Bombaugh et al., 1976; Cavanaugh et al., 1975; Dickerman et al., 1977), as well as information gathered during the three preliminary plant visits. Because of the lack of comprehensive data, the assignment of toxic agents was by no means always straightforward; decisions based on best-available information were frequently necessary.

A second step was added to the matrix system to enable weighting of the various assigned toxic agents or classes of toxic agents. The total number of potential hazards identified for each unit was not sufficient to evaluate each unit in terms of the objectives identified earlier for this phase as well as for the total project. Not all of the chemicals are equally toxic. Four general categories were developed for hazard-rating purposes that did reflect the intent of this matrix system. The following rating system was developed for this project: 
Rating 1: Toxic agents that should not be studied in this project because they have already been extensively studied. Additional data generated by this study would probably not significantly contribute to existing knowledge. Examples of potential hazards in this category are noise, asbestos, and benzene.

Rating 2: Toxic agents with acute or relatively minor chronic toxic properties. Chemical substances in this category would also have a low priority for study in this project.

Rating 3: Toxic agents with established chronic toxic properties but probably not carcinogenic.

Rating 4: Known or suspected carcinogens, mutagens, or teratogens that have not been extensively monitored.

For a particular class of toxic agents, the number rating was not always the same; it depended on the specific compounds within the class that had been identified. For example, for sulfur compounds, if the specific compound was hydrogen sulfide (acute toxicity), the rating was 2; but if it was carbon disulfide (chronic toxicity), the rating was 3 . Again, this was not always a straightforward task.

Several areas of refinery operations could not be effectively incorporated into this type of matrix. Maintenance and turnarounds are examples where it was not possible to generalize typical or common hazards associated with the operations. The type of exposure expected for any specific onsite area maintenance activity or turnaround is determined by the type of maintenance (e.g., pump repair, tank cleaning) and in what specific location of the plant it is performed. While it was realized that onsite maintenance and turnaround activities are important in characterizing worker exposure in refineries, these activities could not be treated as separate refinery units on the matrix. Rather, they were treated as integral activities within each process unit in the matrix. In regard to the maintenance shop, all equipment is normally cleaned with steam and water before being brought into the building, thus greatly minimizing exposure of the maintenance crew to the various petroleum fractions or residues from contaminated refinery equipment. Because the types of worker exposures to potential hazards in refinery maintenance shop operations are quite similar to those in other types of maintenance shops, this particular area of refinery operations was not considered a high priority for this study and was not included in the matrix.

The matrix also did not reflect the potential hazards from all process heaters and desulfurization units. These two processes or subunits are integrated into a number of the major process units and have the potential to emit numerous toxic agents. If the possible emissions associated with these two processes were consistently incorporated into this matrix, a great majority of the matrix would have been filled in, making it very difficult to allow differentiation between units. Consequently, it was decided in formulating the matrix to omit the toxic agents associated with these two operations unless there were particular reasons for suspecting them. Even though not included in the matrix, these subunits were considered in the evaluation 
and ranking of each process unit, and it was decided that they would be included (if present) in the detailed evaluation of the study units.

The use of the completed matrix system (see Figure B-1) was a logical first step in ranking the various process units. The catalytic cracking and residual processing units were by far the two process units that ranked highest in having important groups of potential hazards as defined by the criteria established for this matrix. Crude distillation ranked number three, followed by a significant drop-off and clustering of the remaining units. The selection of catalytic cracking and residual processing was not based solely on the matrix; other factors of importance to these processes which were considered are discussed below.

\section{Catalytic Cracking}

Introduced to the United States in 1937 by Eugene Houdry, catalytic cracking is frequently considered to be the backbone of the modern refinery. The total capacity of these units is about 5 million barrels per day, which is equivalent to almost $30 \%$ of total refinery crude capacity (Cantrel1, 1978). Although there are several different types of catalytic crackers based on the method of catalyst transfer, fluidized-bed or fluid catalytic cracker (FCC) units are now almost exclusively in use. In 1978,123 out of the 142 refineries that had catalytic crackers had the FCC type (waiurcil, 1978).

The feedstock to the catalytic cracker unit is primarily gas oils from the crude unit, thermally cracked gas oils, or deasphalted oils. These all contain the heavier fractions of the crude which contain the polyaromatic and heterocyclic hydrocarbons. These types of compounds can also be formed with the high temperatures in the reactor and through incomplete combustion of fuel oil in the process furnace. Catalytic cracking operations can also be a significant source of toxic emissions because of the necessity for removing the coke which forms on the catalyst during cracking operations. It is removed by a controlled combustion process, with the discharge of the combustion gases including catalyst fines, unburned hydrocarbons, etc. The FCC is one of the few units in a refinery from which there are continuous (excluding fugitive) emissions.

The materials used as catalysts have given rise to concern in the past; these were mainly heavy metals that also had the potential to form carbonyl compounds (Brief et al., 1971). Recently, there has been concern over the use of zeolites in industry (SRI International, 1978). These are a naturally occurring or synthetic mineral group; the synthetic zeolites are used as catalysts in cracking operations. Some of the naturally occurring zeolites (e.g., erionite) are known to be fibrous, with dimensions similar to those of asbestos. There is some question of whether or not the synthetic zeolites are fibrous.

A recent article (Anon., 1978) on the cost of controlling emissions in refineries indicated that the catalytic cracker unit was number one in terms of cost for associated pollution engineering controls. The catalytic cracking process requires "sour-water" stripping, a carbon monoxide boiler, and methods of particulate and $\mathrm{SO}_{2}$ removal from the flue gas. 


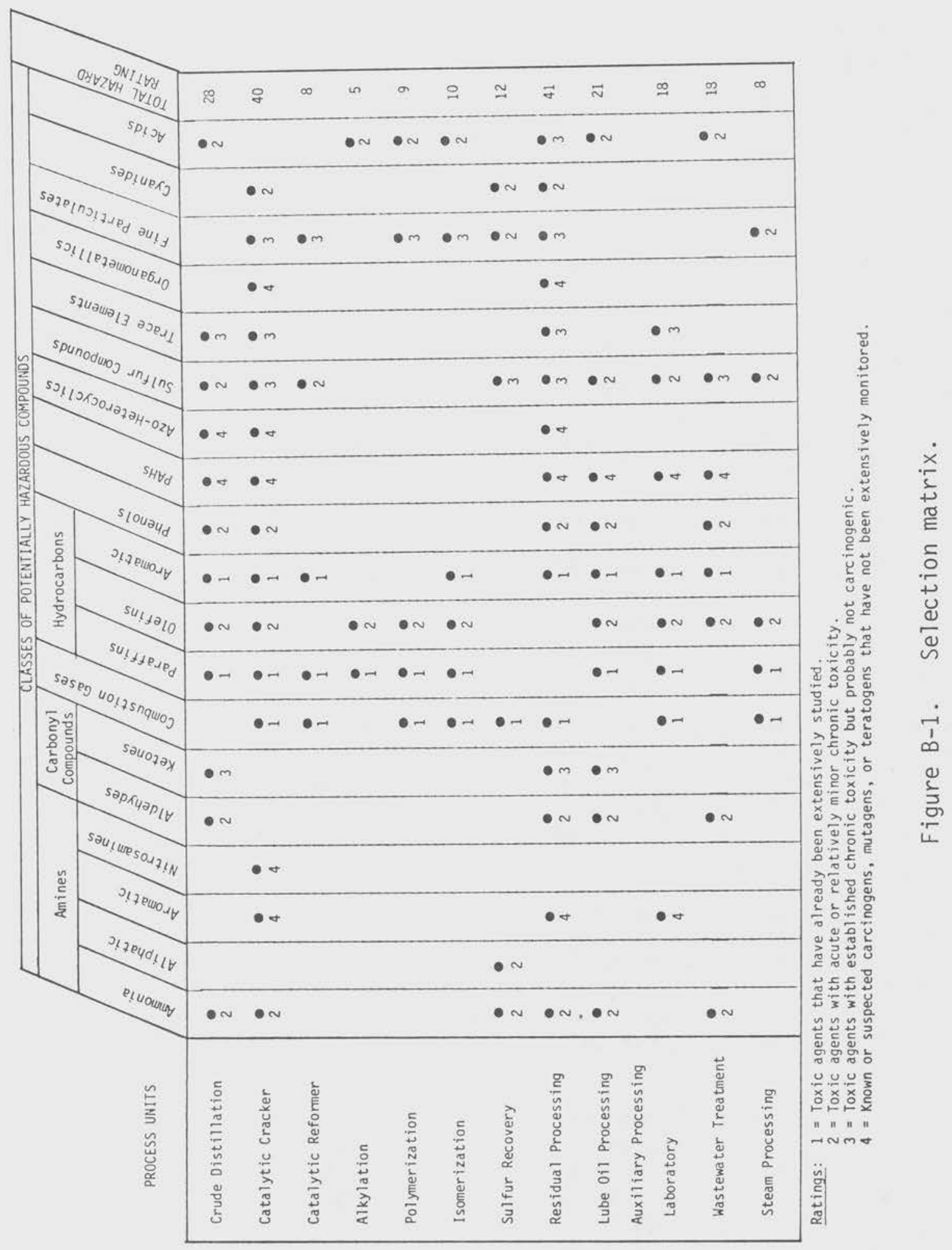


Many refineries upgrade the value of the bottom products of their atmospheric and vacuum distillation by using processes such as:

- deasphalting/asphalt blowing

- visbreaking

- coking

- residual hydrodesulfurization

More than half of the 285 operating refineries have at least one type of residual process unit (Cantrel1, 1978). Of these four processes, deasphalting/asphalt blowing and coking are the two most common. Residual oil hydrodesulfurization has the disadvantages of high hydrogen consumption and relatively short catalyst life due to large amounts of contaminants in residual material. In 1978, there were only 13 operating visbreaking units as compared to 104 deasphalting/asphalt blowing and 52 coking units (Cantre11, 1978). Since it would have been difficult to study or even include all types of residual processing in the nine in-depth surveys, it was recommended that only deasphalting/asphalt blowing and coking be included in the study plan.

Only two limited asphalt processing operations were observed during the preliminary surveys; however, a review of the relevant information in this area (API, 1973; Cavanaugh et al., 1975; Vandervort and Lucas, 1974) indicates that, among refinery operations, residual processing warrants additional study related to worker exposure.

\section{PRELIMINARY SURVEYS AND SELECTION OF PAHS (PHASE II)}

The three preliminary sampling surveys were designed to identify specific potentially carcinogenic compounds associated with the three selected types of process units. Since all three of the refineries visited during this preliminary phase were revisited as part of the in-depth surveys, descriptions of these refineries are included in Appendix C (identified as Refineries $B, E$, and $H$ ).

Area sampling was conducted at the three refineries during the day shift only. A refinery operates in a steady-state mode during the great majority of the time and, during this time, it is expected that the process stream composition within process operations will remain constant. Therefore, for the purpose of this phase, it was assumed that toxic emissions were generally uniform over the three shifts with slight variations due to weather conditions.

Since identification of potentially carcinogenic material was the primary objective of this phase (even very small quantities have to be considered significant), area sampling was more appropriate than personal monitoring. Area sampling enabled a larger volume of air to be sampled at selected locations that were considered to be the most likely areas where the compounds would be found, and therefore maximized the chances for identification. 


\section{Types of Sampling}

The polyaromatic hydrocarbons (PAHs) and azo-heterocyclic compounds were collected using a filter cassette holder containing a silver-membrane filter followed by Chromosorb-102, a porous polymer solid sorbent (see Figure B-2). High-volume, air-driven Gast pumps and high-flow Model S MSA pumps were used with these cassettes. The critical orifices used with the high-volume pumps were calibrated at about 9.2 liters/minute prior to the visit; the MSA pumps were calibrated at about 3.0 liters/minute using a bubble meter. At the refineries, the air-driven pumps were connected to a convenient compressed-air outlet. During sampling, the cassette was wrapped in aluminum foil to minimize photodecomposition of the sample material.

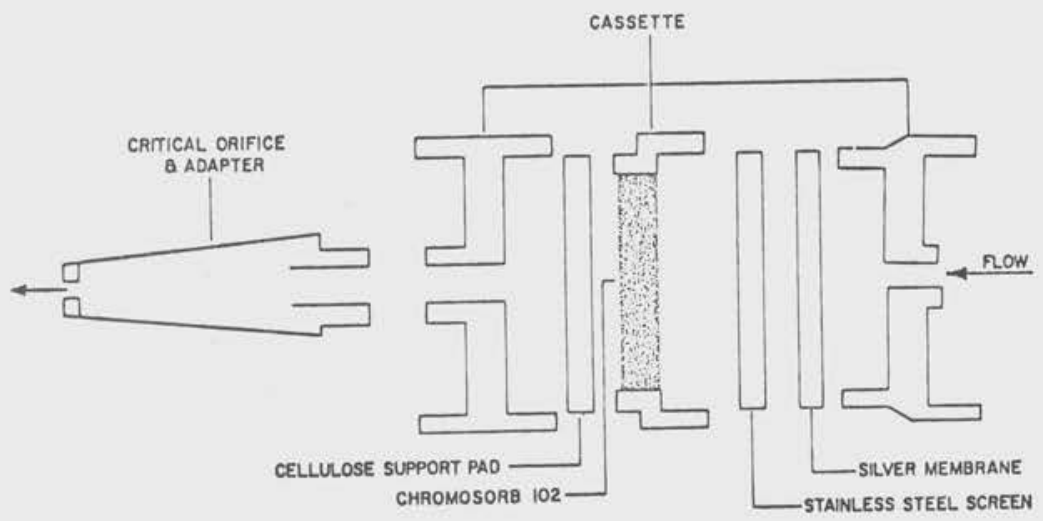

Figure B-2. Phase II PAH sampling assembly.

These samples were analyzed by gas chromatography/mass spectrometry (GC/MS) in conjunction with high-pressure liquid chromatography (HPLC). This sampling and analytical method allowed quantitative analysis of 27 PAH and azoheterocyclic compounds or groups of compounds (shown in Table B-1 which appears in the Results section of this appendix). Among these are several of the potentially carcinogenic PAHs associated with catalytic cracking and residual processing, as well as 16 compounds also considered to be potential carcinogens according to NIOSH's 1980 Registry of Toxic Effects of Chemical Substances (compounds footnoted with an "a" in Table B-1). There was no definitive information to indicate that the other PAHs in this group of 27 were potentially carcinogenic. However, the analytical method allowed them to be conveniently included in the analys is and, for this particular phase of the project, it was felt that the identification of as many PAHs as possible would be beneficial. 
The trace metals identified (Be, As, $\mathrm{Cd}, \mathrm{Cr}, \mathrm{Co}, \mathrm{Ni}$ ) in the assessments of the individual process units were sampled for using NIOSH Method No. P\&CAM 173 (NIOSH, 1977). This included a cellulose ester membrane filter in a closed-face cassette. Calibrated portable MSA Model G pumps set at approximately 2.01 iters/minute were used; analysis was performed by atomic absorption.

Although aromatic amines are indicated as present in various refinery streams, no information could be found on monitoring data, nor was mention of specific compounds found. Because of this, an attempt was made to identify specific aromatic amines. A limiting factor here was that only seven aromatic amines have established NIOSH sampling and analytical methods.

These seven compounds are: aniline, N,N-dimethylaniline, o-toluidine, 2,4xylidine, o- and p-anisidine, and p-nitroaniline. There are numerous aromatic amines, especially aniline derivatives, with some cancer-causing potential (NIOSH, 1980). It was decided that sampling for these seven specific aromatic amines would give a good indication of the presence of this class.

Aromatic amines were collected on large ( $850-\mathrm{mg})$ silica gel tubes using NIOSH Method No. P\&CAM 168 (NIOSH, 1977). Calibrated sampling pumps were set at about $1.01 \mathrm{iter} / \mathrm{minute}$. Analys is was performed by gas chromatography.

There is no NIOSH-validated method for the sampling and analysis of nickel carbonyl. The method used was a modification of the colorimetric technique developed by Brief et al. (1965) and proposed by a NIOSH Special Occupational Hazard Review for nickel carbonyl (Arthur, 1977). In general, the procedure used was as follows. An air sample containing nickel carbonyl is bubbled through an alcohol-iodine solution at a rate of 2.01 iters/minute. The entire bubbler solution was dried and dissolved in dilute acid; this solution was then neutralized and aspirated directly into the flame of a flame-atomic absorption spectrophotometer. The nickel concentration thus determined was used to calculate nickel carbonyl concentration.

There was also no NIOSH-validated method for the sampling and analysis of nitrosamine compounds. The method used for this project was recently developed by Thermo Electron Company (Krull et al., 1978). The sampling train consisted of a solid sorbent (proprietary) with a personal sampling pump calibrated at 2.0 liters/minute. The sample was extracted with a solvent (i.e., dichloromethane/methanol) and analyzed by gas chromatography and highpressure liquid chromatography using a thermal energy analyzer. The sensitivity of the method for individual nitrosamines was $0.1 \mu \mathrm{g} / \mathrm{m}^{3}$ in a 20 to 30-liter air sample. The samples were analyzed for: N-nitrosodimethylamine, $\mathrm{N}$-nitrosodiethylamine, $\mathrm{N}$-nitrosodipropylamine, $\mathrm{N}$-nitrosodibutylamine, $\mathrm{N}$-nitrosopiperidine, $\mathrm{N}$-nitrosopyrrolidine, and $\mathrm{N}$-nitrosomorpholine.

Sampling Locations

In order to keep the number of area samples to a minimum and also to accomplish the objectives of this phase, the proper selection of sampling locations was considered very important. As much information as possible was gathered prior to the site visits on the specific compounds in relation to the processes, equipment, and other factors that might indicate where the 
compounds would most likely occur. A direct-reading $\mathrm{H}$-nu photoionization analyzer was also used during the site visits to determine relative area concentrations of total organics.

The type of information used in preparation for the selection of sampling sites is illustrated below by process units.

\section{Catalytic Cracking Operations}

In the catalytic cracker unit, there are a large number of valves, flanges, pumps, compressors, relief fittings, and drains-all of which can be sources of fugitive emissions. Leakage can result from faulty equipment or inadequate maintenance; however, in some types of equipment, some material loss is expected. In regards to valves, leaks can occur around the packing gland, especially in high-temperature systems. During the preliminary surveys, it was obvious that pumps, and especially compressors, can be sources of fugitive emissions in the catalytic cracker units and in the refinery in general. Reciprocating pumps and compressors are known to be more likely to leak than are centrifugal pumps, and mechanical seals seem to leak less than packed seals.

The off-gas that emanates from the regenerator is the controlled emission source that is of particular concern in the catalytic cracking unit. A coke residue is formed on the catalyst during the cracking process. The catalyst is steam-stripped to remove volatile hydrocarbons and is then transferred into the regenerator unit. Controlled combustion is used here to remove as much of the heavy coke residue from the catalyst as possibie. The regenerator off-gas can contain numerous toxic materials including PAHs, heterocyclic compounds, and trace metals.

From this type of information, a compilation of suspected sources, within the catalytic cracker unit, for the various potentially carcinogenic materials was developed:

- PAHs and azo-heterocyclics: in the various feedstocks; formed in the reactor as part of the coke residue; released in the regenerating process and present in the off-gas; incomplete combustion products of the fuel oil in the process heater.

- Trace metals: in feedstock as organometallic compounds; in reactor converted to part of coke residue; in regenerator off-gas; combustion products from process heater.

- Aromatic amines: in feedstock; formed in reactor; in aqueous phase from steam-stripping of catalyst.

- Metaz carbonyzs: formed in the reactor or the regenerator; emitted in the off-gas.

- Nitrosamines: formed in reactor; in aqueous phase from steamstripping of catalyst; emitted in the off-gas. 
The following table shows the number of each type of sample collected in the FCCUs at the three refineries.

\begin{tabular}{|c|c|c|c|c|}
\hline \multirow{2}{*}{ Sample type } & \multicolumn{4}{|c|}{ Number of samples } \\
\hline & Refinery $H$ & Refinery $E^{a}$ & Refinery B & Total \\
\hline PAHS & 5 & 11 & 4 & 20 \\
\hline Aromatic amines & 8 & 8 & 3 & 19 \\
\hline Metals & 5 & 9 & 2 & 16 \\
\hline Nickel carbonyl & 2 & 4 & - & 6 \\
\hline Nitrosamines & - & 3 & 1 & 4 \\
\hline
\end{tabular}

\section{Coking Operations}

In the delayed coking units, atmospheric emissions can result from the coke dust, storage containers for the water used in cutting the coke, process heaters, and fugitive hydrocarbon leaks.

- PAHs and azo-heterocyclics: in the crude oil residue; released in the coking chamber off-gas; constituents of the coke fines; emitted from the process heaters.

- Trace metals: in the crude oil residue; released in the coking chamber off-gas; coke fines; from process heaters.

- Aromatic amines: in the crude oil residue; released in the coking chamber off-gas; in the aqueous phase used for cutting the coke.

- Nickel carbonyl: released in the coking chamber off-gas.

- Nitrosamines: released in the coking chamber off-gas; in the aqueous phase used for cutting the coke.

The following table shows the number of each type of sample collected in the single delayed coking unit surveyed (Refinery B).

\begin{tabular}{lc}
\hline \multicolumn{1}{c}{ Sample type } & Number of samples \\
\hline PAHs & 6 \\
Aromatic amines & 5 \\
Metals & 3 \\
Nickel carbonyl & 2 \\
Nitrosamines & 2 \\
\hline
\end{tabular}


When the coking drums are being cut, copious amounts of water are used. In two sampling locations beneath the drums where water mist and spray were present, two silica gel tubes were used in series. The purpose of this was to minimize the effect of water on the second tube.

\section{Asphalt Processing Operations}

In the asphalt processing operations, asphalt blowing is the area where toxic emissions are of particular concern. The feed is preheated to between 400 and $600^{\circ} \mathrm{F}$ and pumped into the reactor. Oxygen pumped through the reactor causes an exothermic reaction with hydrogen, while polymerization, alkylation, and isomerization also take place. The gases which are vented from the reactor are a primary source of hydrocarbon vapors and aerosol $0 i 1$ particles. These vent gases are normally incinerated, but the incinerator may still emit toxic material.

- PAHs and azo-heterocyclics: in the feedstock; formed in the reactor; in the vented reactor gas; constituents of asphalt; emitted from the process heater.

- Trace metals: in the feedstock; in the vent gases; emitted from the process heater.

- Aromatic amines: in the feedstock; formed in the reactor; in the vent gases; constituents of asphalt.

- Metaz carbonyz: formed in the reactor; in vent gases; in the aqueous phase.

- Nitrosamines: formed in the reactor; in the vent gases; constituents of asphalt.

The following table shows the number of each type of sample taken at the asphalt processing units. The type of asphalt processing by refinery included: Refinery $\mathrm{H}$ - vacuum distillation; Refinery E - deasphalting; and Refinery B - asphalt blowing and deasphalting.

\begin{tabular}{lcccc}
\hline \multirow{2}{*}{ Sample type } & \multicolumn{4}{c}{ Number of samples } \\
\cline { 2 - 5 } & Refinery & Refinery & Refinery & Total \\
\hline PAHs & 2 & 2 & 5 & 9 \\
Aromatic amines & 2 & 3 & 4 & 9 \\
Metals & 1 & - & 3 & 3 \\
Nickel carbonyl & - & - & 2 & 2 \\
Nitrosamines & - & - & 2 & 2 \\
\hline
\end{tabular}

In addition to these samples mentioned above, at least one upwind PAH sample was taken at each refinery, and appropriate blank samples were prepared for all types of samples. 


\section{RESULTS}

Analytical results of the area samples collected in Phase II revealed no detectable quantities of the seven nitrosamines, the six trace metals, or nickel carbonyl in any of the samples. Very minimal concentrations of aromatic amines were found, in the FCCUs only. The results of the PAH samples did show that most of the areas sampled contained detectable quantities of between 4 and 15 different PAH compounds. The highest cumulative PAH air concentrations were found in the FCCUs, followed by the delayed coker and then the asphalt processing units. The remainder of this section is devoted to a more detailed discussion of these and other findings of Phase II sample analysis.

\section{PAHS}

- Seventeen of the 19 samples analyzed from the FCCUs had detectable quantities of between 4 and 15 different PAHs. The average cumulative concentration of these 17 samples was about $50 \mu \mathrm{g} / \mathrm{m}^{3}$.

- All four samples analyzed from the single coker unit had detectable quantities of between 8 and 11 different PAHS, with a mean cumulative concentration of about $11 \mu \mathrm{g} / \mathrm{m}^{3}$.

- All eight samples analyzed from the various asphalt processing units had detectable quantities of between four and nine different PAHs, with an average cumulative concentration of slightly more than $1 \mu \mathrm{g} / \mathrm{m}^{3}$.

- Three of the four upwind samples showed detectable quantities of between three and five different PAHS, with an average cumulative concentration of less than $1 \mu \mathrm{g} / \mathrm{m}^{3}$.

- The three blank samples had detectable quantities of one or two PAHS, with an average cumulative weight of $137 \mathrm{ng}$. This corresponds to 0.03 to $0.05 \mu \mathrm{g} / \mathrm{m}^{3}$ since the sample volumes ranged from 2.6 to $4.2 \mathrm{~m}^{3}$.

Table B-1 illustrates the results of the PAH samples, by individual compounds and process units. The number of samples that had detectable quantities and the ranges and mean values of these "positive" samples are also given. The four upwind samples are included for comparison.

Although there were wide variations between refineries when a comparison of concentrations was possible, there were certain overall consistencies. The lighter molecular weight 2-ring PAHs, such as naphthalene and the methylnaphthalenes, were found in the highest concentrations in almost all of the samples. Some 3- and 4-ring PAHs (e.g., fluorene, phenanthrene/anthracene, pyrene) were found, as well as very small quantities of some 5-ring compounds (e.g., benzo(e)pyrene, perylene). This was to be expected since molecular weight generally corresponds with volatility. Also, as expected, the area samples collected around pumps, especially in enclosed or partially enclosed areas, showed the highest levels. 
Table B-1. PAHs identified in Phase II by process units.

\begin{tabular}{|c|c|c|c|c|c|c|c|c|c|c|c|c|c|}
\hline \multirow{3}{*}{\multicolumn{2}{|c|}{ COMPOUND (Ring No.) }} & \multicolumn{3}{|c|}{$\begin{array}{c}\text { FCCU } \\
\text { (19 samples analyzed) }\end{array}$} & \multicolumn{3}{|c|}{$\begin{array}{c}\text { COKER } \\
\text { (4 samples analyzed) }\end{array}$} & \multicolumn{3}{|c|}{$\begin{array}{c}\text { ASPHALT } \\
\text { (8 samples analyzed) }\end{array}$} & \multicolumn{3}{|c|}{$\begin{array}{c}\text { UPWIND } \\
\text { (4 samples analyzed) }\end{array}$} \\
\hline & & \multirow{2}{*}{$\begin{array}{l}\text { No. } \\
\text { Positive }\end{array}$} & \multicolumn{2}{|c|}{ Concentration* } & \multirow{2}{*}{$\begin{array}{l}\text { No. } \\
\text { Positive }\end{array}$} & \multicolumn{2}{|c|}{ Concentration* } & \multirow{2}{*}{$\begin{array}{l}\text { No. } \\
\text { Positive }\end{array}$} & \multicolumn{2}{|c|}{ Concentration* } & \multirow{2}{*}{$\begin{array}{l}\text { No. } \\
\text { Positive }\end{array}$} & \multicolumn{2}{|c|}{ Concentration* } \\
\hline & & & Range & Mean & & Range & Mean & & Range & Mean & & Range & Mean \\
\hline Naphthalene ${ }^{a}$ & (2) & 15 & $0.08-268$ & 24.3 & 4 & $0.64-5,34$ & 2.06 & 6 & $0.01-3.72$ & 0.92 & 3 & $0.01-1,17$ & 0.5 \\
\hline Quinoline ${ }^{a}$ & (2) & 6 & $0.05-5.97$ & 2.7 & 3 & $0.17-0.93$ & 0.44 & 1 & $<0.01$ & $<0.01$ & 0 & & \\
\hline 2-Methyl naphthalene & (2) & 16 & $0.14-81.7$ & 15.1 & 4 & $1.04-13.8$ & 5.07 & 8 & $<0.01-0.79$ & 1.08 & 3 & $0.01-1.17$ & 0.3 \\
\hline 1-Methylnaphthalene & (2) & 16 & $0.11-68.4$ & 9.8 & 4 & $0.74-7.08$ & 2.72 & 8 & $<0.01-0.55$ & 0.16 & 3 & $0.07-0.36$ & 0.16 \\
\hline Acenaphthalene & (2) & 5 & $<0.01-0.34$ & 0.14 & 2 & $<0.01-0.12$ & 0.06 & 0 & & & 0 & & \\
\hline Acenaphthene & (2) & 6 & $0.07-5.5$ & 1.2 & 4 & $0.03-0.33$ & 0.11 & 3 & $<0.01$ & $<0.01$ & 0 & & \\
\hline Fluorene & (3) & 9 & $0.04-11.7$ & 1.9 & 4 & $0.16-0.34$ & 0.25 & 5 & $<0.01-0.03$ & 0.01 & 1 & 0.01 & 0.01 \\
\hline $\begin{array}{l}\text { Phenanthrenea/ } \\
\text { Anthracene }{ }^{a}\end{array}$ & (3) & 16 & $0.04-23.5$ & 3.0 & 4 & $0.13-0.66$ & 0.38 & 6 & $0.03-0.26$ & 0.08 & 2 & $0.01-0.06$ & 0.04 \\
\hline Acridine & (3) & 6 & $0.01-3.6$ & 0.94 & 2 & .0 .03 & 0.03 & 3 & $<0.01-0.04$ & 0.02 & 0 & & \\
\hline Carbazole & (3) & 7 & $<0.01-0.76$ & 0.29 & 1 & $<0.01$ & $<0.01$ & 2 & $<0.01-0.01$ & 0.01 & 0 & & \\
\hline Fluoranthene & (4) & 8 & $<0.01-0.65$ & 0.16 & 2 & $<0.01$ & $<0.01$ & 2 & $<0.01$ & $<0.01$ & 0 & & \\
\hline Pyrene ${ }^{a}$ & (4) & 8 & $0.03-2.13$ & 0.44 & 3 & $<0.01-0.02$ & 0.01 & 2 & $<0.01$ & $<0.01$ & 0 & & \\
\hline $\begin{array}{l}\text { Benzo(a)fluorene/ } \\
\text { Benzo(b)fluorene }\end{array}$ & (4) & 3 & $<0.01-0.14$ & 0.06 & 0 & & & 0 & & & 0 & & \\
\hline Benz(a)anthracenea & (4) & 2 & $0.01-1.36$ & 0.69 & 1 & 0.01 & 0.01 & 0 & & & 0 & & \\
\hline Chrysene'Triphenylene & (4) & 1 & 0.17 & 0.17 & 1 & $<0.01$ & $<0.01$ & 0 & & & 0 & & \\
\hline $\begin{array}{l}\text { Dimethylbenz(a)- } \\
\text { anthracene }{ }^{\star \star a}\end{array}$ & (4) & 1 & $<0.01$ & $<0.01$ & 0 & & & 0 & & & 0 & & \\
\hline Benzo(e)pyrenea & (5) & 1 & 0.01 & 0.01 & 0 & & & 0 & & & 0 & & \\
\hline Benzo(a)pyrene ${ }^{a}$ & (5) & 0 & & & 0 & & & 0 & & & 0 & & \\
\hline Perylene & (5) & 1 & 0.01 & 0.01 & 0 & & & 0 & & & 0 & & \\
\hline Dibenz $(a, j)$ acridine ${ }^{a}$ & (5) & 0 & & & 0 & & & 0 & & & 0 & & \\
\hline Dibenz $(a, i)$ carbazole ${ }^{a}$ & (5) & 0 & & & 0 & & & 0 & & & 0 & & \\
\hline Dibenzanthracene $* \star a$ & (5) & 0 & & & 0 & & & 0 & & & 0 & & \\
\hline $\begin{array}{l}\text { Indeno }(1,2,3-\text { cd })- \\
\text { pyrene }\end{array}$ & (6) & 0 & & & 0 & & & 0 & & & 0 & & \\
\hline Benzo $(g, h, i)$ perylene $a$ & (6) & 0 & & & 0 & & & 0 & & & 0 & & \\
\hline Anthanthrene & (6) & 0 & & & 0 & & & 0 & & & 0 & & \\
\hline Dibenzopyrene $\star \star a$ & (6) & 0 & & & 0 & & & 0 & & & 0 & & \\
\hline Coronene & (7) & 0 & & & 0 & & & 0 & & & 0 & & \\
\hline
\end{tabular}

*Concentration in $\mu \mathrm{g} / \mathrm{m}^{3}$.

**Specific isomers not distinguishable by analytical method; reported value represents any one or combinations of existing isamers.

${ }^{a}$ Suggested as having some cancer-causing potential (NIOSH, 1980). 
Of the 17 silica gel samples analyzed from the FCCUs, only four (one from each of the four FCCUs surveyed) had detectable quantities of any of the seven aromatic amines; these four represented very minimal concentrations. Three of these samples contained only p-anisidine in quantities that corresponded to air concentrations less than $0.1 \mathrm{ppm}$ as a time-weighted average over the sampling period. The fourth sample was positive for aniline, oanisidine, and p-anisidine, again all at concentrations less than $0.1 \mathrm{ppm}$. All four of these samples were collected in areas near process pumps.

Eight silica gel samples collected in the asphalt processing units and seven in the coker unit were analyzed; none showed any detectable quantities of the aromatic amines.

In addition to the seven aromatic amines for which the sampling and analytical method is NIOSH-validated, the silica gel samples were also analyzed for 1 -naphthylamine by the same method. This aromatic amine is strongly suspected of being carcinogenic but is not specifically associated with refinery operations. None of the 32 samples analyzed had detectable quantities of this compound.

Trace Metals

There were no detectable quantities of any of the six metals ( $\mathrm{Co}, \mathrm{Cr}, \mathrm{Ni}$, $\mathrm{Cd}$, As, Be) in any of the 18 area samples analyzed ( 11 from the FCCUs; 4 from the asphalt processing units; 3 from the coker unit). The minimum detectable air concentrations for these individual metals were: $6 \mu \mathrm{g} / \mathrm{m}^{3}$ for $\mathrm{Co}, \mathrm{Cr}$, and $\mathrm{Ni} ; 1 \mu \mathrm{g} / \mathrm{m}^{3}$ for $\mathrm{Cd}$; and $0.3 \mu \mathrm{g} / \mathrm{m}^{3}$ for $\mathrm{As}$ and Be. It should be noted that metal catalysts were not used in the FCCUs surveyed.

Nickel Carbonyl

Nickel carbonyl was not detectable in any of the 10 area samples analyzed (six from the FCCUs; two from the asphalt blowing unit; two from the coker). The minimum detectable concentrations for these samples ranged from 1.4 to $3.5 \mu \mathrm{g} / \mathrm{m}^{3}$ depending on the sample volume.

Nitrosamines

There were no detectable quantities of any of the seven nitrosamines in the eight area samples analyzed (four from the FCCUs; two from the coker; two from the asphalt blower). The lower limit of detection was about $5 \mu \mathrm{g} / \mathrm{m}^{3}$ for each nitrosamine. An unknown substance that was thought to be a nitrosamine compound (not one of the seven) was detected in one of the samples collected in the coker unit. It eluted near $\mathrm{N}$-nitrosodibutylamine (NDBA) and was quantitated $\left(44 \mu \mathrm{g} / \mathrm{m}^{3}\right)$ relative to the NDBA reference standard.

Zeolite

All three refineries used a similar type of synthetic zeolite as their FCC catalyst. A bulk sample was collected and checked for fibers using phasecontrast microscopy; no fibers were observed in the sample. The material appeared to be composed entirely of resin beads. 


\title{
APPENDIX C \\ DESCRIPTIONS OF REFINERIES AND STUDY PROCESS UNITS
}

\author{
REFINERY A
}

\section{DESCRIPTION OF REFINERY A}

Refinery $A$ is a "medium" (53,800 bbl/day), "nonmajor" refinery located in northwestern Oklahoma. It originated in 1916 as a 1,000 bbl/day crude oil skimming plant. Currently spread out over 608 acres, it processes over 50,000 barrels of crude a day and produces a full 1ine of petroleum products which includes:

- liquid petroleum gas

(propane, butane)

- jet fuel

- gasolines

- Diesel fuel
- \#2 and \#6 fuel oils

- Tube oils

- coke

- asphalt

The domestic crude refined here is categorized as a "sweet" $(0.23 \%$ sulfur by weight), "mixed base" (containing both paraffins and naphthenes) crude with an API Gravity Index of 39.5. Approximately 32,000 bbl/day come from Oklahoma and 21,500 bbl/day come from west Texas. Most of the crude is received by pipeline; a small percentage is received by tank trucks.

This refinery ships gasolines, fuel oils, and Diesel fuels by a pipeline that goes north to Rock Rapids, Iowa, and south to Oklahoma City. Products are also shipped by trucks and railroad cars.

The major process units at Refinery A include:

- two crude distillation units

- two vacuum distillation units

- duo-sol lube unit

- delayed coker

- asphalt blower
- unifiner

- catalytic reformer

- catalytic isomerization unit

- FCCU

- HF alkylation unit

Almost every major process unit has its own control room. Figure $\mathrm{C}-1$ shows a rough refinery plot plan of the major units. South of the process units, there is also a lubricant packaging plant where 1-quart, 5-gallon, and 50gallon containers are filled. 

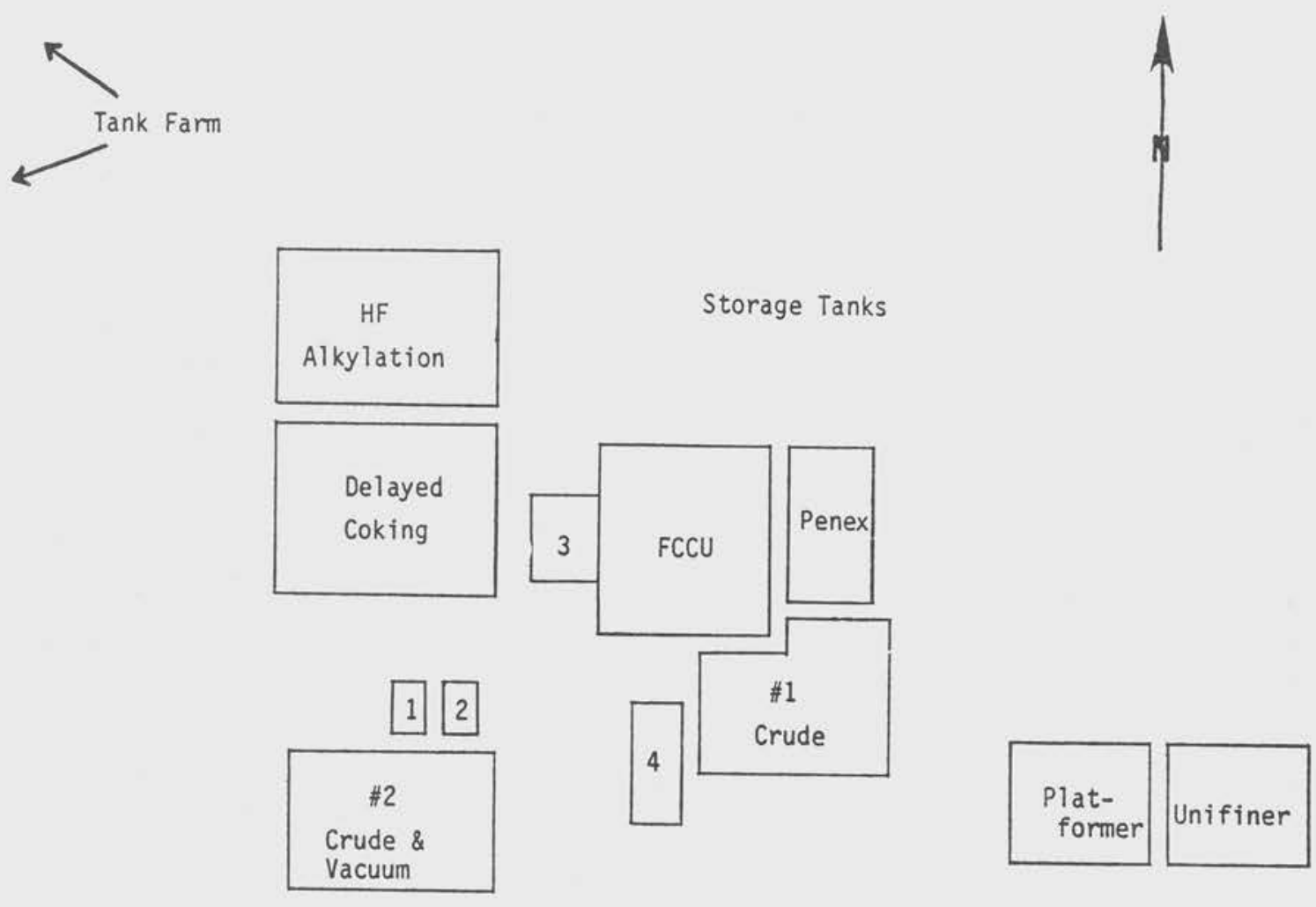

Legend

1. Asphalt Blowing Unit

2. FCCU Charge Heater

3. CO Boiler

4. Alky Feed Treater

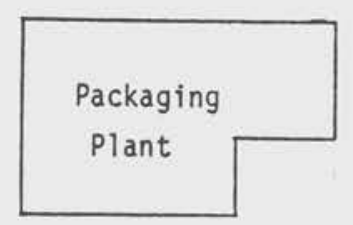

Figure C-1. Refinery A production area. 
There are approximately 270 hourly employees who belong to the union (OCAW) and an additional 20 who are salaried (supervisory personnel). Most of the routine maintenance activity is performed in-house; contractors are brought in for turnarounds and other major maintenance work. The production units operate 24 hours a day over three work shifts.

The safety and health staff at this refinery includes the manager of safety, a safety engineer, two fire and safety helpers, and an occupational nurse. All are under the direct supervision of the refinery superintendent. The nurse is on the premises full time during the day shift; a majority of the supervisors and foremen are trained in first aid and cardiopulmonary resuscitation. The dispensary and treatment room are fully equipped to handle first aid situations and various routine examinations. All of the production workers are given preplacement medical examinations although a set schedule for periodic examinations has not yet been established. A physician in town is under contract to the company to handle examinations and other medical situations.

As part of good industrial hygiene practice, the use of protective clothing and equipment (e.g., hard hats, safety shoes, gloves, eye protection) is emphasized. Eating is allowed in most control rooms, but smoking is permitted only in designated areas away from the production units. Each unit operator is thoroughly trained on the unit equipment, operations, and associated safety hazards. The practice of good personal hygiene such as the washing of hands before eating is also encouraged. Good unit housekeeping is practiced as an important means of minimizing worker exposure to potential hazards. Spills are promptly cleaned up by the unit operators, and routine cleanup is performed by the day shift unit operators. Any necessary equipment or structure repair is also promptly carried out by the unit operators or in-house maintenance crews.

Routine industrial hygiene sampling is not performed at this refinery. Sampling has been carried out on a spot basis for benzene, heptane, hexane, hydrogen sulfide, and sulfur dioxide.

\section{STUDY PROCESS UNITS AT REFINERY A}

Fluid Catalytic Cracking Unit (FCCU)

\section{Unit and Process Description}

The FCCU is located in the middle of the main production area (shown in Figure $(-1)$ about 200 feet east of the delayed coker unit and just to the northeast of the \#1 crude unit. The reactor/regenerator $(R / R)$ structure is a stacked type with the regenerator on top. The total height of the structure is 185 feet. The unit was designed and installed in the early 1950s. A major modification in the riser size was made about 1962 that extended the production capacity to the present-day figure of about $20,000 \mathrm{bbl} /$ day. 
The unit covers an area of about $200 \times 200$ feet, with the $C 0$ boiler located just to the west of this area (Figure $C-2$ ). The FCCU charge heater is about 100 feet to the southwest of the unit, across the main road of the refinery. The main portion of the FCCU is laid out into three areas:

- The R/R structure, the fractionator tower, and the various pumps are located in the center of the unit, running west to east.

- The gas recovery area is situated just to the north of these structures. Gas recovery includes the primary absorber, gas stripper, secondary absorber, and debutanizer towers.

- Just to the south of the R/R structure are the fresh and regenerated catalyst hoppers, the pump room, and the control house. A compressor building is located just south of the pump room.

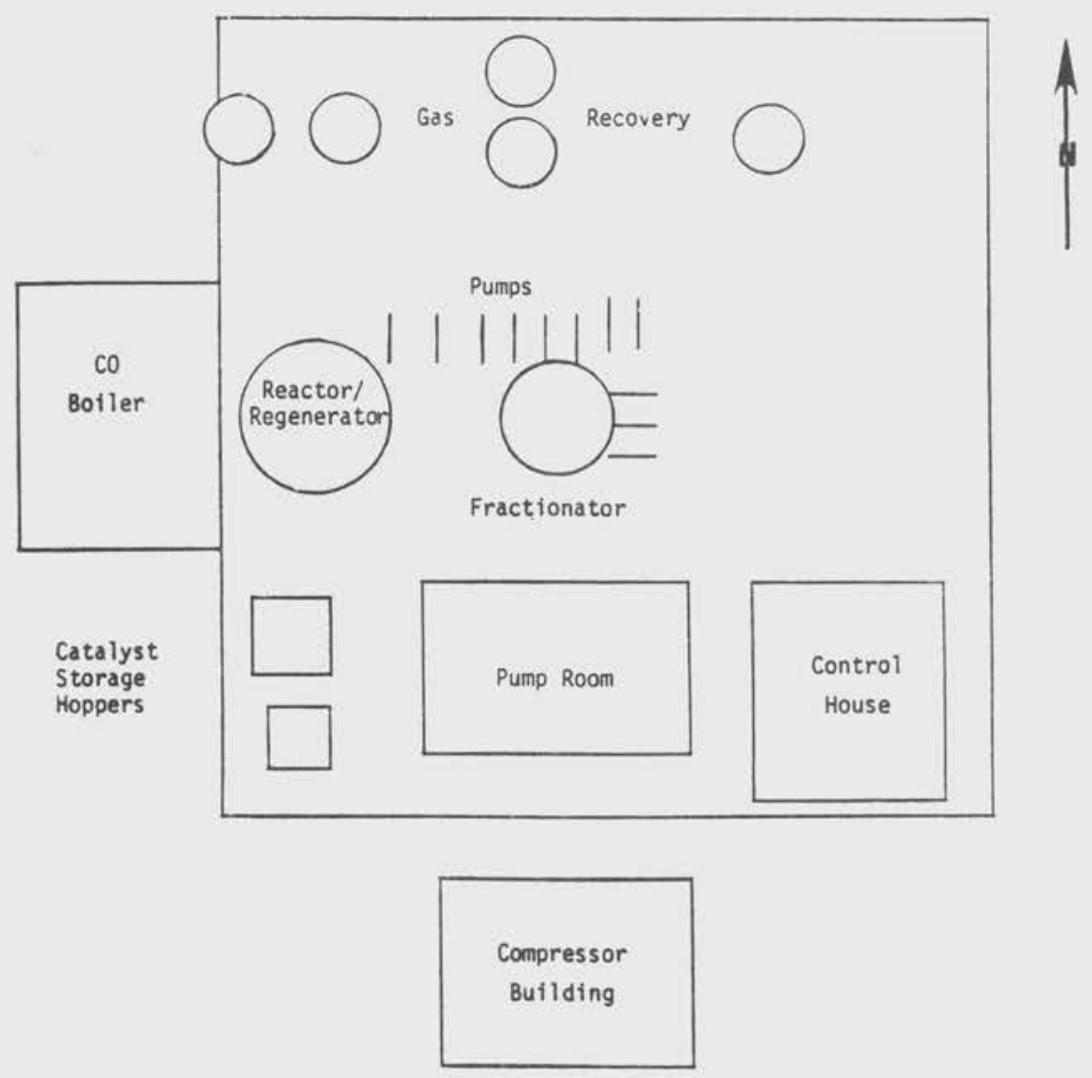

Figure C-2. Refinery A FCCU.

The fresh feed for the FCCU comes from the crude units (atmospheric gas oil) and the vacuum units (mostly light and heavy vacuum gas oils). The feed is preheated to a suitable temperature by a gas-fired furnace. 
This fresh feed plus heavy gas oil recycled from the fractionator are injected into the reactor where catalytic cracking is initiated as the hot oil feed contacts the catalyst. The catalyst used at this refinery is an aluminalike synthetic zeolite, common in other FCCUs studied in this project. The product vapors and the catalyst are separated in the single-feed riser line and the reactor itself. The hydrocarbons are taken to the fractionator tower where the various products are separated. The catalyst is stripped of any remaining oil with steam and delivered to the regenerator where the spent catalyst is reactivated by oxidizing the accumulated carbon at a temperature of about $1,200^{\circ} \mathrm{F}\left(649^{\circ} \mathrm{C}\right)$. The flue gas from the regenerator goes to the $\mathrm{C} 0$ boiler where it is burned before being released to the atmosphere. The regenerated catalyst is stripped of any absorbed oxygen with steam before being recirculated back to the reactor. The continuous circulation of the fluidized catalyst is an important means of heat transfer between the reactor and regenerator.

The main products from the fractionator are:

- butane
- propane
- heavy cat gasoline

- light cycle oil

- decant oil

Work Force

There are normally five workers assigned to the FCCU full time during each shift. In addition, there is an assistant supervisor on duty from 0800 to 1700 each day who spends about $70 \%$ of his time on this unit. Following is a brief description of the duties of the five full-time shift personnel.

- Shift Eoreman: Supervises the overall unit operations paying particular attention to any operational difficulties as well as any specific fire or safety hazards, such as gas leaks. He spends about a third of his time outside the control room directing the helpers.

- Control Room Operator: Spends essentially 100\% of his shift inside, monitoring and logging in the various meters and charts on the control board. He works closely with the shift foreman, as well as with the helpers and operators.

- CO Boizer operator: This outside operator has primary responsibility for the $\mathrm{CO}$ boiler. His duties include collecting water samples and adding chemicals at the FCCU cooling tower and the CO boiler unit, making rounds every 2 hours ( 30 minutes/round) to check meters and gauges, and greasing and lubricating the equipment such as pumps (daily or weekly schedule).

- Operator and Helper: These are two operators who perform the routine outside duties for the main section of the FCCU; their job duties and responsibilities are essentially the same. Periodically they take meter and gauge readings, make visual inspections, gauge tanks, collect process samples once per shift, monitor uptake of chemical additives, keep pumps oiled, and maintain the unit by general housekeeping. 
The primary exposure control measure used at this FCCU is a closed-system process which limits exposure to products, by-products, and intermediates. Also important is a well-organized maintenance program that provides both efficient preventive and repair maintenance services. Under normal operating conditions, exposure to PAHs may occur during sampling of the various streams, during maintenance and housekeeping activities, from fugitive emissions, and from the regenerator flue gas.

The use of sample bombs for collecting process stream samples is a means of minimizing exposure; these bombs are used for collecting at least some of the stream samples at this unit. The sample bomb is placed in an auxiliary process line and the stream is diverted through this line, filling the vessel. The valves at each end of the bomb are closed, and the bomb can be removed with minimum exposure to the collector. Samples are also collected using the spigot-and-bottle method which is not as effective in minimizing exposure.

Exposure during routine maintenance is difficult to minimize. The ground level of the unit is constructed of concrete with an efficient sewer system which simplifies cleanup procedures. The refinery has its own craft maintenance crews (e.g., pipefitters, electricians) that provide preventive and repair services. Hard hats, safety glasses, and neoprene gloves are worn routinely, with safety or slick suits available. Coveralls are not provided and are not normally worn. Disposable ear plugs are used in the enclosed compressor room. There are no routine operations which require the usage of respirators; however, air-purifying and self-contained, breathing-air respirators are available. These respirators are maintained by the refinery safety department.

The areas of the unit handling heavy fractions, which are more likely to contain the PAHs, are in fairly open areas, minimizing potential vapor accumulation. Several of the heavy gas oil, slurry recycle, and decant oil pumps are located very close together around the base of the fractionator tower. This is an area where PAH concentrations might be elevated. The control house, which is air-conditioned but not under positive-pressure ventilation, is normally not directly downwind of the R/R or heavy fraction pumps.

The flue gas from the regenerator is burned in the CO boiler with an auxiliary fuel. The heat produced here is used to generate steam. The c0 boiler removes not only carbon monoxide from the flue gas, but many other hydrocarbons, making the effluent suitable for discharge to the atmosphere. 
Delayed Coker Unit

\section{Unit and Process Description}

The delayed coker unit (as shown in Figure $\mathrm{C}-1$ ) is located just south of the HF alkylation unit; north of the \#2 crude, vacuum, and asphalt blowing units; and west of the FCCU and CO boiler. The unit has two 75-foot coke drums with a daily production capacity of about 200 tons.

The unit, which is about 10 years old, is spread over an area of about $200 x$ 200 feet (Figure C-3). The ground level of the entire unit is constructed of concrete. The control building is located in the central area of the unit and houses the locker and shower facilities in addition to the control board room. Just north of the control building is the coke tower (an open, multilevel structure that includes the two drums and penthouse at the top), with the trough and loading area on the other side. The coke that has been cut is moved from the trough to the loading area by a Diesel-powered crane.

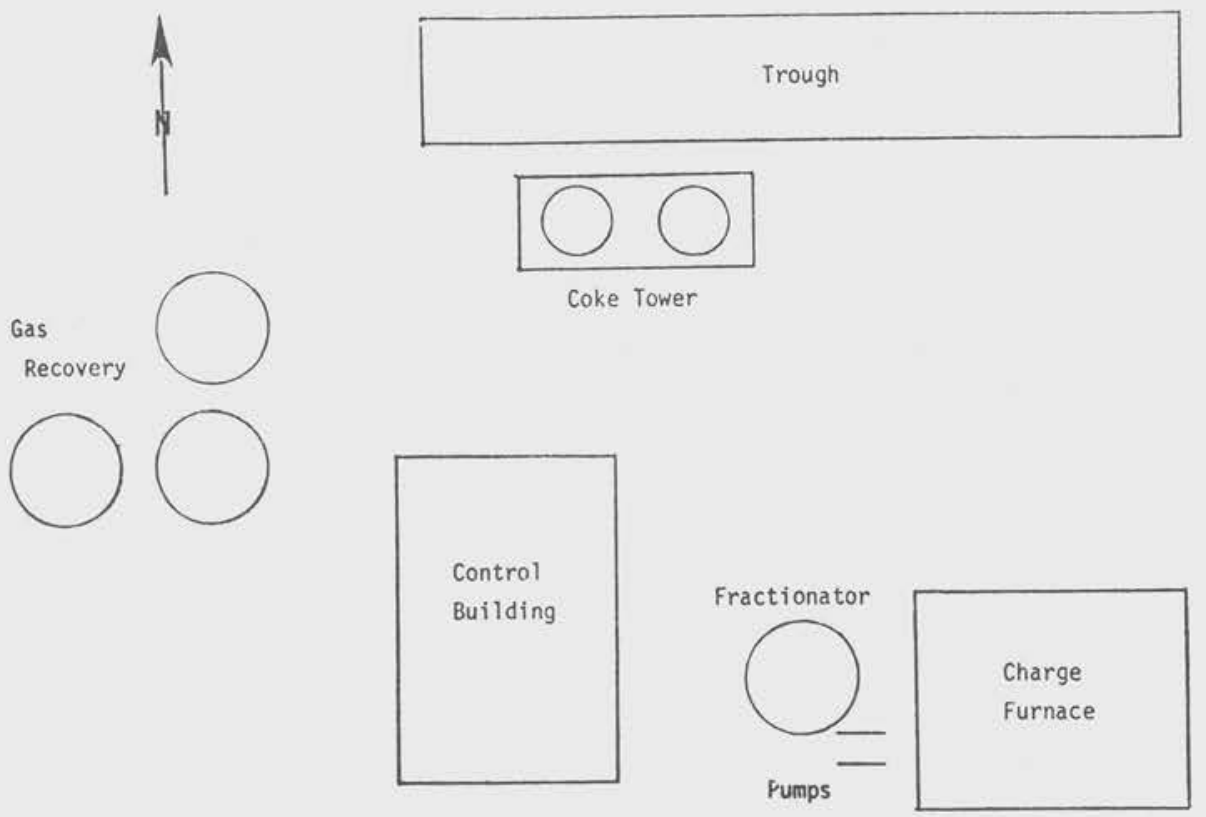

Figure C-3. Refinery A delayed coker unit.

The gas-fired charge furnace is located about 15 yards to the east of the control building, with the fractionator in between. The gas recovery structures and flare are located to the west of the control building and coke tower.

There are two types of coke produced at this refinery: a \#1 grade coke referred to as "needle" coke, and the more commonly produced \#2 grade coke or "sponge" coke. The charge stock is decant oil from the FCCU for needle coke and the residual from the vacuum units for sponge coke. Needle coke is a higher quality coke that is much harder and denser than the sponge type. 
The residual from the vacuum units or the decant oil is pumped from storage tanks and regulated by a charge motor valve to the convection portion of the gas-fired box heater. The heated charge then goes to the fractionator tower where the light ends are flashed off. The bottoms from the fractionator are then pumped to the radiant side of the furnace. At this point, the charge for sponge coke is heated to about $900^{\circ} \mathrm{F}\left(482^{\circ} \mathrm{C}\right)$; the charge for needle coke is heated about $45^{\circ} \mathrm{F}\left(25^{\circ} \mathrm{C}\right)$ higher. The charge then goes to one of the two coking drums. Each drum has a 40-hour cycle, with coke formation lasting about 20 hours. Since the drums are charged alternately, the cutting of a drum occurs every 20 hours. The lighter vapor fractions of the thermal cracking operation are removed from the top of the drum and sent to the fractionator where the various products are separated and eventually recovered. Products from this unit besides coke include: gas oil, gasoline, naphtha, propane, and butane.

The complete cycle of each drum, from drum heating to cutting, is 40 hours. About 9 hours before the cutting operation is scheduled, coke formation is stopped by switching the feed to the other drum. In 30 minutes, steam is introduced into the drum to cool it. This lasts about 5 hours, and then water is added to further cool the drum. Nine hours after the feed is switched, the top and bottom of the drum are opened and the coke is cut from the top with a high-pressure hydraulic bit. The coke falls down a chute into a trough, from which it is moved to a loading area by a Diesel-powered crane. Trucks are used to transport the coke. The drilling lasts from 2 to 4 hours, depending on the type of coke being cut. Since needle coke is much harder, its cutting operation lasts longer.

After cutting is completed, the top and bottom of the drum are replaced; the drum is pressure-tested for seal, heated, and is ready when the feed is switched from the other drum to begin coke formation.

Work Force

The work force for the coker unit is divided into two groups - the operations group and the coke-cutting group. The three-man operations group works the normal 8-hour shift; following is a brief description of their job activities.

- Operator: Is in charge of the normal unit operations. He spends most of his time inside the control room where he can easily monitor operations. He occasionally leaves the control room to assist one of the others or to lead a more difficult task, such as pump repair.

- First Helper: His main responsibilities are to monitor the control board, to make entries into the daily logsheet, and to make the necessary process control adjustments. He spends the majority of his shift inside; he occasionally makes process checks in the production area. 
- Second Helper: Performs most of the routine outside tasks, spending a total of 2 to 4 hours a shift in the production area. About every 2 hours he makes routine rounds checking temperature, pressure, and flow rate gauges, making visual inspection of equipment and processes, and switching valves. He also does most of the daytime cleanup in the production area and draws four water samples once a shift. The samples are sent to the laboratory for routine testing.

The coke-cutting group is made up of the driller, the first and second helpers, and the crane operator. This group works independently of the operations crew. They report for work about 30 minutes before a drum is scheduled to be cut, work until the cutting and cleanup is finished, shower, and leave; this usually takes 5 to 6 hours. The total work group consists of five to six drillers and helpers, and two crane operators.

- Drizzer: Spends about 15 minutes opening the top of the drum and 15 minutes opening the bottom. He then goes back to the top to the "penthouse" where he controls the drilling operation. He usually stays there during the entire cutting operation except for breaks. He helps to close the drum when the operation is completed.

- First Helper: Helps to open the top and the bottom of the drum, and to get the chute in place. While the cutting is being done, he cleans up loose coke with a water hose, and lubricates and prepares all fittings for reassembly.

- Second Helper: Duties similar to those of first helper.

- Crane Operator: Spends most of the shift in the crane cab, moving the coke from the trough to the adjacent truck-loading area. The crane cab is usually open in front. The crane is normally upwind of the cutting operation and trough.

\section{Control Measures}

The coke-cutting operation is one of the few in a refinery that is not a closed system. Because of this, it is more difficult to minimize worker exposure during this operation. During every cutting cycle, the top and bottom of the drum must be opened manually, the coke must be cut by the driller, the helpers must clean and lubricate the fittings, and the crane operator must move the coke out of the trough. Basically, the coke-cutting operations at this refinery were similar to those observed at other refineries; however, there were several key points observed.

The opening of the top and bottom of the drum was done very efficiently and quickly. The three cutters (the driller and two helpers) worked as a team to complete both openings in about 30 minutes. After the bottom is dropped, a chute extender is lifted up from the floor platform to the bottom of the drum and secured with several bolts. This forms a closed system on this level where the helpers spend a good part of their time during the operation. 
The penthouse on the top level and the bottom of the drum on the second level were fairly open areas minimizing accumulation of vapors. In the penthouse, the driller was seated so that he was normally upwind of the top of the drum. The whole cutting operation at this refinery was relatively clean, requiring a minimum of cleanup, usually performed by hosing down the area with water.

A11 workers on this unit wore hard hats, safety glasses, and gloves. Neither the cutters nor the operational crew wore coveralls, but the cutters did normally change into a set of work clothes in the locker room and showered or washed up at the end of their shift. The operations crew ate in the control room, whereas the cutters did not stop to eat. There were no routine operations that required the use of respirators; however, air-purifying and self-contained, breathing-air respirators were available.

The air-conditioned control room was not under positive-pressure ventilation but was normally upwind of the coke tower, furnace, and furnace charge pump. This refinery management is considering changing to one main control room in the future.

The steam that is used to cool the drums down is normally sent through a water-scrubbing system before it is vented to the atmosphere. There is a flare on the west side of the unit that is available for turnarounds or any other conditions that might require it.

Asphalt Processing Unit

Unit and Process Description

The asphalt-blowing unit is a small (approximately 80 by 40 feet) and relatively simple unit in terms of process flow and equipment. The main structures are two towers located side by side, one being the blowing still and the other the water scrubber for the still vent gases. The unit is located between the \#2 crude and vacuum units, and the delayed coker unit. The gasfired FCCU charge heater is next to the unit, just to the east. This unit does not have its own control room; its control board is part of the \#2 crude unit control room located about 75 feet from the blowing tower.

During normal operations, part of the bottoms from the \#2 vacuum tower is pumped to the blow still. Here, a stream of air is blown through the tower oxidizing the heavy residue material. The vent gas is then sent through the adjacent water scrubber and burned in the FCCU charge heater. The blowing process increases the hardness and melting temperature of the asphalt product. After the desired penetration grade is achieved, the asphalt is pumped to storage tanks. The average production of blown asphalt is $500 \mathrm{bbl} / \mathrm{day}$; however, the actual blowing process was not in operation during the survey. The asphalt from the vacuum tower was being pumped through the blow still to the storage tanks without being blown. This is normal procedure when the asphalt tanks are full, or if the market does not demand additional asphalt production.

Work Force

No workers are assigned full time to the asphalt-blowing unit. Two outside operators who have primary responsibility on the \#1 crude unit handle the routine operations for this unit. 


\section{REFINERY B}

\section{DESCRIPTION OF REFINERY B}

Refinery B is a "medium" (95,000 bbl/day), "major" refinery located in eastern OKlahoma along the bank of the Arkansas River. The refinery, which was built in 1913, is spread out over approximately 750 acres and at the dates of the surveys was processing about 88,000 barrels of crude a day. A full line of petroleum products is produced including:
- propane
- butane
- gasolines
- jet fule
- fuel oils (\#1 and \#2)
- asphalt
- lube oils
- waxes
- kerosene
- Diesel fuel
- petrochemicals (benzene, xylene,
- coke
toluene, cyclohexane)

This refinery produces over 300 different types of waxes and is also one of the largest producers of lube oils.

The crude refined here, which is primarily domestic, is categorized as a "sweet" ( $0.2 \%$ sulfur by weight), "mixed base" (containing both paraffins and naphthenes) crude with an API Gravity Index of about 40 . A11 of the crude, which originates from OKlahoma, Texas, and a small percentage from foreign sources, is received by pipeline. Most of the gasolines and fuel oils produced is shipped by pipeline with trucks and railcars also being used, especially for coke and asphalt.

The major process units at refinery $B$ include:
- crude distillation unit
- delayed coker
- continuous asphalt blower
- unifiner
- catalytic reformer
- catalytic isomerization unit

- FCCU

- $\mathrm{HF}$ and $\mathrm{H}_{2} \mathrm{SO}_{4}$ alkylation units

- Tube extraction and hydrogenation units

- propane deasphalting unit

Almost every major process unit has its own control room. Figure $\mathrm{C}-4$ shows a rough refinery plot plan of the major units.

There are approximately 850 employees including maintenance and administrative personnel. Most of the routine maintenance activity is performed inhouse; contractors are brought in for turnarounds and other major maintenance work. The production units operate 24 hours a day over three work shifts, 7 days a week. 

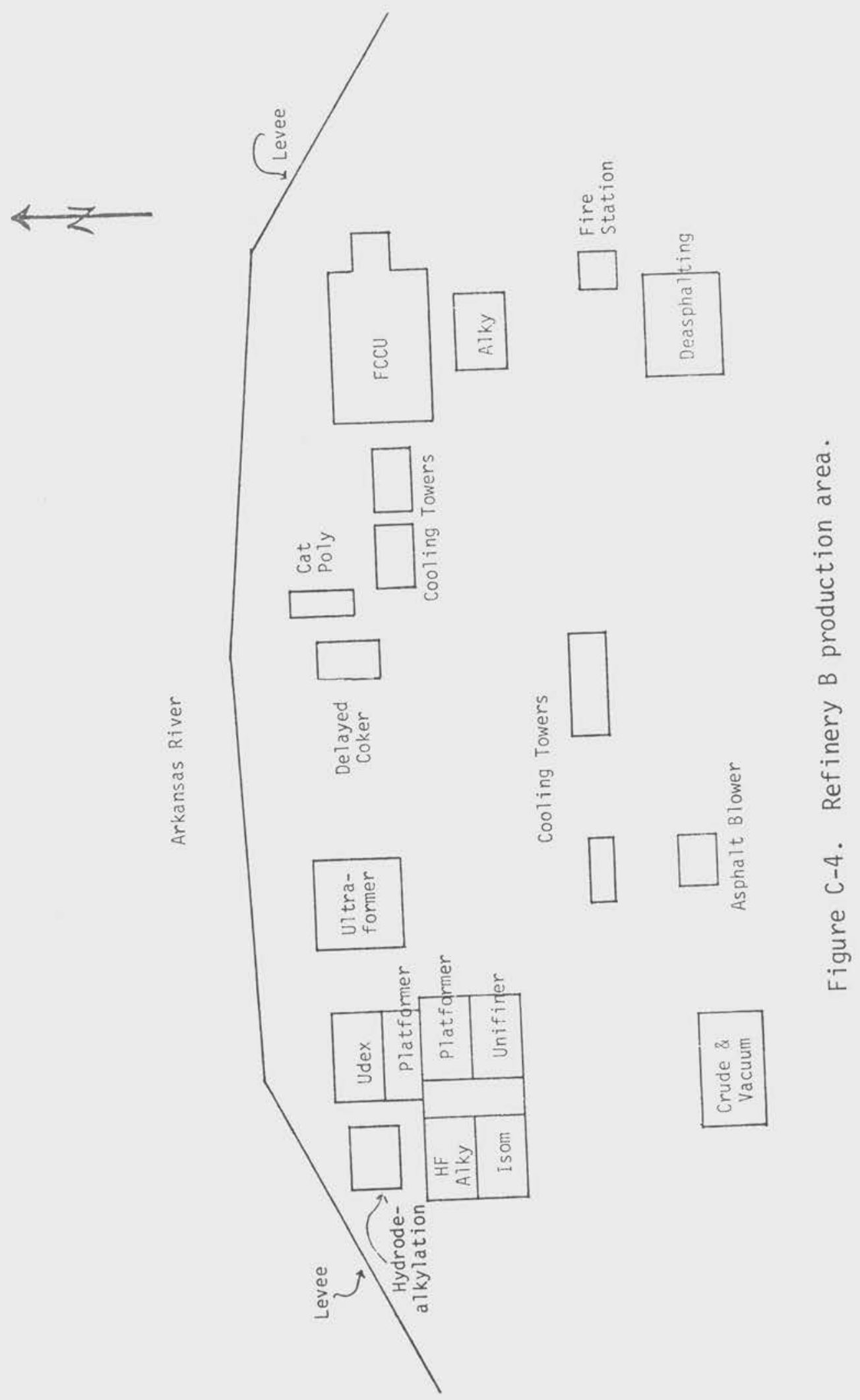

C -12 
The supervisor of personnel and safety heads a refinery safety department that includes:
- a supervisor of fire and safety
- a safety engineer
- four fire marshals
- a chief safety inspector

Although routine industrial hygiene sampling is not performed at this refinery, the safety engineer who is responsible for industrial hygiene is currently developing a sampling program. The corporate industrial hygienist also occasionally performs sampling at this refinery.

As part of good industrial hygiene practice, the use of protective clothing and equipment (e.g., hard hats, safety shoes, gloves, eye protection) is emphasized. Although eating is allowed in most control rooms, smoking is permitted only in designated areas away from the production units. Each unit operator is thoroughly trained on the unit equipment, operations, and associated safety hazards. The practice of good personal hygiene such as the washing of hands before eating is also encouraged. Good unit housekeeping is practiced as an important means of minimizing worker exposure to potential hazards. Spills are promptly cleaned up by the unit operators, and any necessary equipment or structure repair is also promptly carried out by the unit operators or in-house maintenance crews.

There is a medical doctor on the premises 5 days a week from 0900 to 1700 and two nurses 5 days a week, one from 0600 to 1400 and the other from 0900 to 1800. The fire department personnel are trained in first aid for periods when the doctor or nurses are not on duty. All of the production workers are given preplacement medical examinations, and annual examinations are available.

\section{STUDY PROCESS UNITS AT REFINERY B}

Fluid Catalytic Cracker Unit (FCCU)

\section{Unit and Process Description}

The FCCU is located in the northeast section of the main production area (Figure C-4), about 600 feet east of the delayed coker and polymerization units and just north of the No. 1 alkylation unit. A levee runs along the north and northeast boundaries, protecting the unit and the refinery from the Arkansas River. This FCCU was built in 1949, and the CO boiler was added in 1964. Several other modifications have been made, such as adding the various cyclones for the regenerator flue gas. The current production capacity of this unit is about 30,000 bbl/day.

Figure $C-5$ illustrates the layout of this unit which occupies an area about 400 by 225 feet. The side-by-side R/R structure is located east of the fractionator and control room. The catalyst storage and CO boiler are located east of the R/R structure. The main pump area is located just north of the control room building, and the gas recovery area is located farther west. 


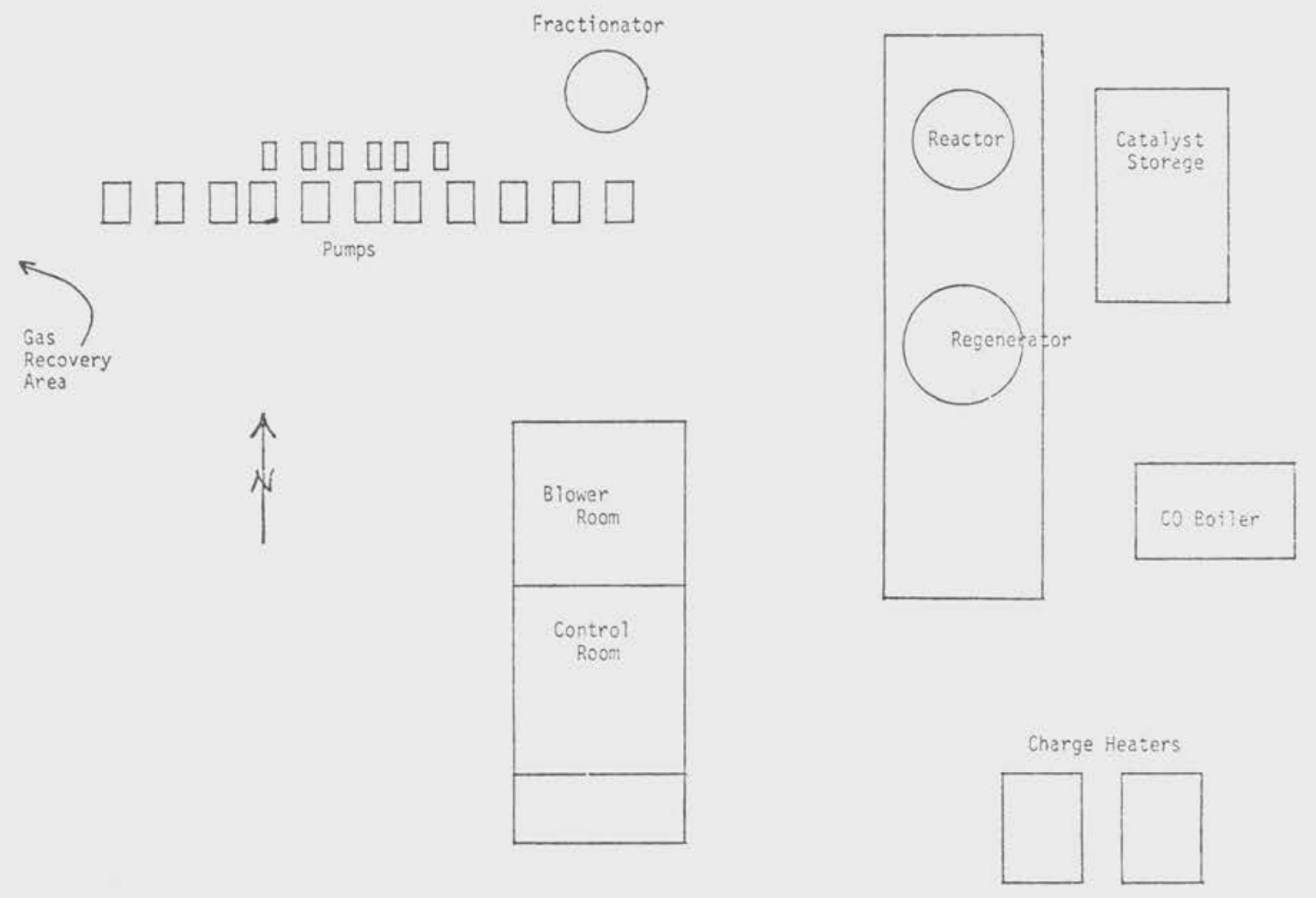

Figure C-5. Refinery B FCCU.

Fresh feed for the FCCU consists of soft wax from the lube oil dewaxing plants, low-pressure distillate from the coker unit, and atmospheric and vacuum gas oils. This feed, preheated by one of the two gas-fired charge heaters (light and heavy charge heaters), plus heavy gas oil and slurry recycle from the fractionator are mixed with the hot catalyst in the two risers leading to the reactor. The catalytic cracking takes place in the risers as well as in the reactor. The catalyst used at this refinery is a synthetic zeolite common to other FCCUs studied in this project. The product vapors and the catalyst are separated (series of cyclones), and the hydrocarbons are taken to the fractionator tower. The catalyst is stripped with steam of any remaining oil and delivered to the regenerator through the "spent catalyst leg." In the regenerator, the catalyst is reactivated by oxidizing the accumulated carbon at a temperature above $1,000^{\circ} \mathrm{F}\left(538^{\circ} \mathrm{C}\right)$. The flue gas from the regenerator goes through a third-stage cyclone to remove catalyst fines and then to the co boiler where it is burned before being released into the atmosphere. The regenerated catalyst is stripped with steam of any absorbed oxygen before being recirculated back to one of the two risers.

The main products from the fractionator are:
- propane
- butane
- gasoline
- olefin feed for the alkylation units C- 14

- light cat cycle oil

- heavy cat cycle oil

- decanted oil 
There are at least five workers assigned to the FCCU full time during each shift. These include the chief process operator (CPO), two control room operators, and at least two (outside) process operators. Normally, there are one or two additional process operators to assist in the outside operations. During both surveys, there was one additional process operator, making a total work force of six per day shift. Following is a brief description of the duties of these six full-time shift personnel.

- Chief Process Operator (CPO): Supervises the overall unit operations. The CPO normally spends the majority of his shift outside the control room, providing direction and assistance to the other operators in both the bas recovery and the main production areas of the unit.

- Control Room Process Operators (2): Both spend essentially $100 \%$ of their shift inside, monitoring and logging in the various meters and charts on the control board. They work closely with the CPO and other process operators to ensure smooth operating conditions.

- (Outside) Process Operators (3): One process operator is responsible for the CO boiler, R/R structure, and the fractionator; another is responsible for the gas recovery side, which includes the absorber, stripper, deethanizer, air blowers, and compressors; and the third is designated a roving process operator responsible for providing overlap coverage to the other two. They spend 80$90 \%$ of their shift outside in the production area. Every 4 hours (twice/shift), they make complete rounds of their respective areas for meter and gauge readings and visual inspection. The quality of the catalyst is checked twice per shift, and process stream samples are usually collected during the day shift.

\section{Exposure Control Measures}

The exposure control measures used at this FCCU are quite typical of those observed at the other FCCUs studied during this project. The primary control measure is a closed-system process which limits exposure to products, by-products, and intermediates. Important also is a well-organized maintenance program that provides both efficient preventive and repair maintenance services. Under normal operating conditions, exposure to PAHs may occur from sampling of the various streams, maintenance and housekeeping activities, fugitive emissions, and the regenerator flue gas.

Process stream samples are normally collected once a day (day shift) for the light and heavy oil charge, decanted oil, slurry recycle, light cat cycle oil, and low-pressure distillate. The spigot-and-bottle method is used with sampling loops which eliminate the flushing of lines. The samples are taken to the laboratory for analysis. 
Exposure during routine maintenance is difficult to minimize. The ground level of the unit is constructed of concrete, and the pump area has a sewer system which simplifies cleanup procedures. The refinery has its own craft maintenance crews (e.g., pipefitters, electricians) that provide preventive and repair services. The last major turnaround for this unit was in the middle of 1978. Hard hats, safety shoes, and rubber gloves with cotton linings are worn routinely by workers at this unit. Safety glasses are furnished by the company and used on a voluntary basis. Coveralls are not provided and are not normally worn. Ear protection is used in the compressor room and the fractionator/pump area. There are no routine operations which require the usage of respirators; however, NIOSH-approved air-purifying and self-contained, breathing-air respirators are available. These respirators are maintained by the refinery safety department.

The areas of the unit handling heavy fractions, which are more likely to contain the PAHs, are in fairly open areas, minimizing potential vapor accumulation. Several of the heavy gas oil, slurry recycle, and decanted oil pumps are located very close together near the fractionator tower. This is an area where PAH concentrations might be elevated. The air-conditioned control room, which is not under positive pressure, is occasionally downwind of the R/R or heavy fraction pumps.

The flue gas from the regenerator goes through a series of cyclones to remove catalyst fumes and is then burned in the CO boiler with an auxiliary fuel. The $\mathrm{CO}$ boiler removes not only carbon monoxide from the flue gas, but also many hydrocarbons, making the effluent suitable for discharge to the atmosphere.

Delayed Coker Unit

\section{Unit and Process Description}

The delayed coker unit, as shown in Figure $\mathrm{C}-4$, is located on the northern edge of the refinery near the river and levee. Several units including a catalytic reformer, two platformers, an HF alkylation, and an isomerization unit are within 200 yards to the west. Just to the east is the catalytic polymerization unit, and to the south are numerous small storage tanks. This coker unit has two 100-foot drums with a daily production capacity of about 200 tons.

The unit, which was built around 1955, is spread over an area of about 300 by 225 feet (Figure $C-6$ ). The ground level of the majority of the unit is constructed of concrete. The air-conditioned control room is part of a larger one-story brick building used for storage and light maintenance; this control room is also used for the polymerization unit located just to the east. The locker and shower facilities, used primarily by the coke cutters, are located in a separate, small brick building on the south side of the coker tower. The coker tower is an open, multilevel structure which includes the two drums, an elevator, and the penthouse at the top. Railroad cars can be positioned directly beneath the bottoms of the drums to provide direct loading as the coke is cut. 


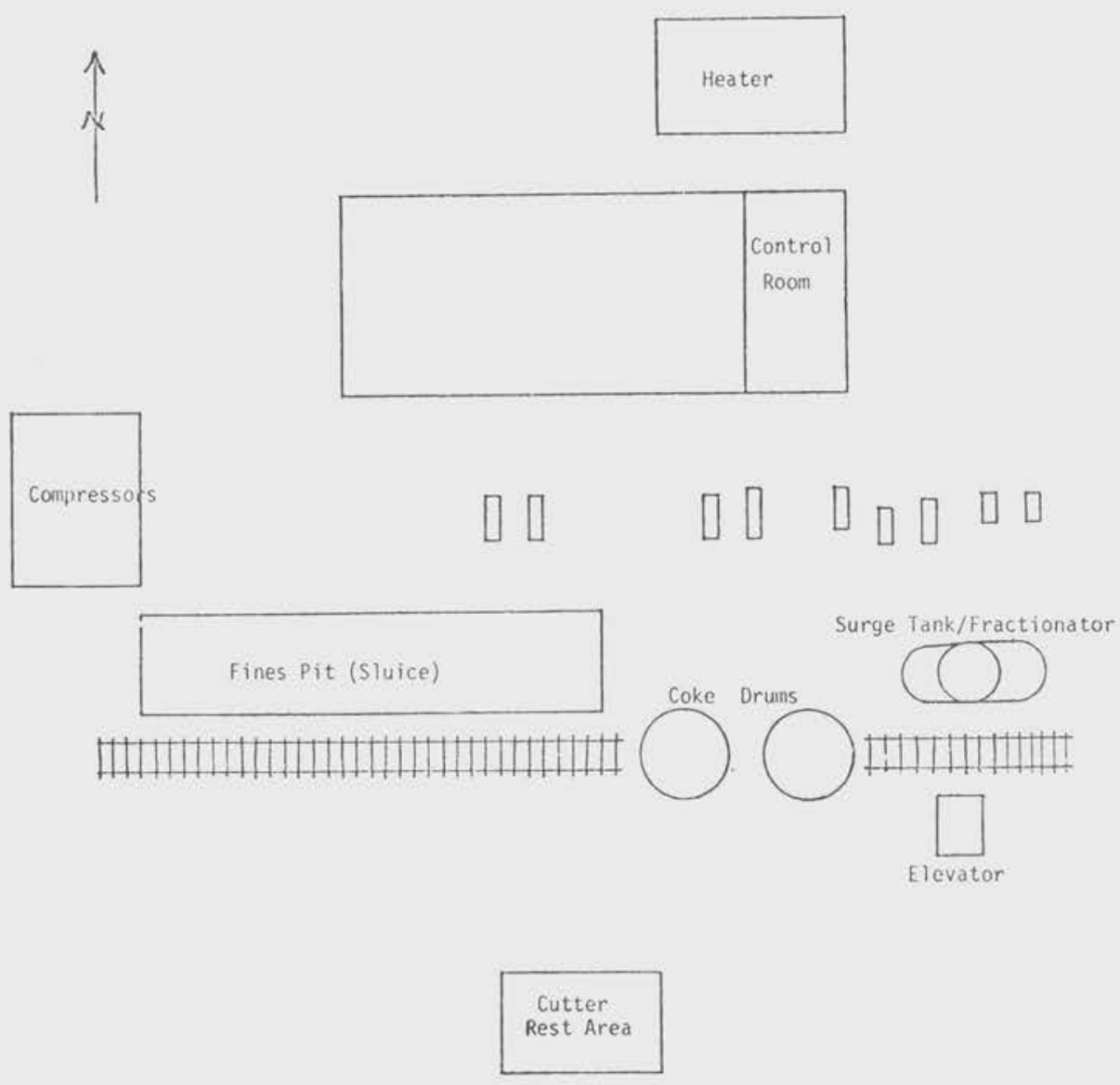

Figure C-6. Refinery B delayed coker unit.

The gas-fired charge furnace is located just to the north of the control room, and the fractionator near the coke drums just to the south. The quench tank (not on Figure C-6) for condensing the steam from the steam-out operation is located south of the elevator.

"Sponge" or \#2 grade coke is the only type of coke produced at this unit. The charge stock is made up of bottoms from the deasphalting and vacuum units. The incoming charge goes either to the feed surge drum where it is stored until needed, or to the fractionator. Prior to going to the fractionator, the charge can pass through the gas-fired preheat furnace if necessary. The light ends are flashed off in the fractionator and eventually go to the FCCU gas recovery. The bottoms from the fractionator are pumped through the convection and radiant sections of the furnace, heating the charge to about $900^{\circ} \mathrm{F}\left(482^{\circ} \mathrm{C}\right)$. The charge then goes to one of the two coking drums. Each drum has a 48-hour cycle, with coke formation lasting about 24 hours. Since the drums work as a pair, cutting of one drum occurs every 24 hours (about 0700 every morning). The lighter vapor fractions of the thermal cracking operation are removed from the top of the drum and sent to the fractionator where the various products are separated and eventually recovered. Besides coke, products from this unit include gasoline, overhead gases, unstabilized gasoline, and gas oil. 
The complete cycle of each drum, from heating to cutting, is 48 hours. About 9 hours before the cutting operation is scheduled, coke formation is stopped by switching the feed to the other drum. In 30 minutes, steam is introduced into the drum to cool it; this lasts about 5 hours, and then water is added to further cool the drum. Nine hours after the feed is switched, the top and bottom of the drum are opened, and an initial hole is bored through the coke from the top with a high-pressure hydraulic bit $(>2,000 \mathrm{psi})$. The bit is changed to a revolving-head type, and the coke is cut from the bottom up. The coke falls directly into a railcar stationed below the drum bottom. A motorized winch is used to move the car to ensure even loading. The actual boring and drilling lasts from 3 to 4 hours.

After cutting is completed, the top and bottom of the drum are replaced; the drum is pressure-tested for seal, heated, and is ready, when the feed is switched from the other drum, to begin coke formation.

\section{Work Force}

The work force for the coker unit is divided into two groups-the operations group and the coke-cutting group. The two-person operations group works the normal 8-hour shift; following is a brief description of their job activities.

- Chief Process Operator (CPO): Is in charge of the overall unit operations. The CPO normally spends 1 to 2 hours per shift outside, checking equipment or making visual inspection of the unit. The CPO can assist the process operator in tasks that require two, such as troubleshooting. Most of the inside time is spent performing normal board operator tasks.

- Process Operator: Performs most of the routine outside tasks such as visual inspection, meter and gauge readings, valve switching, steam pressure-testing of coke drums, starting and shutting down pumps, lubricating and oiling pumps and compressors, and sample collecting (fresh feed, gas oil, and slop samples once per shift). The process operator spends almost all of the shift outside.

The coke-cutting group is normally made up of the head cutter and two helpers, with one of the three performing drilling each cutting shift. During this survey, there was an additional helper being trained. This group works only during the day shift and is responsible for cutting and cleanup operations. Cutting normally takes 3 to 4 hours; cleanup takes an additional 2 hours.

- Head Cutter: Is in charge of the coke-cutting operation. He performs the drilling or assists the helper. During this survey, he was training a new helper and spent all of his shift below at ground level.

- Helpers: When acting as the driller (as during this survey), one helper spends 30 to 40 minutes helping to open the top and bottom of the drum and then goes to the penthouse at the top where he operates the drilling controls. It takes about 40 minutes to 
make the initial "bore through" and then the bit is switched for the actual cutting, which lasts about 3 hours more. He then helps in closing the drum and in general cleanup operations. The nondriller helper(s) assists with opening and closing the drum and positioning the sleeve at the drum bottom. During the rest of the cutting operations, the helpers are below on the ground level or on the first level of the coke tower structure. One helper is positioned in a three-sided shelter open to, and level with, the top of the railcar. From here, he regulates movement of the cars (by motorized winch) to allow even loading of the cars. Another helper is also on this level using a long pole to help distribute the accumulating coke evenly. Cleanup is ongoing during cutting, but everyone helps once the cutting is completed. Large coke pieces on the ground are either picked up or shoveled, and the whole area is hosed down to wash smaller coke particles down into the sluice (fines pit).

At the beginning of the day shift, the coke cutters will often report to the control rooms; however, they rarely go back during the shift. They change and shower in their separate locker room building and eat their lunch there. Smoke breaks are taken in an area to the north of the unit.

\section{Control Measures}

The coke-cutting operation is one of the few in a refinery that is not a closed system; consequently, it is more difficult to minimize worker exposure during this operation. During every cutting cycle, the top and bottom of the drum must be opened manually; the coke must be cut by the driller; and the helpers must clean and prepare the fittings and, at this particular unit, ensure that the railcars are properly loaded, and clean up the coke tower structure and ground area. There are several important advantages and disadvantages concerning worker exposure associated with cutting the coke directly into railcars.

This method using railcars eliminates the need for cranes and any other type of loading equipment such as front-end loaders and trucks. However, this method requires that at least one of the helpers be stationed at the drum bottom area to ensure proper railcar loading. This worker(s) is in very close proximity to the falling coke, splashing water, and water mist. The coke at this point has been cooled, and hydrocarbon vapor is not likely. Exposure is more likely to be dermal and to coke particulates.

The opening of the top and bottom of the drum was done efficiently and quickly. The head cutter and two helpers worked as a team to complete both openings in about 40 minutes. After the bottom is dropped, a metal sleeve is positioned directly under the bottom of the drum. This forms a more closed system on this level where the helpers spend a good part of their time during the operation.

The penthouse on the top level is a relatively enclosed one-room building ( 10 by 20 feet) where the driller operates the overhead drills. There are two circular openings in the roof and several windows; however, natural ventilation did not appear to be good. 
Direct loading of railcars normally requires considerable cleanup at the end of each cutting, as was the case at this unit. The tracks have to be cleared of the large coke chunks, and the entire ground area must be hosed down. This takes up to 2 hours.

A11 workers on this unit wore hard hats, safety shoes, and rubber gloves with cotton lining. Coveralls were not provided by the employer; normally, the cutters put on a jacket or other type of outer clothing in the locker room and showered or washed up at the end of their shift. There were no routine operations that required the use of respirators; however, NIOSHapproved air-purifying and self-contained, breathing-air respirators were available. The operations crew ate in the control room; the cutters ate and rested in their separate building. Both the control room and the building used by the cutters were air-conditioned but not under positive pressure. Because of the changing wind direction, these buildings are occasionally downwind of the coke drums or pumps.

The steam that is used to cool the drums is sent through a quench tank before it is vented to the atmosphere. A flare is available for turnarounds or any other conditions that might require it.

Deasphalting Unit

\section{Unit and Process Description}

The propane deasphalting unit (PDA), as shown in Figure $\mathrm{C}-4$, is just south of the fire station and about 150 yards south of the No. 1 alkylation unit. It is also about 300 yards east of the asphalt-blowing unit. The PDA has two deasphalting towers in the northeast corner of the unit, and has a production capacity of about 5,000 barrels of asphalt per day.

This unit, which is approximately 20 years old, is spread out over an area of about 250 by 150 feet (Figure C-7). The propane storage tanks are 10cated in the southwest corner; just to the east is the air-conditioned control room, which is part of a larger one-story building housing compressor and pump rooms. There are three gas-fired furnaces, in the southeast corner of the unit near the asphalt and oil flash towers. The ground level of the entire unit is constructed of concrete.

There are two separate deasphalting processes within this one unit. One process (designated " $A$ " for this report) yields a larger percentage of asphalt than oil. The asphalt is used for asphalt blowing and coke production, and most of the gas oil is used for FCCU charge. The second process (designated "B") yields a smaller percentage of asphalt than oil; the asphalt is sent to the coker, and the oil produced is used for lube oil and wax production. 


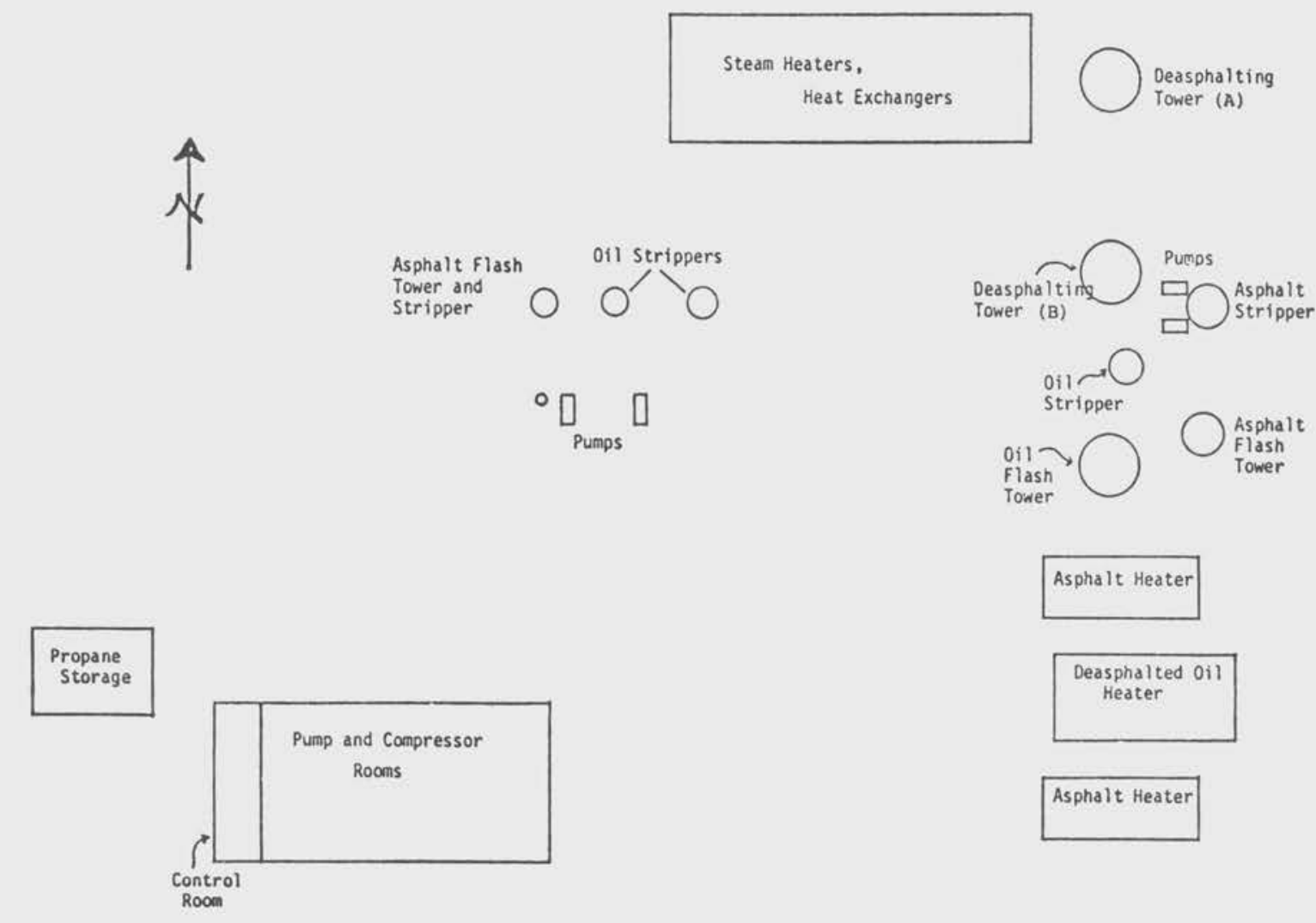

Figure C-7. Refinery B deasphalting unit.

The feed stock for this unit is reduced crude from the crude unit. The feed is steam-heated to operating temperature and fed to the center of the deasphalting towers. Here it comes in contact with liquid propane which has also been steam-heated, and the liquid-liquid extraction process takes place. Asphalt is removed from the bottom of the reactors, and the extracted oil (and propane) are removed from the top. The asphalt from both towers passes through separate gas-fired heaters and then to flash drums where most of the propane is removed. The asphalt then goes to the steam strippers to remove any remaining propane, and then is pumped to the asphalt blower or coker units.

The oil-propane phase from the " $A$ " deasphalting tower is heated and sent to the oil flash tower, where much of the propane is vaporized by indirect steam-heating. The remaining propane is removed from the oil by steamstripping in the oil stripper. This gas oil is pumped to storage tanks until needed as FCCU charge.

The oil-propane phase from the " $B$ " deasphalting tower undergoes a more involved process to separate the propane and oil. There are a series of compressors, settlers, and strippers that separate the oil for use in the lube and wax units. 
Work Force

Three workers are assigned to this unit per shift, including one inside board operator and two outside operators. Job duties are typical of inside and outside operators on totally enclosed, continuous process units.

Asphalt Blowing Unit

Unit and Process Description

The asphalt blowing unit is located about 100 yards east of the crude unit and 100 yards south of a series of cooling towers. There are two blowing towers, side by side, with a maximum capacity of about 6,000 barrels of blown asphalt per day. Normal production ranges from 1,000 to 4,800 barrels per day.

The unit was converted in 1962 from oil distillation stills to the blowing towers. The unit (Figure $\mathrm{C}-8$ ) is a relatively small, simple unit with main structures that include a small brick control building, the two blowing towers, and a thermal oxidizer unit (incinerator) which was added in 1978 to help control the emissions from the towers. The unit work surface is gravel.

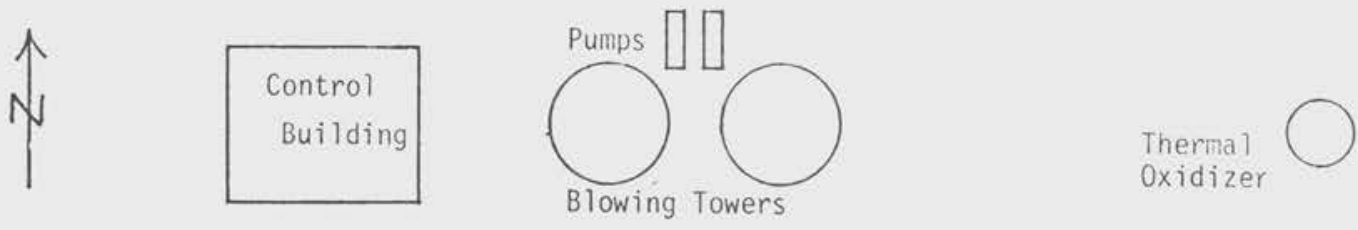

Figure C-8. Refinery B asphalt blowing unit.

The feed to the blowing towers comes from the deasphalting unit and enters the vertical vessels in the upper half at two or three points. The compressed air passes through a knockout drum, to remove any entrained mist and particulates, and is discharged into the bottom of the towers. The blown asphalt is pumped to storage tanks.

Work Force

This unit requires only two workers per shift, one inside control board operator and one outside operator. 


\section{REFINERY C}

\section{DESCRIPTION OF REFINERY C}

Refinery C is a "large" ( 185,000 bbl/day), "nonmajor" refinery located on the Gulf Coast of Texas. The refinery originated in the 1940 s and was purchased by the current company in 1962, when its capacity was 35,000 bbl/day. At the time of the survey, the refinery was spread over 200 acres, processing over 150,000 barrels of crude a day, and producing a full line of petroleum products which includes:

$\begin{array}{ll}\text { - propane } & \text { - \#2 fuel oil } \\ \text { - butane } & \text { \#2 (sponge) coke } \\ \text { - gasolines } & \text { asphalt } \\ \text { - Diesel fuel } & \text { - pulfur } \\ \text { Detrochemicals (benzene, xylene) }\end{array}$

The Middle Eastern (e.g., Iran, Iraq) crude refined here is a high-sulfur ( $2.15 \%$ sulfur by weight), "mixed base" (containing both paraffins and naphthenes) crude with an API Gravity Index of about 33. The crude is received by pipeline and tankers. The products are shipped by pipeline, barges, ships, and trucks.

The major process units at Refinery $C$ include:

- three crude distillation units

- two vacuum distillation units

- FCCU

- three catalytic reformers

- HF alkylation unit

- delayed coker
- benzene, cumene unit

- hydrodealkylation unit (Hydeal)

- two light ends units (LEUs)

- sulfur unit

- hydrodesulfurization units (HDS)

These units are divided into two main production areas designed "east" and "west" and are about one-third of a mile apart. Most of the refinery's sulfur processing is performed in the "west" area. Figures C-9 and C-10 show rough refinery plot plans of each section. Most units, with the exception of the FCCU, do not have their own control building; two to four units normally share a centrally located control building.

There are approximately 400 employees, including maintenance and administrative personnel. Most of the routine maintenance activity is performed inhouse; contractors are brought in for turnarounds and other major maintenance work. The production units operate 24 hours a day over three work shift, 7 days a week.

The safety and health staff at this refinery consists of the safety, security, and fire protection department which includes the supervisor and four safety marshals; the environmental laboratory group made up of the lead environmental engineer, the special projects chemist, and four laboratory 

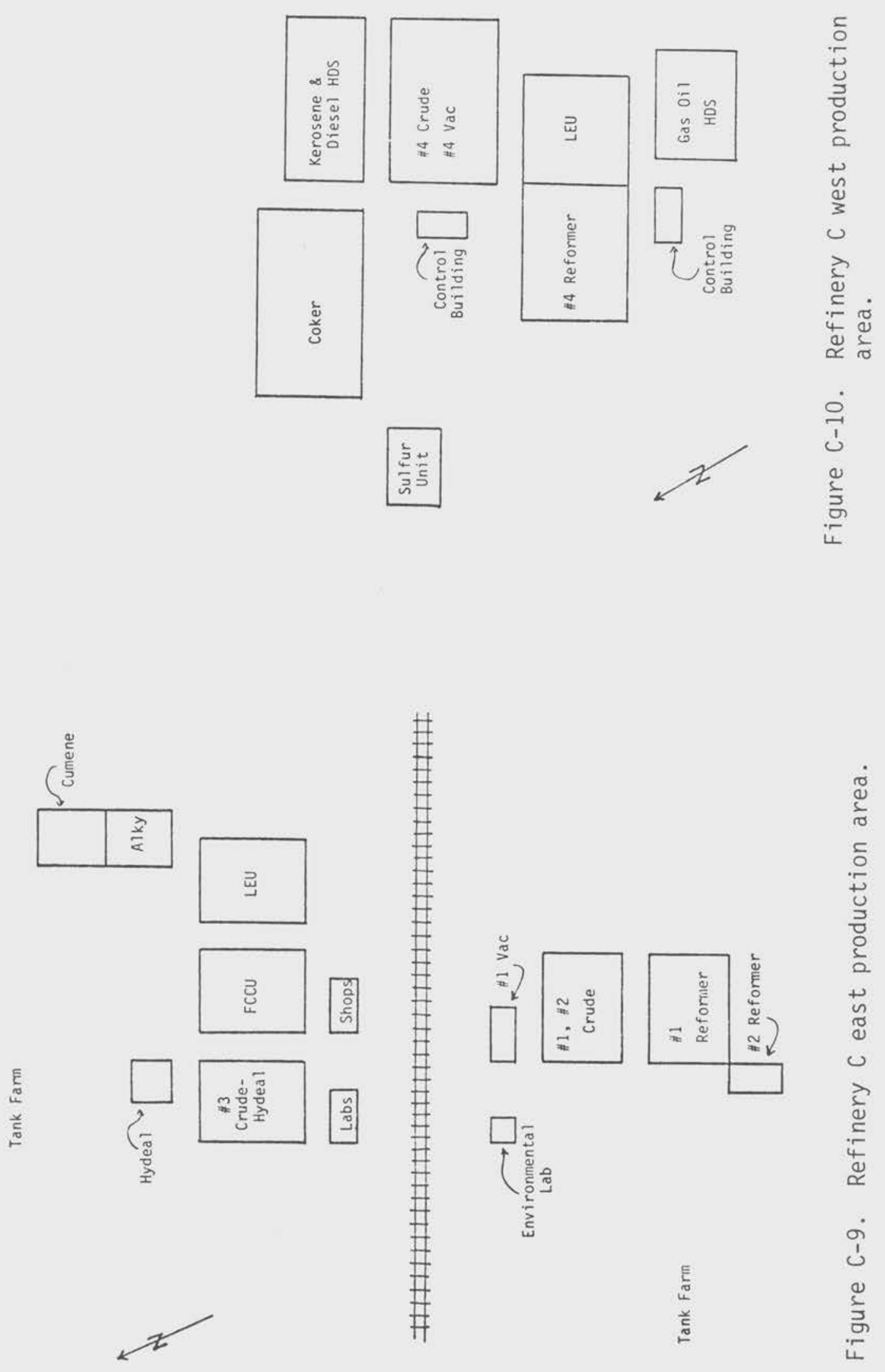
technicians. The safety department staff as well as a number of other refinery personnel are trained in first aid and cardiopulmonary resuscitation. There is also a company physician on retainer. All of the production workers are given preplacement medical examinations, and annual periodic examinations are made available. Although routine industrial hygiene sampling is not performed at this refinery, the special projects chemist is responsible for any sampling required for compliance purposes.

As part of good industrial hygiene practice, the use of protective clothing and equipment (e.g., hard hats, safety shoes, gloves, eye protection) is emphasized. Whereas eating is allowed in most control rooms, smoking is permitted only in designated areas away from the production units. All new employees attend an extensive training session over a 3-week period which includes information on unit equipment, operations, respirator use, safety hazards, fire protection, and first aid. The practice of good personal hygiene such as the washing of hands before eating is also encouraged. Good unit housekeeping is practiced as an important means of minimizing worker exposure to potential hazards. Spills are promptly cleaned up by the unit operators, and any necessary equipment or structure repair is promptly carried out by the unit operators or in-house maintenance crews

\section{STUDY PROCESS UNITS AT REFINERY C}

Fluid Catalytic Cracker Unit (FCCU)

\section{Unit and Process Description}

The FCCU is located in the northern section of the refinery's east production area (Figure C-9) between the light ends unit (LEU) and the No. 3 crude and No. 1 hydeal units. The present FCCU was built in 1963; there have been three major modifications, primarily to the riser, increasing the unit's capacity which is currently about 20,000 bbl/day.

Figure C-11 illustrates the layout of this unit which occupies an area of about 300 by 200 feet. The stacked-type reactor/regenerator (R/R) structure is located south of the control room and north of the charge heater, CO boiler, and precipitator. The fractionator, with several heavy-fraction pumps around it, is located to the west of the $R / R$, and the gas recovery area is located just west of the control room. The No. 2 vacuum unit, which was not in operation during the survey, is situated in the southwest corner.

Fresh feed for the FCCU consists of atmospheric and vacuum gas oil ("raw oil"). This feed is preheated by the gas-fired charge heater or goes to the raw oil drum for temporary storage. The hot charge plus slurry recycle from the fractionator are mixed with the hot catalyst in the riser leading to the reactor. The catalytic cracking takes place in the riser as well as in the reactor. The catalyst used at this refinery is a synthetic zeolite common to other FCCUs studied in this project. The product vapors and the catalyst are separated by using a series of cyclones, and the hydrocarbons are transferred to the fractionator tower. The catalyst is stripped with steam of any remaining oil and delivered to the regenerator through the spent catalyst leg. In the regenerator, the catalyst is reactivated by oxidizing the 
accumulated carbon at a temperature above $1,000^{\circ} \mathrm{F}\left(538^{\circ} \mathrm{C}\right)$. The flue gas from the regenerator normally goes to the $\mathrm{CO}$ boiler where it is burned and is then passed through a precipitator to remove catalyst fines before being released into the atmosphere. The CO boiler and/or the precipitator can be bypassed under certain circumstances.

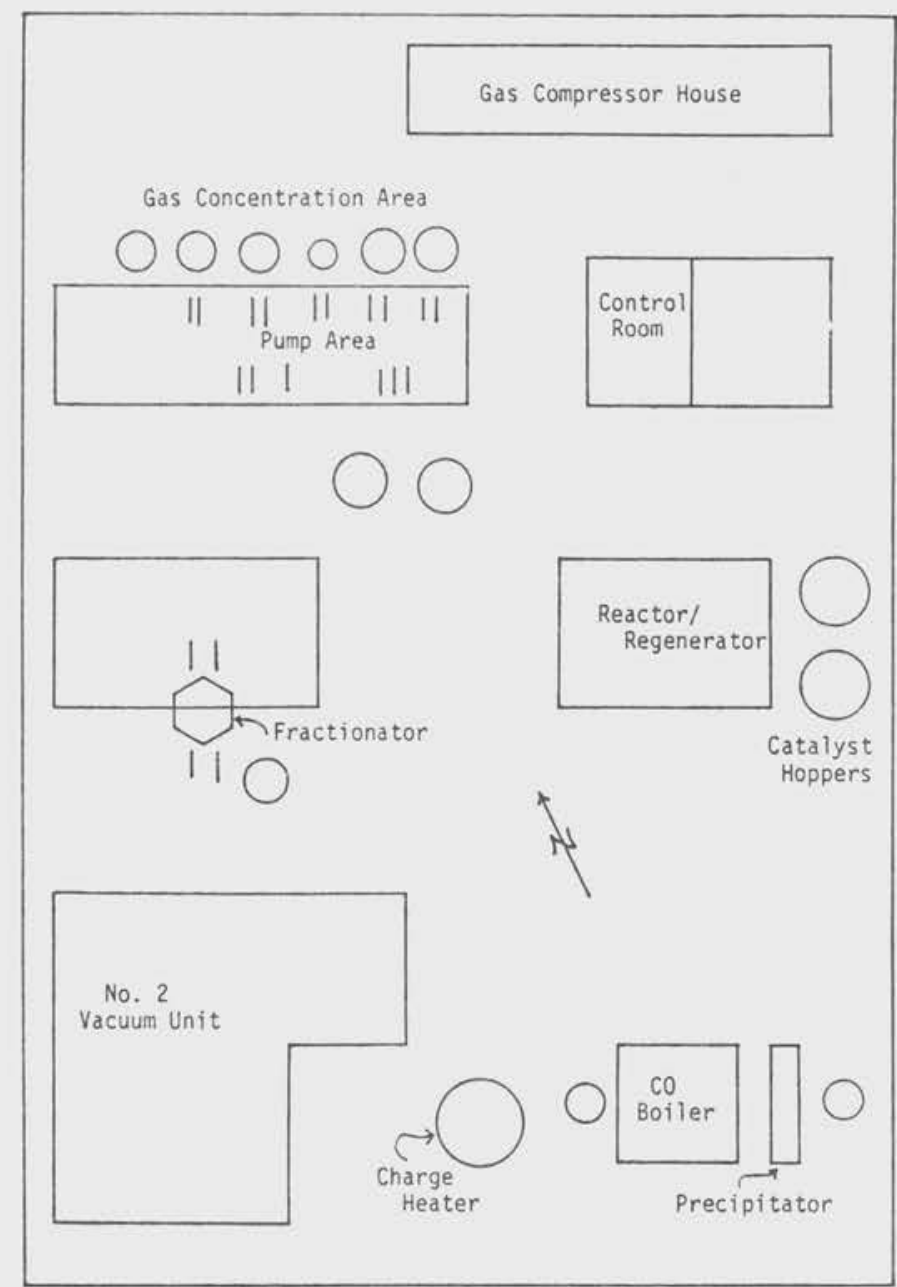

Figure C-11. Refinery C FCCU.

The main products from the fractionator are:

- propane
- butane
- gasoline
- light cat cycle oil

- heavy cat cycle oil

- clarified slurry 
There are normally four full-time workers assigned to the FCCU during each shift. In addition, there is a unit supervisor on duty during each day shift and on call 24 hours a day. Normally the unit supervisor does not spend a full shift at the FCCU; he may be at the maintenance and engineering building or at other refinery locations. Following is a brief description of the activities of the four full-time shift personnel.

- Lead Operator: Supervises routine unit operations, working closely with other operators as well as with the unit supervisor during the day shift. He spends about $50 \%$ of his time outside assisting and supervising other operators in all areas of the FCCU, the No. 2 vacuum unit (when in operation), and the LEU just to the east of the control building.

- Operator \#1 (Boardman): Spends essentially 100\% of his shift inside, monitoring and logging in various meters and charts on the control board. He works closely with the lead operator, as well as with other outside operators.

- Operator \#2 ("A" Helper): Performs routine outside duties for the $R / R$, fractionator, gas concentration, and vacuum unit areas. Periodically he takes meter and gauge readings, makes visual inspections, gauges tanks, monitors uptake of chemical additives, keeps pumps oiled, and maintains the unit by general housekeeping. He spends about $60 \%$ of his shift outside. Although most process stream samples are collected during the morning shift (2300-0700), the day-shift operators do collect a small number of liquid and gas samples (e.g., raw oil charge, light and heavy cat gas oils).

- Operator \#3 ("B" Helper): Performs routine outside duties for the LEU, the treating area, and the gas concentration area. Duties are similar to those of the A helper.

\section{Exposure Control Measures}

The exposure control measures used at this FCCU are quite typical of those observed at other FCCUs studied during this project. The primary control measure is a closed-system process which limits exposure to products, byproducts, and intermediates. Also important is a well-organized maintenance program that provides both efficient preventive and repair maintenance services. Under normal operating conditions, exposure to PAHs may occur during sampling of the various streams, during maintenance and housekeeping activities, from fugitive emissions, and from the regenerator flue gas.

Although most process stream samples are collected during the morning shift, some samples including heavy-fraction samples (e.g., raw oil charge, clarified slurry) are also collected during the other two shifts. Sample bombs are used only for gas samples; liquid samples are collected by the spigotand-bottle method with sampling loops that eliminate the flushing of lines. The samples are taken to the laboratory for analysis. 
Exposure during routine maintenance is difficult to minimize. The ground level of the entire unit is constructed of concrete with a sewer system; this simplifies cleanup procedures. The refinery has its own craft maintenance crews (e.g., pipefitters, electricians) that provide preventive and repair services. The last major turnaround for this unit was in February 1977.

Hard hats, safety shoes, and rubber gloves with cotton linings are routinely worn on this unit, and eye protection is available. There are no routine operations that require the use of respirators; however, air-purifying and self-contained, breathing-air respirators are available.

Areas of the unit handling heavy fractions, which are more likely to contain the PAHs, are in fairly open areas, minimizing potential vapor accumulation. Several of the heavy gas oil, slurry recycle, and raw oil pumps are located close together near the fractionator tower. This is an area where PAH concentrations might be elevated. The control room, which is not under positive-pressure ventilation, is seldom downwind of the R/R or heavy fraction pumps.

Flue gas from the regenerator is burned in the Co boiler with an auxiliary fuel. The heat produced here is used to generate steam. The co boiler removes many hydrocarbons as well as carbon monoxide from the flue gas, which then goes to an electrostatic precipitator to remove catalyst fines before the effluent is discharged through a stack into the atmosphere.

Delayed Coker Unit

\section{Unit and Process Description}

The delayed coking unit is one of about six process units located at the west production area of the refinery (Figure $\mathrm{C}-10$ ). The coker is surrounded by the kerosene and Diesel hydrodesulfurization (HDS) unit to the east, the No. 4 crude and vacuum units to the southeast, the control building to the south, the sulfur recovery unit to the west, and the refinery boundary to the north. This coker unit has two 80 -foot drums with a daily production capacity of about 450 tons of No. 2 or "sponge" coke.

The unit, built in 1972, is spread over an area of about 300 by 300 feet (Figure C-12). There are three main areas divided by two roads. The coker tower, railroad tracks and cars, water recycling, and blowdown drum are located in the north area of the unit. The coker tower is an open, multilevel structure that includes two drums, an elevator, and the penthouse at the top. Railroad cars can be positioned directly beneath the drums to provide direct loading as the coke is cut. Just to the south is the gas-fired charge furnace, the fractionating tower, and the gas-recovery area. The ground level is constructed of concrete. The air-conditioned control building is located farther south across another road. This control building is also used for the No. 4 crude and vacuum units, and the kerosene and Diesel HDS unit. 

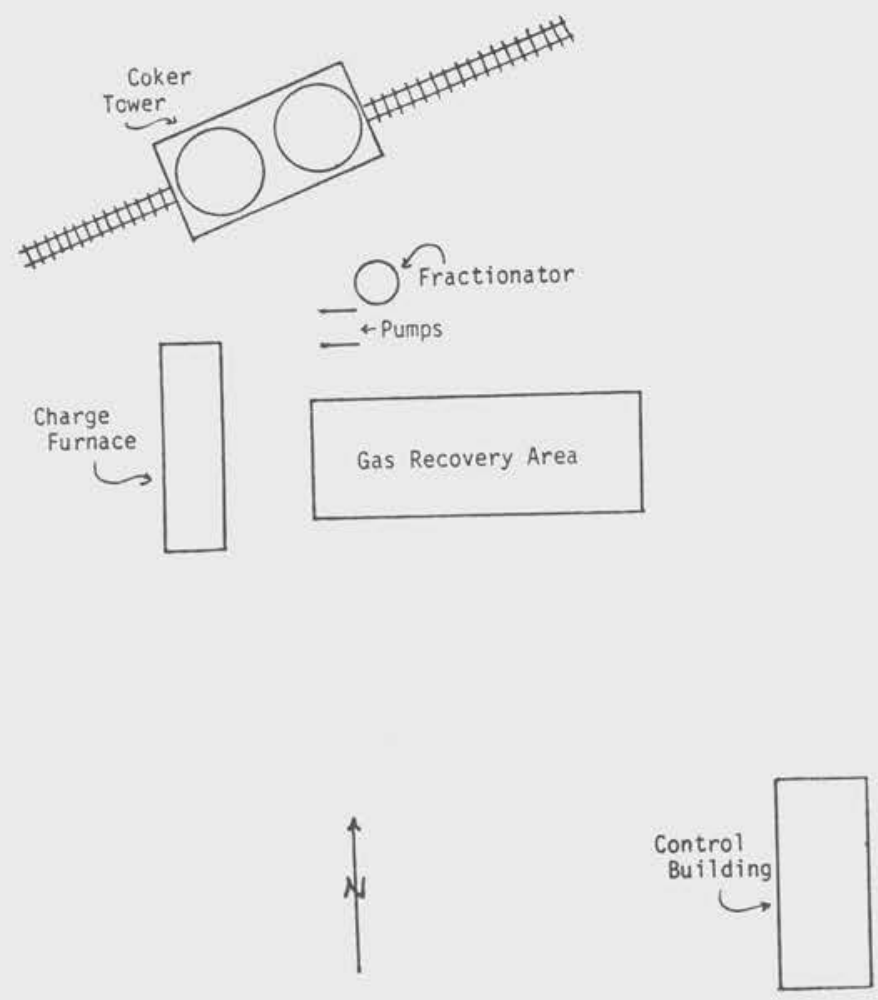

Figure $\mathrm{C}-12$. Refinery $\mathrm{C}$ delayed coker unit.

The coker charge stock comes from the vacuum units (bottoms) and storage tanks to the coker charge drum. From here, the charge is pumped to the convection section of the gas-fired furnace and then to the fractionator where light and heavy ends are separated. The lighter fraction goes through a series of separators, including the coker overhead receiver, primary absorber, and sponge absorber, before finally going to the fuel gas plant. The bottoms from the fractionator are pumped to the radiant section of the furnace where the charge is heated further (probably to about $900^{\circ} \mathrm{F}\left(482^{\circ} \mathrm{C}\right)$ ). The hot charge goes through the switch valve on the second level of the coker tower and is directed to one of the two coke drums. Each drum has a 40-hour cycle, with coke formation lasting about 20 hours. Since the drums work as a pair, cutting of one drum normally occurs every 20 hours; the average "outage" (distance from the coke to the top of the drum) is about 25 feet. Lighter vapor fractions of the thermal cracking operation are removed from the top of the drum and sent to the fractionator where various products are separated and eventually recovered. Besides coke, products from this unit include:

- fuel gas

- light gas oil

- heavy gas oil

- FCCU charge
- propane

- butane

- naphtha 
The complete cycle of each drum, from drum heating to cutting, is 40 hours . About 8 hours before the cutting operation is scheduled, coke formation is stopped by switching the feed to the other drum. In 30 minutes, steam is introduced into the drum to cool it. After about 5 hours, the drum is vented to the atmosphere; then water is added to further cool the drum. Eight hours after the feed is switched, the top and bottom of the drum are opened and an initial hole is bored through the coke from the top with a high-pressure hydraulic bit $(>2,000 \mathrm{psi})$. The bit is changed to a revolvinghead type, and coke is cut from the bottom up. The coke falls directly into a railcar stationed below the drum bottom. A motorized winch is used to move the car to ensure even loading. Contractor personnel then transfer the coke from the railcars to trucks by crane.

After cutting is completed, the top and bottom of the drum are replaced; the drum is pressure-tested for seal, heated, and is ready to begin coke formation when the feed is switched from the other drum. The entire cutting operation normally lasts from 4 to 6 hours.

Difficulties were encountered during both cutting shifts observed during this survey. As a result, the cutting operations lasted longer than normal. During the first cutting shift, it took well over an hour to "drop" the bottom of the drum as it was tightly adhered to the coke. During cutting, the drill bit was bent by too rapid a descent. The total cutting operation lasted about 12 hours. During the second cutting shift, the bottom of the other drum not scheduled to be cut was leaking an asphalt-like material. This had to be tightened before normal operations could be started. The bottom was dropped more easily during this second shift, but the cutting operation again took longer than normal. After a total of 7 hours from the beginning of the cutters' shift, the cutting was completed.

\section{Work Force}

The work force for the coker unit is divided into two groups, the operations group and the coke-cutting group. During the survey, there were only two in the operations group who worked primarily on the coker unit. These two, the boardman and the coke helper, worked the normal 8-hour shift. In addition, there was a lead operator and a unit supervisor whose responsibilities included the coker unit as well as the No. 4 crude and vacuum units, and the kerosene and Diesel HDS unit. The lead operator is a normal shift worker, but the unit supervisor is on duty during the day shift and on 24-hour call. Following is a brief description of job activities of the boardman and coke helper.

- Boardman: Spends essentially $100 \%$ of the shift inside, monitoring and logging in various meters and charts on the control board. Is also the boardman for other units that have their monitors in this control room. Works closely with the helpers.

- Coke Helper: Performs all routine outside tasks preparing for coke-cutting operation, such as switching the charge valve, opening and closing the steam and water lines, and venting the drums. Periodically, performs visual inspection of entire unit, meter and gauge readings, and cleaning and oiling of pumps. Spends about $50 \%$ of his shift outside in the production area.

$$
\text { c-30 }
$$


During the survey, the coke-cutting group consisted of a driller and two bottom cutters; occasionally, there is an additional bottom cutter. This group works independently of the operations crew. They come in about 30 minutes before a drum is scheduled to be cut, work until the cutting and cleanup is finished, wash up, and leave. This usually takes 4 to 6 hours but can take much longer. Following is a brief description of work activities of the three coke cutters.

- Drizler: Spends about 20 to 30 minutes opening the top of the drum and can help with the opening of the bottom and positioning of the sleeve. Controls the drilling operation from his position in the penthouse. He usually stays there during the entire cutting operation except for breaks. He helps to close the drum and to clean up when the operation is completed.

- Bottom Cutters (2): They work as a team to remove the transfer line, to open the bottom of the drum, and to position the sleeve before cutting starts. During cutting, one worker is positioned in an enclosed shelter with a window near the bottom of the drum to observe and direct the railcar loading. They both help with cleanup operations.

\section{Control Measures}

The coke-cutting operation is one of the few in a refinery that is not a closed system. Because of this, it is more difficult to minimize worker exposure during this operation. During every cutting cycle, the top and bottom of the drum must be opened manually; the coke must be cut by the driller; the bottom cutters must clean and prepare the fittings and, at this particular unit, they must ensure that the railcars are properly loaded and clean up the coke tower structure and ground area. There are several important points concerning worker exposure associated specifically with cutting the coke directly into railcars.

This method, using railcars, normally el iminates the need for the crane and any other type of loading equipment such as front-end loaders and trucks. However, this was not the case at this particular coking unit; a crane was used to transfer the coke from the railcar to trucks. The crane operator and truck drivers were not regular refinery employees. This method also requires that one of the cutters be stationed at the drum bottom area to ensure proper railcar loading. Although in an enclosed shelter, this worker is in close proximity to the falling coke, splashing water, and water mist. The coke at this point has been cooled, and hydrocarbon vapor is not likely. Exposure is more likely to be dermal and to coke particulates.

The bottom of the drum normally drops off easily; however, during the survey the coke cutters had to use pneumatic hammers, sledge hammers, iron poles, and shovels to remove the bottom. The operation, which normally takes 30 minutes, took well over an hour. Temperature variability or inconsistent flow of the feed charge could have caused the problem. After the bottom is dropped, a metal sleeve is positioned directly under the drum. This forms a more closed system on this level where the cutters spend a good part of their 
time during the operation. The penthouse on the top level is a relatively enclosed one-room building ( 15 by 40 feet) where the driller operates the overhead drills. Natural ventilation did not appear to be good.

Direct loading of railcars normally requires considerable cleanup at the end of each cutting, as was the case at this unit. The tracks have to be cleared of the large coke chunks, and the entire ground area must be hosed down.

Clean coveralls were provided to the coke cutters daily. They also wore hard hats, eye protection, and gloves. The locker and shower room was part of the control building. During sampling shifts, the control room was downwind of the coke tower and heavy-fraction pumps.

Steam that is used to cool the drums is sent through a blowdown quench drum before it is vented to the atmosphere. A flare is available for turnarounds or any other condition that might require it.

Asphalt Processing

\section{Unit and Process Description}

The asphalt processing at this refinery consists of three vacuum distillation units; the bottoms from the fractionator towers are pumped to storage as asphalt without any further processing. The No. 1 vacuum unit is located just north of the No. 1 and No. 2 crude units in the east production area (Figure $\mathrm{C}-9$ ). The No. 2 vacuum unit, which was not in operation during the survey, is located in the southwest corner of the FCCU (Figures C-9 and C-11). The No. 4 vacuum unit is located just east of the coker control building within the No. 4 crude unit (Figure $\mathrm{C}-10$ ). The asphalt production capacity of this refinery is about $500 \mathrm{bbl} /$ day.

Work Force

No workers are assigned full time to any of the vacuum units. One or more of the outside operators of nearby units spend a small part of their shift covering the vacuum units. For example, when the No. 2 vacuum unit is operating, the lead operator and the A helper of the FCCU are responsible for the vacuum unit. 


\section{REFINERY D}

\section{DESCRIPTION OF REFINERY D}

Refinery $D$ is a "large" (405,000 bbl/day), "major" refinery located in southern California on the Pacific coast. The refinery was originally built in 1911. Currently it occupies over 950 acres and at the time of the survey was processing close to 300,000 barrels of crude a day and producing a fu11 line of petroleum products which included:

$$
\begin{aligned}
& \text { - propane } \\
& \text { - jutane } \\
& \text { - gasolines }
\end{aligned}
$$$$
\begin{aligned}
& \text { - Diesel fuel } \\
& \text { - fuel oils (\#2 and \#6) } \\
& \text { - } \# 2 \text { (spe oils } \\
& \text { - (sponge) coke }
\end{aligned}
$$

The domestic crude refined here during the survey was a combination of California and Alaskan North Slope crude, with a sulfur content of about $1.0 \%$ by weight. The API Gravity Index was 25, and the crude was categorized as a "mixed base" type (containing both naphthenes and paraffins). The crude is received by pipeline and offshore tankers. Products are marketed primarily in the local area and are shipped by pipeline; trucks are used for the coke that is taken to the local docks for shipment overseas.

The major process units at Refinery $D$ include:

- four crude distillation units

- three vacuum distillation units

- delayed coker

- three hydrodesulfurization units
- three catalytic reformers

- $\mathrm{FCCU}$

- $\mathrm{H}_{2} \mathrm{SO}_{4}$ alkylation unit

- polymerization unit

Almost every major process unit has its own control room. Figure $\mathrm{C}-13$ shows a rough refinery plot plan of the area around the units studied during this survey.

There are approximately 1,350 employees at this refinery, including production, administrative, and maintenance workers. Most of the routine maintenance activity is performed in-house; contractors are brought in for turnarounds and other major maintenance work. At the delayed coker unit, contractors are used for some routine production and maintenance activities. The production units operate 24 hours a day over three work shifts; there are four separate production work crews that rotate weekly.

The safety and health staff at this refinery includes three safety engineers, two occupational physicians, and three occupational health nurses.

All are under the direct supervision of the refinery's general manager. The doctors and nurses are on the premises full time during the day shift, 5 days a week. A large number of the refinery employees are trained in first aid and cardiopulmonary resuscitation. The dispensary and treatment room is fully equipped to handle first-aid situations and various routine examinations. All of the production and maintenance workers are given preplacement medical examinations, including audiometric testing. There is also a schedule for periodic physical examinations. 


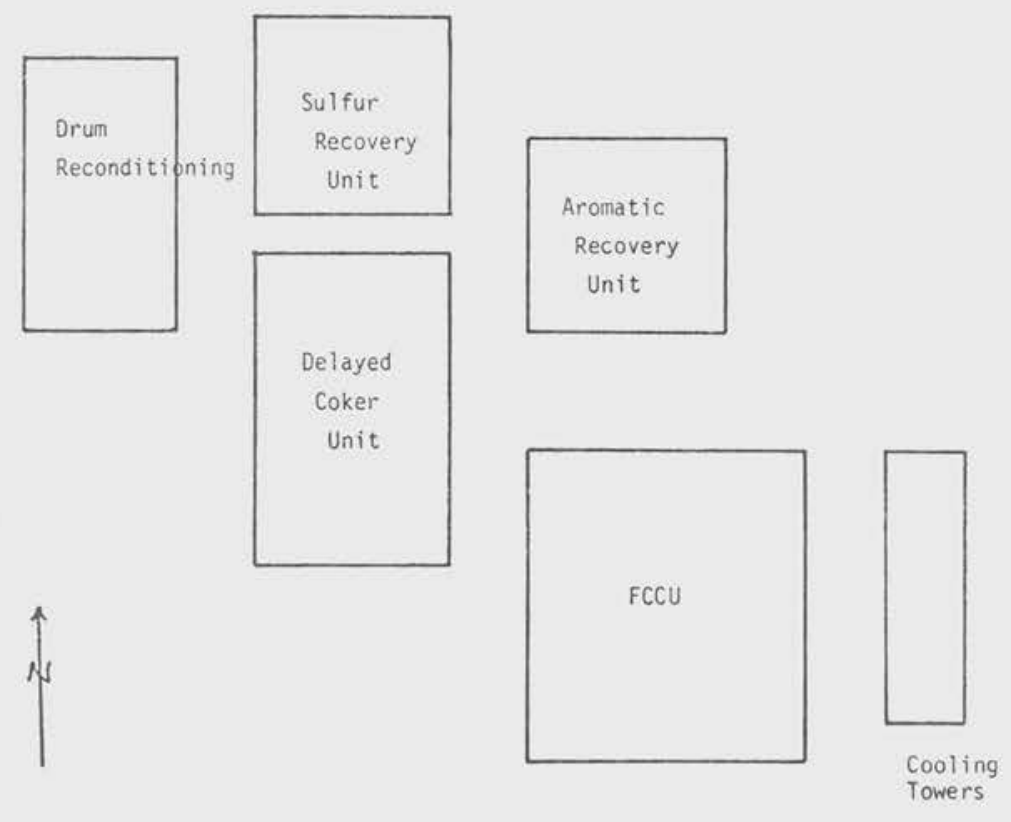

Figure C-13. Refinery D survey study area.

As part of good industrial hygiene practice, the use of protective clothing and equipment (e.g., hard hats, safety shoes, rubber gloves, coveralls, slick suits, eye protection) is emphasized. The company provides fresh coveralls daily and a laundering service. Eating and smoking are allowed in most control rooms. All new employees attend an extensive training session over a 3-week period that includes information on unit equipment, operations, respirator use, safety hazards, fire protection, and first aid. Formal training continues over the first 3 years. The practice of good personal hygiene, such as the washing of hands before eating, is also encouraged. Good unit housekeeping is practiced as an important means of minimizing worker exposure to potential hazards. Spills are promptly cleaned up by the unit operators, and any necessary equipment or structure repair is promptly carried out by the unit operators or in-house maintenance crews.

The safety engineers are responsible for the industrial hygiene sampling. Although a routine sampling schedule is not yet established here, a considerable amount of monitoring is conducted upon request, for compliance purposes, and for any other reasons felt necessary by the refinery personnel. 
STUDY PROCESS UNITS AT REFINERY D

Fluid Catalytic Cracker Unit (FCCU)

\section{Unit and Process Description}

The FCCU is located south of the aromatics recovery unit and southeast of the delayed coker and sulfur recovery units (Figure C-13). The reactor/ regenerator $(R / R)$ structure is a side-by-side type with a single riser to the reactor; the height of both the reactor and the regenerator is about 50 feet. The unit, which was designed and installed in the 1950s, has undergone various modifications, the most recent ones involving the precipitator in 1974 and the deethanizer in 1979. The production capacity of this FCCU is about 55,000 bbl/day; during the survey, it was operating at about $90 \%$ capacity.

The unit covers an area of about 400 by 400 feet (Figure C-14). The regenerator, reactor, fractionator, and two rows of pumps run west to east, about one-third of the distance from the northern boundary of the unit. The airconditioned control building, the compressor platform, and the $\mathrm{H}_{2} \mathrm{~S}$ treating area are located in the north area of the unit. The precipitator and $\mathrm{CO}$ boiler for the regenerator flue gas are located on the west side of the unit, south of the regenerator. The vapor separation and recovery area runs east to west in the central area of the unit.

Fresh feed for the FCCU comes from the crude units (atmospheric gas oil) and vacuum units (light and heavy vacuum gas oils). This fresh feed plus the bottoms (recycle) from the fractionator are injected into the riser where catalytic cracking is initiated as the hot-0il feed contacts the catalyst.

The product vapors and the catalyst are separated in the single-feed riser line and in the reactor itself. The hydrocarbons are taken to the fractionator where the various products are separated. The catalyst is stripped of any remaining oil with steam and delivered to the regenerator where spent catalyst is reactivated by oxidizing the accumulated carbon at a combustion temperature normally greater than $1,000^{\circ} \mathrm{F}\left(538^{\circ} \mathrm{C}\right)$. Flue gas from the regenerator goes through an electrostatic precipitator for removal of most of the catalyst fines and then to the $\mathrm{CO}$ boiler where it is burned before being released to the atmosphere through the stack. The regenerated catalyst is stripped of any absorbed oxygen with steam before being recirculated back to the reactor.

The main products from the fractionator are:
- butane
- propane
- light gas oil

- heavy cat gasoline

- fuel gas 


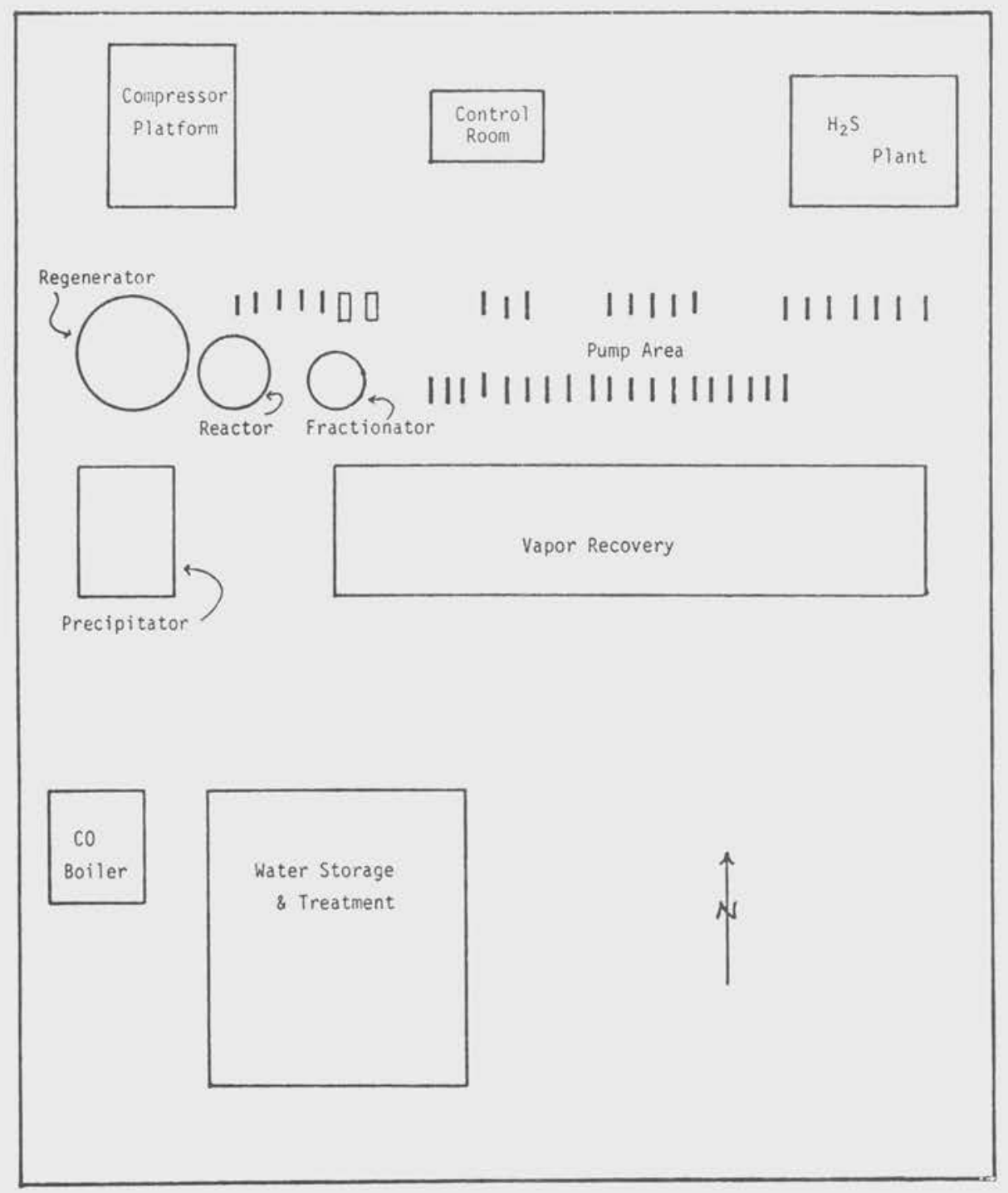

Figure C-14. Refinery D FCCU.

Work Force

There are normally six full-time workers assigned to the FCCU during each shift. Following is a brief description of the duties of these workers.

- Head Operator: Has overall responsibility for the entire unit. This entails working closely with the houseman and supervising outside activities of the four (or more) outside operators. He pays particular attention to any operational difficulties as well as any specific fire or safety hazards, such as gas leaks. He normally spends about $50 \%$ of his shift outside the control room in the various production areas. 
- Unit Operator: Is the primary outside operator who performs routine duties related to the R/R structure, the fractionator, the compressor deck, the CO boiler, and the pump row (pumps p-119 to p-122) that includes the fractionator bottoms pump and the fresh charge pump. Duties include general inspection of all equipment, meter and gauge reading, pump oiling and routine maintenance. He spends about $60 \%$ of his shift outside in the production areas.

- Operator I: This outside operator has primary responsibility for the vapor recovery and caustic sections, the pump row which includes pumps p-143 to p-181, and the blowoff tank. Periodically, he makes visual inspections, takes meter and gauge readings, gauges tanks, monitors uptake of chemical additives, keeps pumps oiled, and maintains the unit by general housekeeping. He spends about $60 \%$ of his shift outside in the production areas.

- Operator II: This outside operator has primary responsibility for the FCCU cooling towers, the $\mathrm{H}_{2} \mathrm{~S}$ treatment plant, and the polyammonia and polysulfide scrubbers. He also acts as an overlap in various other areas of the unit. His duties include periodic inspections, meter and gauge readings, adding chemicals, and collecting water samples at the cooling towers.

- Houseman (Operator III): Spends essentially 100\% of his shift inside the control building, monitoring and logging in the various meters and charts on the control board. He works closely with the head operator, as well as with the other outside operators.

- Operator IV (CO Boiler Operator): This outside operator has primary responsibility for the CO boiler and precipitator hoppers. His duties include collecting water samples and adding chemicals, reading meters and gauges, and greasing and lubing equipment. During the survey, he also spent time painting the separate small CO boiler control room, located just to the east of the CO boiler. He normally spends about $50 \%$ of his shift outside; the rest is spent in the CO boiler control room, where he monitors and logs in the various charts on the control board.

In addition to these six workers, occasionally there are one or two helpers who work wherever they are needed during that day. During the first sampling day, the one extra helper spent about $1 \frac{1}{2}$ hours at the $C 0$ boiler and also did work at the $\mathrm{H}_{2} \mathrm{~S}$ treatment area. During the second sampling day, the extra helper worked at the chemical shed on the outskirts of the unit and in the $\mathrm{CO}$ boiler area.

\section{Exposure Control Measures}

The primary exposure control measure used at this FCCU is a closed-system process which limits exposure to products, by-products, and intermediates. Also important is a well-organized maintenance program that provides both efficient preventive and repair maintenance services. Under normal operating conditions, exposure to PAHs may occur during sampling of the various streams, during maintenance and housekeeping activities, from fugitive emissions, and from the regenerator flue gas. 
The use of sample bombs for collecting process stream samples is a means of minimizing exposure and is used for collecting at least some of the stream samples at this unit. The sample bomb is placed in an auxiliary process line, and the stream is diverted through this line, filling the vessel. The valves at each end of the bomb are closed, and the bomb can be removed with minimum exposure to the collector. Most of the liquid stream samples are collected using the spigot-and-bottle method with sampling loops that eliminate the flushing of lines.

Exposure during routine maintenance is difficult to minimize. The ground level of the unit is constructed of concrete with an efficient sewer system that simplifies cleanup procedures. The refinery has its own craft maintenance crews (e.g., pipefitters, electricians) that provide preventive and repair services. Hard hats, safety shoes, and neoprene gloves are worn routinely, and coveralls and safety or slick suits are available. Disposable ear plugs are used in the compressor areas. There are no routine operations that require the usage of respirators; however, NIOSH-approved air-purifying and self-contained breathing-air respirators are available. These respirators are maintained by the refinery safety department.

The areas of the unit handling heavy fractions, which are more likely to contain the PAHs, are in fairly open areas minimizing potential vapor accumulation. The pumps are south of the control building running in two rows west to east. Several of the heavy-fraction pumps, including the fractionator bottoms pump, are located close together around the base of the fractionator tower. This is an area where PAH concentrations might be elevated. The control house, which is air-conditioned but not under positive-pressure ventilation, is occasionally downwind of the R/R or heavy-fraction pumps.

The flue gas from the regenerator passes through an electrostatic precipitator for removal of spent catalyst fines and then is burned in the CO boiler with an auxiliary fuel. The heat produced here is used to generate steam. The CO boiler removes not only carbon monoxide from the flue gas but many other hydrocarbons, making the effluent suitable for discharge to the atmosphere.

\section{Delayed Coker Unit}

\section{Unit and Process Description}

The delayed coker unit, as shown in Figure C-13, is located south of the sulfur recovery unit, east of the drum reconditioning plant, and west of the aromatic recovery unit and the FCCU. The unit has six 92 -foot coke drums with a daily production capacity of 900 to 2,700 tons (one to three drums cut each day). This is one of the larger delayed coker units in terms of coke production that was visited during this study.

The unit, which is about 11 years old, is spread over an area of about 500 by 300 feet (Figure $\mathrm{C}-15$ ). The ground level of the entire unit is constructed of concrete. The control building is located in the northeast corner of the unit; it houses the shift supervisor room, the kitchen, and the locker and shower facilities, as well as the control board room. The coke tower (an open, multilevel structure that includes the six drums) is 
in the center of the unit running north to south, with the coke storage pit just to the west of it. The coke that has been cut is moved by an overhead crane from the pit to a crushing machine located alongside the pit. The crushed coke travels by conveyor belt about 300 yards to the truck-loading hopper and an A-frame storage structure. The coke fills the hopper initially and then is diverted to storage. Trucks are loaded automatically by driving beneath the hopper and selecting the amount of coke to be dropped. The coke is wetted here, but the trucks are not covered. Most of these trucks are not owned by this oil company.

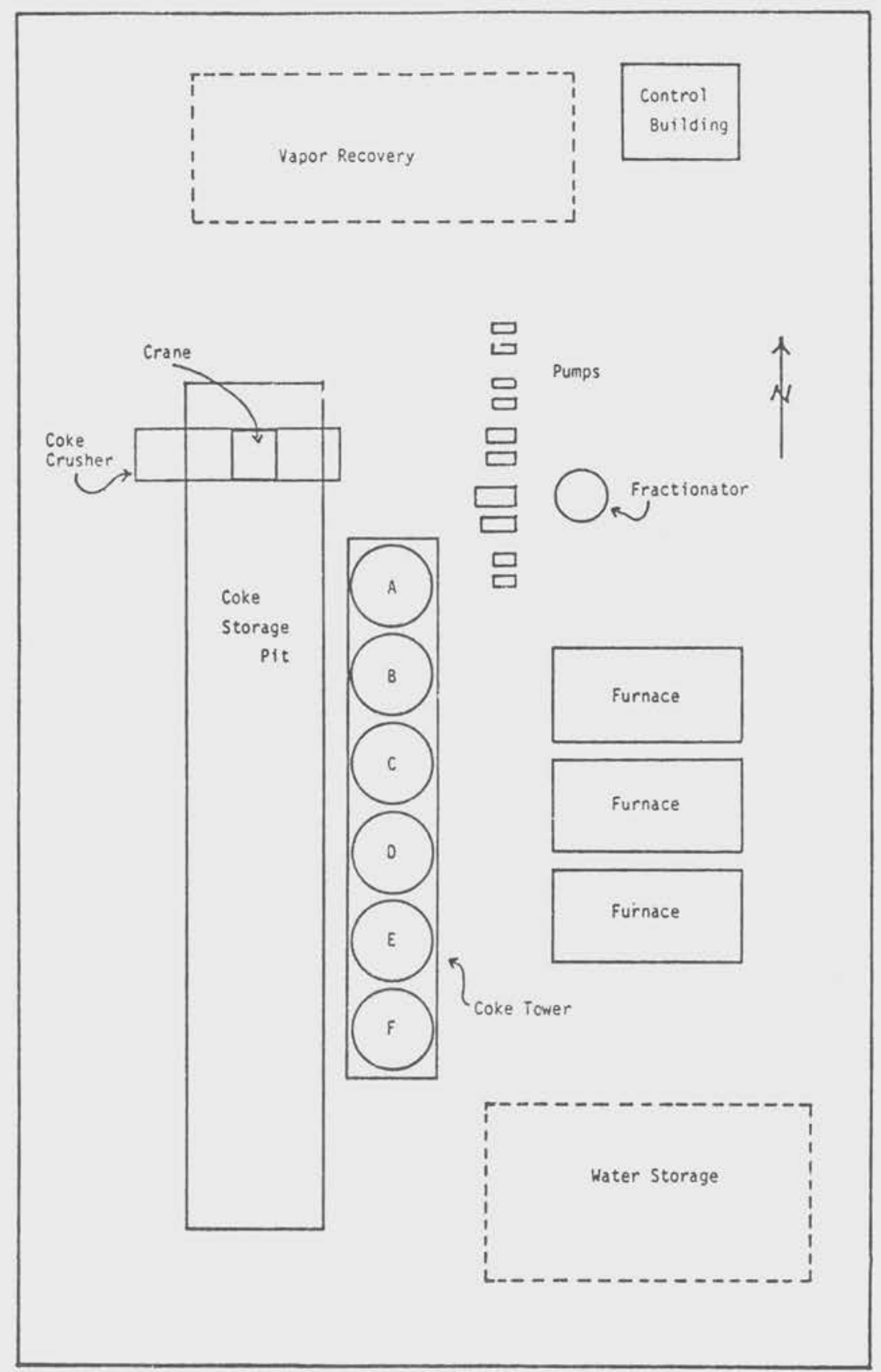

Figure $C-15$. Refinery D delayed coker unit.

$$
\text { C-39 }
$$


The three gas-fired furnaces and the fractionator are located just to the east of the coke tower; the vapor recovery area and blowdown and quench drums are located in the southeast corner of the unit.

Sponge or No. 2 grade coke was the type produced during the survey and is the predominant type produced at this refinery. The charge stock for sponge coke is primarily residual from the vacuum distillation units. The charge is pumped from storage tanks to the fractionator where the lighter fractions are separated and processed in the vapor recovery area. The bottoms from the fractionator are then pumped (pump p-501) to the series of furnaces where they are heated to a suitable reaction temperature (normally about $900^{\circ} \mathrm{F}$ or $482^{\circ} \mathrm{C}$ ). The heated charge then goes to one of six coking drums where the thermal cracking process begins. There are three pairs of drums, and each drum has a 48-hour cycle with coke formation lasting about 24 hours. Normally one drum is cut each shift. The lighter vapor fractions of the thermal cracking operation are removed from the top of the drum and sent to the fractionator where various products are separated and eventually recovered. Products from this unit, other than coke, include: propane, butane, gas oil, and naphtha.

Routine procedures are used at this unit to prepare each drum for cutting. Coke formation is stopped by switching the feed to the other drum of the pair. Steam followed by water is used to cool the drum; this lasts several hours. About 1 hour before cutting is scheduled, the top and bottom of the drum are opened, and the coke is cut with a high-pressure hydraulic bit. An initial hole is bored through the coke, and then the coke is cut from the bottom up. The coke falls down a chute into the coke storage pit. Drilling normally lasts from 3 to 4 hours.

After cutting is completed, the top and bottom of the drum are replaced. The drum is pressure-tested for seal, is heated, and is ready when the feed is switched from the other drum to begin coke formation.

Work Force

The work force for the coker unit can be divided into two groups, the operations group and the coke-cutting and handling group, both of which are supervised by the division shift supervisor. This supervisor works the normal shift and has a separate office in the control building. During a normal day shift, the supervisor spends 50 to $60 \%$ of his time outside monitoring the various operations; he does not usually participate in the work activity. The three-man operations group works the normal 8-hour shift; following is a brief description of their job activities.

- Boardman: Spends essentially $100 \%$ of his shift inside the control building, monitoring and logging in the various meters and charts on the control board. Works closely with other operational workers.

- Head Operator: Spends anywhere from 25 to $75 \%$ of his shift outside in the production area, depending on operating conditions. During the first sampling day, the head operator was frequently outside (up to $60 \%$ of shift) near the crusher and conveyor line because of the problems with the crusher; the second day few problems occurred, 
so he was outside about $30 \%$ of his shift. This person is very experienced on the unit and works closely with the other process operators to ensure smooth operating conditions.

- Outside Operator: Performs most of the routine outside tasks, spending about $50 \%$ of his shift in the production area. Conducts periodic tours of the unit taking pressure and flow readings, checking the furnaces, opening and closing various valves, and conducting general visual inspection of all processes and equipment. He can also oversee maintenance work being done and runs water sample tests in the control building.

The coke-cutting and handling group consists of the driller, driller helper, beltman, deck operator, and crane operator. This group also works the normal 8-hour shift. Several members of this group are employed by an outside contractor (i.e., driller helper, beltman, crane operator), but all work together as a team. Following is a brief description of their job activities.

- Drizzer: Helps with opening and closing the coke drum top and bottom and with positioning the coke chute. Spends most of his shift on the top level where he operates the hydraulic cutting bit. Normal cutting operation lasts about 3 to 4 hours.

- Drizzer Helper: Performs a variety of duties on and around the coke tower which includes relieving the driller during cutting operations, shoveling coke onto the conveyor line, helping to drop the drum bottom and position the chute, and hosing down various areas at the end of a cutting operation. Spends entire shift outside except for breaks, which are normally taken in the control room.

- Deck Operator: Helps with opening and closing the drum and with positioning of the chute and transfer line. Performs duties such as valve switching on various decks of the tower (e.g., 23 and 42 deck). Spends about $70 \%$ of the shift outside and the rest inside the control room taking care of paperwork (end of shift).

- Beltman: Is in charge of the coke crusher, conveyor belt, and A-frame storage structure. Spends about 6 hours each shift in checking the belts, the coke hopper, and the amount of coke in the A-frame, and on other outside activities such as shoveling coke onto the conveyor line and hosing down the ground area. His duties also include relieving the crane operator for 1 hour during lunch. Because of problems with the crusher on the first sampling day, he spent an unusually large percentage of his shift in that area.

- Crane Operator: Normally spends 7 hours a shift in one of the two overhead crane cabs transferring the cut coke from the pit into the crusher. He takes a 1-hour lunch break in the control building. 
During the survey, there was also a deck operator trainee. The trainee was in the same area as the deck operator, either performing or assisting in routine duties. During the first sampling day, there were also four contractor maintenance workers cleaning the area around the coke pit. This entailed either shoveling or using a front-end loader to transfer coke back into the pit from which it had spilled. Use of the front-end loader was quite unusual, but these maintenance workers are used about every other day for some cleanup work.

\section{Control Measures}

The coke-cutting operation is one of the few in a refinery that is not a closed system; consequently, it is more difficult to minimize worker exposure during this operation. During every cutting cycle, the top and bottom of the drum must be opened manually, the coke must be cut by the driller, the operators must clean and lubricate the fittings, and the crane operator must move the coke from the coke pit to the crusher. From here, the crushed coke is transported some 300 yards to the A-frame storage structure. Basically, the coke-cutting operations at this refinery were similar to those observed at other refineries; however, there were several key points observed related to worker exposure.

The opening of the top and bottom of the drum was done in a time period comparable to that observed at other coke units. The deck operator, trainee, driller, and driller helper worked as a team to complete both openings in about 1 hour. After the bottom plate is moved manually by pulley onto a cart (on tracks), a chute extender is lifted from the floor platform to the bottom of the drum and secured. This forms a closed system on this level where the operators spend a good part of their time during the operation.

The top level at this coker unit was very large (about 50 by 13 yards) and totally open, compared to the typical penthouse top level observed at other units. There was a partially enclosed work station for the driller. This open top level and normally high winds minimize the accumulation of vapors. Work areas near the bottom of the drums (23 level) were also fairly open.

The coke crusher itself does not appear to generate large quantities of coke dust. Coke is wet from the pit, and the size of the crushed coke is large enough to prevent fine-dust generation. However, there were operational difficulties with the crusher during the first cutting shift; apparently this is not uncommon. When this occurs, coke overflows the holding pit necessitating added cleanup. This is normally performed by the contract maintenance group.

Typical protective clothing worn at this unit included hard hats, safety shoes, rubber gloves, and coveralls (provided daily by the company). Several of the coke cutters wore slick suits and rubber boots during deheading and cleanup operations. Showering time was provided at the end of the shift; lockers and shower facilities were in the control building.

The air-conditioned control room was not under positive pressure and was occasionally downwind of the coke tower, furnace, and furnace charge pump. The steam that is used to cool the drums is normally sent through a waterscrubbing system before it is vented to the atmosphere. 


\section{REFINERY E}

\section{DESCRIPTION OF REFINERY E}

Refinery $E$ is a "large" (210,000 bbl/day capacity), "major" refinery located in eastern Pennsylvania. The refinery, which was built in 1924, is currently spread over approximately 600 acres. At the time of Phase I and Phase II surveys, the refinery was operating at close to capacity; during the Phase III survey, it was operating at considerably less than capacity due to the turnaround on one of the FCCUs. A full line of petroleum products is produced including:

- propane

- butane

- gasolines (three grades)

- jet fuel

- fuel oils (\#2 and \#6)
- lube oils

- cumene

- sulfur

The crude refined here, which is primarily Nigerian and Libyan, is categorized as a "light," "low-sulfur," "mixed base" (containing both paraffins and naphthenes) crude. Occasionally, some North Sea crude ( $1 \%$ sulfur by weight) is also refined here. All of the crude is received by tankers which unload at a nearby docking station. The petroleum products produced here serve 11 nearby states. The products are transported primarily by ship and tank trucks.

The major process units at Refinery $E$ include:

- two atmospheric and vacuum distillation units

- solvent decarbonizer (deasphalting unit)

- two gulfiners (desulfurizing units)

- two catalytic reformers

(platformers)
- two FCCUs
- HF alkylation unit
- sulfur recovery unit
- dehazer unit
- benzene/cumene unit

Figure $\mathrm{C}-16$ shows a rough plot plan of the main production area which is located in the northwest section of the refinery. Almost every major process unit has its own control room.

There is an approximate total of 1,350 employees; this includes 175 supervisory, 100 adminstrative, 360 maintenance, and 715 production workers. Most of the routine maintenance activity is performed in-house; a number of contractors are normally on the premises for other major maintenance work including turnarounds. The production units operate 24 hours a day, 7 days a week. There are normally four work crews that rotate on a unit. Both 8hour and 12-hour shifts are used depending on the unit. 


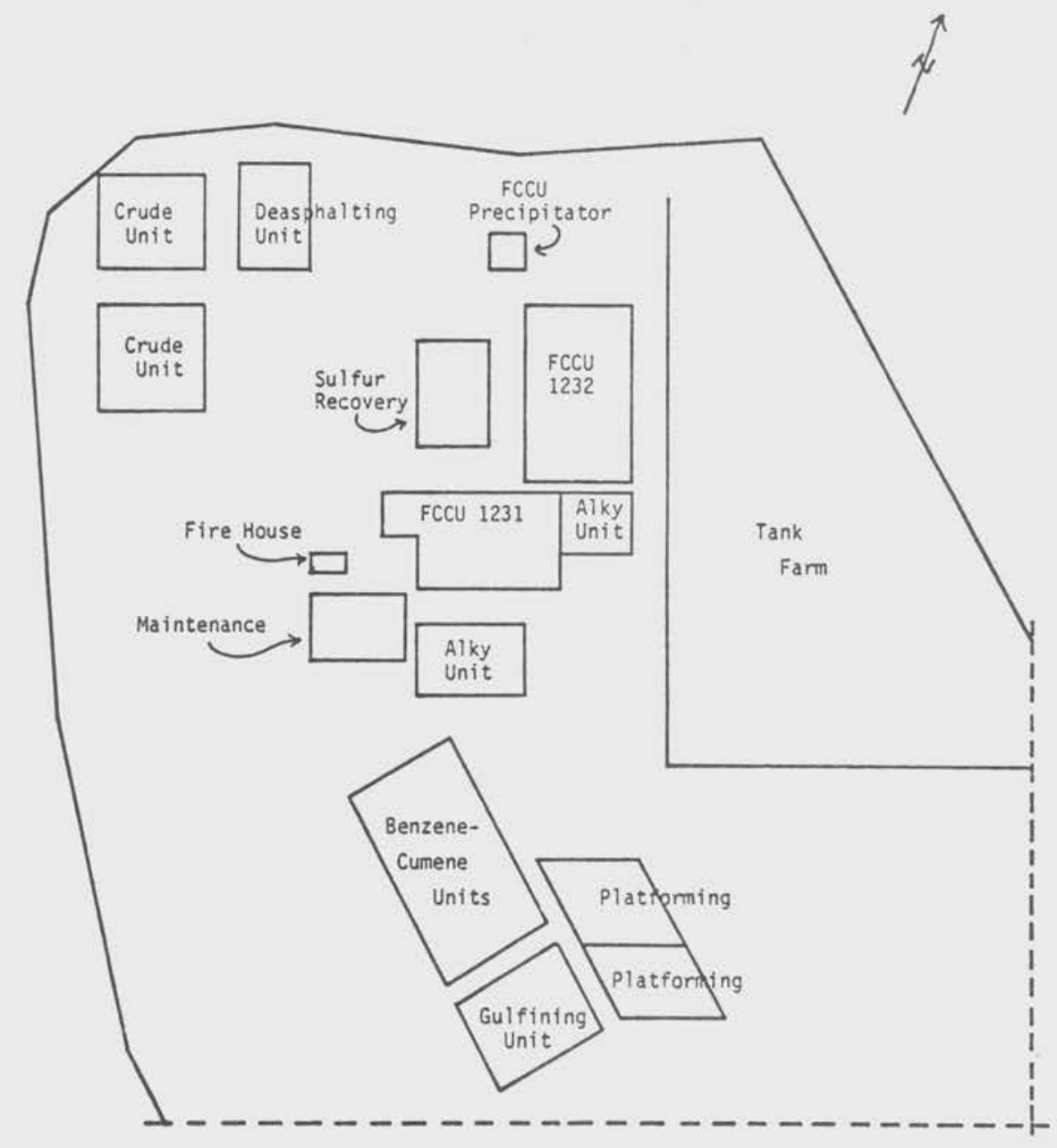

Figure C-16. Refinery E production area.

The refinery safety department consists of the Supervisor of Accident and Fire Prevention and three safety inspectors. The refinery also has a fullyequipped fire department staffed by nine firemen. Industrial hygiene services are primarily provided by the corporate industrial hygiene staff; five corporate industrial hygienists have responsibility for the company's eastern region. Industrial hygiene sampling for benzene is conducted here on a quarterly basis; the Supervisor indicated that there were no problems at this refinery with the current benzene worker exposure standards. Other monitoring at this refinery is conducted for compliance purposes (e.g., noise, lead), on an as-needed or request basis (e.g., detector tubes for ammonia, sulfur compounds), or for any other reasons deemed necessary by the refinery or corporate personnel (e.g., total hydrocarbons with direct-reading instrument, charcoal tubes for alkanes). Two refinery safety inspectors are trained to perform routine monitoring, and the corporate industrial hygienists also make periodic surveys. 
As part of good industrial hygiene practice, the use of protective clothing and equipment (e.g., hard hats, safety shoes, gloves, eye protection) is emphasized with strict requirements in acid and caustic areas. While eating is allowed in most control rooms, smoking is permitted only in designated areas away from the production units. All new employees attend an extensive training session which includes information on unit equipment, operations, respirator use, safety hazards, fire protection, and first aid. The practice of good personal hygiene such as the washing of hands before eating is also encouraged; shower and locker facilities are provided at several refinery locations. Good unit housekeeping is practiced as an important means of minimizing worker exposure to potential hazards. Spills are promptly cleaned up by the unit operators, and any necessary equipment or structure repair is promptly carried out by the unit operators or in-house maintenance crews.

The refinery employs a physician and two nurses who work out of the dispensary in the main administrative building. All employees receive preemployment medical examinations, and most production workers also receive yearly examinations. Approximately 150 refinery personnel are formally trained in first aid including cardiopulmonary resuscitation.

\section{STUDY PROCESS UNITS AT REFINERY E}

Three process units were studied at this refinery, two FCCUs and one deasphalting unit. All three were surveyed in Phase II; in Phase III, one of the FCCUs was not in operation due to a turnaround.

FCCUs - Units No. 1231 and No. 1232

\section{Unit and Process Description}

The two FCCUs are located about 200 yards apart in the northern section of the refinery (Figure $\mathrm{C}-16)$ ). A Claus-type sulfur recovery unit and an HF alkylation unit are located nearby. Unit No. 1232 is the newer and larger of the two FCCUs; it was built in 1954 and has a capacity of about 60,000 bbl/day. Unit No. 1231 was built in 1944 and has a capacity of about 28,000 $\mathrm{bbl} /$ day. Both units have side-by-side reactor/regenerator (R/R) structures, CO boilers, separate control rooms and work crews, and similar operating conditions; both also use a synthetic zeolite catalyst. The primary differences between the units are their age, capacity, and the fact that the older FCCU No. 1231 is much more enclosed.

Figure C-17 illustrates the layout of FCCU No. 1232 which occupies an area of about 125 by 75 yards. The side-by-side R/R structure is located in the middle of the unit at the north boundary. The fractionator and gas-oil stripper towers are located just south of the reactor; a row of about 20 centifugal pumps is just to the west of these towers. Several heavy-fraction pumps including the charge, slurry reflux and recycle, and decant oil pumps are among these. The control building and $\mathrm{CO}$ boiler are situated farther west, and the electrostatic precipitator is situated across a road north of the $\mathrm{CO}$ boiler. An enclosed compressor building and catalyst hoppers are on 
the east side of the R/R area. The recovery section of the unit, which includes the absorber-stripper, lean oil still, debutanizer, depropanizer, and numerous pumps, compressors, and heat exchangers, occupies a large area south of the control building.
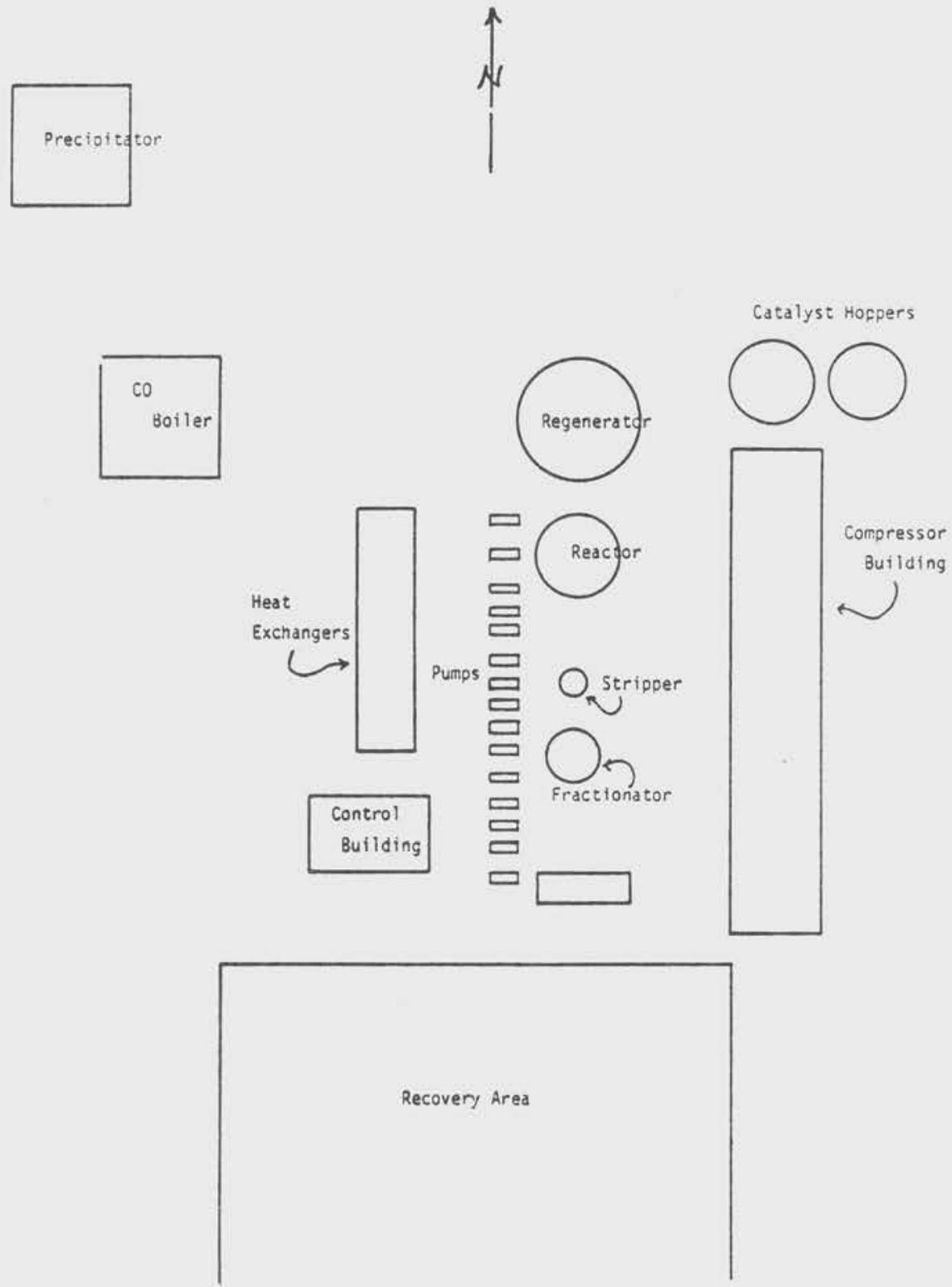

Figure C-17. Refinery E FCCU No. 1232.

Figure $\mathrm{C}-18$ illustrates the layout of the main portion of FCCU No. 1231 which occupies an area of about 100 by 50 yards. A long, narrow, one- and two-story brick building running north and south divides the unit in half. The ground floor of this building is divided into three enclosed pump rooms. The first room (cold-pump room) includes the two charge pumps; the second

$$
\text { C }-46
$$


room (hot-pump room) includes the slurry recycle, heavy gas oil, and decant oil pumps; and the third room contains the two steam turbine blowers for the spent catalyst leg. The control room is located on the second level of this building above the cold-pump room.
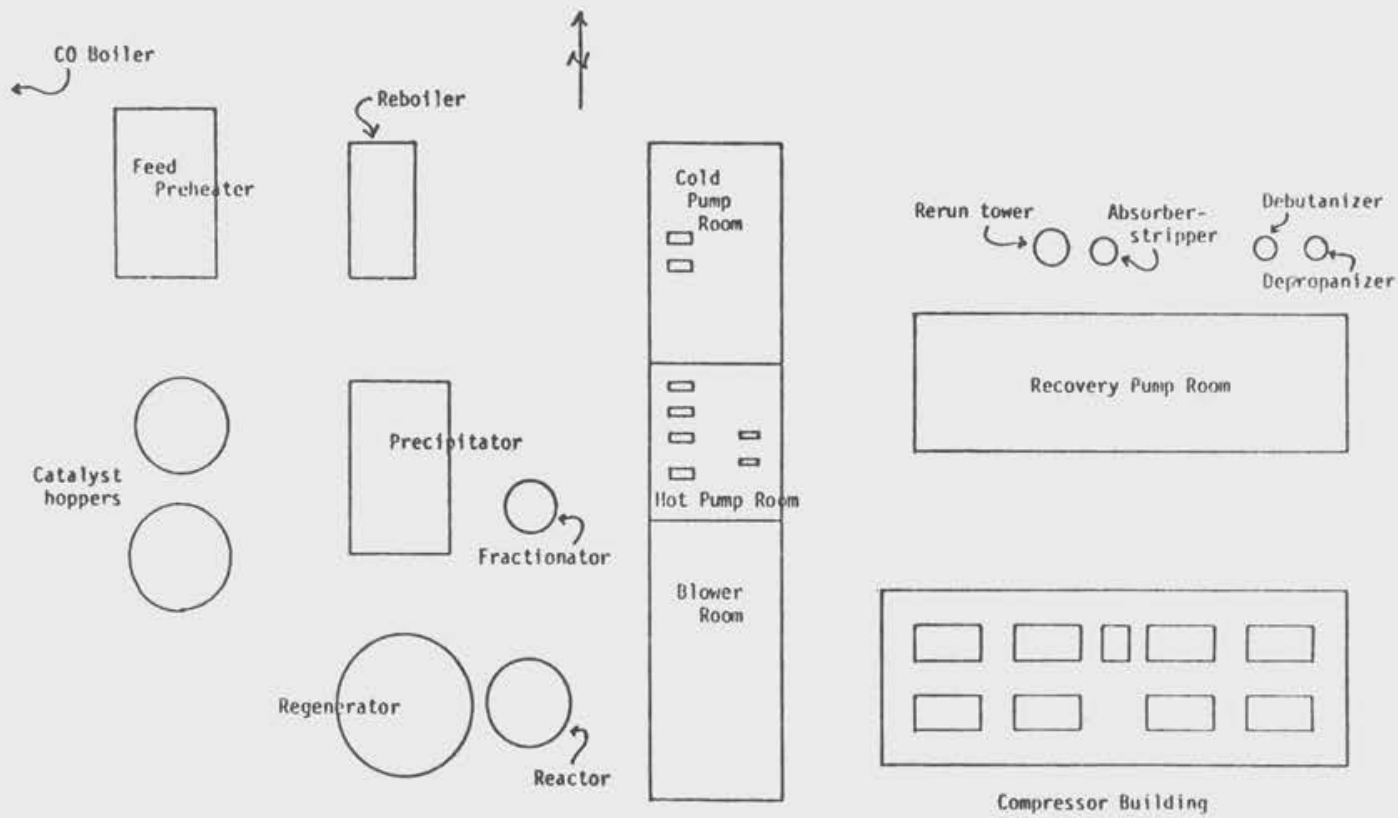

Figure C-18. Refinery E FCCU No. 1231.

The "cat" side of the unit is located west of this main pump building. The side-by-side R/R, fractionator, precipitator, catalyst hoppers, and furnaces are located in this area. The CO boiler (not shown in Figure C-18) is 10cated farther west of this area across a main refinery road. The recovery side of the unit is located on the east side of the unit and includes two one-story brick buildings. One contains eight large compressors, and the other contains a number of smaller pumps. To the north of these two buildings are the depropanizer, debutanizer, absorber-stripper, and first rerun towers. During the Phase III survey, FCCU No. 1231 was undergoing a major turnaround to eliminate the enclosed pump and compressor buildings.

The basic catalytic cracking process is essentially the same at both FCCUs. Fresh feed consists of atmospheric and vacuum gas oils, and deasphalted gas oils. This feed, preheated by gas-fired charge heaters, plus heavy gas oil and slurry recycle from the fractionator are mixed with the hot catalyst in the two risers at each unit leading to the reactor.

The catalytic cracking takes place in the risers as well as in the reactor. The catalyst used at the refinery is a synthetic zeolite common to other FCCUs studied in this project. The product vapors and the catalyst are separated (series of cyclones), and the hydrocarbons are taken to the fractionator tower. The catalyst is stripped of any remaining oil with steam and 
delivered to the regenerator through the "spent catalyst leg." In the regenerator, the catalyst is reactivated by oxidzing the accumulated carbon at about $1,250^{\circ} \mathrm{F}\left(677^{\circ} \mathrm{C}\right)$. The flue gas from the regenerator goes through a steam generator, through an electrostatic precipitator to remove catalyst fines, and then to the CO boiler where it is burned before being released into the atmosphere. The regenerated catalyst is steam-stripped of any absorbed oxygen before being recirculated back to one of the two risers.

The main products from the fractionator are:

- propane/propene

- butane/butene

- fuel gas
- heavy and light cat gasoline

- heavy and light gas oil

Work Force

The work force and job descriptions at both FCCUs are similar. There are normally eight full-time workers per shift at each unit. There are three 8hour shifts per day, and a total of four work crews rotate to cover the unit 7 days a week. The day shift runs from 0715 to 1515 . Each unit is divided into the "cat" side (R/R, fractionator, catalyst hoppers, furnaces) and the "recovery" side for the distribution of job responsibilities. During Phases I and II, there were only seven operators at FCCU No. 1231; one operator was handling both sides. Following is a brief description of job activities for the eight full-time workers at FCCU No. 1232; however, job titles and description are essentially the same at both units.

- Operator - Cat Side: Oversees routine operations of the cat side of the unit which includes the $R / R$, fractionator, heavy-fraction pumps, enclosed compressor building, $\mathrm{CO}$ boiler, and precipitator. Normally spends about $50 \%$ of his shift outside making visual inspections, supervising and assisting the other operators. When a problem occurs such as a leak or pump failure, he may spend the majority of his shift outside. Works closely with the control operator and assistant operator to ensure smooth operations of this portion of the unit.

- Assistant Operator - Cat Side: Works for the operator; spends about $70 \%$ of his shift outside checking pumps, blowers, and other cat side equipment on the ground level as well as above on the various structures. Can perform minor maintenance on equipment.

- Control operator - Cat Side: Spends about $7 \frac{1}{2}$ hours of his shift inside the control room, monitoring and logging in various meters and charts on the cat side of the control board. Once during the day shift he makes a 30-minute round outside in the cat area, taking about 25 gauge and meter readings.

- Operator - Recovery Side: Performs the same duties on the recovery side as the cat operator. The recovery side of the unit is located to the south of the cat area; this includes the absorber-stripper, depropanizer, deethanizer, compressors, and pumps. 
- Assistant Operator - Recovery Side: General duties similar to those of the cat assistant operator.

- Control operator - Recovery Side: Duties similar to the other control operator, including the daily round.

- Outside Control Operator: This outside operator, who spends about $70 \%$ of his shift in the production area, is not assigned to a particular area of the unit. He can act as a helper wherever he is needed on a particular shift; also has routine duties such as taking quality control samples (mainly evening shift), checking levels, draining and filling various drums, and making periodic rounds of the unit every 2 hours.

- Assistant Operator - Engineer: Spends about $75 \%$ of his shift outside primarily ensuring the smooth running of the pumps, blowers, compressors, and boilers. Performs minor preventive and routine maintenance on this equipment. Spends a good part of his time in and around the enclosed compressor building.

Exposure Control Measures

The exposure control measures used at the FCCUs are similar and are typical of those observed at other. FCCUs studied during this project. The primary control measure is a closed-system process which limits exposure to products: by-products, and intermediates. Also important is a well-organized maintenance program that provides both efficient preventive and repair maintenance services. Under normal operating conditions, exposure to PAHs may occur from fugitive emissions (especially from pumps), from the regenerator flue gas, during sampling of the various streans, and during maintenance and housekeeping activities.

The fact that the heavy-fraction pumps for FCCU No. 1231 are in enclosed rooms without mechanical ventilation greatly increases the potential for airborne PAH accumulation. Pumps such as those for slurry recycle and decant oil streams have been associated with fugitive PAH emissions in previous surveys. It is especially important at this unit that these pumps be maintained properly and that workers spend as little time as possible in these enclosed rooms. FCCU No. 1232 is a much more open unit. Although the heavy-fraction pumps are not in an enclosed room, they are located close together near a series of towers (i.e., R/R structure). This is an area where PAH concentration might also be elevated. Both control rooms are airconditioned but not under positive pressure. FCCU No. 1232 's control room is occasionally downwind of the R/R or heavy-fraction pumps, while FCCU No. 1231 's control room is directly above the cold-and hot-pump rooms. Again, it should be noted that one of the major objectives of the turnaround being performed on FCCU No. 1231 during the Phase III survey was to eliminate the enclosed pump and compressor rooms. 
The regenerator flue gas is treated the same way at both units. First it goes to an electrostatic precipitator to remove catalyst fines and then is burned in a $\mathrm{CO}$ boiler with an auxiliary fuel. The heat produced here is used to generate steam. The CO boiler removes many hydrocarbons as well as carbon monoxide from the flue gas before the effluent is discharged through a stack into the atmosphere.

Most process stream samples, especially the heavy-fraction samples, are collected during the evening shift (1515-2315). Sample bombs are used only for gas samples; liquid samples are collected primarily by the spigot-and-bottle method with sampling loops that eliminate the flushing of lines. The samples are taken to the laboratory for analysis.

Exposure during routine maintenance is difficult to minimize, especially if it occurs in any of the enclosed buildings in FCCU No. 1231. There are concrete floors with effective sewer systems in most of these rooms, simplifying cleanup procedures. Most of the major equipment areas (e.g., around pumps) at FCCU No. 1232 also have a concrete foundation with a sewer system. The refinery has its own craft maintenance crews (e.g., pipefitters, electricians) that provide preventive and repair services. Both units also have relatively large normal work crews (eight) that can provide a prompt and effective maintenance program.

Hard hats, safety shoes, and rubber gloves with cotton lining are worn routinely by workers on these units, and eye protection is available. There are no routine operations that require the use of respirators; however, NIOSH-approved air-purifying and self-contained, breathing-air respirators are available.

Deasphalting Unit

Unit and Process Description

The deasphalting unit (solvent decarbonizer) and the two crude distillation units are located in the northwest corner of the refinery (Figure C-16). The No. 137 crude unit is directly to the west of the deasphalting unit, and the river is to the north. This deasphalting unit processes the residuals from the vacuum tower (crude units) by solvent extraction to produce gas oil and asphalt. The gas oil is used as FCCU feed, and the asphalt is used to produce No. 6 oil. The capacity of the unit is about $22,000 \mathrm{bbl} /$ day of residual. The unit was down during the Phase I visit but was operating at almost $70 \%$ of capacity during the Phase II and Phase III visits.

This unit is spread out over an area of about 250 by 200 feet (Figure C-19). The two deasphalting towers are located in the southwest corner of the unit, with the charge oil drum and the gas oil flash tower to the north. The three oil charge pumps are just to the northeast of the deasphalting towers. The two gas-fired furnaces are in the northwest corner, and the air-conditioned control room is located on the extreme east side of the unit. The asphalt flash tower, stripper, and pumps, as well as the solvent accumulators, are just to the west of the control room. A series of cooling fans (fin fans) runs from north to south in the center of the unit. 


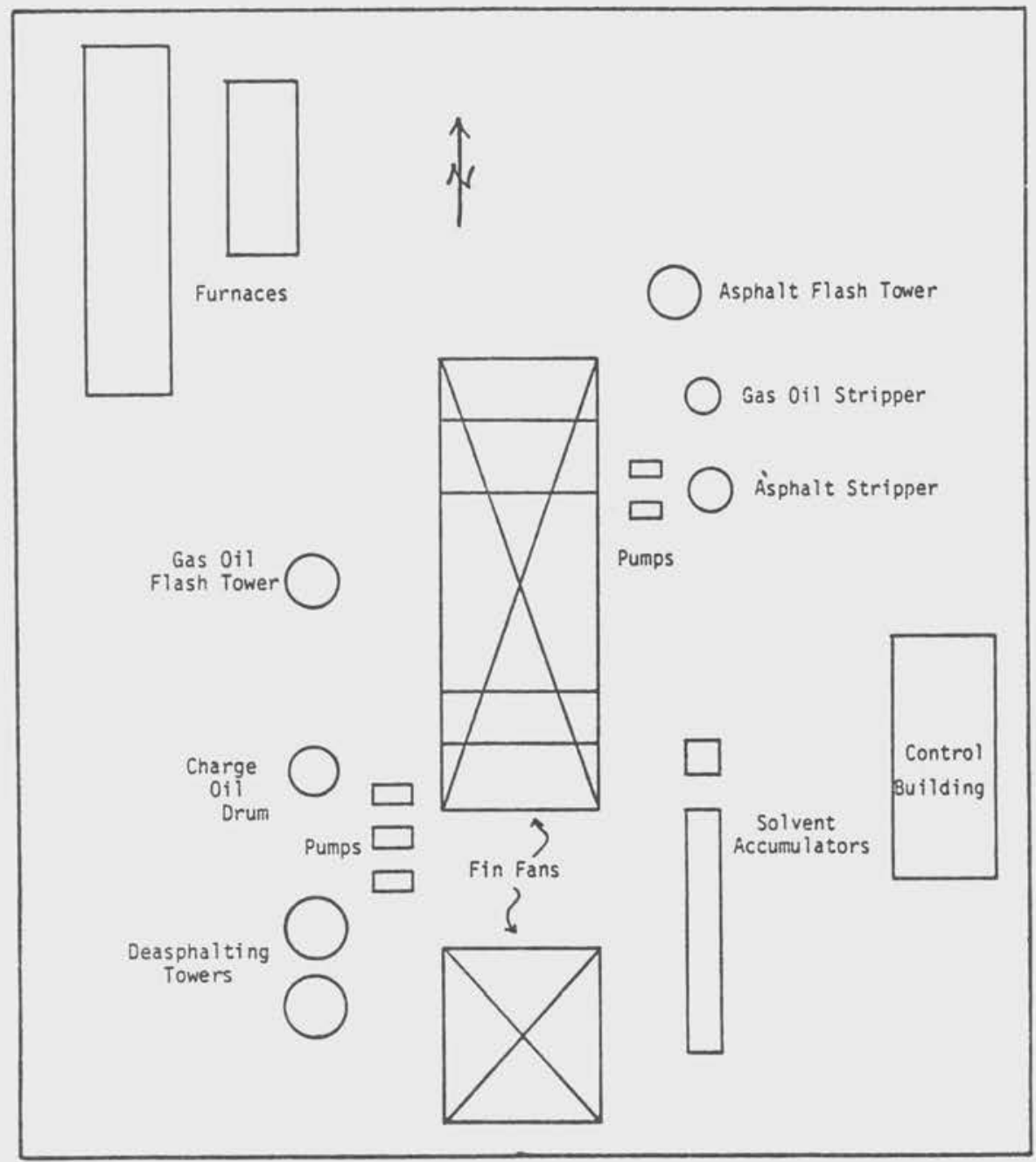

Figure C-19. Refinery E deasphalting unit.

The residuals from the crude units are received in the charge oil drum. The feed is heated by heat exchangers and diluted with solvent before being fed (oil charge pumps) to the center of the deasphalting towers. There it comes in contact with the 1iquid butane/propane $(70: 30)$ and the 1iquid-1iquid extraction process takes place. Asphalt is removed from the bottom of the reactors, and the extracted oil (gas oil) and propane are removed from the top. The asphalt from both towers passes through a gas-fired heater and then to a flash drum where most of the propane is removed and recycled back to the solvent accumulator. The asphalt then goes to the steam-stripper to remove any remaining propane and is pumped (asphalt product pumps) out of the unit to be cut to No. 6 fuel oil.

The oil-propane phase from the deasphalting towers is sent to the oil flash tower where much of the propane and butane is vaporized and recycled back to the solvent accumulator. The oil from the first stage of this flash tower is sent to the gas-fired heater and returned to the flash tower to allow 
further solvent removal. The remaining solvent is removed from the oil by steam-stripping in the oil stripper. This gas oil is pumped to storage tanks until needed as FCCU charge.

Work Force

There are three workers assigned full time to the deasphalting unit; shift hours are from 0700 to 1900 . There are four crews that rotate to cover the 7-day-a-week operation. In addition to these three workers, there is a unit supervisor who has responsibility for this unit and the No. 136 crude unit Monday through Friday from 0700 to 1500 . This supervisor normally splits his shift between the control rooms of the two units. Following is a brief description of the duties of the three full-time shift personnel.

- Operator: Supervises overall unit operations. He normally spends about $80-90 \%$ of his shift inside, where he has responsibility for monitoring and logging in various meters and charts on the control board. He works closely with the two assistant operators. He makes periodic inspections of the whole unit and may oversee minor maintenance work.

- Assistant Operators (2): These are the two workers who perform the routine outside tasks for this unit; duties are very similar. They normally spend between 50 and $75 \%$ of their shift outside making visual inspections, periodically checking gauges and meters, switching valves, oiling pumps, and performing minor maintenance and general unit housekeeping. They collect a small number of process stream samples (e.g., gas oil, asphalt) during the midnight shift only.

\section{Control Measures}

As with the two FCCUs, the primary control measure at this deasphalting unit is a closed system. The unit is fairly open without any enclosed production structures or areas, minimizing potential vapor accumulation. The only areas of the unit handling heavy fractions with a possibility of PAH accumulation are around the oil charge pumps and around the asphalt pumps and stripper.

The small control room of this unit is air-conditioned and under positive pressure. An alarm is triggered when the unit is not under positive pressure, usually indicating that one of the doors has been left partially open. This is important since the control room is often directly downwind of the asphalt pump area.

The assistant operators performed routine cleanup of the unit, which is especially important around the asphalt pumps where leaks often occur. The asphalt is cleaned as much as possible with steam. The ground level of the unit is constructed of concrete to simplify cleanup. 


\section{REFINERY $F$}

\section{DESCRIPTION OF REFINERY F}

Refinery $F$ is a "large" (127,000 bbl/day capacity), "nonmajor" refinery 10cated in Minnesota. The refinery, currently spread over about 1,000 acres, originated in 1955. At the time of the survey, the refinery was operating at about $90 \%$ of capacity and producing a full line of petroleum products which includes:

- liquid petroleum gas (propane, butane)

- gasolines (three grades)

- Diesel fuel
- fuel oils (\#1, \#2, and \#6)

- sponge coke

- asphalt

- sulfur

Although the source varies, the crude refined here is categorized as a "heavy," "sour" (>1\% sulfur by weight), naphthenic crude. Approximately 50\% of the crude comes from Canada by pipeline. The rest comes from various domestic and foreign sources by pipeline and barge. Finished products are shipped by pipeline, railcars, trucks, and barges.

The major process units at refinery $F$ include:
- two crude distillation units
- two vacuum distillation units
- two delayed coker units
- hydrotreating units
- two catalytic reformers
- catalytic polymerization unit
- FCCU
- $\mathrm{H}_{2} \mathrm{SO}_{4}$ alkylation unit
- sulfur recovery unit

There are four main control buildings for the whole production area. The delayed coker has its own, the FCCU shares one with the alkylation unit, and the asphalt processing units (vacuum units) share a control building with the crude and other adjacent units. Figure $\mathrm{C}-20$ shows a rough refinery plot plan of the major production units.

There are approximately 370 hourly employees, including 120 maintenance workers, that belong to the union ( 011 , Chemical and Atomic Workers) and an additional 130 who are salaried (supervisory and administrative personnel). Most of the routine maintenance activity is performed in-house; contractors are brought in for turnarounds and other major projects. The production units operate 24 hours a day over three work shifts.

The safety and health staff at this refinery includes the Health and Safety Coordinator, a safety engineer, a fire marshal, and an occupational heaTth nurse. A11 are under the direct supervision of the Industrial Relations Manager who reports to the Refinery Manager. The nurse is normally on the premises ful1 time during the day shift, 5 days a week; during turnarounds, a nurse is on tine premises at all times. Approximately 325 of the 500 employees are formally trained in first aid. The dispensary ana treatment 
room is fully equipped to handle first aid situations and various routine examinations. All workers are given preemployment medical examinations. Employees assigned to the miscellaneous trades group are given annual physical examinations because of possible asbestos exposure. Several physicians in the area work with the refinery.

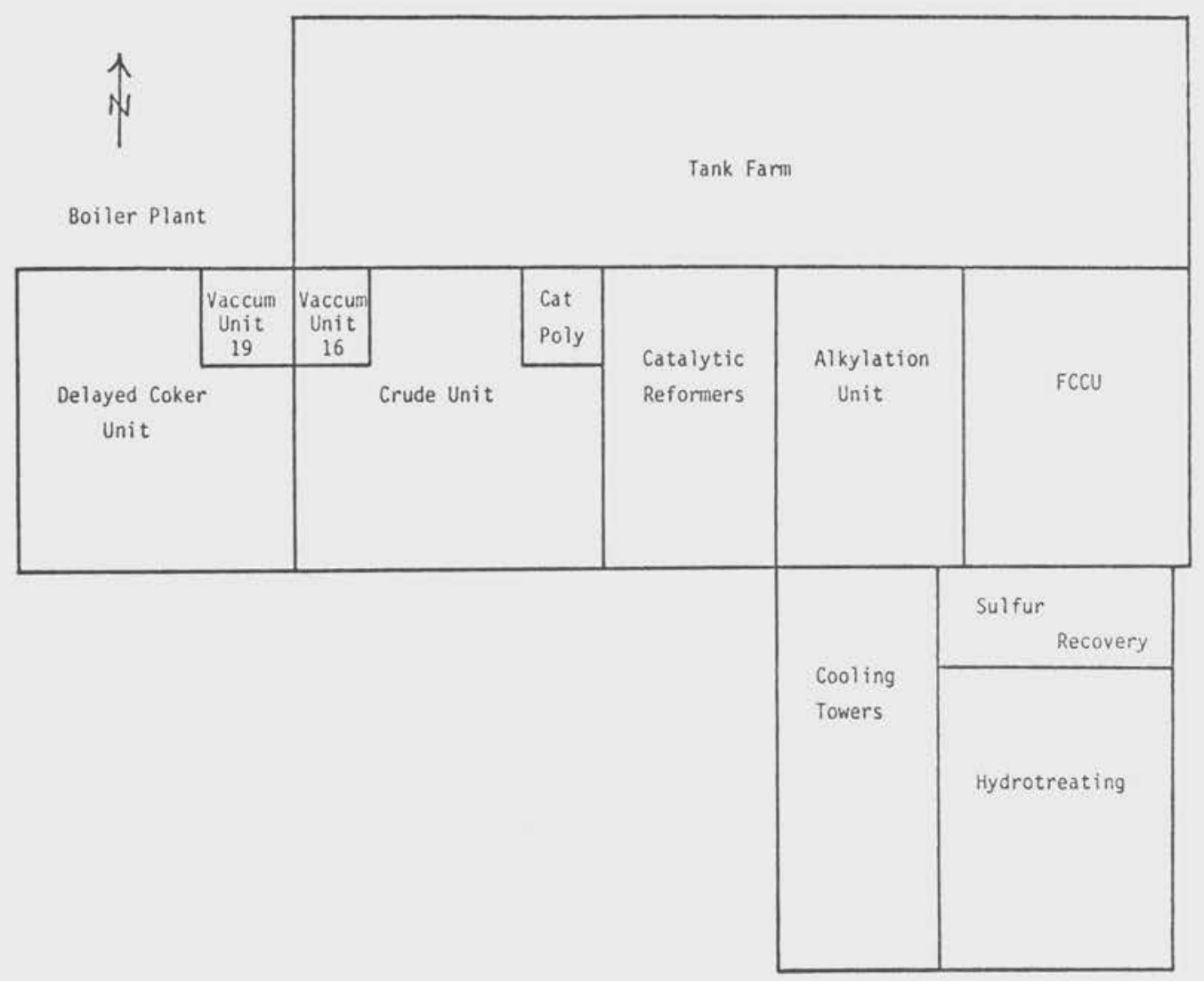

Figure C-20. Refinery F production area.

As part of good industrial hygiene practice, the use of protective clothing and equipment (e.g., hard hats, safety shoes, gloves, eye protection) is emphasized. While eating is allowed in most control rooms, smoking is permitted only in designated areas away from the immediate production areas. Each unit operator is thoroughly trained on the unit and in the classroom on the unit equipment, operations, and associated safety hazards. The practice of good personal hygiene such as the washing of hands before eating is also encouraged. Good unit housekeeping is practiced as an important means of minimizing worker exposure to potential hazards. Spills are promptly cleaned up by the unit operators, and routine cleanup is performed by the day-shift operators. Any necessary equipment or structure repair is also promptly carried out by the unit operators or in-house maintenance crews.

Routine industrial hygiene sampling is not performed at this refinery. In the past, consulting firms have been used to investigate problems as they arise and have performed sampling for chromates (cooling towers), benzene, asbestos, and noise. 


\section{STUDY PROCESS UNITS AT REFINERY F}

\section{Fluid Catalytic Cracker Unit (FCCU)}

\section{Unit and Process Description}

The FCCU is located on the east side of the main production area (Figure C20). The $\mathrm{H}_{2} \mathrm{SO}_{4}$ alkylation unit is to the west, the sulfur recovery unit to the south, garage and laboratory to the east, and storage tanks to the north. The FCCU, including the CO boiler, was constructed and put on stream in 1968. In 1974, major modifications were made to the present unit including the addition of a riser extension to increase capacity, and cyclones in the reactor and regenerator. At the time of the survey, the production capacity of the unit was about $45,000 \mathrm{bbl} /$ day and the FCCU was operating at about $85 \%$ of this capacity.

Figure C-21 illustrates the layout of this unit which occupies an area of about 200 by 150 feet. The fractionator and side-by-side reactor/regenerator $(R / R)$ structure are located in the center of the unit. The feed drum and furnace are just to the west of these structures; and the control building, shared by the adjacent alkylation unit, is farther west on the edge of the FCCU. The catalyst hoppers are at the south end of the unit, and the CO boiler is in the southeast corner. The whole north end of the unit is the gas recovery area, which includes the primary and secondary absorbers, stripper, and debutanizer.

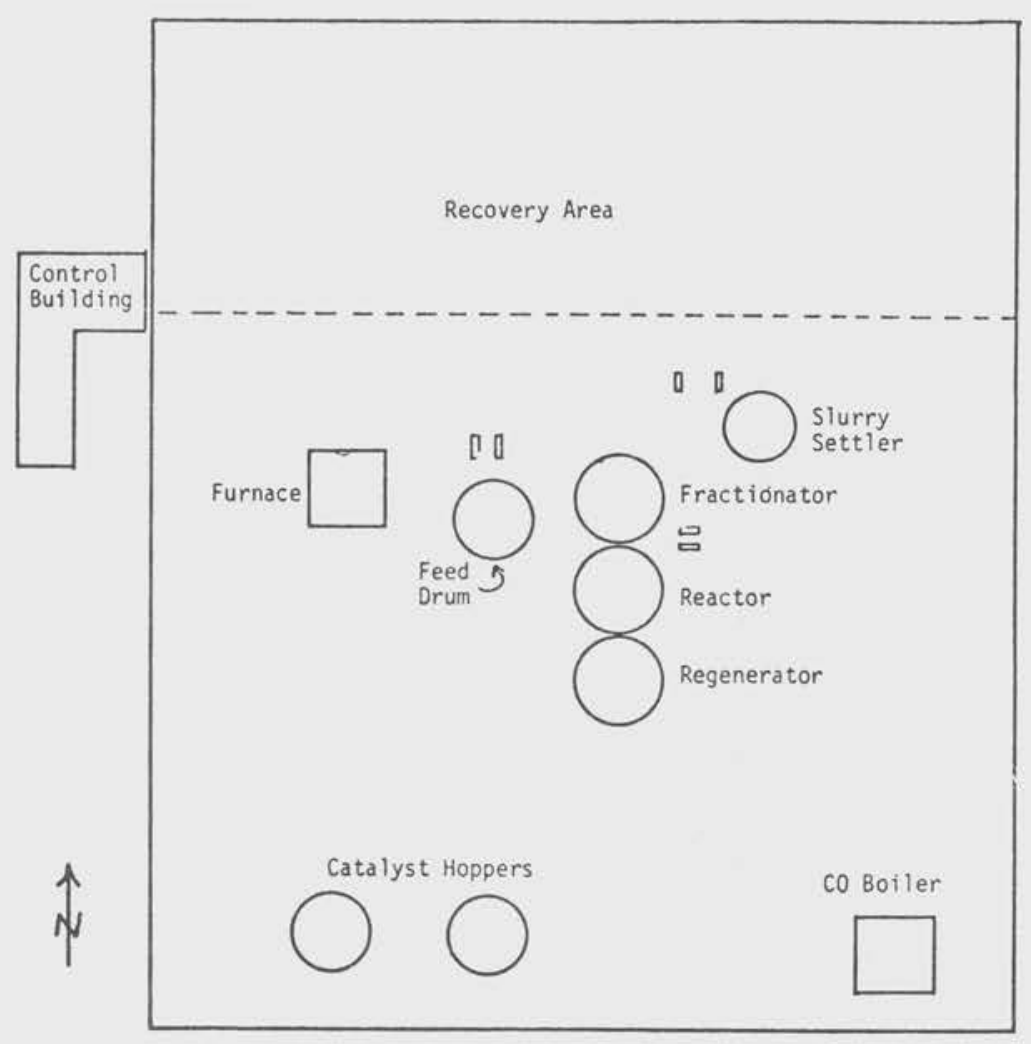

Figure C-21. Refinery F FCCU. 
Fresh feed for the FCCU consists of desulfurized atmospheric and vacuum gas oils. This feed, preheated by a gas-fired charge heater, plus slurry recycle from the fractionator are mixed with the hot catalyst in the single riser leading to the reactor. The catalytic cracking takes place in the riser as well as in the reactor. The catalyst used at this refinery is a synthetic zeolite common to other FCCUs studied in this project. The product vapors and the catalyst are separated (series of cyclones), and the hydrocarbons are taken to the fractionator tower. The catalyst is stripped with steam of any remaining oil and delivered to the regenerator through the spent catalyst leg. In the regenerator, the catalyst is reactivated by oxidizing the accumulated carbon at a temperature above $1,000^{\circ} \mathrm{F}\left(538^{\circ} \mathrm{C}\right)$. The regenerator has a series of cyclones which separate the catalyst fines from the flue gas. From the regenerator, the flue gas goes through an orifice chamber (back-pressure stabilizer) before going on to the co boiler. There it is burned with an auxiliary fuel before being released into the atmosphere. The regenerated catalyst is stripped with steam of any absorbed oxygen before being recirculated back to the riser.

The main products from the fractionator are:

$$
\begin{aligned}
& \text { - propane } \\
& \text { - butane } \\
& \text { - gasoline }
\end{aligned}
$$

- light cycle oil

- heavy cycle oil

- clarified oil (decant oil)

Work Force

There are normally four workers assigned to the FCCU full time during each shift. This includes one \#1 operator and three \#2 operators, including the boardman. In addition, there is a supervisor in charge of personnel, scheduling, and operations of both the FCCU and the adjacent alkylation unit. This supervisor spends about half of his time inside the joint control room and the other half split equally between the production areas of the two units. He visually inspects the units, monitors and assists the operators; and it is his overall duty to ensure smooth operations. Following is a brief description of the duties of the four full-time FCCU operators.

- \#1 Operator: This is the "master" operator on the unit who must understand the entire unit operation. He is in charge of the other operators and assigns daily work tasks. He routinely inspects the entire unit and can assist the operators in performing any of their duties. He normally spends about $60 \%$ of the shift inside the control room.

- \#2 Operator/Boardman: Spends essentially $100 \%$ of his shift inside the control building, monitoring and logging in the various meters and charts on the control board. He works closely with the \#1 operator, as well as with the other outside operators.

- \#2 Operators: These two outside operators perform the routine daily tasks in the production areas under the supervision of the \#1 operator. One is primarily responsible for the cat side, which includes the R/R structure, fractionator, catalyst hoppers, furnace, etc.; the other is responsible for the recovery area which includes the structures in the northern part of the unit. Duties 
include operating and regulating valves, pumps, and compressors to direct flow of process streams; checking temperature and pressure gauges and flow meters; and checking equipment for any malfunctions. The cat side operator samples process streams for gasoline, light cycle oil, slurry recycle, decant oil, as well as the flue gas. He also runs tests on the boiler feedwater for chemical characteristics. Both operators perform various manual tasks to maintain process control. During an average shift, they spend about $40 \%$ of the time outside in the production area.

During both sampling shifts of the survey, there was also a \#1 operator trainee. This person worked very closely with the \#1 operator, observing and occasionally performing the various duties.

\section{Exposure Control Measures}

The primary exposure control measure used at this FCCU is a closed-system process which limits exposure to products, by-products, and intermediates. Also important is a well-organized maintenance program which provides both efficient preventive and repair maintenance services. Under normal operating conditions, exposure to PAHs may occur during sampling of the various streams, during maintenance and housekeeping activities, from fugitive emissions, and from the regenerator flue gas.

Liquid process stream samples are collected by the open-spigot-and-bottle method without sampling loops. The operator flushes the sample lines directly into the unit sewer system before filling the sample bottle. Product coolers (water coolers) are used to cool hot process streams before sampling. Most of the heavy-fraction process stream samples (more likely to contain the PAHs) are collected by the \#2 operator assigned to the cat side. Propane and butane gas samples are collected by laboratory technicians using sample bombs.

Exposure during routine and any emergency maintenance is difficult to minimize. The ground level of the unit is mostly sand and gravel with concrete foundations around structures. The lack of a complete concrete foundation may pose a cleanup problem for major spills. The refinery has its own craft maintenance crews (e.g., pipefitters, electricians) that provide preventive and repair services. The last major turnaround of this unit was during 1978 with the next one scheduled for October of 1980.

Hard hats and safety shoes are worn routinely; eye and ear protection and slick suits are available. Coveralls are not provided and are not normally worn. There are no routine operations that require the use of respirators; however, NIOSH-approved air-purifying and self-contained, breathing-air (SCBA) respirators are available. The air-purifying equipment is maintained by the individual operators while the SCBAs are maintained by the refinery safety department.

The areas of the unit handling heavy fractions are fairly open, minimizing potential vapor accumulation. Several of the charge, slurry recycle, and decant oil pumps are located in the same vicinity near the fractionator; the 
surrounding pipes and structures create a "tunnel-effect" here. This is an area where PAH concentrations might be elevated. The control house is airconditioned and under positive pressure. A 35-foot stack provides the incoming air supply. The control building is not normally downwind of the R/R or heavy-fraction pumps.

The flue gas from the regenerator is burned in the $\mathrm{CO}$ boiler with an auxiliary fuel. The heat produced here is used to generate steam. The CO boiler removes not only carbon monoxide from the flue gas but many other hydrocarbons, making the effluent suitable for discharge to the atmosphere.

Delayed Coker Unit

\section{Unit and Process Description}

The delayed coker unit is located on the west end of the main production area (Figure $\mathrm{C}-20)$. The boiler plant is to the north, and the crude and vacuum units are to the east and northeast. The delayed coker unit is actually two identical operational units within the same physical unit. There are two pairs of 98-foot coke drums, two charge furnaces, and two fractionators. There is one coke recovery area and one control building. The total unit has a daily production capacity of about 1,300 tons of sponge coke.

The unit was built in 1955-1956 with drums A and B; the other two drums were added in 1963. Drums A and B were replaced during the 1977-1978 unit turnaround. The unit is spread over an area of about 200 by 200 feet (Figure $\mathrm{C}-22$ ). The ground level of the entire unit is constructed of concrete. The control building is located in the central area of the unit and houses the locker and shower facilities in addition to the control board room. West of the control building is the coke tower (an open, multilevel structure that includes the four drums and penthouse at the top) with the sluiceway and coke field farther west. The coke that has been cut is moved from the sluiceway to the coke field with a dragline consisting of a cable-drawn bucket scoop. The coke is allowed to dry on the coke field and is then moved by bulldozers to the screening area where the coke is sized and loaded onto railcars and trucks by conveyor.

The two gas- and oil-fired charge furnaces are located to the north and south of the coke tower; the two fractionators are located between these furnaces and the control building. The coker gas recovery unit is to the east of the control building. The coker flare is located remotely to the south of the coker unit.

Sponge or No. 2 grade coke is the only type produced at this refinery. The charge stock is primarily residual (asphalt) from the vacuum distillation units. The charge is pumped to the fractionators where the lighter fractions are separated and processed in the vapor recovery area. The bottoms from the fractionators are then pumped to the furnaces where they are heated to a suitable reaction temperature (normally about $900^{\circ} \mathrm{F}$ or $482^{\circ} \mathrm{C}$ ). The heated charge then goes to one of the four coking drums where the thermal cracking process begins. There are two pairs of drums, and each drum has a 40-hour cycle (each pair has a 20-hour cycle) with coke formation lasting 
about 20 hours. Normally one drum is cut every 10 hours. Vapors off the top of the drum are sent to the fractionators where various products are separated and eventually recovered. Products from this unit, other than coke, include propane, butane, gas oil, and naphtha.

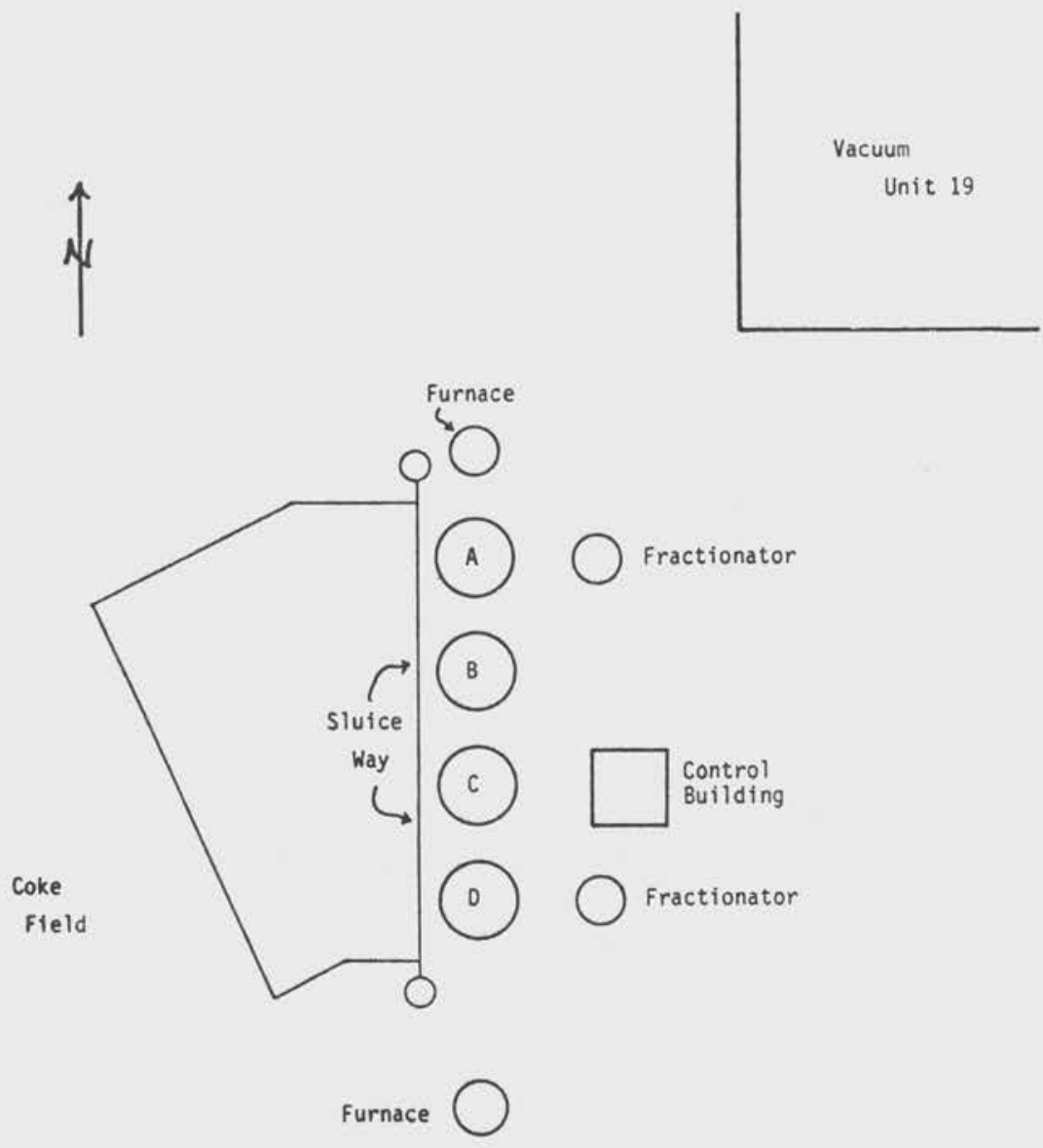

Figure C-22. Refinery F delayed coker unit.

Routine procedures are used at this unit for preparing each drum for cutting. Coke formation is stopped by switching the feed to the other cirum of the pair. Steam followed by water is used to cool the drum; this lasts several hours. About 1 hour before cutting is scheduled, the top and bottom of the drum are opened, and the coke is cut with a high-pressure hydraulic bit. An initial hole is bored through the coke, and then the coke is cut from the bottom up. The coke then falls down a chute into the sluiceway. Drilling normally lasts from 3 to 5 hours.

After cutting is completed, the top and bottom of the drum are replaced; the drum is pressure-tested for seal, is heated, and is ready when the feed is switched from the other drum to begin coke formation. 
The work force for the delayed coker unit is divided into two groups, the operations group and the decoker (coke cutting and handling) group. Both groups work the normal 8-hour shift. The operations group is normally made up of one \#1 operator, three \#2 operators (including the boardman), and the unit supervisor; following is a brief description of their job activities.

- Supervisor: Has overall responsibility for both the delayed coker unit and the adjacent boiler plant. He generally spends about $75 \%$ of his shift dealing with the delayed coker unit and $25 \%$ with the boiler plant. He spends about 1 to $1 \frac{1}{2}$ hours per shift in the control room and periodically patrols the production areas, but he also spends a good part of any shift in other parts of the refinery (e.g., shift supervisor's office).

- \#1 Operator: Duties very similar to those of the \#1 operator for the FCCU. He is the "master" operator and supervises the other operational personnel. He normally spends about $60 \%$ of the shift inside the control room and works closely with the boardman and the other \#2 operators. He normally delegates the routine outside tasks but may occasionally assist. He does perform periodic visual inspections of the production areas.

- \#2 Operator/Boardman: Spends essentially $100 \%$ of his shift inside the control building, monitoring and logging in the various meters and charts on the control board. He works closely with the \#1 operator, as well as with the other outside operators.

- \#2 operators: During the two sampling shifts of the survey, these two outside operators worked together to perform the routine outside tasks. This included opening and closing valves to direct charge to the various drums, depressurizing drums, steam-testing drums for leaks, testing spare pumps, draining the fire drum and clarifier, cooling the drums, and making periodic rounds to detect any equipment malfunction. They spend about $40 \%$ of their shift outside in the production area.

The decoker group is made up of the supervisor, a \#1 decoker (dri11er), and four \#2 decokers. They do not work out of the main control building but a small separate building at the foot of the coke pile (coke field); most of their shift is spent outside. Following is a brief description of their job duties.

- Supervisor: Spends about $75 \%$ of his shift outside; about $90 \%$ of that time is spent in the coke-loading area. He primarily patrols the various areas, monitoring workers and directing operations.

- \#1 Decoker (Drizler): He is the lead decoker and delegates various tasks. During the survey, he directed the deheading of the drum and then performed the drilling from the penthouse at the top of the coke tower. When cutting is not performed during a particular shift, he may assist in any of the coke-handling activities. 
- \#2 Decokers: Normally there are four \#2 decokers per shift. They help dehead the top and bottom of the drum before cutting, position the drum extender, close the drum after cutting, and clean up. While the drum is being cut, they perform the coke-handling duties. One decoker ("Sauerman") is stationed in an elevated cubicle on the north end of the sluiceway and operates the mechanical scoop that moves the coke to the coke field. Another decoker operates the bulldozer moving the coke from the coke field to the screening and loading area, and the other may be at the loading area. The decokers alternate what they do from shift to shift, as well as during a shift.

\section{Control Measures}

The coke-cutting operation is one of the few in a refinery that is not a closed system. Because of this, it is more difficult to minimize worker exposure during this operation. During every cutting cycle, the top and bottom of the drup must be opened manually; the coke must be cut by the driller; the Sauerman must move the coke out of the sluiceway; and the other coke handlers must move and load the coke. Basically, the coke-cutting operations at this refinery were similar to those observed at other refineries; however, coke handling was more extensive after the coke was cut.

The opening of the top and bottom of the drum was done very efficiently and quickly. The three coke cutters worked as a team to complete both openings in about 30 minutes. After the bottom is dropped, a chute extender is lifted up from the floor platform to the bottom of the drum and secured with a chain mechanism ("chain fall"). This forms a closed system on this level. Once cutting starts, the cutters (except the driller) leave the coke tower to switch to coke-handling duties. The whole cutting operation at this refinery is relatively clean requiring a minimum of cleanup, usually performed by hosing down the area with water.

All workers on this unit wore hard hats, safety glasses, and gloves. Neither the cutters nor the operational crew wore coveralls, but the cutters did normally change into a set of work clothes in the locker room and showered or washed up at the end of their shift. The cutters did wear rain gear or slick suits when deheading the drums. The operations crew ate in the control room while the decokers usually ate in their work building. There were no routine operations that required the use of respirators; however, NIOSHapproved air-purifying and self-contained, breathing-air respirators were available.

The steam that is used to cool the drums down goes through a condensation system froin which uncondensed steam and/or hydrocarbon vapors go to the coker flare. As with the FCCU, the air-conditioned control room was under positive pressure and supplied with intake air from a stack extending 35 feet above ground level. 
Asphalt Processing

Unit and Process Description

The asphalt processing at this refinery consists of two vacuum distillation units; the bottoms from the fractionating towers are pumped to storage (and blending) or to the delayed coker unit as charge. The two vacuum units are adjacent to each other; vacuum unit No. 16 is in the northwest corner of the crude area, and unit No. 19 is in the northeast corner of the delayed coker area (Figure $\mathrm{C}-20$ ). Both vacuum units are monitored from the control room located in the middle of the crude area. The asphalt production capacity of this refinery is about $35,000 \mathrm{bbl} /$ day.

Work Force

No workers are assigned full time to either of the vacuum units. One or more of the outside operators of the crude units spend a small part of their shift covering these units. 
DESCRIPTION OF REFINERY G

Refinery G is a "large" (120,000 bbl/day), "major" refinery located in northern Ohio near Lake Erie. The refinery was built originally in 1911; almost all of the major process units have been rebuilt since 1958 . Currently the refinery occupies about 450 acres and produces a full 1 ine of petroleum products which includes:
- propane
- butane
- hydrogen
- gasoline
- fuel oils (No. 2)
- Diesel oil
- kerosene
- sponge and needle coke
- asphalt

Most of the crude refined here is a mixture of foreign crudes. During the survey, the crude being refined at the No. 1 unit was a combination of North Sea, Trinidad, East Texas, Michigan, and several others, categorized together as a "sweet" (0.3-0.4\% sulfur by weight), "mixed base" (containing both paraffins and naphthenes) crude with an API Gravity Index of 40.3. The crude refined at the No. 2 unit was primarily Arabian with small percentages from Texas and Trinidad; this crude was categorized as a "sour" (1.3-1.5\% sulfur by weight), "mixed base" crude with an API Gravity Index of 34. Most of the crude is received by pipelines; most of the products are shipped by pipeline, barges, and railcars.

The major process units at Refinery G include:
- two crude distillation units
- two vacuum distillation units
- two catalytic reformers
- three alkylation units
- two isocracking units
- FCCU
- asphalt blower unit
- catalytic polymerization unit
- delayed coker unit
- hydrogen production unit
- naphtha treater
- sulfur recovery

There is one main control building ("nerve center") located west of the FCCU and naphtha treater, and several smaller control buildings ("satellites") located throughout the production areas. Figure $\mathrm{C}-23$ shows a rough refinery plot plan of the major units.

There are approximately 380 hourly employees that belong to the union (OCAW) and an additional 180 that are salaried (supervisory and administrative personnel). Most of the routine maintenance activity is performed in-house; contractors are brought in for turnarounds and other major maintenance work. The production units operate 24 hours a day over three work shifts. 


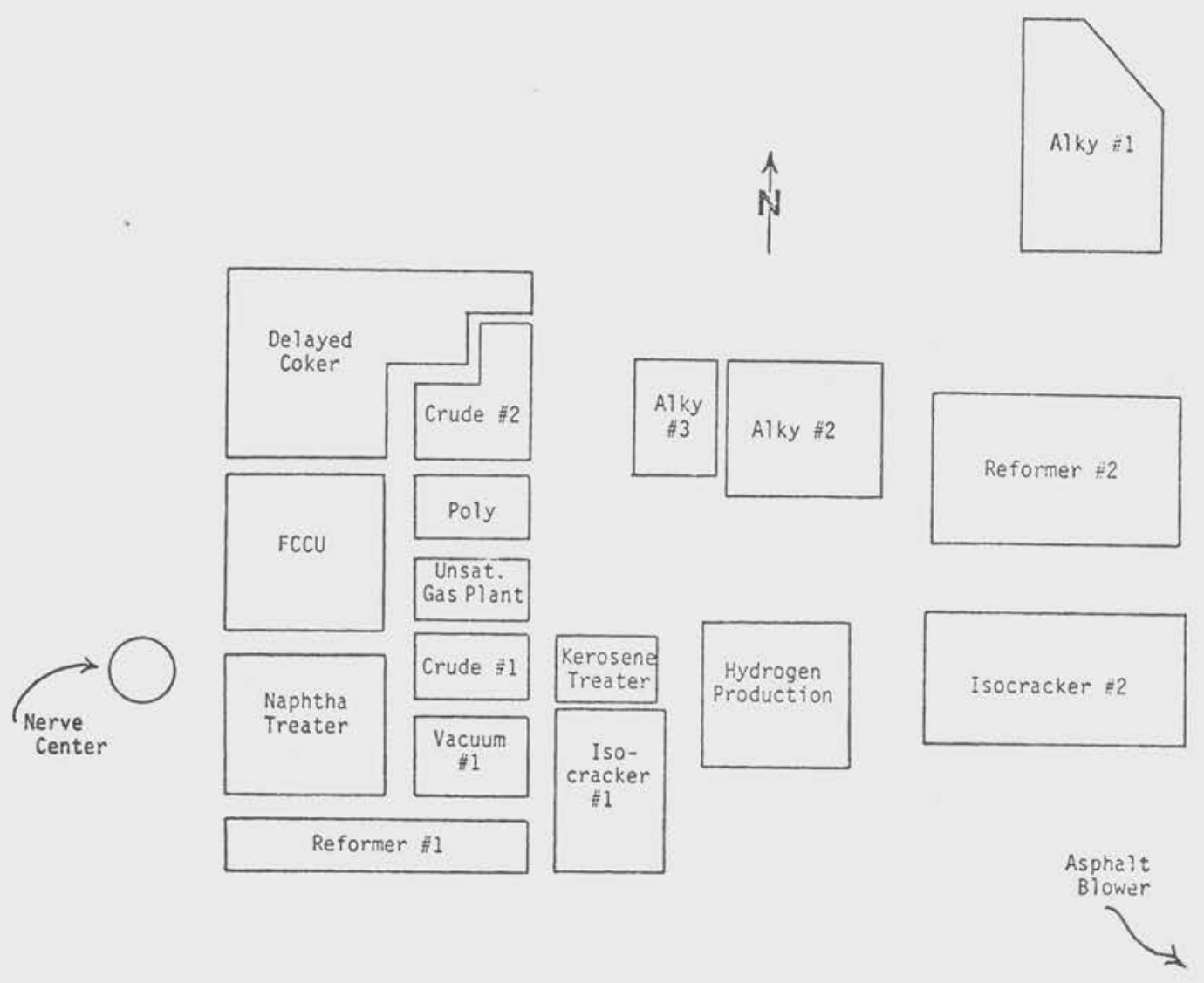

Figure C-23. Refinery G main production area.

The safety and health staff at this refinery includes the safety director, the fire protection specialist, the health and safety specialist, the general safety specialist, the security and safety officer, and the plant nurse. The nurse is on the premises from 0730 to 1600,5 days a week. Al1 newly hired employees undergo an 8-hour Red Cross first aid training session; in addition, a small number of employees (especially safety personnel) have been trained in cardiopulmonary resuscitation. The dispensary and treatment room is fully equipped to handle first aid situations and various routine examinations. All of the production workers are given preplacement medical examinations; periodic examinations are given at least once every 5 years. Physical examinations are given by a physician hired by the company.

As part of good industrial hygiene practice, the use of protective clothing and equipment (e.g., hard hats, safety shoes, long-sleeved shirts, eye protection) is emphasized. Eating is allowed in most control rooms; smoking is not allowed in the production or storage areas. All new employees attend an extensive training session over a 1 -week period which includes information on unit equipment, operations, respirator use, safety hazards, fire protection, and first aid. New employees usually spend their first year in maintenance where formal training continues, and then, once on a unit, the new operators are trained for at least another 2 months on the job. Good unit 
housekeeping is practiced as an important means of minimizing worker exposure to potential hazards. Spills are promptly cleaned up by the unit operators, and any necessary equipment or structure repair is promptly carried out by the unit operators or in-house maintenance crews.

The safety staff is responsible for the industrial hygiene sampling. Although a routine sampling schedule is not yet established here, a considerable amount of monitoring is conducted upon request, for compliance purposes, and for any other reasons felt necessary by the refinery personnel.

\section{STUDY PROCESS UNITS AT REFINERY G}

Fluid Catalytic Cracker Unit (FCCU)

\section{Unit and Process Description}

The FCCU is located on the west side of the main refinery production area (Figure $\mathrm{C}-23$ ), south of the delayed coker unit and north of the naphtha treater. The present unit, including the $\mathrm{CO}$ boiler, was built in 1958 and currently has a production capacity of about 55,000 bbl/day.

The unit is divided into two main sections, FCC \#1 and FCC \#2, that together occupy an area of about 250 by 200 feet (Figure C-24). FCC \#1 includes the CO boiler, side-by-side reactor/regenerator (R/R) structure, fractionator, two catalyst hoppers, and numerous pumps (including several heavy-fraction pumps). FCC \#2 is located to the north of FCC \#1 and includes the air blower, gas compressors, numerous heat exchangers, pumps, and drums. Most of the process streams in FCC \#2 are the lighter fractions. The unsaturated gas plant is located east of FCC \#1 and includes gas recovery structures such as the secondary absorber, gasoline splitter, depropanizer, gasoline and other distillate treaters, and numerous pumps. The unsaturated gas plant is considered a separate unit from the FCCU and is run out of a different control rocm by separate operators.

There is a long, enclosed building to the west of FCC \#1; this building houses numerous compressors and a separate work station for the two FCCU operators. South of this long building is the main control building ("nerve center") for the FCCU, delayed coker, and several other units located in this area.

The fresh feed for the FCCU comes from the crude units (atmospheric gas oil), the vacuum units (mostly light and heavy vacuum gas oils), and the delayed coker unit (gas oil). The feed is preheated to a suitable temperature by a gas-fired furnace located in the naphtha treater unit.

This fresh feed plus slurry recycle from the fractionator are injected into the reactor where catalytic cracking is initiated as the hot oil feed contacts the catalyst. The catalyst used at this refinery is an alumina-like synthetic zeolite common in other FCCUs studied in this project. The product vapors and the catalyst are separated in the single-feed riser line and the reactor itself. The hydrocarbons are taken to the fractionator tower where the various products are separated. The catalyst is stripped of any 
remaining oil with steam and delivered to the regenerator where the spent catalyst is reactivated by oxidizing the accumulated carbon at a temperature of about $1,200^{\circ} \mathrm{F}\left(649^{\circ} \mathrm{C}\right)$. The flue gas from the regenerator goes to the $\mathrm{C} 0$ boiler where it is burned before being released to the atmosphere. The regenerated catalyst is stripped of any absorbed oxygen with steam before being recirculated back to the reactor.

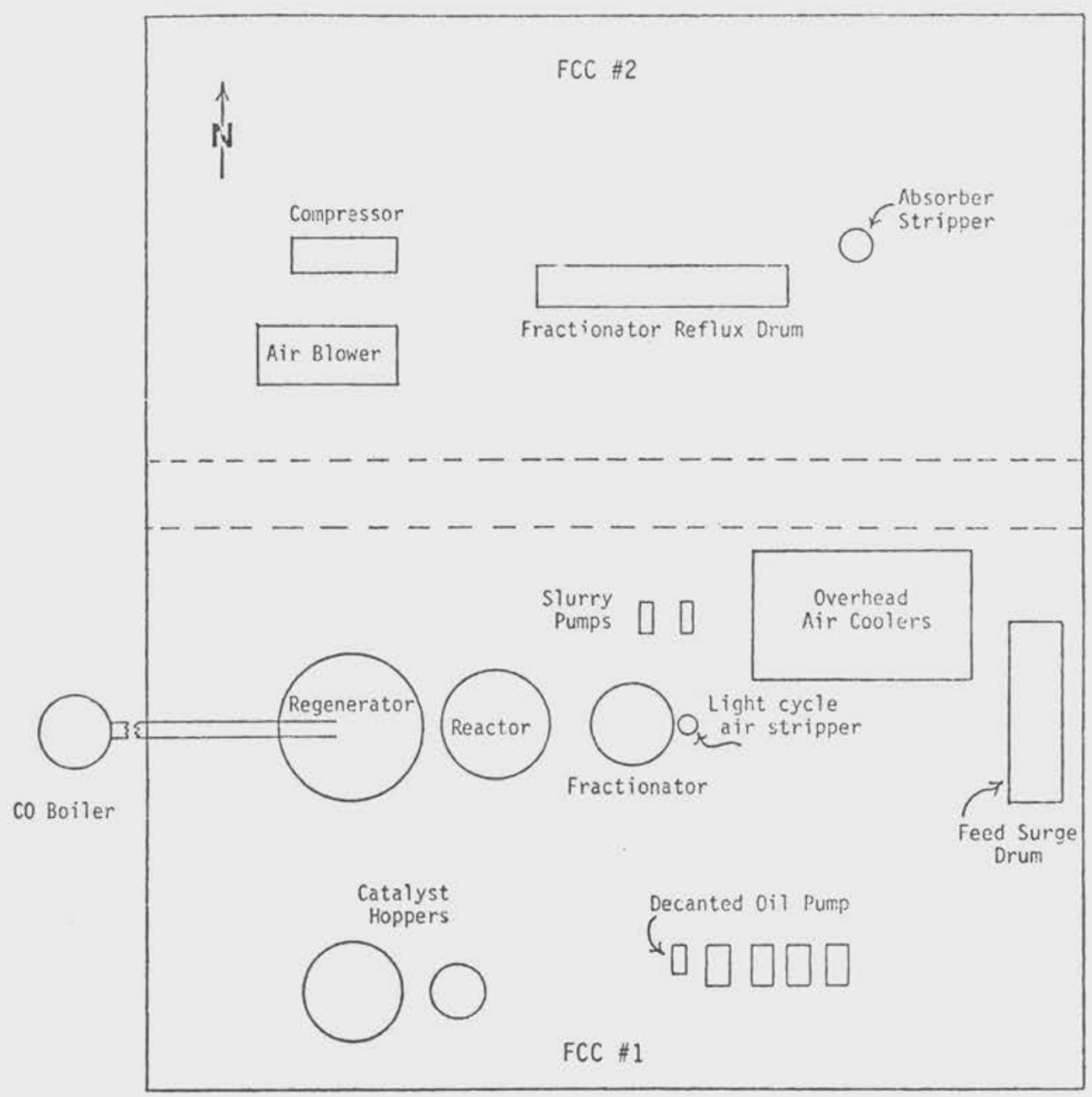

Figure C-24. Refinery G FCCU.

The main products from the fractionator are:

- butane

- isobutane (alky feed)

- propane

- propylene
- cat gasoline

- light cat gas oil (furnace oil)

- decant oil 
There are normally only two operators (one each for FCC \#1 and FCC \#2) assigned full time to the FCCUs during each shift. Both operators work out of the small work station in the long building just north of the nerve center. In addition, there are three workers who have responsibilities for all "north-side units," including the FCCU. These three north-side workers operate out of the nerve center. Following is a brief description of the activities of these five workers.

- FCC \#1 Operator: Performs the routine outside tasks for the FCC \#1 section. This includes maintaining the numerous pumps, taking temperature and pressure readings, supplying and adding fresh catalyst, and periodically patrolling the entire FCC \#1 section to detect any leaks or malfunctions. Performs minor cleanup and maintenance tasks. He also collects spent catalyst and process stream samples (e.g., decant oil, slurry recycle, fresh feed, light gas 0il, heavy gas oil). Spends about $60 \%$ of the shift in the FCC \#1 area and the rest in the work station.

- FCC \#2 Operator: Performs outside duties similar to those of the FCC \#1 operator for the FCC \#2 section. Duties include regulating valves, pumps, compressors, and auxiliary equipment to direct flow of products; checking temperature and pressure gauges and flow meters; and patrolling the section for any malfunction. Spends about $60 \%$ of the shift in the FCC \#2 area and the rest in the work station.

- North Inside General Operator: Spends essentially $100 \%$ of his shift inside the nerve center, monitoring and logging in the various meters and charts on the control board.

- North outside General Operator: Lends assistance to the operators on any of the north-side units; this includes the FCC \#1, FCC \#2, unsaturated gas plant, polymerization, cokers 1 and 2 , crude vacuum No. 2, and the cooling towers. This requires a very experienced operator who knows how to perform all of the various tasks on the north side. Normally spends about $90 \%$ of his shift outside.

- North Operating Foreman: Monitors and supervises the operations of the north-side process units. Periodically visits each unit, checking with the various unit operators for any problems or unusual conditions. His responsibility is to ensure the smooth operations of these units. Can answer technical questions, direct emergency procedures, or provide communications to any of the other refinery sectors. This foreman spends about $95 \%$ of his shift outside. 
The exposure control measures used at this FCCU are quite typical of those observed at the other FCCUs studied during this project. The primary control measure is a closed-system process which limits exposure to products, by-products, and intermediates. Important also is a well-organized maintenance program that provides both efficient preventive and repair maintenance services. Under normal operating conditions, exposure to PAHs may occur during sampling of the various streams, during maintenance and housekeeping activities, from fugitive emissions, and from the regenerator flue gas.

Sample bombs and the open-spigot-and-bottle method are used to collect process samples at this unit. Sample bombs are used to collect the lighter fraction gases (e.g., propane, butane, isobutane); these samples are collected by laboratory technicians and are taken to the laboratory for analysis. The liquid process stream samples, including several heavy-fraction streams (e.g., decant oil, slurry recycle), are collected by the unit operators by the open-spigot-and-bottle method. Sampling loops are not used; the sample lines are flushed directly into the sewer system. The only type of control measure used for this type of sampling is the water-cooling of hot liquid samples before collection. This reduces sample vaporization during sampling. Although the operators normally perform the sampling quickly and without skin contact, this is a definite potential source of PAH exposure.

Exposure during routine maintenance is difficult to minimize. The ground level of the unit is constructed of concrete, and the pump area has a sewer system which simplifies cleanup procedures. The refinery has its own craft crews (e.g., pipefitters, electricians) that provide preventive and repair services. The last major turnaround for this unit was in 1977.

Hard hats, safety shoes, eye protection, and long-sleeved shirts are required on this unit. Coveralls are not provided and are not normally worn. Ear protection is used in the compressor room and fractionator/pump area. There are no routine operations that require the usage of respirators; however, NIOSH- approved air-purifying and self-contained, breathing-air respirators are available. These respirators are maintained by the refinery safety department and the unit operators.

The areas of the unit handling heavy fractions, which are more likely to contain the PAHs, are in fairly open areas, minimizing potential vapor accumulation. Several of the heavy gas oil, slurry recycle, and decant oil pumps are located close together near the fractionator tower. This is an area where PAH concentrations might be elevated. The operators' work station and the nerve center are both air-conditioned but not under positive pressure and are occasionally downwind of the R/R, fractionator, and heavyfraction pumps.

The flue gas from the regenerator goes through a series of cyclones to remove catalyst fines and is then burned in the $\mathrm{CO}$ boiler with an auxiliary fuel. The CO boiler removes not only carbon monoxide from the flue gas but also many hydrocarbons, making the effluent suitable for discharge to the a tmosphere. 
Delayed Coker Unit

\section{Unit and Process Description}

The delayed coker unit, as shown in Figure $\mathrm{C}-23$, is located at the north end of the refinery production area. The FCCU is to the south and the No. 2 crude and vacuum units are to the south and east. There are actually two separate delayed coking units within the one area. Coker \#1, built in 1958, has two 89-foot coke drums with a daily production capacity of about 440 tons of sponge coke. Coker \#2, built in 1966, has two 64-foot coke drums with a daily capacity of 240 tons of needle coke.

The unit is spread over an area of about 500 by 250 feet, with the No. 2 crude vacuum unit in the southeast corner of the unit (Figure C-25). Both coke towers (open, multilevel structures that include the coke drums) are at the north end of the unit; parallel railroad tracks run beneath each pair of drums. Both sets (coker \#1 and coker \#2) of charge furnaces, charge furnace pumps, and fractionators (bubble towers) are to the south of the coke towers and railroad tracks. The single control building, also housing the locker and tool room, is located about 30 feet south of the coker \#2 charge furnace. The blowdown drum and containment pit are located about 200 feet east of the coke towers.

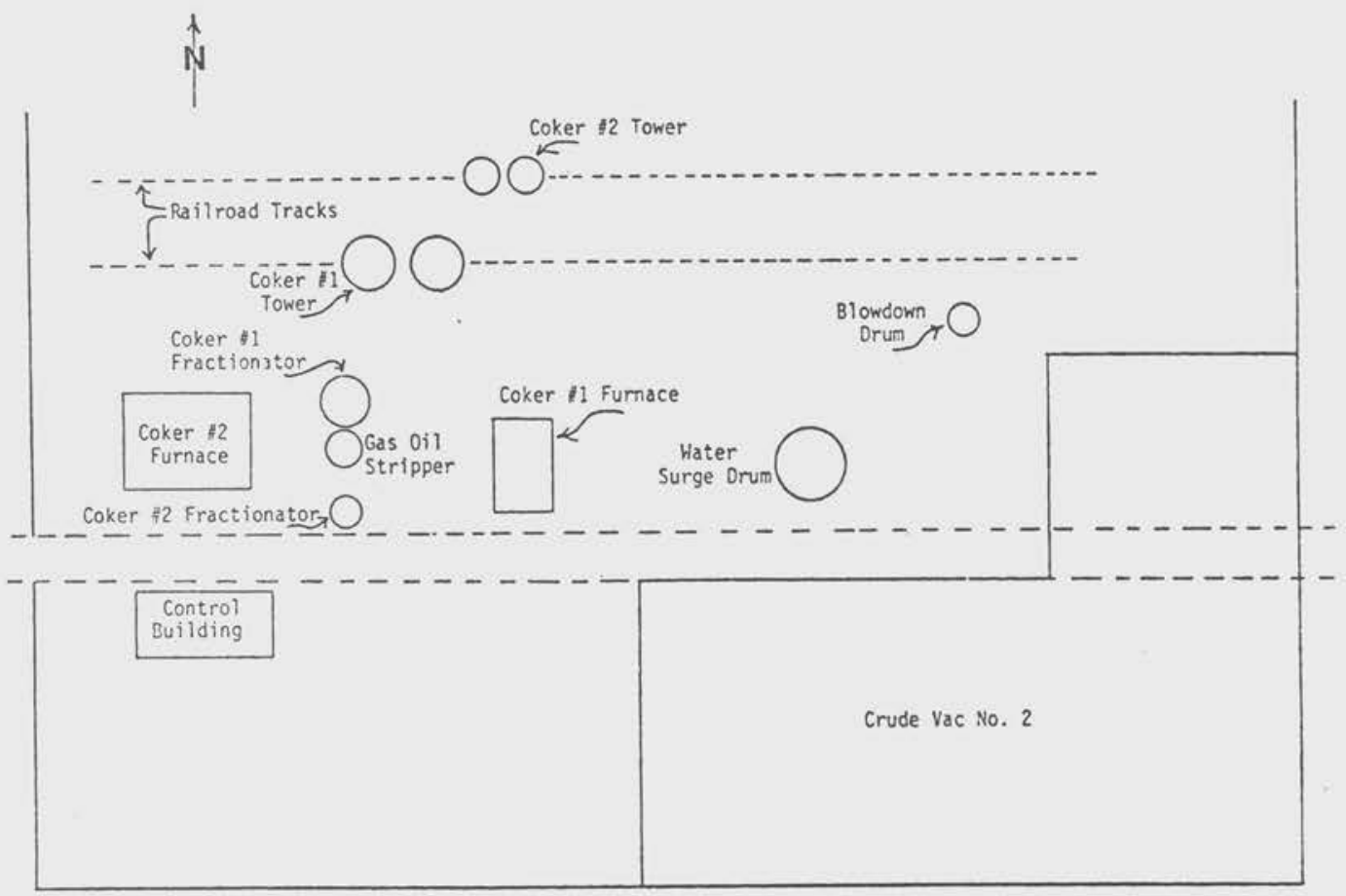

Figure C-25. Refinery G delayed coker unit. 
Coker \#1 produces a \#2 grade coke referred to as sponge coke. The residual from the vacuum units is pumped from storage to the coker \#1 fractionator where the lighter fractions are separated and recovered. The bottoms from the fractionator are then pumped (furnace charge pump) to the gas-fired furnace where they are heated to about $900^{\circ} \mathrm{F}\left(482^{\circ} \mathrm{C}\right)$. The heated charge then goes to one of the two coker \#1 drums where the thermal cracking process begins. Each drum has a 48-hour cycle with coke formation lasting about 24 hours. One coker \#1 drum is cut about every 24 hours. The 1 ighter vapor fractions of the thermal cracking operation are removed from the top of the drum and sent to the fractionator where the various products are separated and eventually recovered. Products from coker \#1, other than sponge coke, include: fuel gas, gasoline, intermediate distillate, and FCCU charge (gas oil).

Coker \#2 produces a \#1 grade coke referred to as needle coke, a higher quality coke that is much harder and denser than the sponge type. The unit utilizes a different feedstock from coker \#1, and the operating parameters, temperature and pressure, are also different. Otherwise, the two units are quite similar in operation with each drum operating on a 48-hour cycle. The products from coker \#2, other than needle coke, include: fuel gas, propane/ butane fraction to crude overhead receiver, and FCCU feed (gas oil).

A complete cycle of each drum from heating to cutting is 48 hours. About 9 hours before the cutting operation is scheduled, coke formation (24 hours)

is stopped by switching the feed to the other drum. In 1 hour, steam is introduced into the drum to cool it. This lasts about 2 hours, and then water is added to further cool the drum ( 6 hours). Nine hours after the feed is switched, the top and bottom of the drum are opened, and the coke is cut with a high-pressure hydraulic bit. An initial hole is bored through

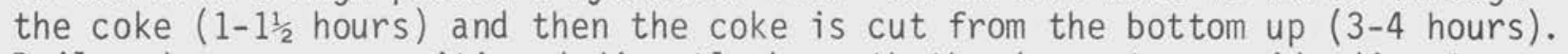
Railroad cars are positioned directly beneath the drums to provide direct loading as the coke is cut.

After cutting is completed, the top and bottom of the drum are replaced; the drum is pressure-tested for seal, heated, and is ready to begin coke formation when the feed is switched from the other drum. The entire cutting operation normally lasts up to 8 hours.

Work Force

The work force for the delayed coker unit is divided into two groups, the operational group and the coke-handling group. The two-person operational group works the normal 8-hour shift; following is a brief description of their job activities.

- Coker \#1 Operator: This operator and the coker \#2 operator perform all of the routine outside tasks for this unit. The coker \#1 operator has responsibility for the areas including the coke tower, furnaces, containment pit, and jet pump area. Performs visual inspection tours of this area four times per shift, checking for leaks, spills, or any malfunctions that may create an unsafe condition. 
These tours usually last from 15 to 30 minutes. Other duties include meter and gauge readings, valve switching, and also monitoring and logging in the various charts and gauges in the control room. Normally spends about $50 \%$ of the shift outside in the production areas.

- Coker \#2 Operator: Has responsibility for the various pumps, fractionators, and other gas recovery towers and equipment. Duties include visual inspection of equipment, meter and gauge readings, starting and shutting down pumps, lubricating and oiling pumps, and sample collecting. Eight process streams are normally sampled each day shift; these streams include light distillate, intermediate distillate, gas oil, furnace charge, and decant oil feed. This operator normally spends about $50 \%$ of the shift outside in the production areas.

The coke-handling group is normally made up of the driller and three others during the day shift; during the evening shift (1500-2300), there is one less worker. Following is a brief description of their job activities.

- Drizzer: Deheads the top of the drum with or without help, and sometimes helps with the bottom. The great majority of the shift is spent at the drilling station in the coke tower penthouse. It takes about an hour to make the initial "bore-through" and then the bit is switched for the actual cutting, which lasts about $2 \frac{1}{2}$ hours for sponge coke and 5-6 hours for needle coke. He then helps to close the drum and with the general cleanup operations.

- \#2 Cleaner: Acts as the relief man and assistant to the driller and \#3 cleaner. Periodically takes over the drilling operation in the penthouse, allowing the driller to take breaks. Most of his shift is spent down below on the second level (deheading the drum bottom, directing the loading of the railcars) or on the ground level cleaning up the general area of loose coke.

- \#3 Cleaner: Helps with the opening and closing of the drum bottom and positioning of the movable platform at the start of every cutting operation. During much of the cutting operation, he is positioned in an enclosed shelter, level with the top of the railcar. From here through a window, he regulates the movement of the cars (by motorized winch) to allow even loading of the cars. Cleanup is ongoing during cutting, but everyone helps once the cutting is completed. Large pieces on the ground are either picked up or shoveled, and the whole area is hosed down.

- \#4 Cleaner: Primary duties are to help and relieve the \#3 cleaner; this can include deheading the bottom, directing the railcar loading, and cleaning up the ground level. He also greases and oils the winch and motor and other equipment. 
The coke-cutting operation is one of the few in a refinery that is not a closed system. Because of this, it is more difficult to minimize worker exposure during this operation. During every cutting cycle, the top and bottom of the drum must be opened manually; the coke must be cut by the driller; the coke handlers must clean and prepare the fittings, and, at this particular unit, ensure that the railcars are properly loaded, and clean up the coke tower structure and ground area. There are several important advantages and disadvantages concerning worker exposure associated with cutting the coke directly into railcars.

This method using railcars eliminates the necessity of the crane and any other type of loading and handling equipment such as front-end loaders and trucks. However, this method requires that at least one of the coke handlers be stationed at the drum bottom area to ensure proper railcar loading. Although in an enclosed station, this worker is in very close proximity to the falling coke, splashing water, and water mist. The coke at this point has been cooled, and hydrocarbon vapor is not likely. Exposure is more likely to be dermal and to coke particulates.

The opening of the top and bottom of the drum was done efficiently and quickly. The driller normally opens and closes the top of the drum by himself; this takes about 30 minutes. At least two of the coke handlers work as a team to position the hydraulic supports, to drop the bottom of the drum, and to move the sliding platform to the side. This normally takes about 45 minutes. No metal sleeve or chute extender is used at this unit; the coke falls directly from the drum into the railcar.

The two penthouses on the top level are relatively enclosed one-room buildings ( $45 \times 20$ feet) where the driller operates the overhead drills. There are two openings in the roof and several windows; however, natural ventilation did not appear to be good. It can also get very hot in these rooms. The drillers attempt to keep the top of the drum as covered as possible to minimize any vapor or particulate escape into the penthouse during the drilling operation. This is done by positioning wooden panels around the drill shaft.

Direct loading of railcars normally requires considerable cleanup at the end of each cutting, as was the case at this unit. The tracks have to be cleared of the large coke chunks, and the entire ground area must be hosed down. This done during cutting, and also after it is finished.

Al1 workers on this unit wore hard hats, safety shoes, and at least longsleeved shirts. Some of the coke handlers wore coveralls that are provided by the company. These coke handlers changed into their coveralls or separate work clothes in their small locker room in the same building and adjacent to the unit control room. Shower facilities are located at the front of the refinery. There were no routine operations that required the use of respirators; however, air-purifying and self-contained, breathing-air respirators were available. The operations crew ate in the control room while the cutters ate and rested in their separate room. Neither room was under 
positive pressure; the control room was air-conditioned. Because of the changing wind direction at this refinery, the control building is occasionally downwind of the coke tower and production area.

The steam that is used to cool the drums is sent through a knockout drum before it is vented to the atmopshere. A flare is available for turnarounds or any other conditions that might require it.

Asphalt Blowing Unit

\section{Unit and Process Description}

The asphalt blowing unit is by itself about $\frac{1}{2}$-mile from the main production area in the southeast corner of the refinery. This unit is not shown in Figure $\mathrm{C}-23$. There are two blowing towers, side by side, with a production capacity of 7,000 barrels of blown (oxidized) asphalt per day.

The unit (Figure $\mathrm{C}-26$ ) is a relatively small (250 $\times 120$ feet), simple unit with the main structures being the control building, the air blower (compressor), the two blowing towers, the asphalt vent gas knockout drum, and the asphalt fume incinerator. There are also several pumps including the two asphalt product pumps. The unit foundation is gravel.

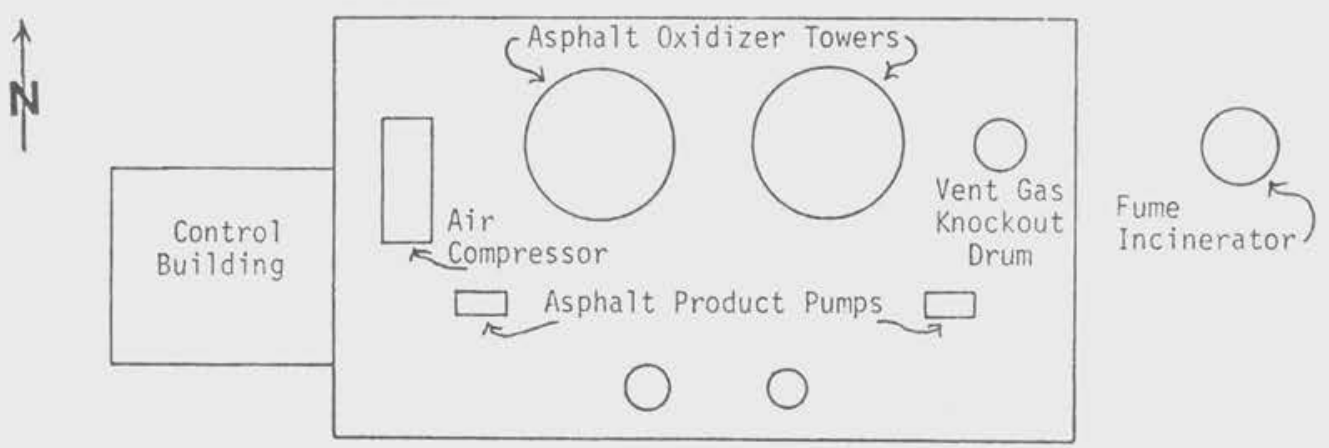

Figure $\mathrm{C}-26$. Refinery $\mathrm{G}$ asphalt blowing unit.

The feed to the blowing towers comes from storage tanks (vacuum bottoms) and enters the two vertical vessels at several points in the upper half. The compressed air is discharged into the bottom of the towers and oxidizes the asphalt. The vent gas first goes to a knockout drum to remove any entrained mist and particulates and then to the fuel-oil-fired incinerator. The asphalt product is pumped to storage.

Work Force

This unit requires only two workers per shift, one inside control board operator and one outside operator. 


\section{DESCRIPTION OF REFINERY H}

Refinery $\mathrm{H}$ is a "small" (7,000 bbl/day capacity), "major" refinery located in Montana. The refinery, which was built in the $1920^{\prime} s$, had several owners before the current company purchased it in 1947. The refinery is currently spread over approximately 200 acres. At the time of all three surveys, the refinery was operating at or very near to capacity. The petroleum products produced here included:

- gasolines
- bropane
- jet fuel

- intermediate fuel oils

- Diesel oil

- asphalt

Approximately two-thirds of the crude refined here is from Montana and is received mainly by pipeline; the remaining one-third is Canadian and received by pipeline. This crude.is categorized as a "sour" (1-2\% sulfur by weight), "mixed base" (containing both paraffins and naphthenes) crude with an API Gravity Index normally ranging from 32 to 36 . The petroleum products produced here are marketed within 300 miles and are shipped by tank trucks or railcars.

The major process units at Refinery $H$ include:
- crude distillation unit
- vacuum distillation unit
- FCCU

- catalytic reformer unit

- polymerization unit

Figure $\mathrm{C}-27$ shows a rough plot plan of the main production area which is 10cated in the northeast section of the refinery. There is only one main control building for the five process units.

Besides being the smallest refinery visited during the study in terms of crude capacity, this refinery also has the smallest work force. There is a total of 57 employees including 18 production workers, 15 administrative or supervisory personnel, 20 maintenance, and 4 laboratory workers. Most of the routine maintenance activity is performed in-house, while contractors and company employees from other refineries can be called in for major maintenance work including turnarounds. The production units operate 24 hours a day, 7 days a week; there are normally four rotating work crews. The maintenance crew works 0800 to 1630 daily.

Safety and health programs are handled by the refinery safety director and the laboratory and stock supervisor with the assistance of corporate personnel. The company that owns this refinery has recently developed a comprehensive health maintenance program which enables computerized retrieval of medical and industrial hygiene data. Two employees at each facility are trained to conduct quarterly industrial hygiene sampling; these samples are analyzed at the corporate laboratory, and the results are entered into the 
computer. In the past, the corporate industrial hygienists performed periodic surveys at this and other facilities. Surveys at this refinery were conducted in 1972, 1975, 1977 , and 1978 for such hazards as asbestos, ammonia, total and respirable dust, benzene and other organics, hydrogen sulfide, mercaptans, and welding fumes.

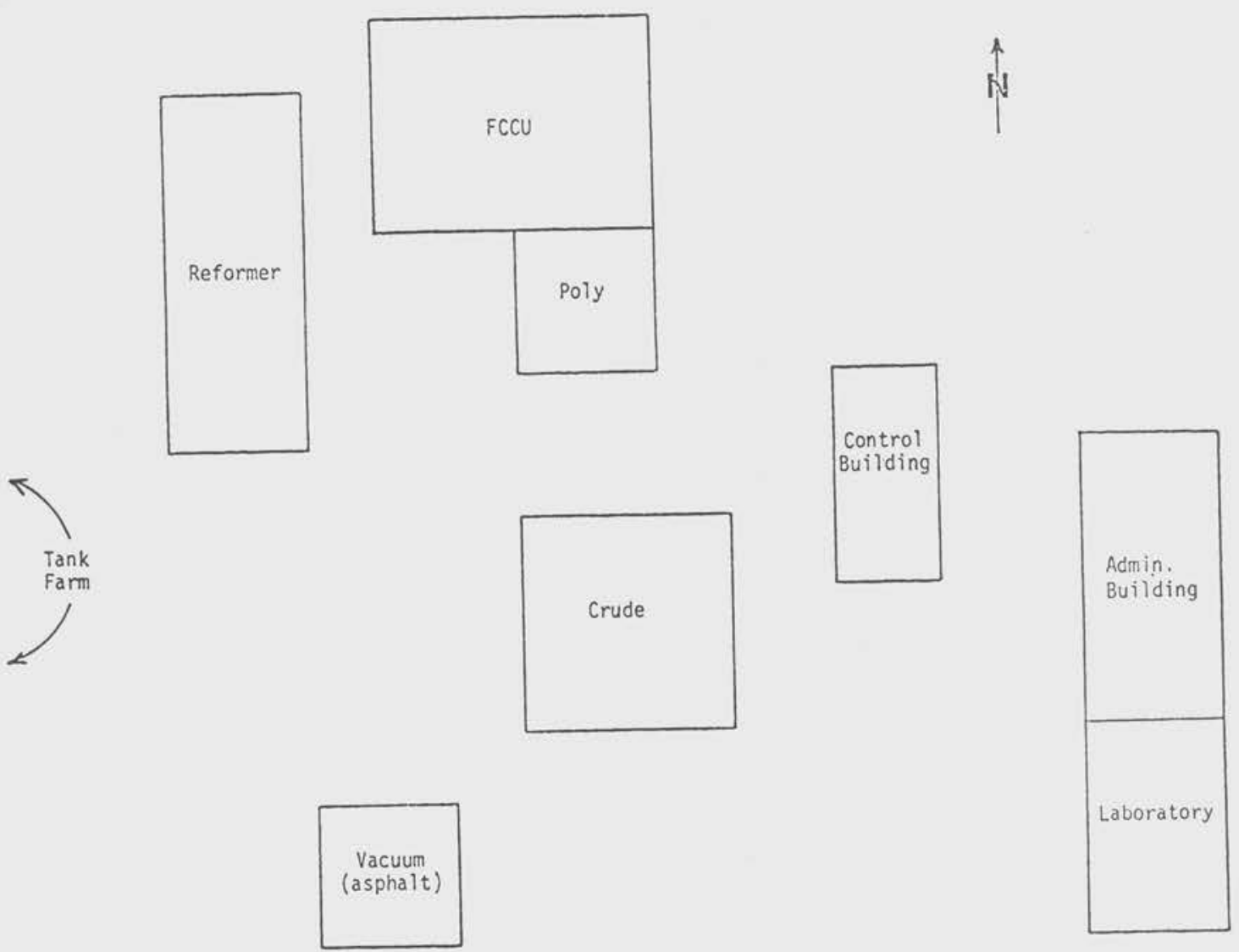

Figure C-27. Refinery $\mathrm{H}$ production area.

A11 employees receive preemployment medical examinations; periodic examinations are scheduled for every 5 years for those up to 45 years of age, every 3 years for those between 45 and 55, and every 2 years for those over 55 . The refinery is considering annual examinations for all employees; insulators currently receive annual examinations. The size of the refinery does not warrant a nurse or physician on the premises; a hospital emergency facility is nearby, and two physicians in the area have arrangements with the refinery. All employees have received Red Cross first aid training and a small number of employees have received cardiopulmonary resuscitation training. 
As part of good industrial hygiene practice, the use of protective clothing and equipment (e.g., hard hats, safety shoes, eye protection) is emphasized. Eating and smoking are allowed in the control room; smoking is also allowed in several other designated areas of the refinery (e.g., stock operator's office, part of the laboratory). All new employees are initially trained in safety with the Dupont "New Employee Safety Training" manual. The safety training is continued over the first 3 months with additional Dupont training guides. Good unit housekeeping is practiced as an important means of minimizing worker exposure to potential hazards. Spills are promptly cleaned up by the maintenance crews, and any necessary equipment or structure repair is also promptly carried out by the unit operators or in-house maintenance crews.

\section{STUDY PROCESS UNITS AT REFINERY H}

Fluid Catalytic Cracking Unit (FCCU)

\section{Unit and Process Description}

The FCCU is located in the north section of the main production area (Figure C-27) near the catalytic reformer and polymerization units. Since the entire production area is quite small (100 x 50 yards), all five process units and the control building are relatively close together. The reactor/regenerator $(R / R)$ structure is a stacked type with the reactor on top. The FCCU was completely rebuilt in 1956, and there have not been any major modifications to the unit since then. The production capacity of the unit is about $2,000 \mathrm{bbl} / \mathrm{day}$. The single control building was rebuilt in 1963 after an explosion destroyed the previous one.

The FCCU covers an area of about 100 by 100 feet (Figure C-28). The catalyst hopper, the $R / R$, and deethanizer tower are located in the north corner of the unit. Just to the east are two enclosed blower and compressor buildings. The fractionator ("syn" tower), several heavy-fraction pumps, and the vapor recovery structures (e.g., stabilizer, syn tower overhead accumulator, heavy cycle oil stripper, and gas sponge absorber) are to the south and mixed with the polymerization unit structures. There is no FCCU charge furnace or $\mathrm{CO}$ boiler which most other FCCUs in this study have had. The control building ( $20 \times 45$ feet) is located southeast of the FCCU near the administration building (Figure $\mathrm{C}-27$ ).

The fresh feed for the FCCU comes from the crude unit (atmospheric gas oil) and the vacuum unit (mostly light and heavy vacuum gas oils). This fresh feed plus the bottoms (recycle) from the fractionator are injected into the reactor where catalytic cracking is initiated as the hot oil feed contacts the catalyst. The catalyst used at this refinery is an alumina-like synthetic zeolite common in other FCCUs studied in this project. The product vapors and the catalyst are separated in the single-feed riser line and in the reactor itself. The hydrocarbons are transferred to the fractionator tower where the various products are separated. The catalyst is stripped of any remaining oil with steam and delivered to the regenerator where the spent catalyst is reactivated by oxidizing the accumulated carbon at a temperature normally greater than $1,000^{\circ} \mathrm{F}\left(538^{\circ} \mathrm{C}\right)$. The flue gas from the regenerator passes through the waste heat boiler (steam generator) before 
being released to the atmosphere. The regenerated catalyst is stripped of any absorbed oxygen with steam before being recirculated back to the reactor.
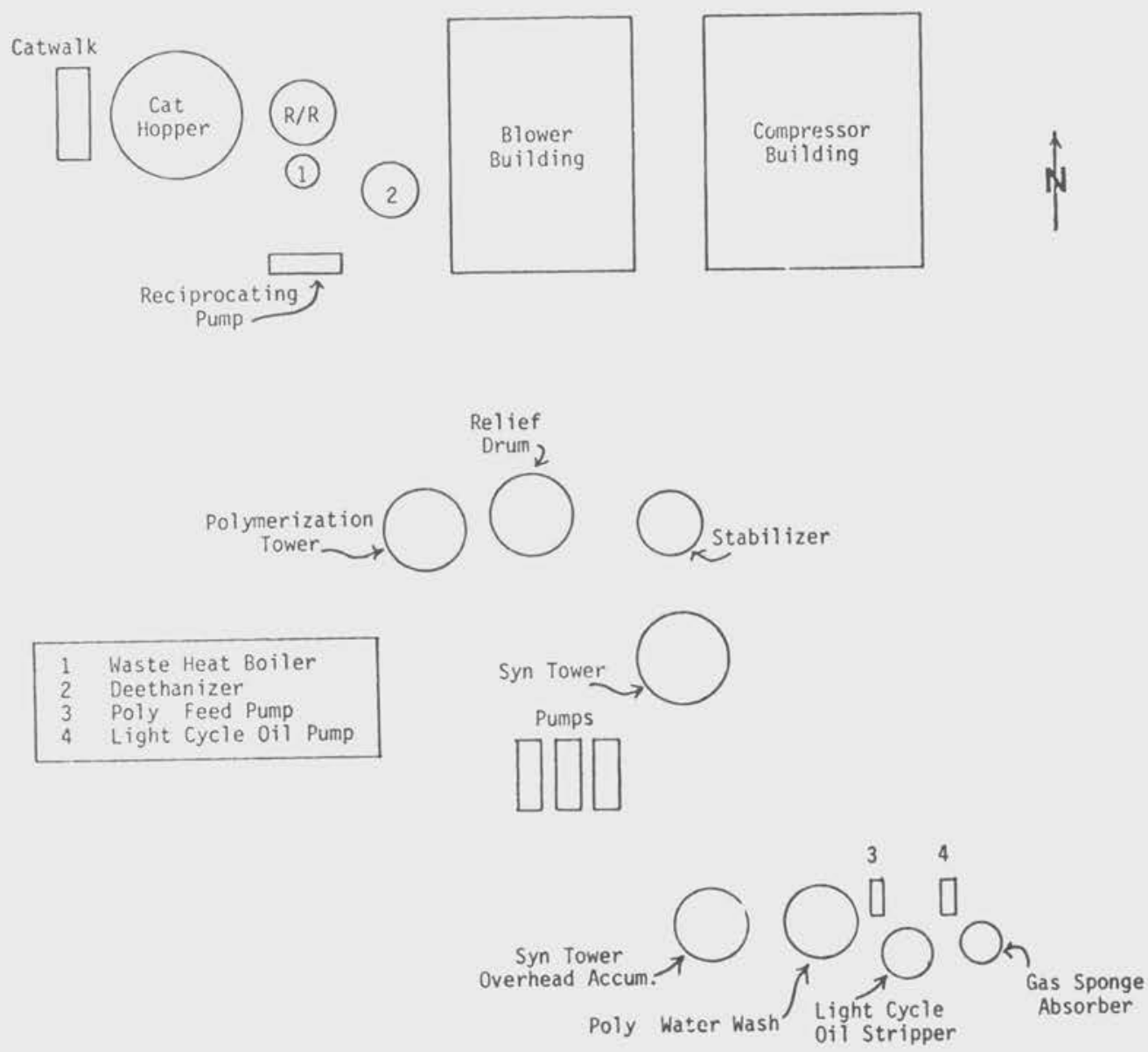

Figure C-28. Refinery H FCCU.

The main products from the fractionator are:

- butane

- propane

- cat gasoline
- poly feed

- fuel gas

Work Force

The small production capacity and physical size of this refinery is also reflected in its work force. There are normally only three workers per shift who handle all five process units. Following is a brief description of these three full-time personnel. 
- Chief operator: Has overall responsibility for the operations and the two other operators. During the first hour of the shift, he makes a comprehensive tour of the production area checking for leaks, spills, or any indications of malfunction. The remainder of the shift he spends inside the control building, monitoring and logging in the various meters and charts.

- A Operator: Interacts frequently with the chief operator and is in charge of the outside operations. He periodically makes tours of the production area and the tank farm to visually inspect all equipment and structures. He normally collects several process stream samples, such as reformer charge and crude, once a shift. Normal1y he spends about $60-70 \%$ of his shift outside, with about 1 hour in the FCCU area and less than 1 hour in the asphalt area.

- B operator: Performs most of the routine outside tasks such as maintaining the boiler, oiling the various pumps, taking caustic and process stream samples (e.g., slurry recycle and heavy cycle oil), adding fresh catalyst, and filling additive pots. He normally spends about 75\% of his shift outside, with about 1 hour in the FCCU area and 15 minutes in the asphalt area.

\section{Exposure Control Measures}

The primary exposure control measure used at this FCCU is a closed-system process which limits exposure to products, by-products, and intermediates. Also important is a well-organized maintenance program that provides both efficient preventive and repair maintenance services. Under normal operating conditions, exposure to PAHs may occur during sampling of the various streams, during maintenance and housekeeping activities, from fugitive emissions, and from the regenerator flue gas.

Most of the liquid stream samples are collected at the FCCU and the other process units using the spigot-and-bottle method without sampling loops. The lines are normally flushed into the sewer system. Although the sampling is normally performed quickly and without dermal contact, this is a potential source of PAH exposure when heavy-fraction streams are sampled.

Exposure during routine maintenance is difficult to minimize. The ground level of the entire production area is constructed of concrete with an efficient sewer system that simplifies cleanup procedures. The refinery has its own craft maintenance crews (e.g., pipefitters, electricians) that provide preventive and repair services during the day shift. Hard hats, safety shoes, and neoprene gloves are worn routinely. Disposable earplugs are used in the compressor areas. There are no routine operations that require the usage of respirators; however, NIOSH-approved air-purifying and selfcontained, breathing-air respirators are available. These respirators are maintained by the refinery safety department. 
The areas of the unit handling heavy fractions, which are more likely to contain the PAHs, are in fairly open areas, minimizing potential vapor accumulation. There are two enclosed compressor buildings on the north end of the unit; however, PAH accumulation is not expected here because heavyfraction process streams are not involved. Several of the heavy-fraction pumps, including the slurry and heavy-oil pumps, are located close together near the base of the fractionator tower. This is an area where PAH concentrations might be elevated. The control building, which is air-conditioned but not under positive pressure, is occasionally downwind of the R/R or heavy-fraction pumps.

The flue gas from the regenerator passes through a waste gas boiler (a steam generator) and is then discharged into the atmosphere. There is no precipitator (for catalyst fines) or CO boiler at this unit.

Asphalt Processing

\section{Unit and Process Description}

The asphalt processing at this refinery consists of the vacuum distillation unit (Figure C-29); the bottoms from the fractionating tower are pumped directly to storage. The final asphalt products are further processed when needed by using automatic blending and emulsifying processes. Most of the asphalt produced at this refinery is used as "road oil" that is applied before the actual asphalt layer.

The vacuum unit is located in the south section of the production area, almost due west of the laboratory (Figure $\mathrm{C}-27$ ). Two gas-fired furnaces are to the west, the crude unit is to the northeast, and the desalter and cooling tower are to the south. The vacuum unit is very small (about $30 \times 20$ feet); the main components are the vacuum fractionating tower, a centrifugal asphalt pump (to storage) to the east, and three centrifugal gas oil pumps to the south.

\section{Work Force}

As mentioned in the FCCU section, three operators handle all five process units. Technicians from the laboratory collect asphalt process stream samples four or five times a day using an uncovered metal container. Samples are taken to the laboratory, cooled, and then analyzed for penetration properties. 

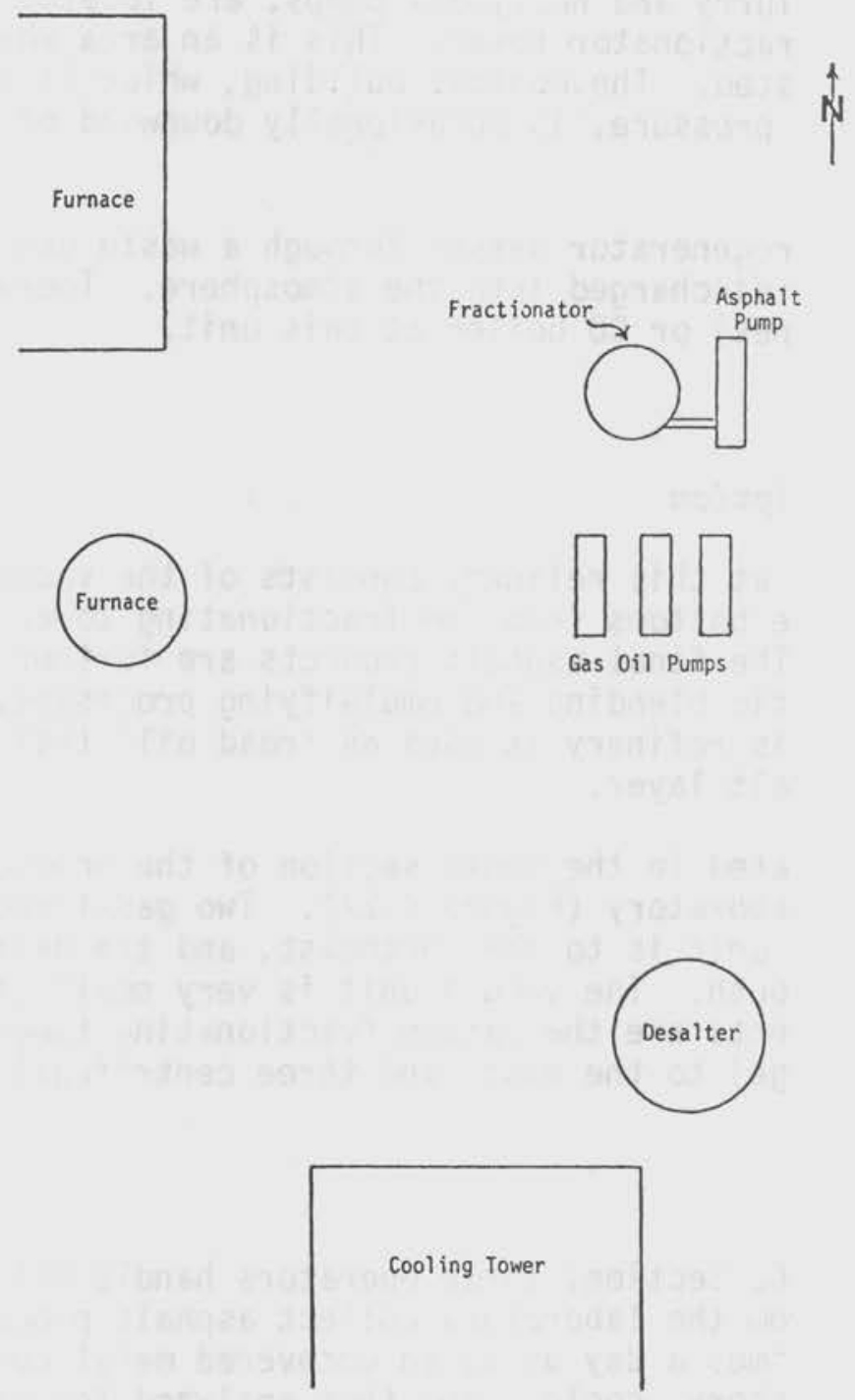

Figure $\mathrm{C}-29$. Refinery $\mathrm{H}$ asphalt processing (vacuum) unit. 


\section{REFINERY I}

\section{DESCRIPTION OF REFINERY I}

Refinery I is a "sma11" (21,000 bbl/day capacity), "major" refinery located in Wyoming. The refinery was originally built in the 1920s and currently occupies over 300 acres. At the time of the survey, it was operating at close to capacity and producing a fu11 line of petroleum products which included:

$\begin{array}{ll}\text { - propane } & \text { - kerosene } \\ \text { - butane } & \text { sponge coke } \\ \text { - Dasoline } & \text { - \#6 fult oil }\end{array}$

Two types of Wyoming crude are separately refined here at different times. The primary type (about 67\%) is categorized as a "light," "low-sulfur" $(0.3 \%$ sulfur by weight), "mixed base" (containing both paraffins and naphthenes) crude with an API Gravity Index of 39.0. The other type of crude is a "heavy," "sour" (3.0\% sulfur by weight), "mixed base" type with an API Gravity Index of 24.5 . At the time of the survey, the latter type was being refined. All of the crude is received by pipeline while the products are shipped primarily by pipeline and tank truck; railcars are used to a limited extent.

The major process units at Refinery I include:

- crude distillation unit (includes vacuum unit)

- hydrotreating unit

- catalytic reformer

\author{
- FCCU \\ - polymerization unit \\ - delayed coker unit \\ (pressure coke sti11)
}

Figure $\mathrm{C}-30$ shows a rough plot plan of the main production area. The FCCU and delayed coker have their own separate control rooms; the crude, hydrotreating, and catalytic reformer units share a common control room. Several tank farms are to the east, north, and west of the production area. The crude storage tanks are located to the north across the river.

There is a total of approximately 200 employees; this includes 40 supervisory and administrative, and 50 maintenance workers. Most of the routine maintenance activity is performed in-house; contractors are brought in for turnarounds and other major maintenance work. The production units operate 24 hours a day, 7 days a week. There are normally four work crews that rotate on a unit (8-hour shifts).

The safety and health staff at this refinery includes the safety supervisor, an occupational nurse, and a part-time physician. The nurse is on the premises full time during the day shift, 5 days a week; the physician is at the refinery 2 days a week. The dispensary and treatment room is fully equipped to handle first aid situations and various routine examinations. Almost all of the employees are trained in first aid. All of the production and maintenance workers are given preplacement medical examinations, and annual follow-ups are available. 


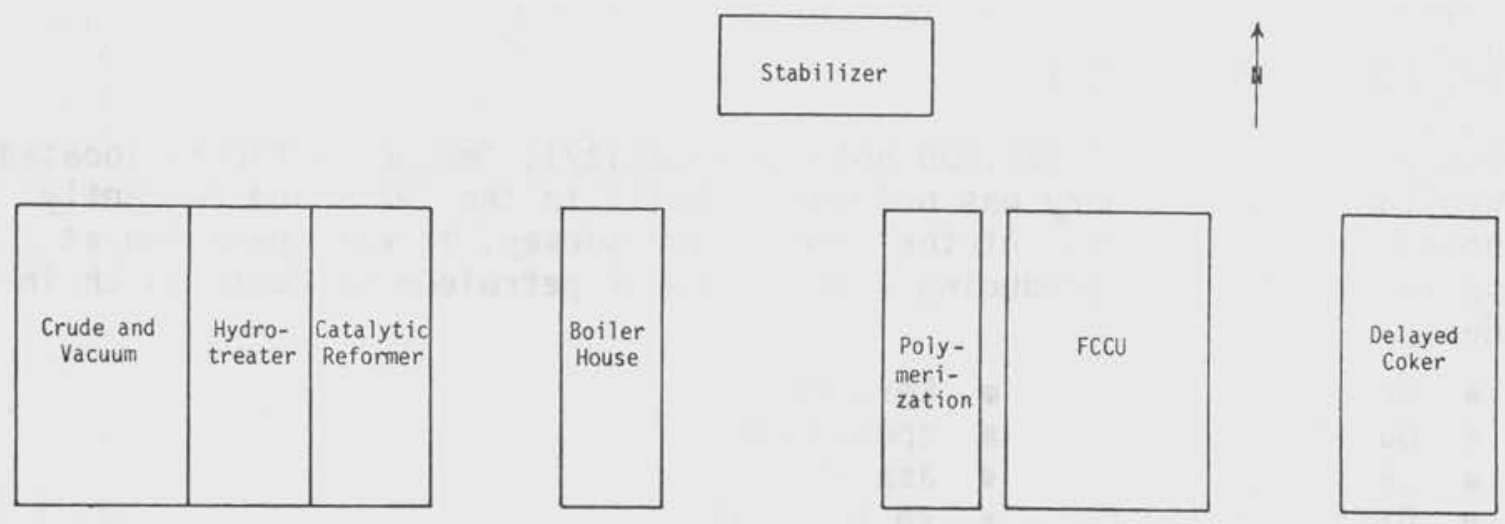

Figure C-30. Refinery I main production area.

The safety supervisor performs industrial hygiene sampling for such hazards as benzene, hydrogen sulfide, asbestos, lead, and hydrocarbons. This company also has a staff of corporate industrial hygienists who perform specialized periodic surveys at the various facilities. At this refinery, they have sampled for welding fumes, silica, and PAHs (benzene-soluble fraction). In the near future, the corporate industrial hygiene group will develop a specific periodic sampling program that each refinery will follow.

As part of good industrial hygiene practice, the use of protective clothing and equipment (e.g., hard hats, safety shoes) is emphasized. Special work clothes are not worn by the production workers at this refinery. Each unit has locker and wash facilities; shower facilities are located at the entrance of the refinery. While eating is allowed in most control rooms, smoking is permitted only in designated areas away from the production units. A11 new employees attend an intensive 1-week training course which includes information on unit equipment, operations, respirator use, safety hazards, fire protection, and first aid.

\section{STUDY PROCESS UNITS AT REFINERY I}

Fluid Catalytic Cracking Unit (FCCU)

\section{Unit and Process Description}

The FCCU is located in the main production area, about 200 feet west of the delayed coker unit (Figure C-30). The present unit was built in 1947; the single riser to the reactor has been replaced and enlarged several times. The current production capacity is about 7,000 bbl/day.

The unit covers an area of about 200 by 150 feet and includes three separate enclosed buildings (Figure C-31). On the west side of the unit, a long building running north to south houses the control room and the compressors. At the north end of the unit, a second building contains all of the major 
process stream pumps in two separate rooms. These pumps include the decant oil, slurry recycle, debutanizer, light cycle gas $0 i 1$, and slurry reflux. The third building along the south border of the unit contains the bottom sections of the reactor, regenerator, flue gas cooler, and precipitator. Just to the east of this building are the two catalyst hoppers and the gasfired furnaces. In the middle of the unit running west to east are the fractionator, slurry boiler, decant oil holding drum, absorber, and debutanizer. The ground level of the entire unit is constructed of concrete.

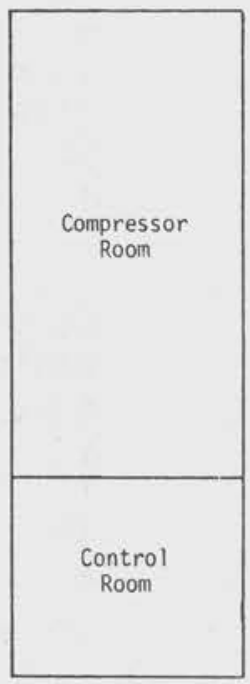

\begin{tabular}{|c|c|}
\hline 000 & 000 \\
Pump Room & Pump Room \\
$00 \quad 00$ & \\
\hline
\end{tabular}
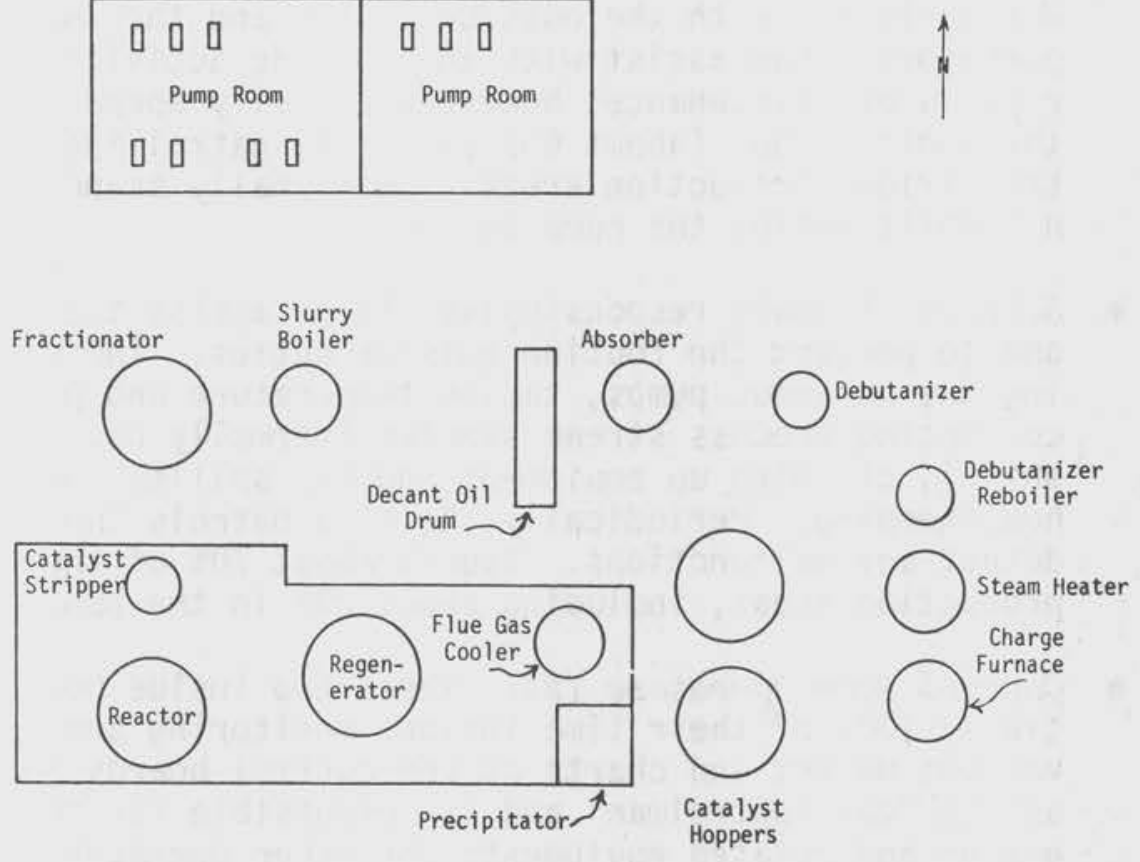

Figure C-31. Refinery I FCCU.

The fresh feed (atmospheric and vacuum gas oils) for the FCCU comes from the crude unit and is preheated to a suitable temperature by the gas-fired furnaces. This fresh feed plus slurry recycle from the fractionator are injected into the reactor where catalytic cracking is initiated as the hot oil feed contacts the catalyst. The catalyst at this refinery is an aluminalike synthetic zeolite common in other FCCUs studied in this project. The product vapors and the catalyst are separated in the single-feed riser line and the reactor itself. The hydrocarbons are taken to the fractionator tower where the various products are separated. The catalyst is stripped of any remaining oil with steam and delivered to the regenerator where the spent catalyst is reactivated by oxidizing the accumulated carbon at a temperature of about $1,200^{\circ} \mathrm{F}\left(649^{\circ} \mathrm{C}\right)$. The flue gas from the regenerator goes to the flue gas cooler and the electrostatic precipitator before being released to the atmosphere. 
The main products from the fractionator are:

- butane
- gropane
gasoline

Work Force
- light cycle oil

- decant oil

- fuel gas

There are normally four workers assigned to the FCCU full time during each shift. Following is a brief description of the duties of these personnel.

- Stizlman: Supervises the overall unit operations, paying particular attention to any problems such as leaks or equipment malfunctions. Works closely with the outside helper and the two control room operators. Can assist with any outside activity, including minor repairs or maintenance; however, normally spends his time outside the control room (about $60 \%$ of shift) patrolling and inspecting the various production areas. He normally spends about $15 \%$ of his shift inside the pump building.

- Helper: Primary responsibility is to assist the stillman as needed and to perform the routine outside duties. These include maintaining the numerous pumps, taking temperature and pressure readings, collecting process stream samples (normally not during the day shift), cleaning up equipment and any spills, and general unit housekeeping. Periodically, he also patrols the entire FCCU to detect any malfunctions. Spends about $70 \%$ of the shift in the production areas, including about $20 \%$ in the pump building.

- Control Room Operators (2): These two inside boardmen spend essentially $100 \%$ of their time inside, monitoring and logging in the various meters and charts on the control boards. One is designated as the "cat controlman" and is responsible for the reactor/regenerator and related equipment; the other operator is designated as the "fractionator controlman." They both work closely with the stillman.

\section{Exposure Control Measures}

The primary exposure control measure used at this FCCU is a closed-system process which limits exposure to products, by-products, and intermediates. Also important is a wel1-organized maintenance program that provides both efficient preventive and repair maintenance services. Under normal operating conditions, exposure to PAHs may occur from fugitive emissions (especially from pumps), from the regenerator flue gas, during sampling of the various streams, and during maintenance and housekeeping activities.

Enclosed buildings housing equipment are of great advantage during the winter months, reducing maintenance due to freezeups and also facilitating any work on the equipment. The major disadvantage of these buildings which do not have mechanical ventilation is that the potential for vapor (e.g., PAH) accumulation from spills and fugitive emissions greatly increases. Heavy- 
fraction pumps, such as those for slurry recycle and decant oil, have been associated with fugitive PAH emissions in previous surveys. It is especially important at this unit that these pumps be maintained properly and that the workers spend as little time as possible in this building. The building housing the base of the reactor, regenerator, and flue gas cooler also houses process streams containing PAHs; however, fugitive emissions are not expected to be as likely here since pumps are not involved. Increased $\mathrm{PAH}$ levels should not be a factor in the compressor room since heavy-fraction streams are not normally present there. The control room is not air-conditioned or under positive pressure, and is frequently downwind of the production areas. This is of particular concern since several operators spend a considerable portion of their shift there.

The regenerator flue gas first goes to a flue gas cooler and then to an electrostatic precipitator to remove catalyst fines before being discharged through a stack into the atmosphere. The recovered heat produced here is used to generate steam.

Most process stream samples are collected during the evening (1500-2300) or morning (2300-0700) shifts; samples are not normally collected during the day shift. Laboratory technicians collect gas samples (e.g., regenerator flue gas) using a rubber inner tube; the unit operators (usually the helper) collect liquid samples (e.g., naphtha, light cycle gas oil, slurry recycle, fresh feed) by the open spigot-and-bottle method without sampling loops. The samples are taken to the laboratory for analysis.

Exposure during routine maintenance is difficult to minimize, especially if it occurs in any of the enclosed buildings. There are concrete floors with effective sewer systems in the pump buildings and throughout the unit, simplifying cleanup procedures. The refinery has its own craft maintenance crews (e.g., pipefitters, electricians) that provide preventive and repair services. The last major turnaround for this unit was during September 1978.

Hard hats and safety shoes are worn routinely on these units, and eye protection is available. There are no routine operations that require the use of respirators; however, NIOSH-approved air-purifying and self-contained, breathing-air respirators are available. These respirators are maintained by the foremen.

\section{Delayed Coker Unit (Pressure Coke Still)}

\section{Unit and Process Description}

The delayed coker unit is referred to as a pressure coke still (PCS) at this refinery. Although it is slightly different from the other delayed coker units surveyed during this study, the thermal cracking process is essentially the same. Therefore, for the purposes of this study, this unit is considered a delayed coker unit. It is located at the east end of the production area, directly east of the FCCU (Figure C-30). This unit, built in 1946, has two pairs of 44-foot coke drums with a daily capacity of about 125 tons of sponge coke. 
Figure C-32 illustrates the layout of this unit which covers an area of about 150 by 150 feet. The large brick building at the north end of the unit houses the control and locker rooms and two pump rooms. The larger of the two pump rooms is called the "hot pump room" and contains several heavyfraction pumps including the charge pumps. Just to the south of the hot pump room are the \#1 and \#2 tower fractionators, the coke tower (an open, multilevel structure that includes the four coke drums), and the soaker. To the north and west of the building are the blowdown tank, lean oil cooling box, naphtha accumulator, and coke handlers' locker and wash room. The charge furnace and absorber are in the southeast corner of the unit. The ground level of the entire unit is constructed of concrete.

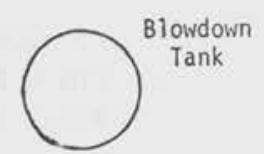

\section{$\hat{\imath}$}
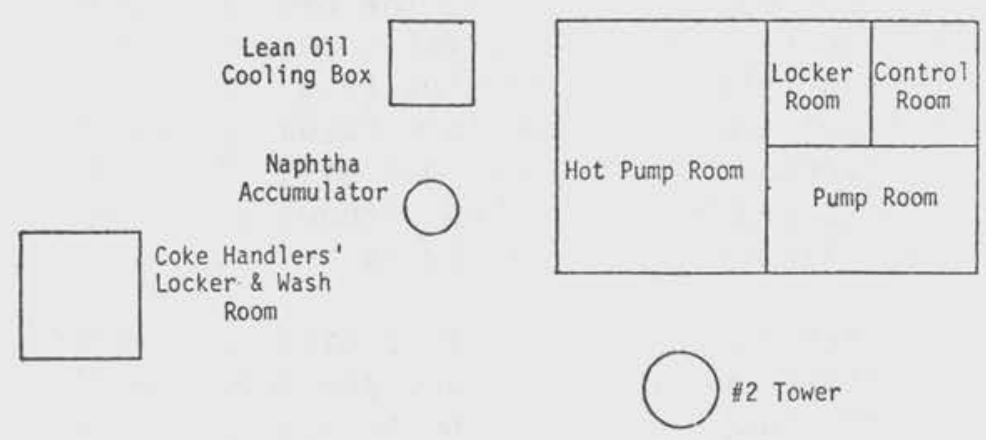

\#2 Tower

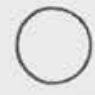

1 Tower
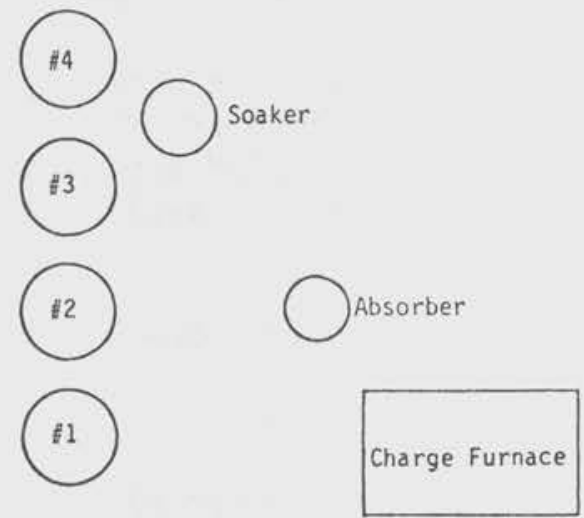

Figure C-32. Refinery I delayed coker unit (pressure coke sti11). 
The coke drums are cut with a steam-driven mechanical drill; the drill shaft is housed beneath each drum below ground level. As the coke is cut, it falls onto a moving conveyor belt which loads a dump truck positioned just to the west of the charge furnace. The truck takes about 10 loads of coke per cutting to a nearby company that performs a calcining operation. The company is located about 300 yards east of the unit within the refinery boundary lines.

The type of coke produced here is a \#2 grade, referred to as sponge coke. The charge is a mixture mainly of vacuum residual from the crude unit with smaller amounts of light cycle gas oil and decant oil from the FCCU and recycled gas oil ("clean oil"). This mixture is pumped to the \#1 tower fractionator that separates the lighter fraction from the heavy "black oil." This black oil is pumped directly to the soaker, while the lighter fraction goes on to the \#2 tower fractionator where "clean oil" is separated from the naphtha and fuel gas fraction. The clean oil is pumped to the charge furnace, then to the soaker where it mixes with and heats the black oil. This heated mixture of clean and black oils is then directed to one of the four drums where the thermal cracking process begins. Each drum as a 32-hour cycle, with coke formation lasting about 16 hours. Because there are four drums, one drum is cut every 8 hours. The lighter vapor fractions of the thermal cracking operation are removed from the top of the drum and recycled back to the \#1 tower fractionator. The clean oil, most of which is not thermally cracked, is included in this recycled portion. Products from this unit, other than sponge coke, include fuel gas, propane, butane, naphtha, cycle gas oil, and cycle fuel oil.

About 6 hours before the cutting operation is scheduled, coke formation is stopped by switching the feed valve to the other drum of the pair. Immediately, steam is introduced into the charge lines to cool the drum. This lasts about an hour, and then water is added to further cool the drum ( 3 hours). Six hours after the valve is switched, the top and bottom of the drums are opened; the coke is then cut from the bottom with the steam-driven metal dri11. The cutting operations lasts about 2 hours.

After cutting is completed, the top and bottom of the drum are replaced; the drum is pressure-tested for seal, heated, and is ready to begin coke formation when the charge valve is switched from the other drum.

Work Force

The work force for the delayed coker unit is divided into two groups, the operational group and the coke-handling group. The two-person operational group works the normal 8-hour shift; following is a brief description of their job activities.

- Stizlman: Has overall responsibility for the operations of this unit, including coke cutting; works closely with the controlman and head cleaner. Normally spends from 25 to $33 \%$ of his shift in the control room; the rest of the shift he patrols the entire unit, including the various levels of the coke tower, to monitor the other operators and to detect any equipment malfunction. 
Other duties include opening and closing valves to direct process streams, oiling the various pumps, and occasionally collecting process stream samples (e.g., fresh feed).

- Controlman: Spends the great majority of his shift in the control room, monitoring and logging in the various meters and charts on the control board. Works closely with the stillman. He normally collects two process stream samples (i.e., naphtha and clean oil) during each shift.

The coke-handling group is normally made up of the head cleaner and still cleaner who also work the normal 8-hour shift. During the survey, there were also two trainees for the still cleaner position. Following is a brief description of the duties of the two regular coke handlers.

- Head CZeaner: Supervises the entire cutting operation. His duties include directing the positioning of the deheading platform and cutting engine, supervising the deheading operation, opening and closing various valves for water and steam lines, and performing the actual cutting. The cutting station is on the ground level about 10 to 15 feet from the cutting engine. After cutting is finished, he spends part of the remainder of his shift in the coke handlers' locker and wash room.

- Stizl C.Zeaner: Works under the supervision of the head cleaner. Deheads the top and bottom of the drum, positions the deheading platform and cutting engine, positions and secures the steam lines, and cleans the area of loose coke. He also operates the dump truck.

\section{Control Measures}

The coke-cutting operation is one of the few in a refinery that is not a closed system. Because of this, it is more difficult to minimize worker exposure during this operation. During every cutting cycle, the top and bottom of the drum must be opened manually; the deheading platform, the cutting engine, and blades must be positioned; the coke must be cut by the head cleaner; and the general area must be cleaned of loose coke. At this unit a metal drill is used to cut the coke instead of the more usual hydraulic type, and the driller (head cleaner) is positioned at ground level instead of in the penthouse located at the top of the drum. The cut coke falls directly onto a conveyor that loads a dump truck. There are several important advantages and disadvantages concerning worker exposure associated with the cokecutting method used at this unit.

The use of the conveyor belt to move the coke directly to the dump truck eliminates the necessity of a crane or any other type of coke-handling equipment that has been associated with worker exposure to PAHs in previous surveys. The elimination of the enclosed room at the top of the drum (penthouse) is also an advantage since this room is considered a likely area for PAH accumulation. However, at this unit the driller (head cleaner) was situated within 15 feet of the bottom of the drum being cut and occasionally 
directly downwind of the steam and particulates being generated. The coke at this point has been cooled and hydrocarbon vapor is not likely, but exposure from dermal contact and to coke particulates is likely.

The mechanical cutting eliminates the copious amounts of water associated with hydraulic cutting and also eliminates the related water-holding and recycling structures (e.g., sluiceway, containment pit, filtering system). The disadvantage of the decreased water usage is the increased potential for coke dust generation. However, this was not noticed during the survey; this may be due to the fact that the drums are filled with water for cooling, and the coke is sufficiently wet to suppress dust generation during cutting.

The opening of the top and bottom of the drum was done efficiently and quickly. The two cleaners normally open the top and bottom of the drum within about 45 minutes. The cutting engine is positioned directly beneath the drum and, at this point, the still cleaner must manually position the cutting blades so that they are in the correct cutting position. The still cleaner normally wears a slick suit and face shield during this operation since considerable water is still draining from the drum. Cleanup is performed at the end of each cutting operation. This consists of removing fallen coke from around the conveyor system and hosing down the entire area.

All workers at this unit wore hard hats and safety shoes. Although coveralls were provided by the company, at least during the survey, they were not normally worn. Lockers and wash facilities were available in both the main control room (operational workers) and the separate building for the coke handlers. Shower facilities are located near the front entrance of the refinery. There are no routine operations that require the use of respirators; however, NIOSH-approved air-purifying and self-contained, breathing-air respirators are available. The operations crew ate in the control room; the coke handlers ate and rested in their separate building. Neither room was air-conditioned or under positive pressure.

Like the FCCU, the pumps are in enclosed rooms without mechanical ventilation. PAH accumulation is a possibility, especially in the larger hot pump room which contains several heavy-fraction pumps. It is important that the pumps be properly maintained to minimize fugitive emissions and that the operators spend as little time as possible in the enclosed pump rooms.

The steam that is used to cool the drums is sent through a blowdown drum before it is vented to the atmosphere. A flare is available for turnarounds or any other conditions that might require it.

Asphalt Processing Unit (Vacuum Pipe Sti11)

\section{Unit and Process Description}

The asphalt processing at this refinery is limited to the vacuum distillation process which is part of the crude unit; the bottoms from the fractionating tower are pumped to storage (and blending) and to the delayed coker unit as asphalt without any further processing. The atmospheric and vacuum 
distillation processes are located together at the west end of the production area (Figure C-30) and called the vacuum pipe still (VPS). The VPS is monitored out of the control room which is also shared with the adjacent hydrotreating and reformer units. The asphalt production capacity of this refinery is about $1,500 \mathrm{bbl} /$ day.

Work Force

No worker is assigned full time to the vacuum section of the VPS. One or more of the outside operators spend a small part of their shift covering the equipment associated with asphalt processing. 
APPENDIX D

PAH EXTRACTION AND ANALYTICAL PROCEDURES

(FOR AREA CASSETTES ONLY)

The Chromosorb-102 (C-102) absorbant and stainless steel backup screen were placed in a foil-wrapped soxhlet extractor fitted with a 500-me round-bottom flask, and extracted with 300 me of glass-distilled methylene chloride/ methanol $(1: 1 ; v: v)$ for 22 hours. The extract was concentrated to approximately $10 \mathrm{ml}$ in the round-bottom flask fitted with a 3-ball Synder column. The concentrate was filtered through a Millipore sample clarifier $(0.45-\mu m$ Teflon filter) into a 15-me screwcap centrifuge tube. The extract was further concentrated in a Kontes heating block, regulated at $35^{\circ} \mathrm{C}$ under a stream of purified nitrogen. When approximately $1 \mathrm{ml}$ in volume, the concentrate was quantitatively transferred to a 2-me serum vial, fitted with a Teflon- 1 ined rubber septum and crimp cap, and stored at $-20^{\circ} \mathrm{C}$ in the dark until analysis.

The extraction procedure used for the silver-membrane filter was a modification of the NIOSH-validated Method No. P\&CAM 217 (NIOSH, 1977). The modifications included multiple extractions instead of a single extraction, and cyclohexane in place of the leukemogenic benzene. The silver-membrane filter was ultrasonically extracted in a 200-watt Bransonic-52 bath for 15 minutes with 5 me of glass-distilled cyclohexane. The extract was placed in a 15-me centrifuge tube. This process was repeated two additional times. Once filtered, the extract was placed in a heating block regulated at $63^{\circ} \mathrm{C}$ and concentrated to approximately $1 \mathrm{me}$. The extract was then quantitatively transferred to the serum vial containing the $\mathrm{C}-102$ extract and subsequently placed in the freezer at $-20^{\circ} \mathrm{C}$.

Just prior to analysis by gas chromatography/mass spectrometry (GC/MS), the combined extract was further concentrated at ambient temperature under purified nitrogen to approximately $200 \mu \mathrm{l}$. The volume of the extract was measured with a calibrated syringe. $D_{10}$ anthracene (hydrogen atoms replaced by deuterium) was added at a concentration of $100 \mathrm{ng}$ per $100 \mu \mathrm{l}$ of extract as an internal reference standard.

The extracts were analyzed on a Finnigan Model 4023 Gas Chromatograph/Mass Spectrometer (GC/MS) that includes the 2300 Data General computer system. A glass jet separator was used as the interface. Electron impact spectra are obtained in a repetitive scanning mode. Operating conditions are summarized in Table D-1. Columns were conditioned at $300^{\circ} \mathrm{C}$ for 48 hours. The MS is scanned from 40 to 350 AMU at 158 AllU/second. The accelerating voltage is $3.5 \mathrm{kV}$, emission current $500 \mathrm{~mA}$, and the electron energy is $70 \mathrm{eV}$. The MS is calibrated with perfluorotributylamine with a calibration range from 69 to 614 AMU. Masses are assigned to the computer using a least-squares analysis to an error of less than 150 millimass units. The mass spectrum is stable to \pm 0.05 AMUs or better over an 8-hour period. 
Table D-1. Chromatographic operating conditions.

\begin{tabular}{|c|c|}
\hline $\begin{array}{ll}\text { GC Column: } & 6 \mathrm{ft} \times 0.079 \text { in } \mathrm{i} \\
& 3 \% \text { oV }-1780 / 100\end{array}$ & $\begin{array}{l}\text { glass column packed with } \\
\text { h Supelcoport }\end{array}$ \\
\hline Injector Temperature: & $260^{\circ} \mathrm{C}$ \\
\hline GC/MS Interface Temperature: & $300^{\circ} \mathrm{C}$ \\
\hline Transfer Line Temperature: & $280^{\circ} \mathrm{C}$ \\
\hline MS Ionizer Block Temperature: & $300^{\circ} \mathrm{C}$ \\
\hline Carrier Gas Flow: & Helium, $10 \mathrm{ml} / \mathrm{min}$ \\
\hline Initial Temperature: & $50^{\circ} \mathrm{C}$; held 4 minutes \\
\hline Program Temperature: & $8^{\circ} \mathrm{C} / \mathrm{min}$ \\
\hline Final Temperature: & $26 \mathrm{C}^{\circ} \mathrm{C}$; held 50 minutes \\
\hline
\end{tabular}

Synthetic quantitative mixtures of PAHs were prepared to verify each stage of $\mathrm{GC} / \mathrm{MS}$ operations and to standardize the data processing parameters such as response thresholds and time windows for peak identification.

Al1 GC analyses of the referenced PAH compounds produced symmetrical Gaussian peaks with the exception of quinoline, which tails slightly. Table D-2 1ists the 23 PAHs or groups of PAHs that were analyzed by this method along with their retention times relative to $D_{10}$ anthracene and the extracted ion used to quantitate the individual compounds found within the elution time window.

PAHs are identified and quantified by external concentration calibration. Use of $D_{10}$ anthracene provided an internal standard for relative retention time calculations. Due to its chemical reactivity, its use as an internal quantitation standard was considered inappropriate. A11 the PAHs have been measured separately (externally) from the sample extracts. The measured detector response from the external standard was used to calibrate the concentration measurement of the same compound in the sample. 
Table D-2. Parameters used for identification and quantification of PAHs.

\begin{tabular}{|c|c|c|}
\hline Compound & $M / E^{*}$ & $\begin{array}{l}\text { Relative retention } \\
\text { time ( } 6 \text { replicates) }\end{array}$ \\
\hline 1. Naphthalene & 128 & $0.527 \pm 0.605$ \\
\hline 2. Quinoline & 129 & $0.611 \pm 0.004$ \\
\hline 3. 2-Methylnaphthalene & 142 & $0.616 \pm 0.005$ \\
\hline 4. 1-Methylnaphthalene & 142 & $0.634 \pm 0.003$ \\
\hline 5. Acenaphthalene & 152 & $0.757 \pm 0.002$ \\
\hline 6. Acenaphthene & 154 & $0.780 \pm 0.003$ \\
\hline 7. Fluorene & 166 & $0.854 \pm 0.007$ \\
\hline 8. Phenanthrene/Anthracene & 178 & $1.001 \pm 0.005$ \\
\hline$D_{10}$ Anthracene & 188 & 1.000 \\
\hline 9. Acridine & 179 & $1.026 \pm 0.005$ \\
\hline 10. Cärbazole & 167 & $1.062 \pm 0.003$ \\
\hline 11. Fluoranthene & 202 & $1.172 \pm 0.003$ \\
\hline 12. Pyrene & 202 & $1.206 \pm 0.002$ \\
\hline 13. Benzofluorene & 216 & $1.268 \pm 0.003$ \\
\hline 14. Benz(a)anthracene/Chrysene/Triphenylene & 228 & $1.397 \pm 0.004$ \\
\hline 15. Benzo(e)pyrene/Benzo(a)pyrene & 252 & $1.610 \pm 0.009$ \\
\hline 16. Perylene & 252 & $1.629 \pm 0.009$ \\
\hline 17. Dibenz $(a, j)$ acridine & 279 & $1.838 \pm 0.139$ \\
\hline 18. Dibenz $(a, i)$ carbazole & 267 & $1.891 \pm 0.029$ \\
\hline 19. Indeno $(1,2,3$-cd)pyrene & 276 & $1.918 \pm 0.033$ \\
\hline 20. Dibenzanthracene & 278 & $1.927 \pm 0.034$ \\
\hline 21. Benzo $(g, h, i)$ perylene & 276 & $2.017 \pm 0.037$ \\
\hline 22. Coronene & 300 & $2.964 \pm 0.106$ \\
\hline 23. Dibenzpyrene & 302 & $3.176 \pm 0.099$ \\
\hline
\end{tabular}

* Mass/Charge. 



\section{APPENDIX E \\ SURVEY DATA}

Table E-1. Environmental conditions during surveys.

\begin{tabular}{|c|c|c|c|c|c|c|}
\hline Refinery & Date & Shift & General conditions & $\begin{array}{l}\text { Temperature } \\
\left({ }^{\circ} \mathrm{C}\right)\end{array}$ & $\begin{array}{l}\text { Relative humidity } \\
(\%)\end{array}$ & $\begin{array}{c}\text { Wind velocity } \\
\text { (mph) }\end{array}$ \\
\hline \multirow[t]{2}{*}{ A } & $11 / 30 / 79$ & Day & Clear & $-1-10$ & $12-40$ & $4-13$ \\
\hline & $12 / 1 / 79$ & $\begin{array}{l}\text { Day } \\
\text { Evening }\end{array}$ & $\begin{array}{l}\text { Clear } \\
\text { Clear }\end{array}$ & $\begin{array}{l}0-7 \\
0-7\end{array}$ & $\begin{array}{l}52-60 \\
52-60\end{array}$ & $\begin{array}{l}3-6 \\
3-6\end{array}$ \\
\hline \multirow[t]{2}{*}{ B } & $12 / 4 / 79$ & Day & Clear & $10-17$ & $37-57$ & $2-7$ \\
\hline & $12 / 5 / 79$ & Day & Clear & $14-23$ & $28-48$ & $7-9$ \\
\hline \multirow[t]{2}{*}{ C } & & $\begin{array}{l}\text { Morning } \\
\text { Day }\end{array}$ & $\begin{array}{l}\text { Overcast with moderate rain } \\
\text { Overcast with light rain }\end{array}$ & $\begin{array}{r}10-16 \\
9-12\end{array}$ & $\begin{array}{c}45-75 \\
93 \text { (noon) }\end{array}$ & $5-15$ \\
\hline & $12 / 14 / 79$ & $\begin{array}{l}\text { Mcrning } \\
\text { Day }\end{array}$ & $\begin{array}{l}\text { Clear, overcast } \\
\text { Light rain }\end{array}$ & $\begin{array}{r}10-13 \\
9-13\end{array}$ & $\begin{array}{c}70-80 \\
97 \text { (noon) }\end{array}$ & $10-15$ \\
\hline \multirow[t]{2}{*}{0} & $1 / 16 / 80$ & Day & Cloudy & $13-21$ & $68-85$ & $3-5$ \\
\hline & $1 / 17 / 80$ & Day & Clouds: & $16-21$ & $70-75$ & $3-12$ \\
\hline \multirow[t]{2}{*}{$E$} & $4 / 2 / 80$ & Day & Partly cloudy & $7-21$ & $40-80$ & $3-12$ \\
\hline & $4 / 3 / 80$ & Day & Clear & $7-21$ & $35-80$ & $0-10$ \\
\hline \multirow[t]{2}{*}{ F } & $5 / 14 / 80$ & Day & Clear & $13-17$ & $47-53$ & $2-10$ \\
\hline & $5 / 15 / 80$ & Day & Clear & $13-20$ & $32-60$ & $3-12$ \\
\hline \multirow[t]{3}{*}{ G } & $5 / 28 / 80$ & Evening & Clear & $26-31$ & $26-42$ & $5-10$ \\
\hline & $5 / 29 / 80$ & Day & Light rain, clear & $18-29$ & $45-70$ & $5-7$ \\
\hline & $5 / 30 / 80$ & Day & Overcast, partly cloudy & $20-29$ & $59-73$ & $3-12$ \\
\hline \multirow[t]{2}{*}{ H } & $6 / 11 / 80$ & Day & Partly cloudy & $13-27$ & $44-60$ & $4-12$ \\
\hline & $6 / 12 / 80$ & Day & Partly cloudy & $13-22$ & $44-65$ & $0-3$ \\
\hline \multirow[t]{2}{*}{ I } & $8 / 13 / 80$ & Day & Partly cloudy & $16-27$ & $35-69$ & $0-3$ \\
\hline & $8 / 14 / 80$ & Day & Overcast, clear & $15-27$ & $40-75$ & $0-10$ \\
\hline
\end{tabular}




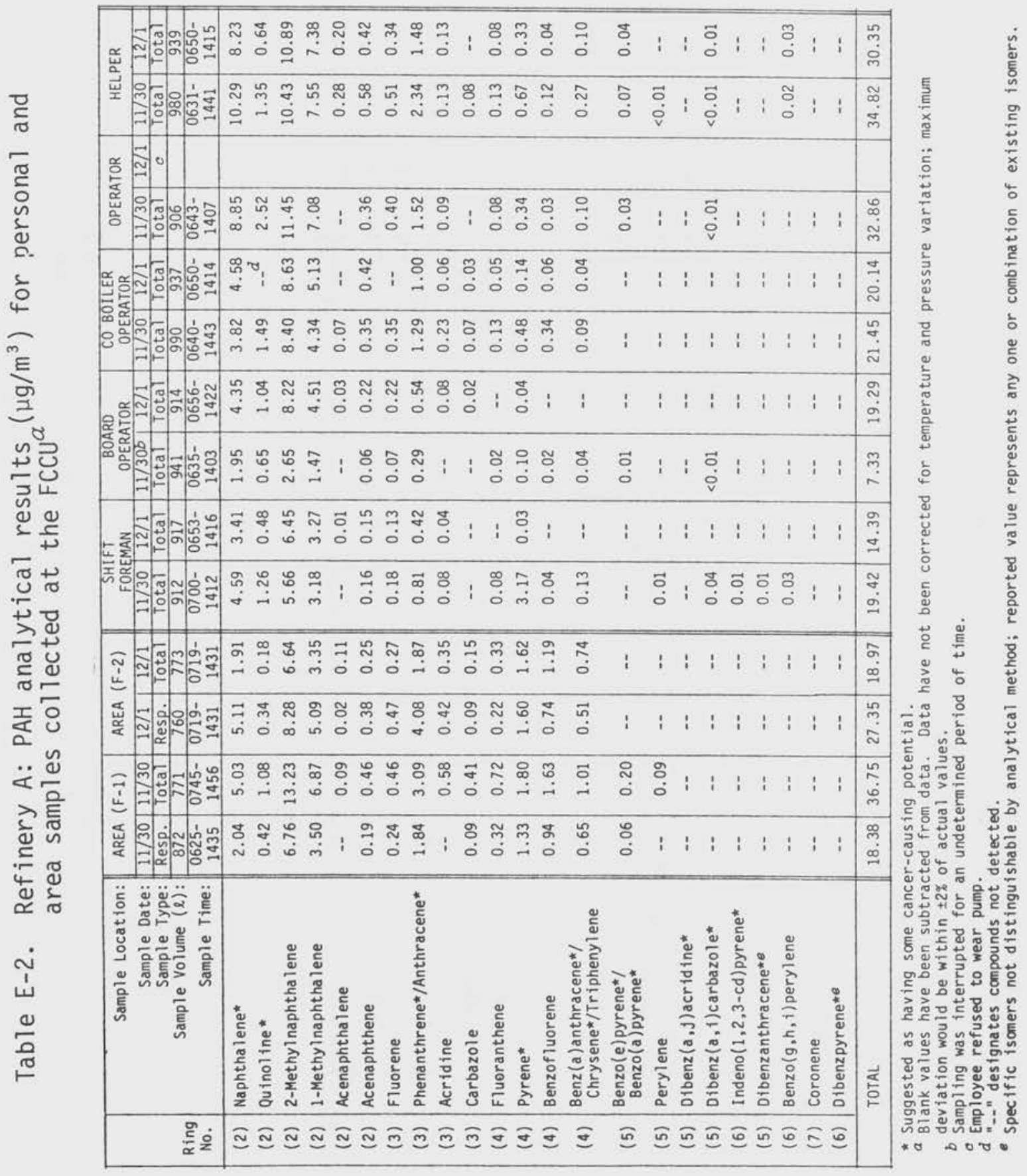




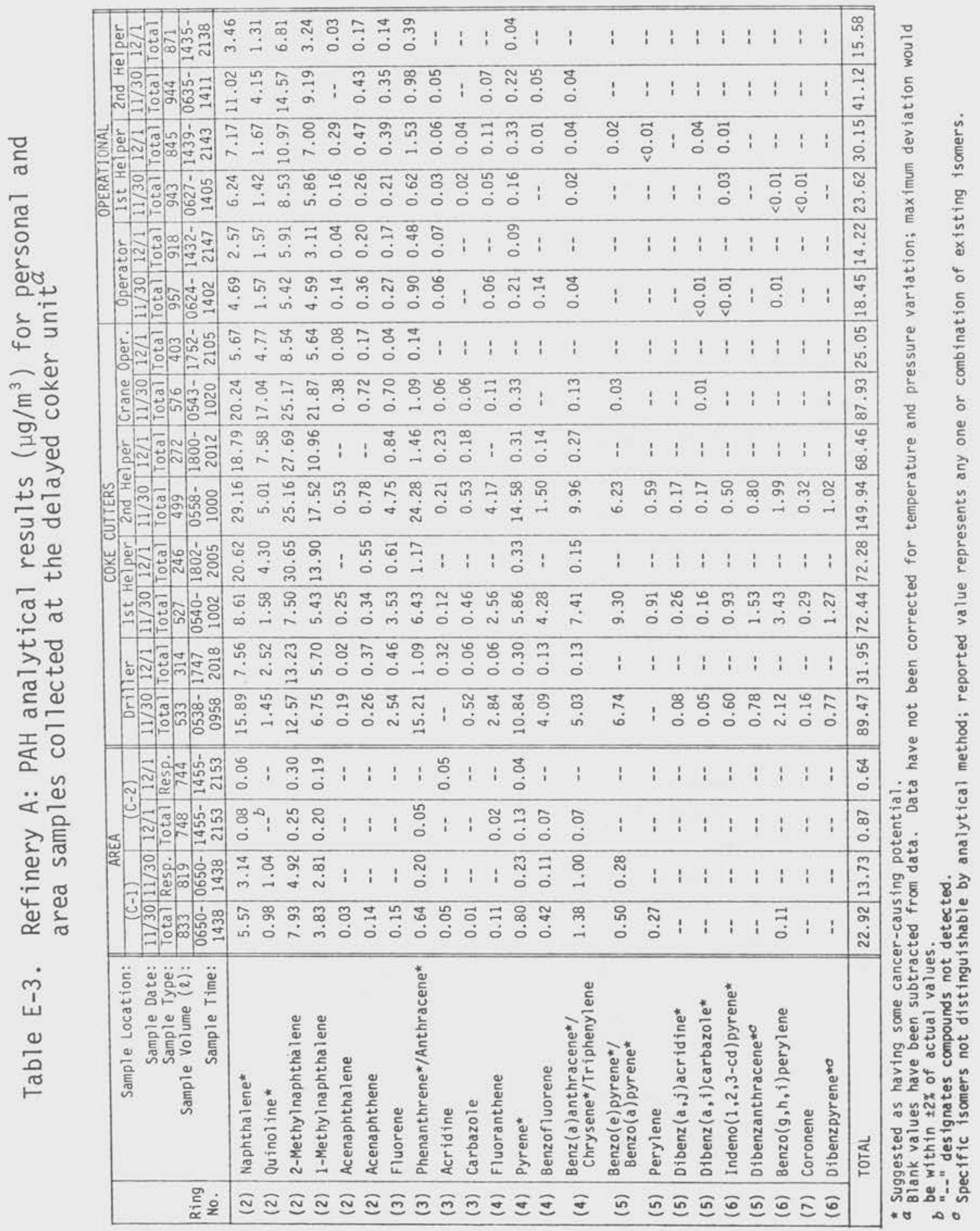


Table E-4. Refinery A: PAH analytical results $\left(\mu \mathrm{g} / \mathrm{m}^{3}\right)$ for area samples collected at the asphalt unit and upwind locations ${ }^{a}$

\begin{tabular}{|c|c|c|c|c|c|c|c|}
\hline \multirow{5}{*}{$\begin{array}{l}\text { Ring } \\
\text { No. }\end{array}$} & \multirow{5}{*}{$\begin{array}{r}\text { Sample Location: } \\
\text { Sample Date: } \\
\text { Sample Type: } \\
\text { Sample Volume }(\ell): \\
\text { Sample Time: }\end{array}$} & \multicolumn{4}{|c|}{ AREA } & \multicolumn{2}{|c|}{ UPWIND } \\
\hline & & $11 / 30$ & $11 / 30$ & $12 / 1$ & $12 / 1$ & $11 / 30$ & $12 / 1$ \\
\hline & & Total & Resp. & Total & Resp. & Total & Total \\
\hline & & 831 & 823 & 757 & 744 & 922 & 873 \\
\hline & & $\begin{array}{l}0703- \\
1447 \\
\end{array}$ & $\begin{array}{l}0703- \\
1448 \\
\end{array}$ & $\begin{array}{l}0734- \\
1437\end{array}$ & $\begin{array}{l}0734- \\
1437 \\
\end{array}$ & $\begin{array}{l}0724- \\
1505 \\
\end{array}$ & $\begin{array}{l}0656- \\
1422 \\
\end{array}$ \\
\hline (2) & Naphthalene* & 2.14 & 1.27 & 0.33 & 0.59 & 0.40 & 0.29 \\
\hline (2) & Quinol ine* & 1.49 & 0.55 & 0.13 & $\ldots b$ & -- & 0.07 \\
\hline (2) & 2-Methyl naphtha lene & 8.04 & 4.71 & 1.12 & 1.59 & 0.19 & 0.04 \\
\hline (2) & 1-Methyl naphthalene & 4.63 & 3.00 & 0.43 & 0.95 & 0.11 & 0.01 \\
\hline (2) & Acenaphthalene & 0.10 & -- & -- & - & -- & -- \\
\hline (2) & Acenaphthene & 4.55 & 0.52 & -- & -- & -- & -. \\
\hline (3) & Fluorene & 7.61 & 0.56 & - & -- & $<0.01$ & -. \\
\hline (3) & Phenanthrene ${ }^{\star} /$ Anthracene ${ }^{\star}$ & 1.66 & 1.14 & 0.03 & 0.15 & 0.07 & -- \\
\hline (3) & Acridine & 0.30 & 0.20 & - & -. & $<0.01$ & -- \\
\hline (3) & Carbazole & 0.09 & 0.07 & - & - & $<0.01$ & - \\
\hline (4) & Fluoranthene & 0.03 & 0.05 & -- & - & 0.02 & -- \\
\hline (4) & Pyrene* & 0.09 & 0.08 & -. & 0.03 & 0.04 & -. \\
\hline (4) & Benzofluorene & -- & -- & - & -- & -- & -- \\
\hline (4) & $\begin{array}{l}\text { Benz (a)anthracene*/ } \\
\text { Chrysene*/Triphenylene }\end{array}$ & - & -- & - & -- & -- & -- \\
\hline (5) & $\begin{array}{l}\text { Benzo(e)pyrene* } \\
\text { Benzo(a)pyrene* }\end{array}$ & -- & -- & - & -- & -- & -- \\
\hline (5) & Perylene & -- & -- & - & - & - & -. \\
\hline (5) & Dibenz $(a, j)$ acridine* & -- & - & -- & -- & -- & - \\
\hline (5) & Dibenz $(a, i)$ carbazole $e^{\star}$ & -- & - & - & -- & -- & -- \\
\hline (6) & Indeno $(1,2,3-c d)$ pyrene* & -- & -- & -- & -- & -- & -- \\
\hline (5) & Dibenzanthracene ${ }^{\star c}$ & -- & -- & -- & - & -- & -- \\
\hline (6) & Benzo $(g, h, i)$ perylene & -- & - & -- & - & - & -- \\
\hline (7) & Coronene & -- & - & -- & -- & $<0.10$ & - \\
\hline (6) & Dibenzpyrene ${ }^{\star c}$ & -- & - & -- & - & -- & - \\
\hline & TOTAL & 30.73 & 12.15 & 2.04 & 3.31 & 0.83 & 0.41 \\
\hline
\end{tabular}

* Suggested as having some cancer-causing potential.

a Blank values have been subtracted from data. Data have not been corrected for temperature and pressure variation; maximum deviation would be within $\pm 2 \%$ of actual values.

$b$ ".-." designates compounds not cetected.

c specific isomers not distinguishable by analytical method; reported value represents any one or combination of existing isomers. 


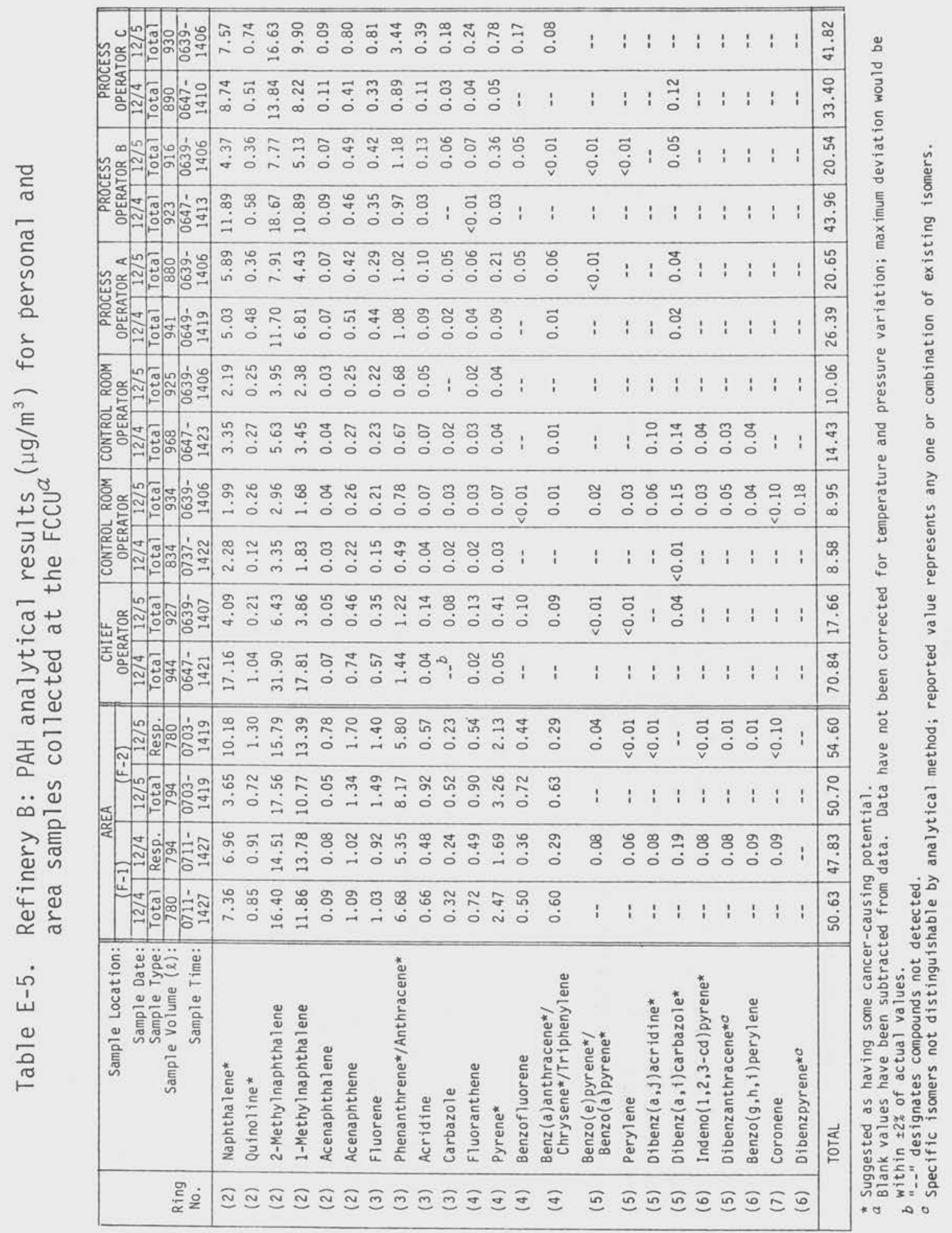




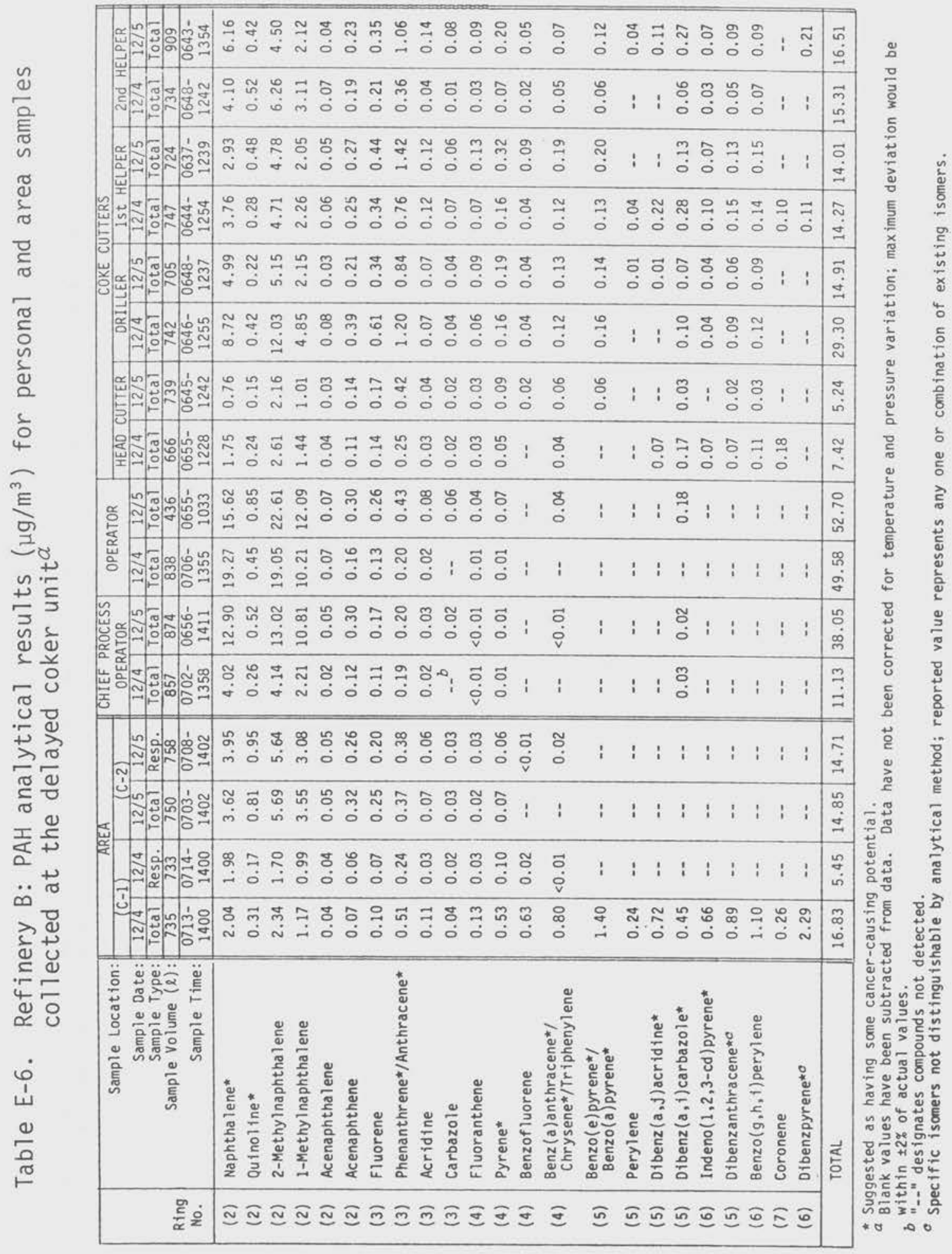


Table E-7. Refinery B: PAH analytical results $\left(\mu \mathrm{g} / \mathrm{m}^{3}\right)$ for area samples collected at the asphalt units and upwind location ${ }^{a}$

\begin{tabular}{|c|c|c|c|c|c|c|c|c|}
\hline \multirow[b]{6}{*}{$\begin{array}{l}\text { Ring } \\
\text { No. }\end{array}$} & \multirow{5}{*}{$\begin{array}{r}\text { Sample Location: } \\
\text { Sample Date: } \\
\text { Sample Type: } \\
\text { Sample Volume }(\ell):\end{array}$} & \multicolumn{4}{|c|}{ ASPHALT BLOWING AREA } & \multicolumn{2}{|c|}{ DEASPHALTING AREA } & \multirow{2}{*}{ UPWIND } \\
\hline & & & & & & $(A-3)$ & $(A-4)$ & \\
\hline & & $12 / 4$ & $12 / 4$ & $12 / 4$ & $12 / 4$ & $12 / 5$ & $12 / 5$ & $12 / 4$ \\
\hline & & Total & Resp. & \begin{tabular}{|l|} 
Total \\
\end{tabular} & Resp. & Total & Total & Total \\
\hline & & 727 & 737 & 704 & 723 & 733 & 717 & 799 \\
\hline & Sample Time: & $\begin{array}{l}0724- \\
1410\end{array}$ & $\begin{array}{l}0727- \\
1410 \\
\end{array}$ & $\begin{array}{l}0738- \\
1416\end{array}$ & $\begin{array}{l}0740- \\
1417\end{array}$ & $\begin{array}{l}0740- \\
1432\end{array}$ & $\begin{array}{l}0745- \\
1430\end{array}$ & $\begin{array}{l}0754- \\
1420\end{array}$ \\
\hline (2) & Naphthalene* & 1.13 & 1.50 & 0.37 & 2.21 & 0.12 & 2.68 & 0.28 \\
\hline (2) & Quinoline * & 0.05 & 0.06 & 0.08 & 0.09 & 0.12 & 0.35 & 0.10 \\
\hline (2) & 2-Methyl naphthalene & 0.85 & 1.09 & 0.56 & 1.55 & 0.49 & 5.22 & 0.31 \\
\hline (2) & 1-Methyl naphthalene & 0.69 & 0.64 & 0.36 & 1.22 & 0.40 & 3.19 & 0.20 \\
\hline (2) & Acenaphthalene & 0.01 & 0.02 & 0.01 & 0.03 & 0.03 & $-{ }^{b}$ & $<0.01$ \\
\hline (2) & Acenaphthene & $<0.01$ & 0.02 & 0.01 & 0.03 & 0.04 & 0.14 & 0.03 \\
\hline (3) & Fluorene & 0.02 & 0.03 & 0.04 & 0.04 & 0.07 & 0.14 & 0.03 \\
\hline (3) & Phenanthrene ${ }^{\star} /$ Anthracene ${ }^{\star}$ & 0.07 & 0.06 & 0.11 & 0.10 & 0.13 & 0.29 & 0.06 \\
\hline (3) & Acridine & $<0.01$ & 0.02 & -- & 0.02 & 0.03 & -- & 0.01 \\
\hline (3) & Carbazole & $<0.01$ & 0.01 & -- & $<0.01$ & 0.01 & - & 0.01 \\
\hline (4) & Fluoranthene & 0.01 & 0.01 & 0.01 & 0.01 & $<0.01$ & -- & $<0.01$ \\
\hline (4) & Pyrene* & 0.02 & 0.02 & $<0.01$ & 0.02 & $<0.01$ & - & $<0.01$ \\
\hline (4) & Benzofluorene & -- & - & -- & -- & -- & -- & - \\
\hline (4) & $\begin{array}{l}\text { Benz(a)anthracene*/ } \\
\text { Chrysene*/Triphenylene }\end{array}$ & $<0.01$ & -- & -- & -- & -- & - & 0.04 \\
\hline (5) & $\begin{array}{l}\text { Benzo(e)pyrene* } \\
\text { Benzo(a)pyrene* }\end{array}$ & -. & - & -- & - & -- & -- & -- \\
\hline$(5)$ & Perylene & -- & - & -- & - & - & -. & - \\
\hline$(5)$ & Dibenz $(a, j)$ acridine* & -- & - & - & -- & -- & -- & -- \\
\hline$(5)$ & $\operatorname{Dibenz}(a, i)$ carbazole* & 0.04 & 0.05 & - & -- & - & -- & - \\
\hline$(6)$ & Indeno $(1,2,3$-cd)pyrene* & - & - & -- & - & - & - & -- \\
\hline$(5)$ & Dibenzanthracene ${ }^{\star c}$ & - & - & - & - & - & - & - \\
\hline (6) & Benzo( $g, h, i)$ perylene & -- & - & - & - & -- & - & -- \\
\hline (7) & Coronene & $\cdots$ & - & - & - & -- & - & -- \\
\hline (6) & Dibenzpyrene ${ }^{\star c}$ & -- & -- & -- & -- & -- & -- & -- \\
\hline & TOTAL & 2.89 & 3.53 & 1.55 & 5.32 & 1.44 & 12.01 & 1.07 \\
\hline
\end{tabular}

* Suggested as having some cancer-causing potential.

alank values have been subtracted from data. Data have not been corrected for temperature and pressure variation; maximum deviation would be within $\pm 2 \%$ of actual values.

$b$ "--" designates compounds not detected.

c Specific isomers not distinguishable by analytical method; reported value represents any one or combination of existing isomers. 


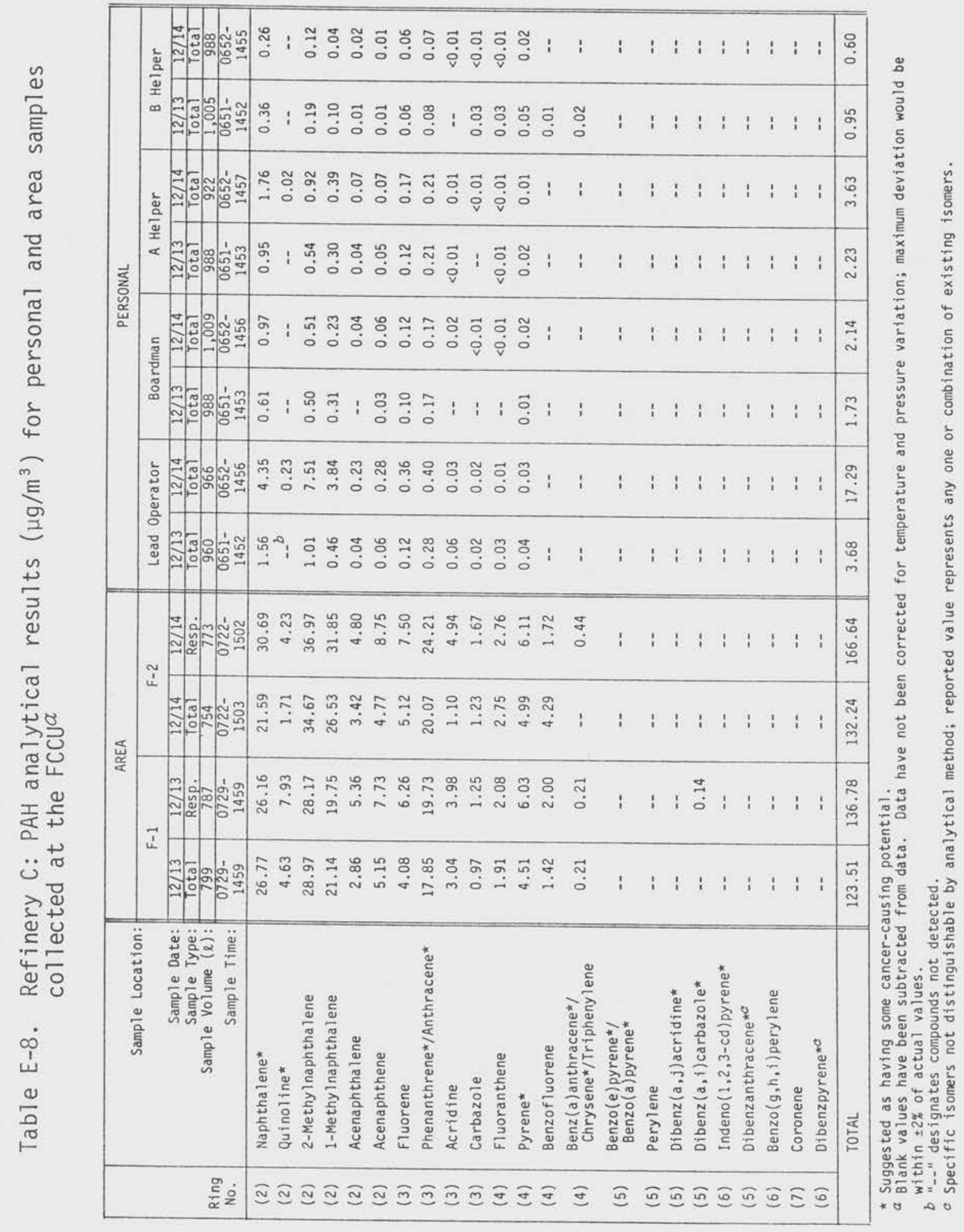




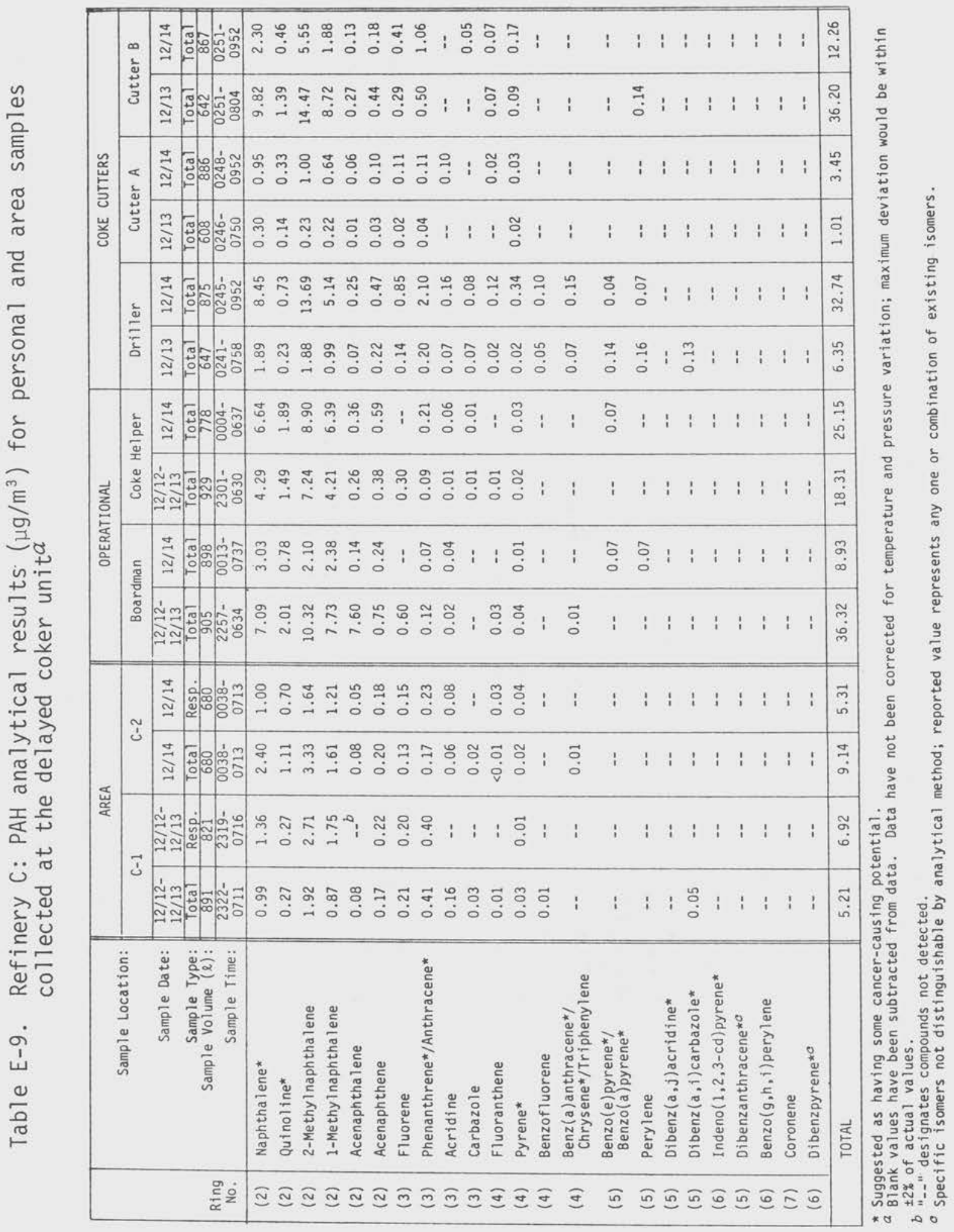


Table E-10. Refinery C: PAH analytical results $\left(\mu \mathrm{g} / \mathrm{m}^{3}\right)$ for area samples collected at the asphalt units and upwind locationa

\begin{tabular}{|c|c|c|c|c|c|c|c|c|}
\hline \multirow[b]{5}{*}{$\begin{array}{l}\text { Ring } \\
\text { No. }\end{array}$} & \multirow{5}{*}{$\begin{array}{r}\text { Sample Location: } \\
\text { Sample Date: } \\
\text { Sample Type: } \\
\text { Sample Volume }(\ell): \\
\text { Sample Time: }\end{array}$} & \multirow{2}{*}{\multicolumn{3}{|c|}{$\begin{array}{l}\text { \#1 Vacuum Unit } \\
\text { AREA }\end{array}$}} & \multirow{2}{*}{\multicolumn{3}{|c|}{$\begin{array}{l}\text { \#4 Vacuum Unit } \\
\text { AREA }\end{array}$}} & \multirow{3}{*}{$\begin{array}{l}\text { UPWIND } \\
12 / 14\end{array}$} \\
\hline & & & & & & & & \\
\hline & & $12 / 13$ & $12 / 13$ & $\frac{A-2}{12 / 14}$ & $\begin{array}{l}A-3 \\
12 / 12- \\
12 / 13\end{array}$ & $12 / 14$ & $12 / 14$ & \\
\hline & & $\frac{\text { Total }}{774}$ & $\frac{\text { Resp. }}{779}$ & $\frac{\text { Total }}{812}$ & $\frac{\text { Total }}{761}$ & $\frac{\text { Total }}{751}$ & $\frac{\text { Resp. }}{668}$ & $\begin{array}{c}\text { Total } \\
963\end{array}$ \\
\hline & & $\begin{array}{l}0752- \\
1515\end{array}$ & $\begin{array}{l}0752- \\
1515 \\
\end{array}$ & $\begin{array}{l}0740- \\
1522 \\
\end{array}$ & $\begin{array}{r}2310- \\
0637\end{array}$ & $0025-$ & $\begin{array}{r}0025- \\
0658\end{array}$ & $\begin{array}{l}0829- \\
1614\end{array}$ \\
\hline (2) & Naphthalene* & 1.24 & 1.19 & 0.66 & 3.64 & 0.45 & 3.26 & 0.06 \\
\hline (2) & Quinoline* & 1.13 & 1.01 & 0.40 & 0.40 & $--b$ & 0.15 & -- \\
\hline (2) & 2-Methylnaphthalene & 3.44 & 3.49 & 1.26 & 3.76 & 0.67 & 2.01 & - \\
\hline (2) & 1-Methylnaphthalene & 2.16 & 2.29 & 0.84 & 3.06 & 1.66 & 1.85 & - \\
\hline (2) & Acenaph tha lene & 0.40 & 0.32 & 0.07 & 0.09 & 0.08 & 0.03 & $\cdots$ \\
\hline (2) & Acenaphthene & 0.83 & 0.79 & 0.13 & 0.18 & 0.19 & 0.08 & -- \\
\hline (3) & Fluorene & 0.73 & 0.69 & 0.13 & 0.19 & 0.17 & 0.06 & -- \\
\hline (3) & Phenanthrene*/Anthracene* & 2.56 & 2.14 & 0.32 & 0.37 & 0.30 & 1.14 & 0.01 \\
\hline (3) & Acridine & 0.94 & 0.73 & 0.35 & 0.13 & 0.10 & 0.03 & -- \\
\hline (3) & Carbazole & 0.52 & 0.44 & 0.06 & 0.13 & 0.04 & 0.07 & -- \\
\hline (4) & Fluoranthene & 0.32 & 0.26 & $\cdots$ & 0.14 & 0.03 & 0.04 & - \\
\hline (4) & Pyrene* & 0.45 & 0.37 & 0.17 & 0.15 & 0.04 & 0.09 & -- \\
\hline (4) & Benzofluorene & 0.74 & 0.58 & 0.11 & 0.09 & - & -- & -- \\
\hline (4) & $\begin{array}{l}\text { Benz(a)anthracene }{ }^{\star} / \\
\text { Chrysene }{ }^{\star} / \text { Triphenylene }^{-}\end{array}$ & 0.19 & 0.22 & 0.04 & 0.10 & -- & 0.03 & -- \\
\hline (5) & $\begin{array}{c}\text { Benzo(e)pyrene*/ } \\
\text { Benzo(a)pyrene* }\end{array}$ & 0.06 & 0.05 & 0.10 & 0.14 & -- & $\cdots$ & -- \\
\hline (5) & Perylene & -- & 0.03 & 0.13 & 0.12 & -- &.- & -- \\
\hline (5) & Dibenz $(a, j)$ acridine* & -- & 0.07 & -- & -- & -- & -- & -- \\
\hline (5) & Dibenz $(a, i)$ carbazole ${ }^{\star}$ & -- & 0.17 & -- & 0.14 & -- & 0.19 & $\cdots$ \\
\hline (6) & Indeno $(1,2,3$-cd) pyrene* & -- & -- & - & -- & -- & - & - \\
\hline$(5)$ & Dibenzanthracene ${ }^{\star 0}$ & $\cdots$ & $\cdots$ & -- & -- & $-\cdot$ & $\cdots$ & -- \\
\hline (6) & Benzo $(g, h, 1)$ perylene & -- & $\cdots$ & $-\cdot$ & - & -- & 0.06 & -- \\
\hline (7) & Coronene & -- & - & -- & - & -- & $\cdots$ & -- \\
\hline (6) & Dibenzpyrene*c & -- & -- & -- & $\cdots$ & -- & $\cdots$ & -- \\
\hline & TOTAL & 15.71 & 14.84 & 4.77 & 12.83 & 4.73 & 8.09 & 0.07 \\
\hline
\end{tabular}

* Suggested as having some cancer-causing potential.

a Blank values have been subtracted from data. Data have not been corrected for temperature and pressure variation; maximum deviation would be within $\pm 2 \%$ of actual values.

b "--" designates compounds not detected.

a Specific isomers not distinguishable by analytical method; reported value represents any one or combination of existing isomers. 


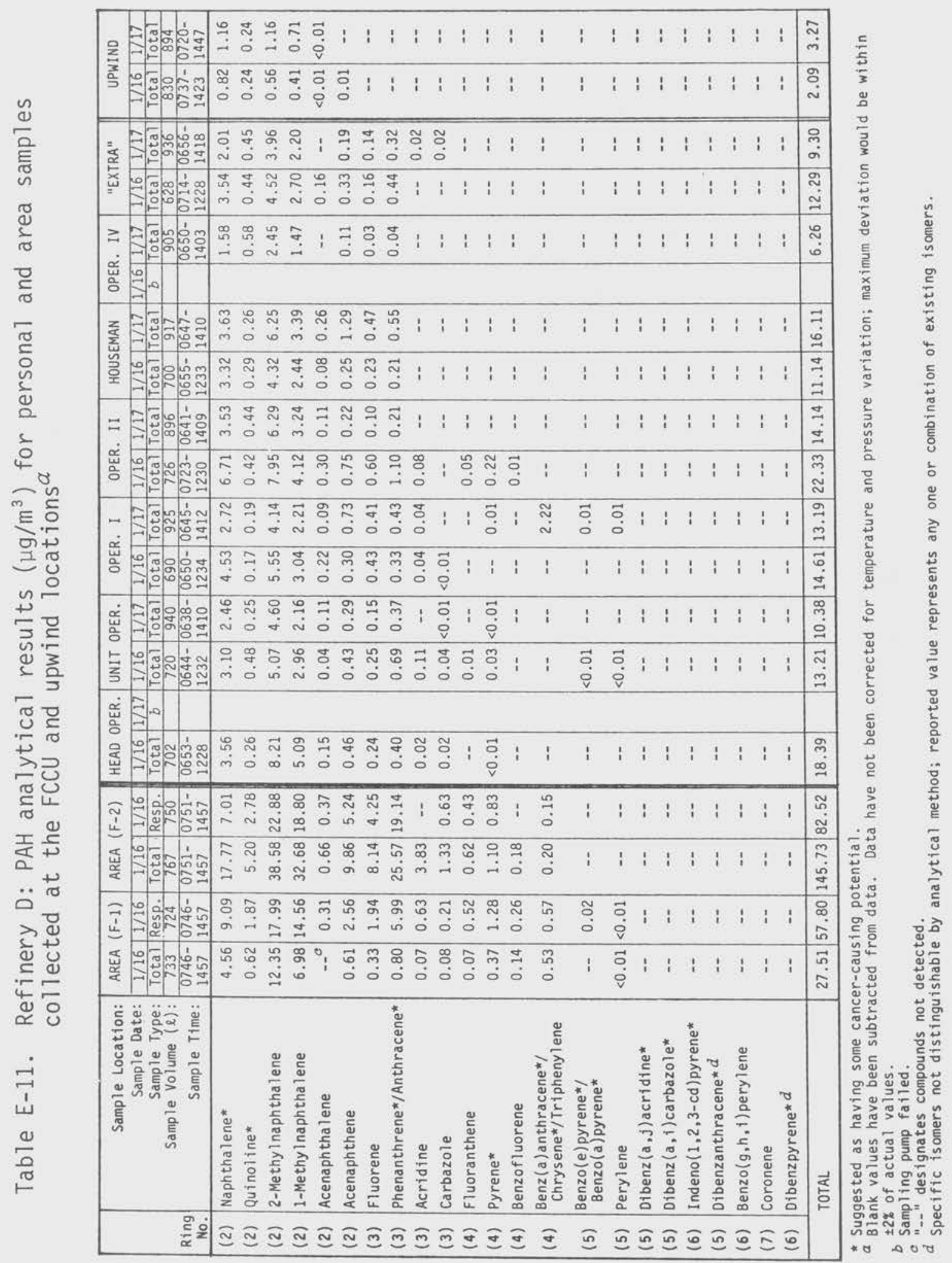




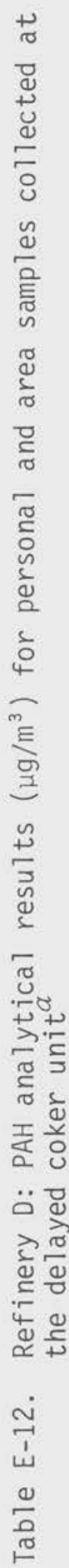

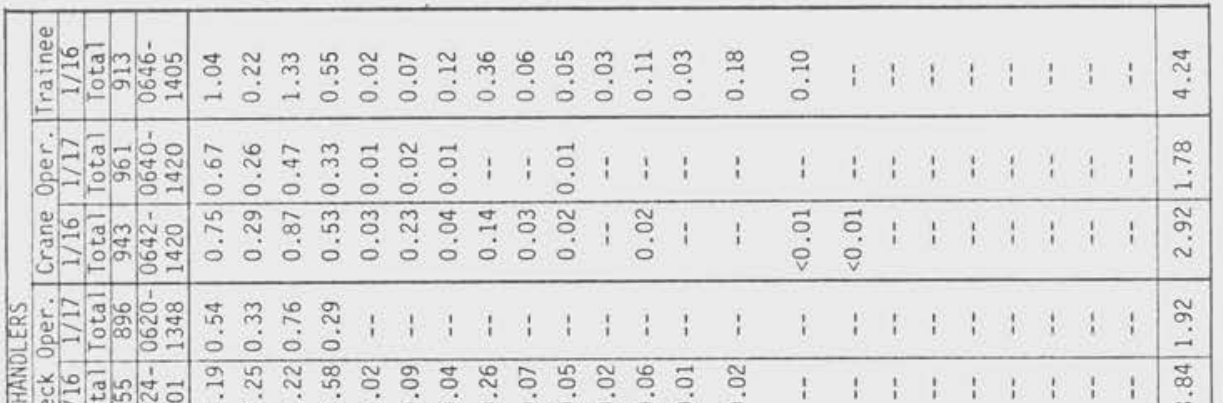

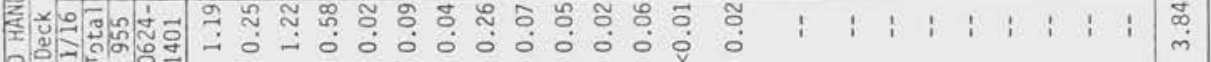

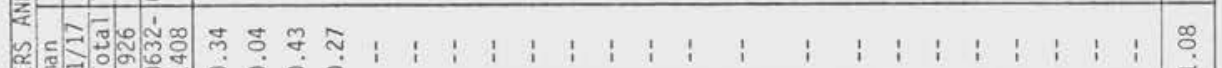

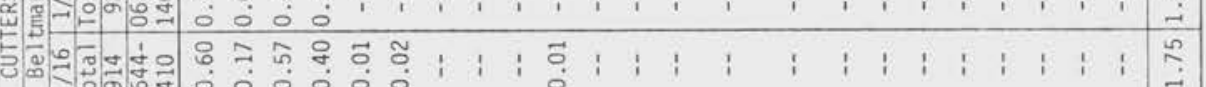

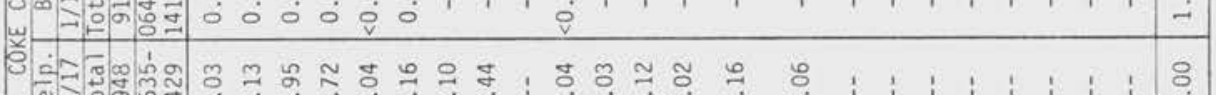

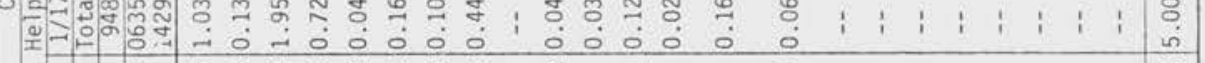

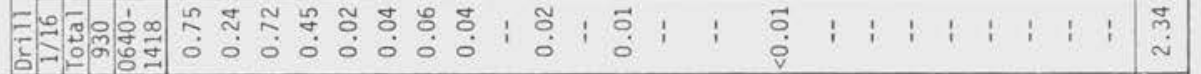

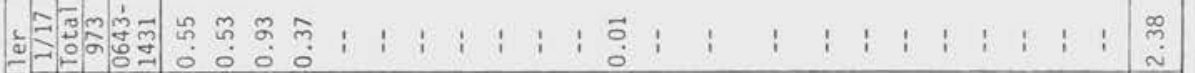

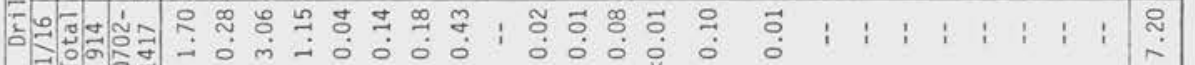

$\therefore=\bar{\pi} \div$.

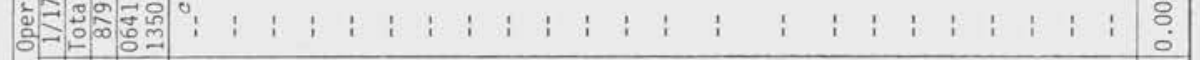

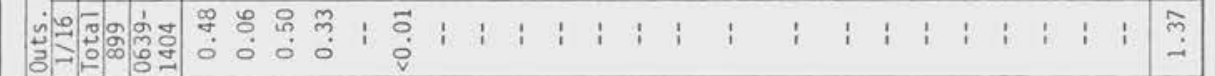

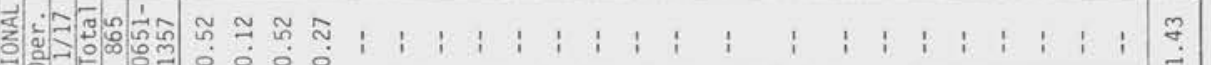

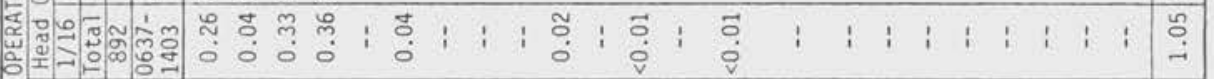

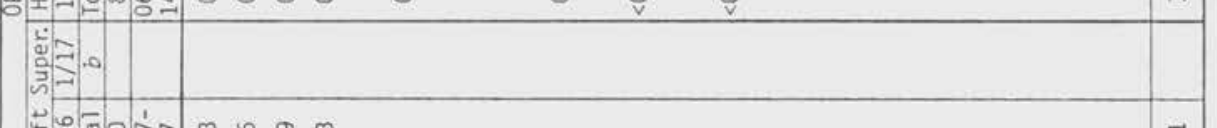

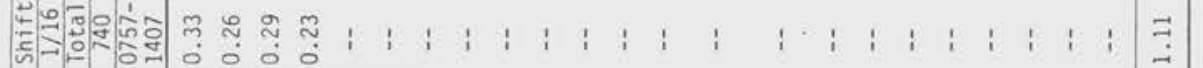

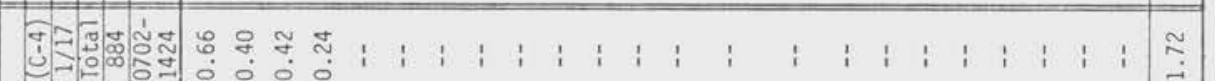

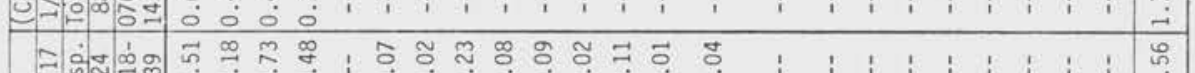

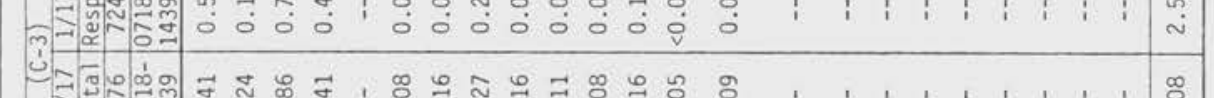

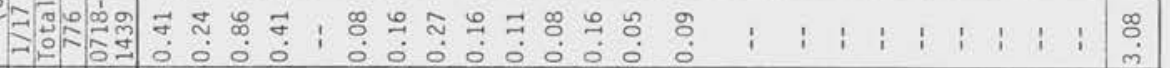

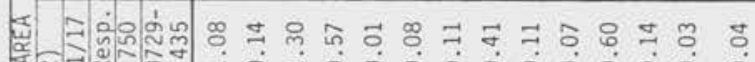

A

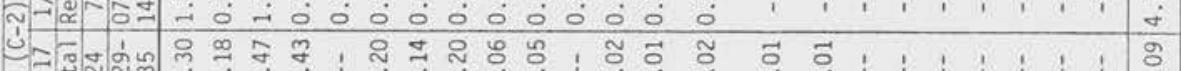

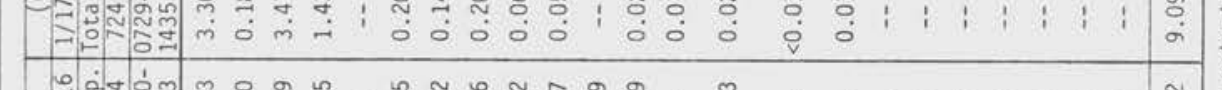

7)

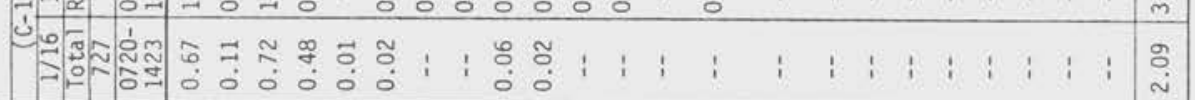

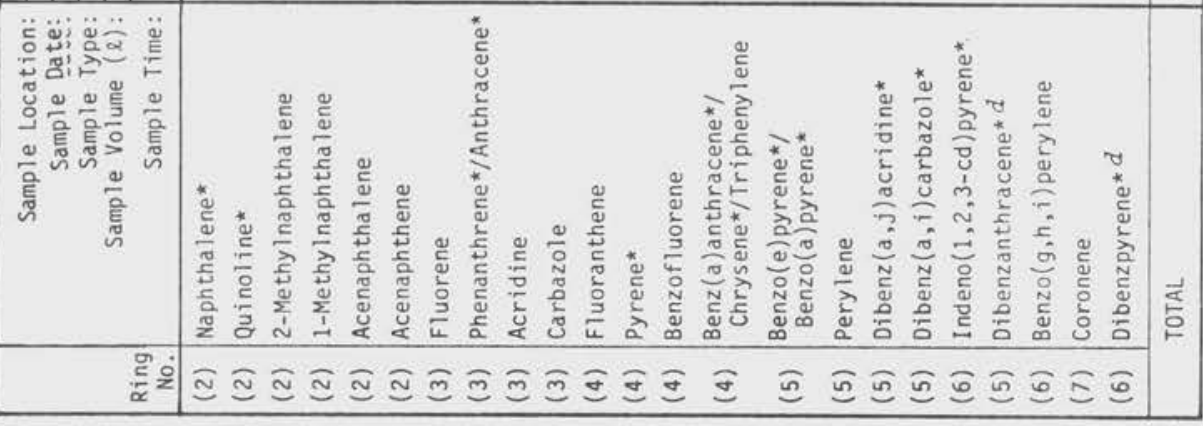

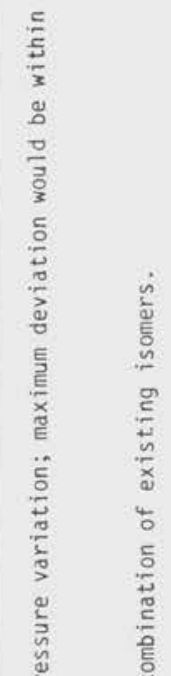




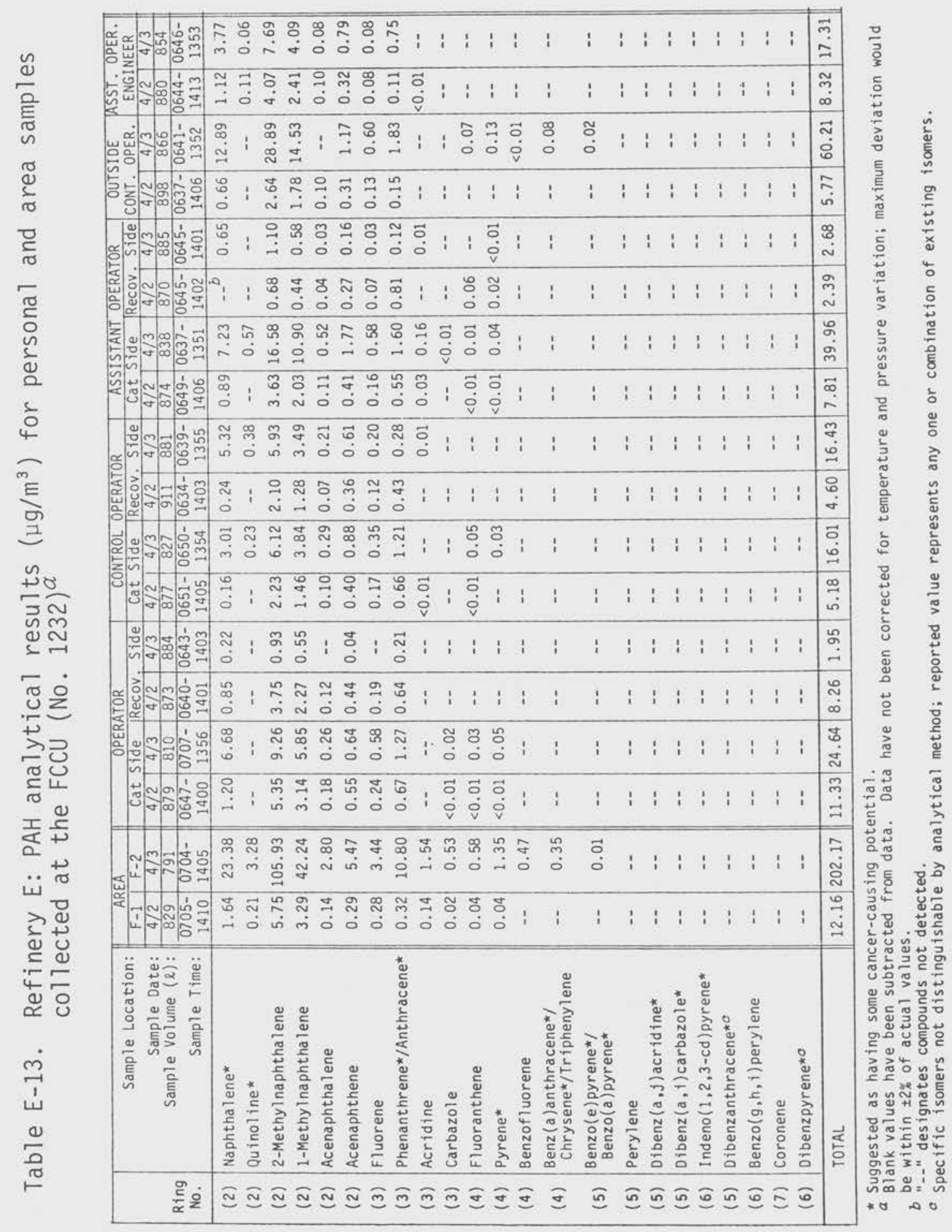




\section{Table E-14. Refinery E: PAH analytical results $\left(\mu \mathrm{g} / \mathrm{m}^{3}\right)$ for personal and area samples collected at the deasphalting unit and upwind locations ${ }^{a}$}

\begin{tabular}{|c|c|c|c|c|c|c|c|c|c|c|c|}
\hline \multirow[b]{3}{*}{$\begin{array}{l}\text { Ring } \\
\text { No. }\end{array}$} & \multirow{3}{*}{$\begin{array}{r}\text { Sample Location: } \\
\text { Sample Date: } \\
\text { Sample Volume }(\ell): \\
\text { Sample Time: }\end{array}$} & $\frac{A F}{D-1}$ & $E A$ & \multicolumn{2}{|c|}{ OPERATOR } & \multicolumn{2}{|c|}{$\begin{array}{l}\text { ASSISTANT } \\
\text { OPERATOR } 1\end{array}$} & \multicolumn{2}{|c|}{$\begin{array}{l}\text { ASSISTANT } \\
\text { OPERATOR } 2 \\
\end{array}$} & \multicolumn{2}{|c|}{ UPWIND } \\
\hline & & $\begin{array}{l}4 / 2 \\
878\end{array}$ & $\begin{array}{l}4 / 3 \\
789\end{array}$ & $\frac{4 / 2}{879}$ & $\frac{4 / 3}{858}$ & $\frac{4 / 2}{864}$ & \begin{tabular}{|l|}
$4 / 3$ \\
836
\end{tabular} & $4 / 2$ & \begin{tabular}{|l|l|}
$4 / 3$ \\
828
\end{tabular} & $4 / 2$ & $4 / 3$ \\
\hline & & $\begin{array}{l}878 \\
0738- \\
1440\end{array}$ & \begin{tabular}{c|}
789 \\
$0735-$ \\
1424 \\
\end{tabular} & $\begin{array}{c}879 \\
0721- \\
1436 \\
\end{array}$ & $\begin{array}{c}858 \\
0718- \\
1427 \\
\end{array}$ & $\begin{array}{c}864 \\
0723- \\
1437\end{array}$ & \begin{tabular}{c|}
836 \\
$0731-$ \\
1429
\end{tabular} & $b$ & \begin{tabular}{|c|}
838 \\
$0731-$ \\
1422
\end{tabular} & $\begin{array}{c}850 \\
0758- \\
1459\end{array}$ & $\begin{array}{l}700 \\
0623- \\
1213\end{array}$ \\
\hline (2) & Naphthalene* & 36.93 & 24.92 & 18.13 & 2.52 & 42.15 & 19.69 & & 1.71 & $-{ }^{c}$ & 0.29 \\
\hline (2) & Quinol ine* & - & 0.06 & - & $<0.01$ & 0.12 & -- & & - & - & $<0.01$ \\
\hline (2) & 2-Methylnaphthalene & 2.81 & 2.31 & 1.47 & 0.57 & 4.67 & 0.81 & & 0.38 & - & 0.24 \\
\hline (2) & 1-Methylnaphthalene & 1.07 & 1.06 & 0.81 & 0.33 & 2.25 & 0.40 & & 0.36 & -- & 0.25 \\
\hline (2) & Acenaphthalene & -- & 0.04 & -- & - & 0.04 & -- & & -- & -- & -. \\
\hline (2) & Acenaphthene & - & 0.11 & - & 0.02 & 0.18 & -- & & $<0.01$ & -- & - \\
\hline (3) & Fluorene & - & 0.07 & -- & - & 0.09 & - & & - & -- & -- \\
\hline (3) & Phenanthrene*/Anthracene ${ }^{\star}$ & 0.33 & 0.18 & 0.33 & -- & 0.22 & 0.39 & & 0.05 & - & - \\
\hline (3) & Acridine & -- & 0.05 & -- & - & 0.03 & -- & & $\ldots$ & - & -. \\
\hline (3) & Carbazole & $<0.01$ & 0.01 & -- & - & -- & -- & & - & -- & -- \\
\hline (4) & Fluoranthene & 0.01 & 0.03 & -- & - & $<0.01$ & -- & & -- & -- & - \\
\hline (4) & Pyrene* & 0.01 & 0.04 & -- & -- & -- & -- & & -- & -- & - \\
\hline (4) & Benz of luorene & - & - & -- & -- & -- & -- & & -- & -- & - \\
\hline (4) & $\begin{array}{l}\text { Benz (a)anthracene } \\
\text { Chrysene }{ }^{\star} / \text { Triphenylene }\end{array}$ & - & -- & -- & -- & -- & -. & & -- & -- & -- \\
\hline (5) & $\begin{array}{l}\text { Benzo(e)pyrene }{ }^{\star} \\
\text { Benzo(a)pyrene* }\end{array}$ & - & -- & -- & -- & -- & - & & -- & -- & -- \\
\hline (5) & Perylene & - & -- & -- & -- & - & -- & & - & -- & $\cdots$ \\
\hline (5) & Dibenz $(a, j)$ acridine* & -. & -. & -- & -- & - & - & & -- & -- & -- \\
\hline (5) & $\operatorname{Dibenz}(a, i)$ carbazole* & $\cdots$ & -. & - & - & - & -- & & -- & -- & -- \\
\hline (6) & Indeno $(1,2,3-c d)$ pyrene* & - & -- & -- & - & - & - & & - & - & -. \\
\hline (5) & Dibenzanthracene ${ }^{\star d}$ & - & -- & -- & -- & $\cdots$ & - & & -- & -. & - \\
\hline$(6)$ & Benzo $(g, h, i)$ perylene & - & - & -- & - & - & -. & & -- & -- & -. \\
\hline (7) & Coronene & - & - & -- & -- & $\cdots$ & -- & & -- & -- & - \\
\hline (6) & Dibenzpyrene ${ }^{\star d}$ & $\cdots$ & $-\cdot$ & - & -- & - & - & & -- & - & - \\
\hline & TOTAL & 41.16 & 28.88 & 20.74 & 3.44 & 49.75 & 21.29 & & 2.50 & 0.00 & 0.78 \\
\hline
\end{tabular}


Table E-15. Refinery F: PAH analytical results $\left(\mu \mathrm{g} / \mathrm{m}^{3}\right)$ for personal and area samples collected at the FCCUa

\begin{tabular}{|c|c|c|c|c|c|c|c|c|c|c|c|c|c|}
\hline \multirow[b]{3}{*}{$\begin{array}{l}\text { Ring } \\
\text { No. }\end{array}$} & \multirow{3}{*}{$\begin{array}{r}\text { Sample Location: } \\
\text { Sample Date: } \\
\text { Sample Volume }(\ell): \\
\text { Sample Time: }\end{array}$} & \multicolumn{2}{|c|}{ AREA } & \multicolumn{2}{|c|}{ SUPERVISOR } & \multicolumn{2}{|c|}{ \#1 OPERATOR } & \multicolumn{2}{|c|}{$\begin{array}{l}\text { \#1 OPERATOR } \\
\text { TRAINEE }\end{array}$} & \multicolumn{2}{|c|}{$\begin{array}{l}\text { \#2 OPERATOR } \\
\text { RECOVERY }\end{array}$} & \multicolumn{2}{|c|}{$\begin{array}{l}\text { \#2 OPERATOR } \\
\text { CAT SIDE }\end{array}$} \\
\hline & & $\frac{5 / 14}{916}$ & $\frac{5 / 15}{b}$ & $\frac{5 / 14}{932}$ & $\frac{5 / 15}{1,000}$ & $\frac{5 / 14}{921}$ & $\frac{5 / 15}{914}$ & $\frac{5 / 14}{906}$ & $\frac{\frac{102}{5 / 15}}{941}$ & $\frac{5 / 14}{882}$ & $\frac{5 / 15}{932}$ & $\frac{5 / 14}{900}$ & $\frac{5 / 15}{926}$ \\
\hline & & $\begin{array}{l}0740- \\
1515\end{array}$ & & $\begin{array}{l}0746- \\
1535\end{array}$ & $\begin{array}{l}0731- \\
1553\end{array}$ & $\begin{array}{l}0755- \\
1531\end{array}$ & $\begin{array}{l}0755- \\
1535\end{array}$ & $\begin{array}{l}0801- \\
1532\end{array}$ & $\begin{array}{l}0749- \\
1541\end{array}$ & $\begin{array}{l}0800- \\
1519\end{array}$ & $\begin{array}{l}0802- \\
1543\end{array}$ & $\begin{array}{l}0759- \\
1529\end{array}$ & $\begin{array}{l}0758- \\
1542 \\
\end{array}$ \\
\hline (2) & Naphthalene* & 2.96 & & 0.51 & 3.06 & 1.78 & 2.39 & 0.25 & 0.44 & 0.58 & 0.55 & 0.68 & 0.42 \\
\hline (2) & Quinoline* & $-a^{c}$ & & $\cdots$ & -- & -- & -- & -- & -. & -. & -- & -- & -- \\
\hline (2) & 2-Methylnaphthalene & 9.73 & & 0.61 & 3.11 & 2.15 & 2.23 & 0.74 & 0.50 & 0.91 & 0.56 & 1.03 & 0.43 \\
\hline (2) & 1-Methyl naphthalene & 5.93 & & 0.45 & 1.88 & 1.11 & 1.40 & 0.46 & 0.30 & 0.65 & 0.33 & 0.64 & 0.29 \\
\hline (2) & Acenaphthalene & 0.39 & & $\cdots$ & - & -- & -- & -- & -- & -- & -- & -- & 0.01 \\
\hline (2) & Acenaphthene & 1.57 & & 0.24 & 0.72 & 0.45 & 0.84 & 0.32 & 0.17 & 0.20 & 0.19 & 0.29 & 0.08 \\
\hline (3) & Fluorene & 1.32 & & 0.15 & 0.30 & 0.21 & 0.23 & 0.19 & 0.09 & 0.04 & 0.12 & 0.14 & 0.02 \\
\hline (3) & Phenanthrene*/Anthracene* & 7.82 & & 0.28 & 0.48 & 0.13 & 0.17 & 0.09 & -- & $\cdots$ & 0.05 & 0.14 & 0.04 \\
\hline (3) & Acridine & -- & & -. & $<0.01$ & - & -- & $\cdots$ & -- & -- & -- & -- & -- \\
\hline (3) & Carbazole & -- & & - & - & -- & -- & 0.05 & 0.02 & -- & -- & 0.03 & -- \\
\hline (4) & Fluoranthene & 0.56 & & $\cdots$ & -- & 0.02 & -- & 0.02 & $<0.01$ & -- & $<0.01$ & 0.02 & -- \\
\hline (4) & Pyrene* & 1.70 & & -. & -. & 0.03 & -- & 0.06 & 0.02 & -- & 0.02 & 0.08 & -- \\
\hline (4) & Benzofluorene & -- & & -- & -- & -- & -- & $<0.01$ & -- & - & - & $-\cdot$ & - \\
\hline (4) & $\begin{array}{l}\text { Benz (a) anthracene }{ }^{\star} / \\
\text { Chrysene } \star \text { Triphenylene }\end{array}$ & 0.34 & & $-\cdot$ & -. & -- & -- & 0.03 & -- & -- & -. & 0.02 & - \\
\hline (5) & $\begin{array}{l}\text { Benzo(e)pyrene*/ } \\
\text { Benzo(a)pyrene* }\end{array}$ & -- & & -- & $\cdots$ & -- & -- & -- & -- & -. & -- & -- & -- \\
\hline (5) & Perylene & $\cdots$ & & $\cdots$ & $\cdots$ & - & -- & -- & -. & - & - & -- & -- \\
\hline (5) & Dibenz $(a, j)$ acridine* & -- & & -- & -. & -. & -. & - & -. & - & - & -- & -- \\
\hline (5) & Dibenz $(a, i)$ carbazole* & -. & & -. & $\cdots$ & -- & -. & -- & -- & -- & - & - & -- \\
\hline (6) & Indeno $(1,2,3-c d)$ pyrene $e^{\star}$ & -- & & -- & - & -- & -- & -- & - & - & -. & -- & - \\
\hline (5) & Dibenzanthracene ${ }^{\star d}$ & -- & & -- & - & -- & -- & -- & -- & -- & -- & -- & -- \\
\hline (6) & Benzo $(g, h, i)$ perylene & -- & & -- & $\cdots$ & -- & -- & -- & $-\cdot$ & -- & - & - & - \\
\hline (7) & Coronene & -- & & -. & - & -. & -- & -. & -. & -- & - & -- & - \\
\hline (6) & Dibenzpyrene ${ }^{\star d}$ & -- & & - & $\cdots$ & - & -- & -- & + & $\cdots$ & - & - & -- \\
\hline & TOTAL & 32.57 & & 2.24 & 9.55 & 5.88 & 7.26 & 2.21 & 1.54 & 2.38 & 1.82 & 3.07 & 1.29 \\
\hline
\end{tabular}

* Suggested as having some cancer-causing potential.

Blank values have been subtracted from data. Data have not been corrected for temperature and pressure variation;

maximum deviation would be within $\pm 2 \%$ of actual values.

Sample lost during analysis.

c "--" designates compounds not detected.

d specific isomers not distinguishable by analytical method; reported value represents any one or combination of existing isomers. 


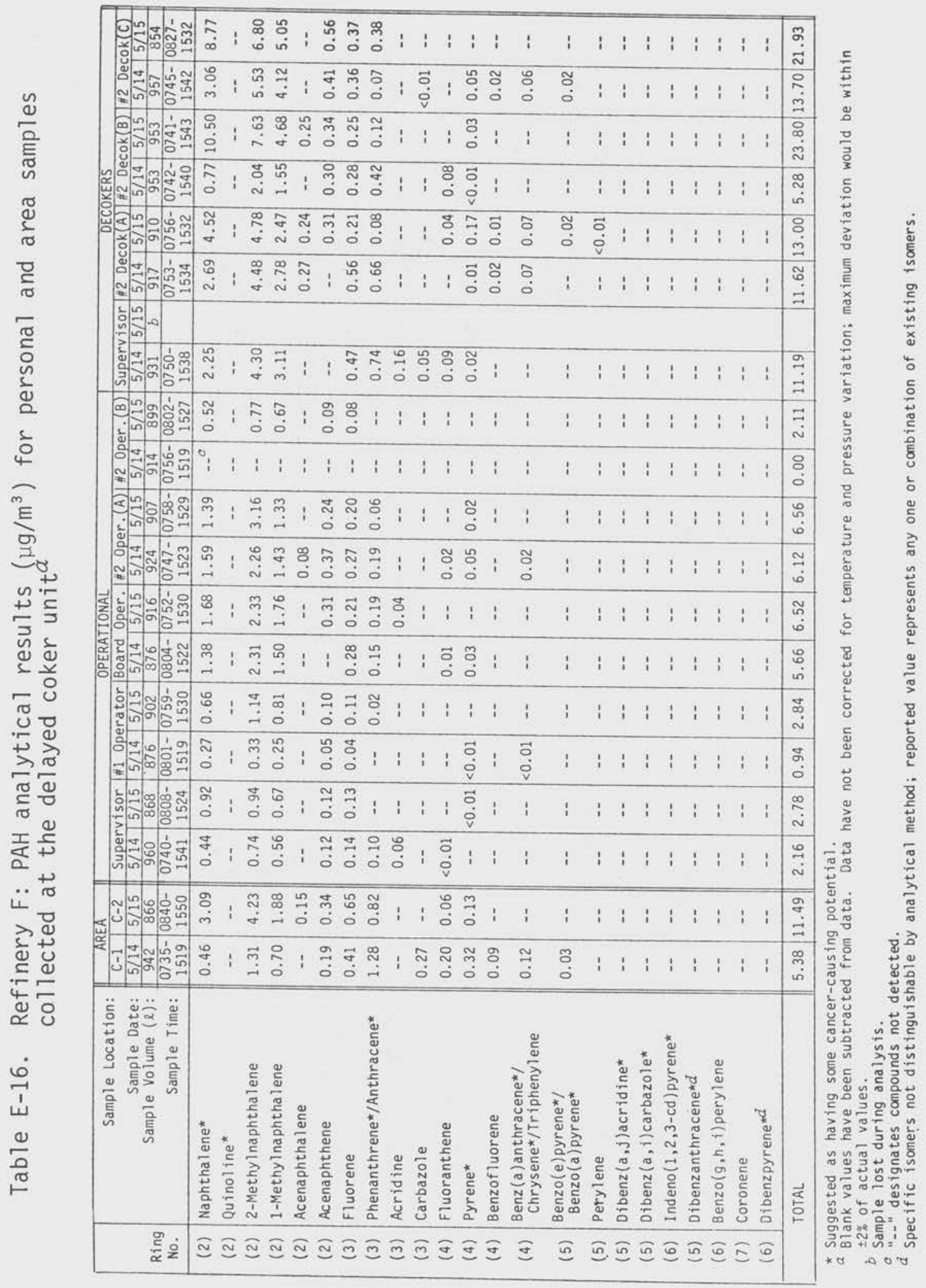


Table E-17. Refinery F: PAH analytical results $\left(\mu \mathrm{g} / \mathrm{m}^{3}\right)$ for area samples collected at the asphalt units and upwind locations $a$

\begin{tabular}{|c|c|c|c|c|c|c|}
\hline \multirow[b]{4}{*}{$\begin{array}{l}\text { Ring } \\
\text { No. }\end{array}$} & \multirow{4}{*}{$\begin{array}{r}\text { Sample Location: } \\
\text { Sample Date: } \\
\text { Sample Volume }(\ell): \\
\text { Sample Time: }\end{array}$} & \multicolumn{3}{|c|}{ AREA } & \multirow{2}{*}{\multicolumn{2}{|c|}{ UPWIND }} \\
\hline & & $A-1$ & & & & \\
\hline & & $\frac{5 / 14}{838}$ & $\begin{array}{l}5 / 15 \\
909\end{array}$ & $\frac{5 / 15}{796}$ & $\frac{5 / 14}{660}$ & $\frac{5 / 15}{604}$ \\
\hline & & $\begin{array}{l}0825- \\
1520\end{array}$ & $\begin{array}{l}0832- \\
1600\end{array}$ & $\begin{array}{l}0825- \\
1503\end{array}$ & $\begin{array}{l}0930- \\
1459\end{array}$ & $\begin{array}{l}1010- \\
1512\end{array}$ \\
\hline (2) & Naphthalene* & 2.68 & 1.39 & $\ldots b$ & 0.20 & -- \\
\hline (2) & Quinoline* & -- & -- & -- & -- & -- \\
\hline (2) & 2-Methylnaphthalene & 6.08 & 5.14 & 0.62 & 0.07 & -- \\
\hline (2) & 1-Methylnaphthalene & 6.32 & 4.28 & 0.34 & 0.07 & -- \\
\hline (2) & Acenaphthalene & -- & 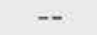 & -- & -- & -- \\
\hline (2) & Acenaphthene & -- & 0.72 & - & -. & -- \\
\hline (3) & Fluorene & 1.15 & 0.72 & 0.05 & $<0.01$ & -- \\
\hline (3) & Phenanthrene*/Anthracene ${ }^{\star}$ & 0.98 & 0.68 & 0.12 & -- & -- \\
\hline (3) & Acridine & -- & 0.31 & 0.06 & -- & -- \\
\hline (3) & Carbazole & -- & 0.06 & 0.24 & -- & -- \\
\hline (4) & Fluoranthene & 0.04 & -- & 0.08 & - & -- \\
\hline (4) & Pyrene* & 0.07 & $<0.01$ & 0.25 & -- & -- \\
\hline (4) & Benzofluorene & -- & -- & -- & -- & - \\
\hline (4) & $\begin{array}{l}\text { Benz (a)anthracene*/ } \\
\text { Chrysene } e^{\star} / \text { Triphenylene }\end{array}$ & - & - & 0.06 & -- & $\cdots$ \\
\hline (5) & $\begin{array}{c}\text { Benzo(e)pyrene*/ } \\
\text { Benzo(a)pyrene* }\end{array}$ & -- & -- & - & -- & -- \\
\hline (5) & Perylene & - & -- & - & - & - \\
\hline (5) & Dibenz $(a, j)$ acr id ine* & -- & $\sim$ & -- & - & -- \\
\hline (5) & Dibenz $(a, i)$ carbazole* & -- & -- & -- & -- & -- \\
\hline (6) & Indeno $(1,2,3-c d)$ pyrene* & -- & -- & - & -- & -- \\
\hline$(5)$ & Dibenzanthracene $\star c$ & -- & -- & -- & -- & -- \\
\hline (6) & Benzo $(g, h, i)$ perylene & -- & -- & -- & -- & -- \\
\hline (7) & Coronene & -- & -- & -- & - & -- \\
\hline (6) & Dibenzpyrene ${ }^{\star c}$ & - & -- & $\cdots$ & -- & $-\cdot$ \\
\hline & TOTAL & 17.32 & 13.30 & 1.82 & 0.34 & 0.00 \\
\hline
\end{tabular}

* Suggested as having some cancer-causing potential.

a Blank values have been subtracted from data. Data have not been corrected for temperature and pressure variation; maximum deviation would be within $\pm 2 \%$ of actual values.

b "--" designates compounds not detected.

c Specific isomers not distinguishable by analytical method; reported value represents any one or combination of existing isomers. 


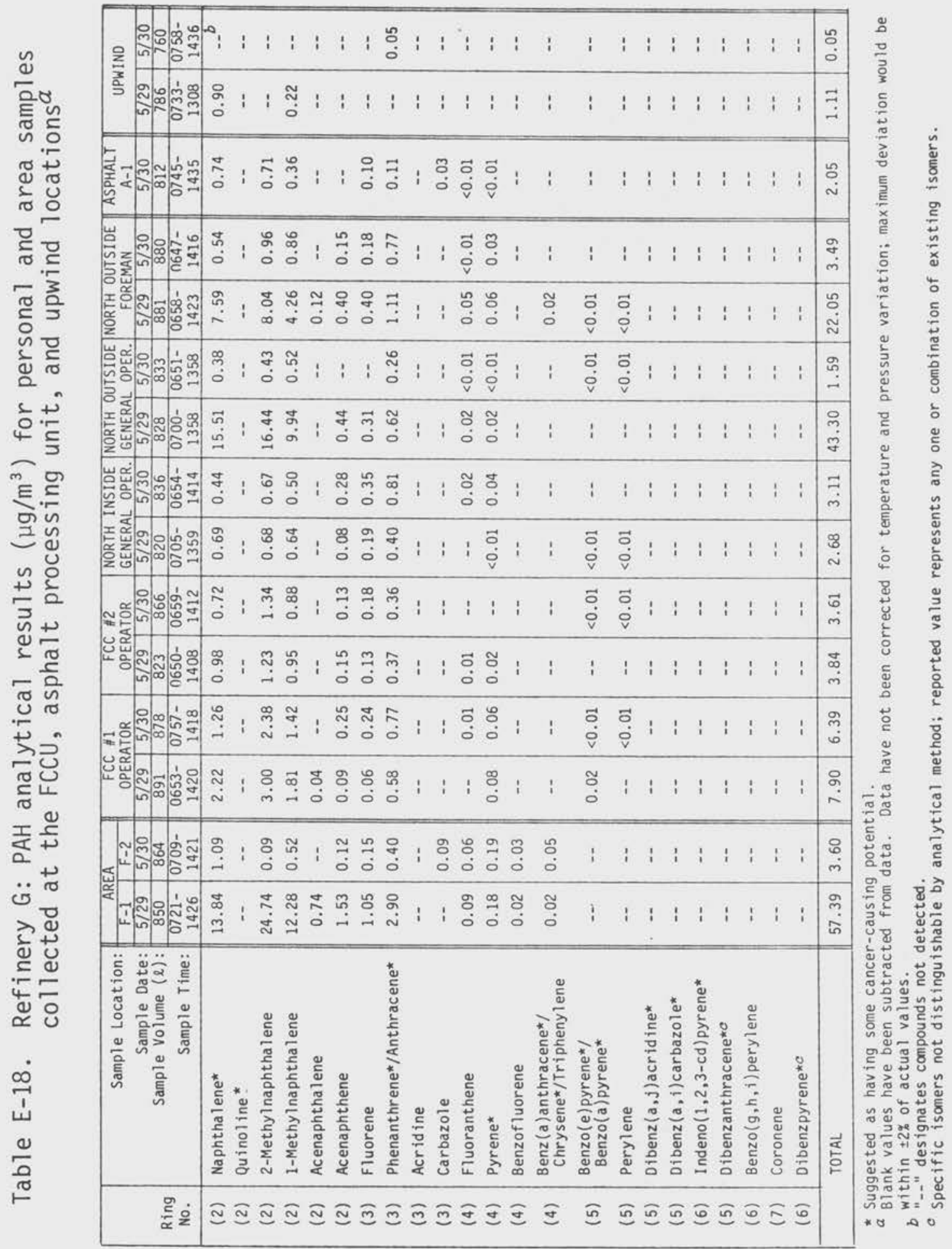




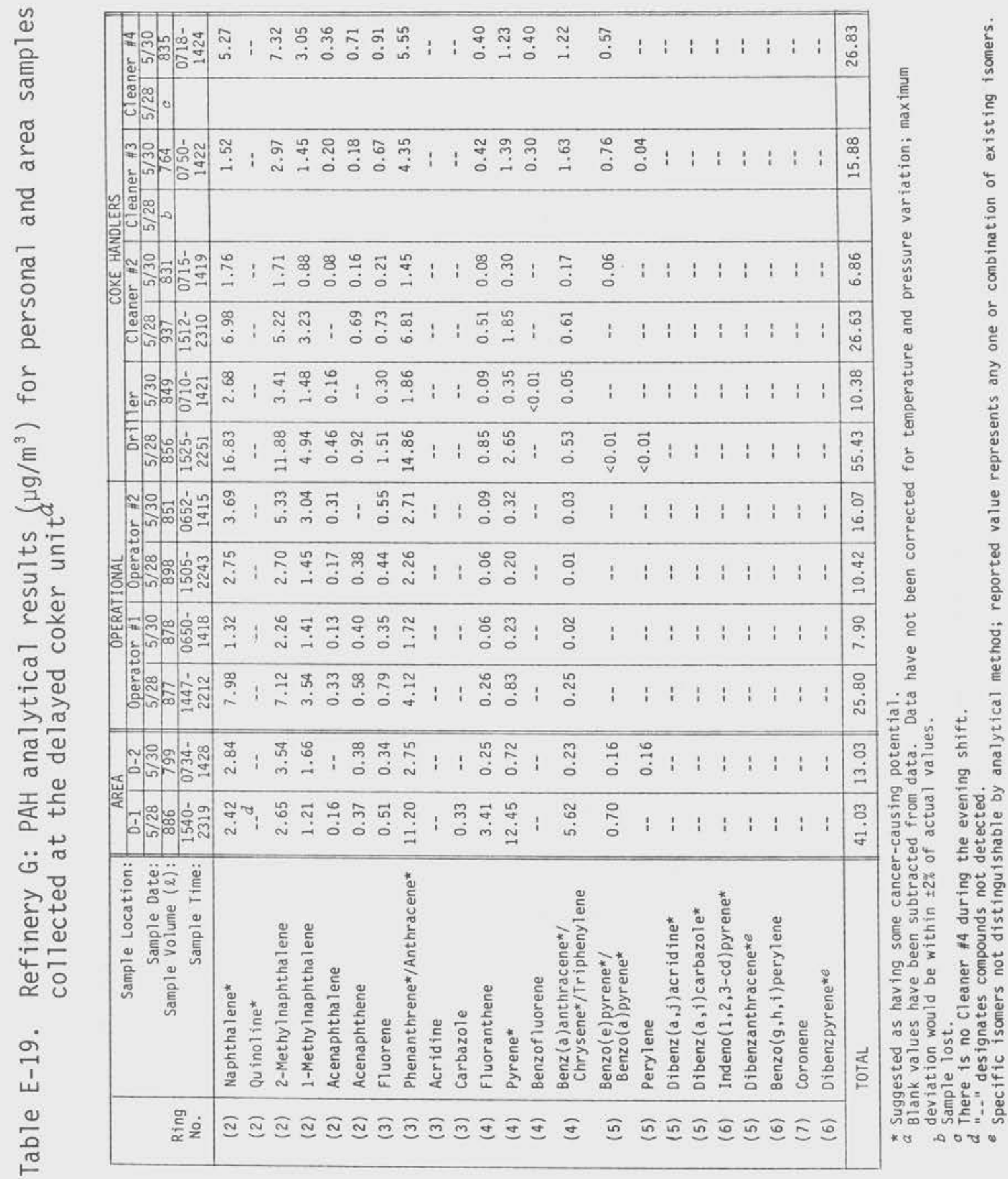




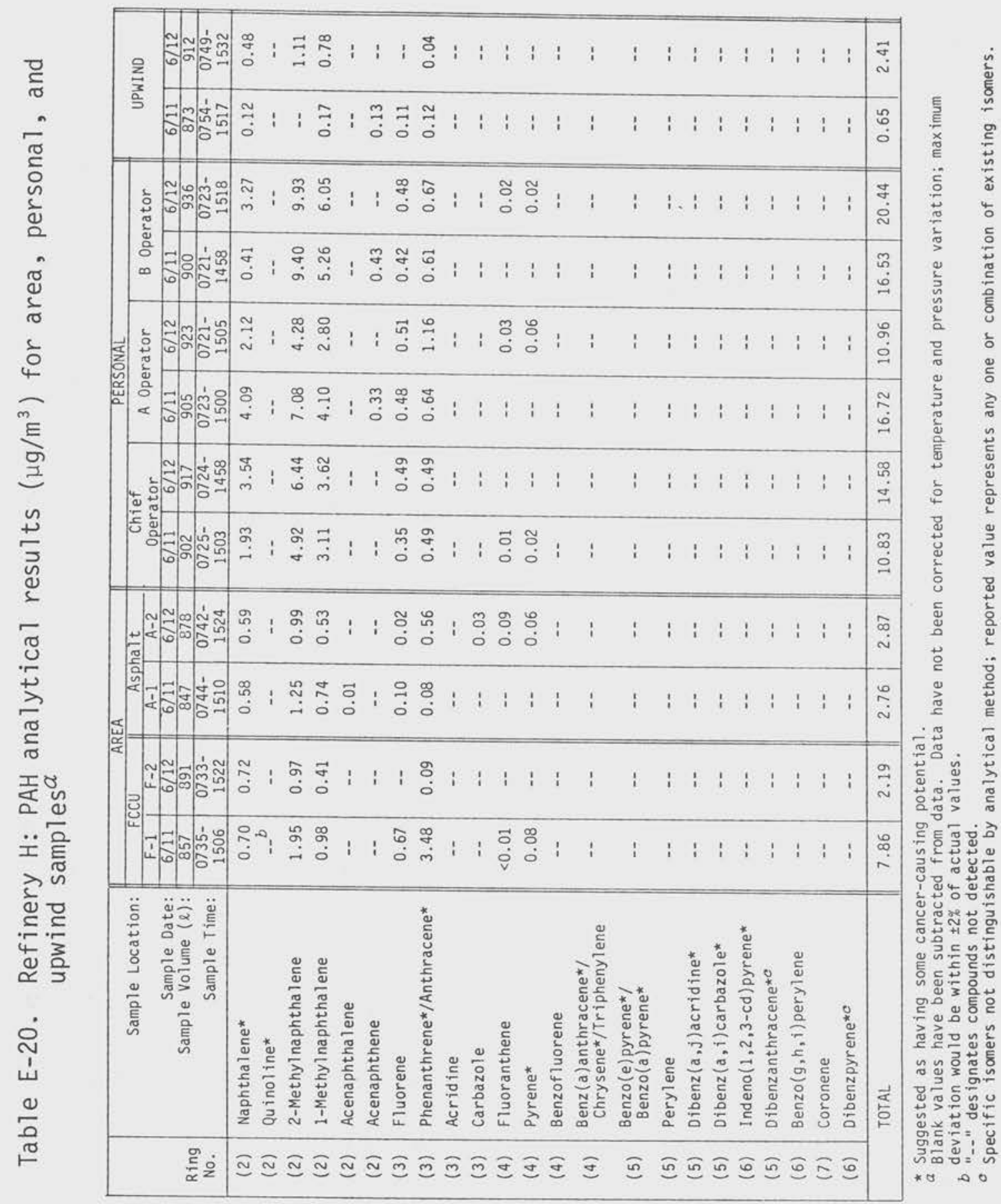




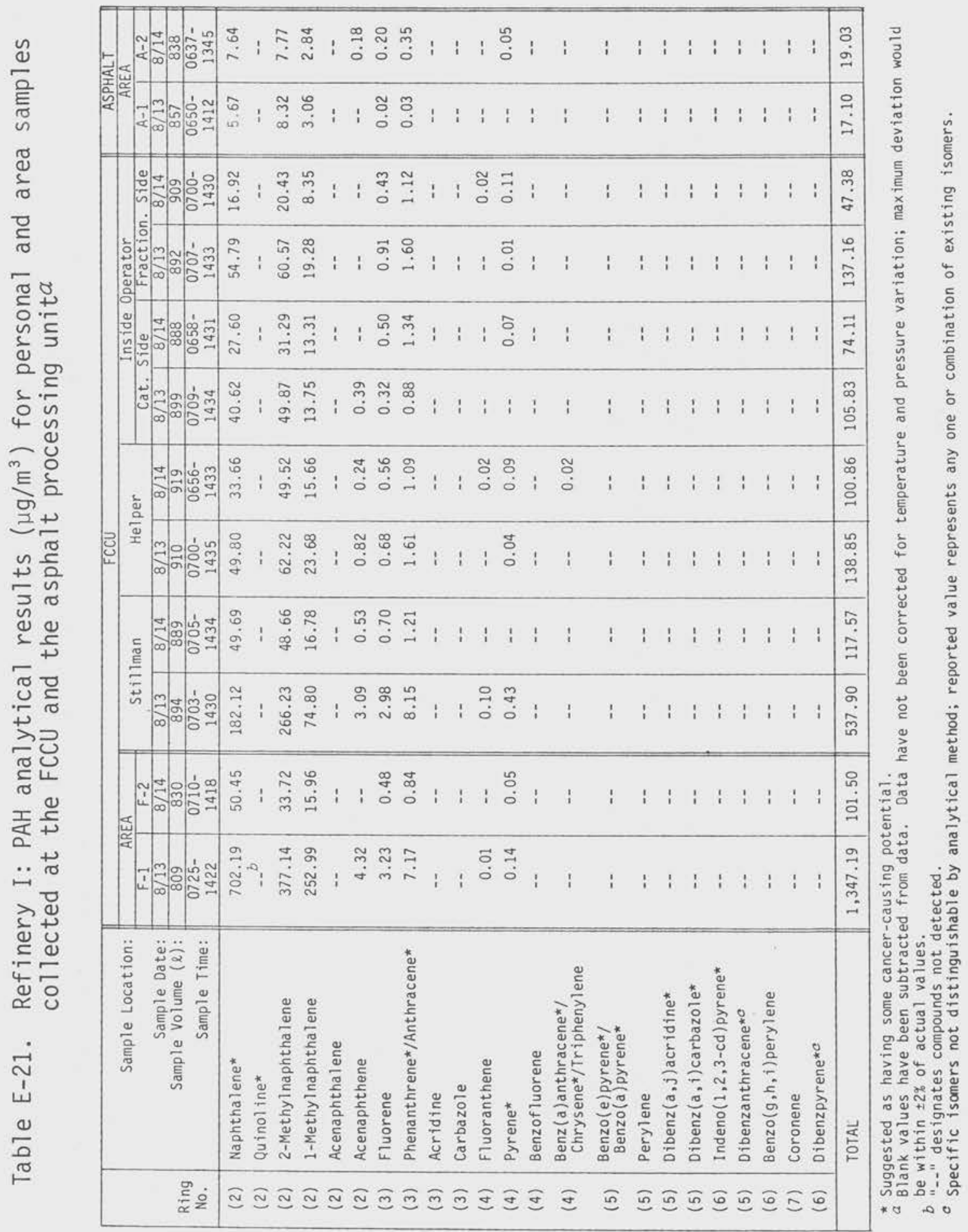




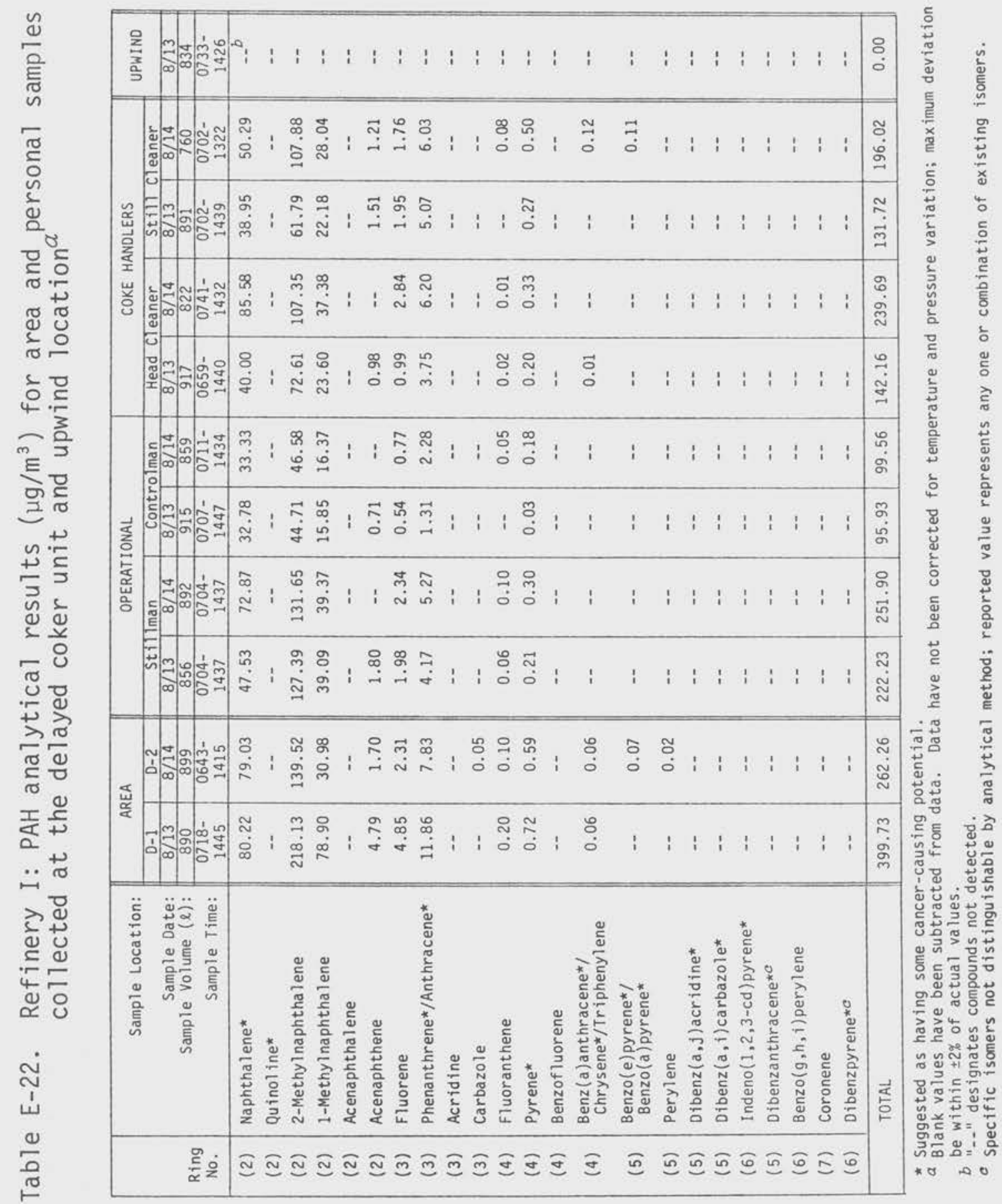




DEPARTMENT OF HEALTH AND HUMAN SERVICES

PUBLIC HEALTH SERVICE CENTERS FOR DISEASE CONTROL

NATIONAL INSTITUTE FOR OCCUPATIONAL SAFETY AND HEALTH ROBERT A. TAFT LABORATORIES

4676 COLUMBIA PARKWAY, CINCINNATI, OHIO 45226

OFFICIAL BUSINESS

PENALTY FOR PRIVATE USE. $\$ 300$
Special Fourth Class-Book

POSTAGE AND FEES PAID U.S. DEPARTMENT OF HHS HHS 396 